

\section{DISCLAIMER}

This report was prepared as an account of work sponsored by an agency of the United States Government. Neither the United States Government nor any agency Thereof, nor any of their employees, makes any warranty, express or implied, or assumes any legal liability or responsibility for the accuracy, completeness, or usefulness of any information, apparatus, product, or process disclosed, or represents that its use would not infringe privately owned rights. Reference herein to any specific commercial product, process, or service by trade name, trademark, manufacturer, or otherwise does not necessarily constitute or imply its endorsement, recommendation, or favoring by the United States Government or any agency thereof. The views and opinions of authors expressed herein do not necessarily state or reflect those of the United States Government or any agency thereof. 


\section{DISCLAIMER}

Portions of this document may be illegible in electronic image products. Images are produced from the best available original document. 
BNL -51398

BNL 51398

UC-11

DE82 011691

(Environmental Control Technology and

Earth Sciences - TIC-4500)

\title{
AUTOMATED NUTRIENT ANALYSES IN SEAWATER
}

\author{
Terry E. Whitledge, Stewart C. Malloy, \\ Charles J. Patton, and Creighton D. Wirick
}

February 1981

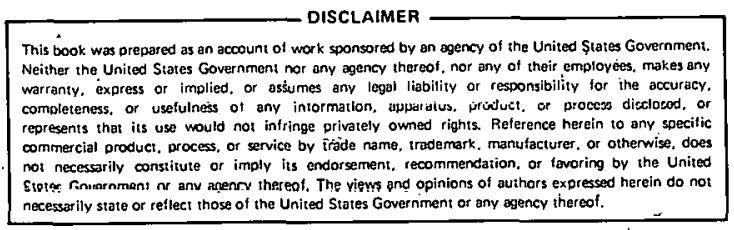
OCEANOGRAPHIC SCIENCES DIVISION DEPARTMENT OF ENERGY AND ENVIRONMENT BROOKHAVEN NATIONAL LABORATORY ASSOCIATED UNIVERSITIES, INC.

Under Contract No. DE-AC02-76CH00016 with the UNITED STATES DEPARTMENT OF ENERGY 


\section{DISCLAIMER}

This report was prepared as an account of work sponsored by an agency of the United States Government. Neither the United States Government nor any agency thereof, nor any of their employees, nor any of their contractors, subcontractors, or their employees, makes any warranty, express or implied, or assumes any legal liability or responsibility for the accuracy, completeness, or usefulness of any information, apparatus, product, or process disclosed, or represents that its use would not infringe privately owned rights. Reference herein to any specific commercial product, process, or service by trade name, trademark, manufacturer, or otherwise, does not necessarily constitute or imply its endorsement, recommendation, or favoring by the United States Government or any agency, contractor or subcontractor thereof. The views and opinions of authors expressed herein dn nnt necessarily state or retlect those of the United States Government or any agency, contractor or subcontractor thereof.

\section{Printed in the United States of America$$
\text { Available from }
$$ \\ National Technical Information Service \\ U.S. Department of Commerce \\ 5285 Port Royal Road \\ Springfield, VA 22161}

NTIS price codes:

Printcd Copy: A10; Microfiche Copy: A01 
This report is being prepared with some trepidation because of the inability to describe the "perfect" automated chemistry system. Everyone who operates an automated chemical analyzer whether it is a Technicon AutoAnalyzer or some similar instrument does so with his own individual style. Often different styles originate from the different emphasis needed to solve the questions being asked. For example, some investigations will require the maximum sensitivity with a relatively small number of samples while others might need lower sensitivity with a large number of samples. Therefore, we will not be able to answer all of your questions but we hope to include enough discussion that you may be able to solve most of your problems. Specifically, this manual has been assembled to use as a guide to analyze the nutrient content of seawater samples collected in the marine coastal zone of the Northeast United States and the Rering Sea. Some modifications (changes in dilution or sample pump tube sizes) may be necessary to achieve optimum measurements in very pronounced oligotrophic, eutrophic or brackish areas. 
Foreword........................................

1. Theory and Mechanics of Automated Analysis................. 1

2. Continuous Flow System Description................... 5

Specific Component Description.................... 7

3. Operation of Autoanalyzer system.................... 13

Storage of Nutrient Samples......................... 14

Starting Up and Shutting Down...................... 15

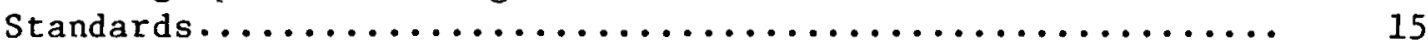

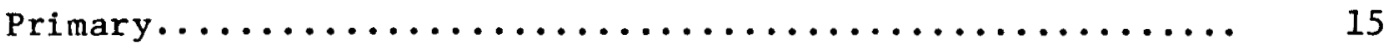

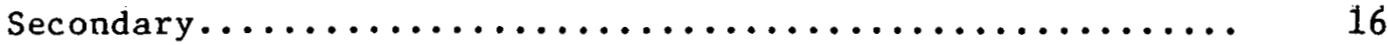

Table for Mixed/Working Standards for Nutrient Analysis.... 18

Deionized Water................................ 19

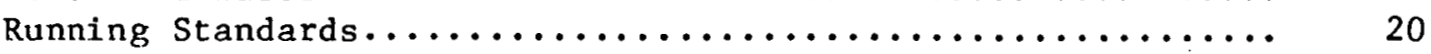

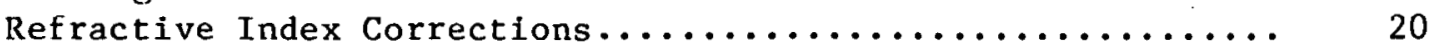

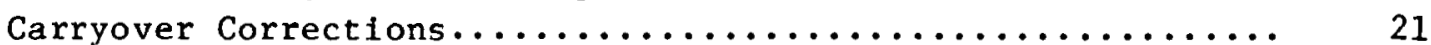

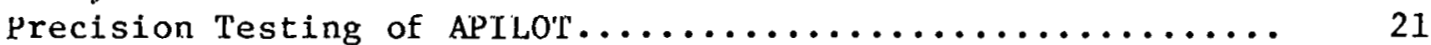

Comparison of Automated and Manual Data Logging........... 22

Comparison of Slow and Fast Sample Analysis Rate.......... 23

Underway Mapping................................... 40

Wet Laboratory System.............................. 40

4. Cookbook of Current Nutrient Methods..................... 47

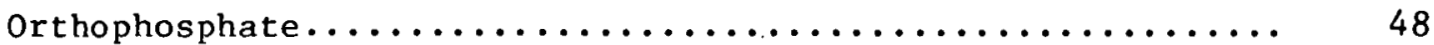

Orthosilicic Acid............................... 49

Nitrate + Nitrite, Nitrite........................ 50

Preparation of the Nitrate Reduction Colunn............ 52

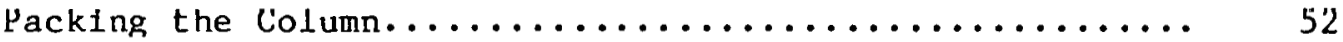

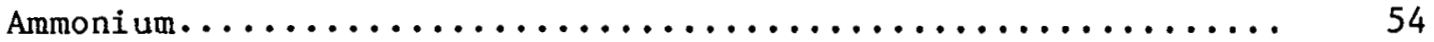

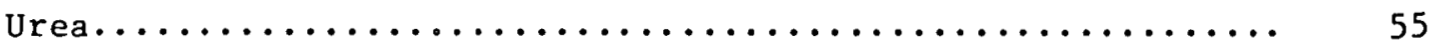

Chemicale - Storage and Handling................... 56

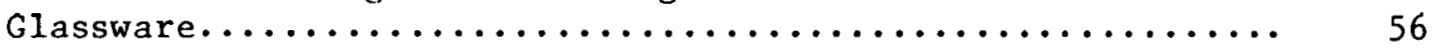

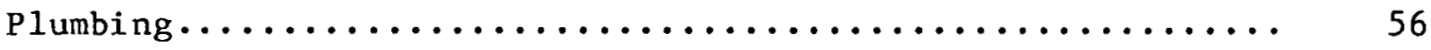

Pump Tubes.................................. 57 
5. Automated Analyzer and Data Analysis Software................ 59

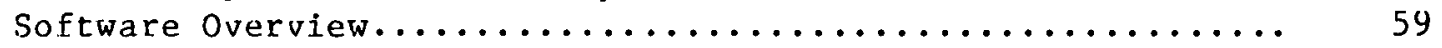

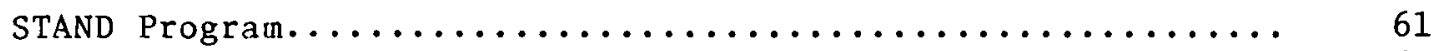

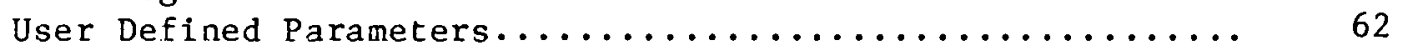

APILOT Program - Automated Peak Reading Routine............ 68

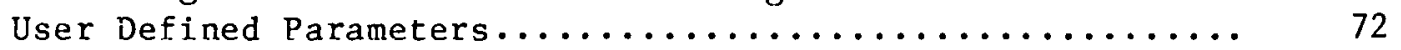

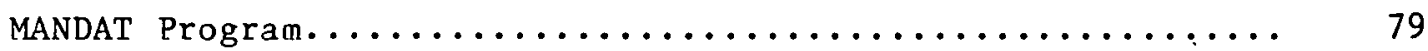

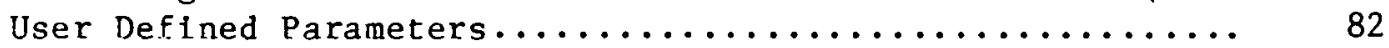

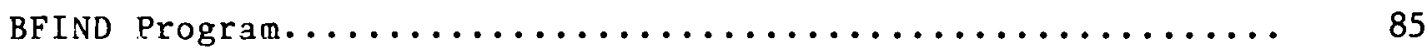

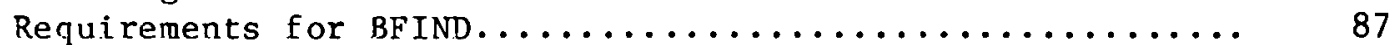

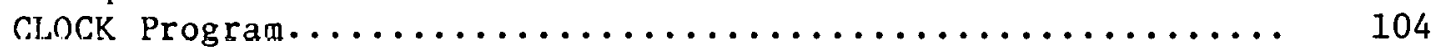

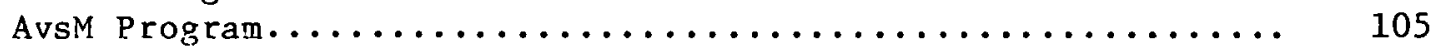

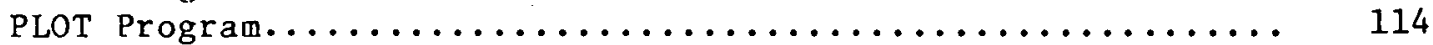

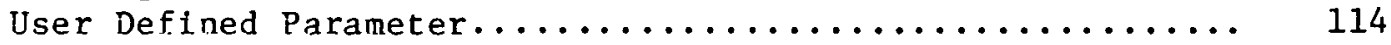

SECS Program..................................... 119

6. Computer Interfacing and Hardware Modifications.............. 132

Computer Interfacing................................. 132

Description of the Analog Multiplexer Interface to Computer... 132

Computer to AutoAnalyzer Sampler Interface.............. 136

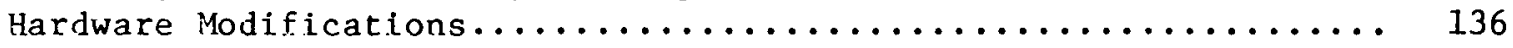

Knobelsdorff Precision Sampler Timer Instructions.......... 136

Conversion of AutoAnalyzer Sampler for 2 oz. Poly Bottles..... 140

Scale Expander................................... 140

7. Trouble Shooting.................................... 145

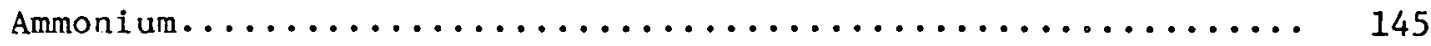

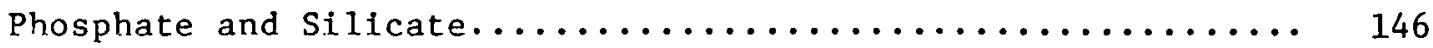

Nitrate plus Nitrite, Nitrite...................... 146

Appendix A - References and Additional Reading.............. . . 147

Appendix B - Manifold Components and Chemicals...............159

Appendix C - Software Listings........................... 164 
Figure 1-1 Figure 1-2 Figure 1-3 Figure 1-4 Figure 2-1 Figure 2-2

Figure 2-3

Figure 2-4

Fl gure $3-1$ Finute 3-2 Figure 3-3 Figure 3-4 Figure 4-1 Figure 4-2

Figure 4-3 Figure 4-4 Figure 4-5

Figure 4-6 Figure 4-7 F1 gure $b-1$

F1gure $\bar{b}-2$

Figure 6-3

Figure 6-4 Figure 6-5 Figure 6-5
Raw AutoAnalyzer data showing peaks.................. 1 Dispersion effect of a single segment of dye........... 2 Dispersion effect of a continuous input of dye.......... 3 Exponential lag phases of $r i s e$ and fall curves of a peak.. 4 Schematic diagram of computer-AutoAnalyzer system....... 8 AutoAnalyzer in the laboratory in a sea-going

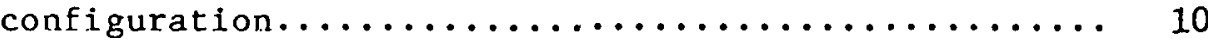

Ammonium manifold showing vertical orientation of flow

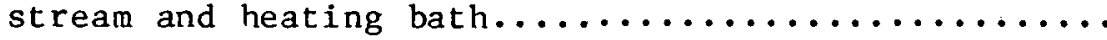
Arrangement of AutoAnalyzer sampler, pump and colorimeters which reduces the total length of the flow system....

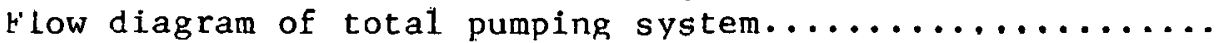

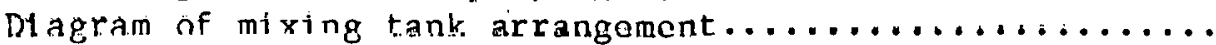

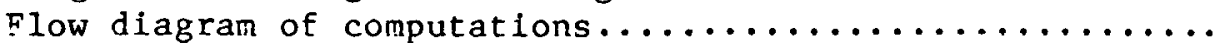
Example of survey grid and mapping pattern........... Orthophosphate manifold for AutoAnalyzer II............ Orthosilicic acid (silicate) manifold for

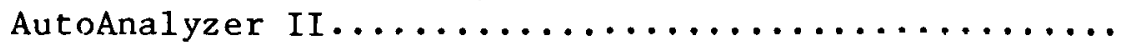
Nitrate plus nitrite manifold for AutoAnalyzer II........ Nitrite manifold for AutoAnalyzer II................ A) Cadmium column for nitrate plus nitrite in running mode.......................... 53

B) Column ready for packing with cadmium filings....... 53 Ammonium manifold for AutoAnalyzer II............... 54 Urea manifold for AutoAnalyzer II................ 55

Schematic of AutoAnalyzer sampler controller that is interfaced to computer through DAC output of

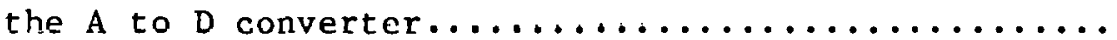

Brass cam for AutoAnalyzer sampler modification for 2 oz. polycthylene sample bottles.............. 141 Plexiglass sample tray for AutoAnalyzer sampler modification tor $2 \mathrm{oz}$. polyethylene sample bottles... 141

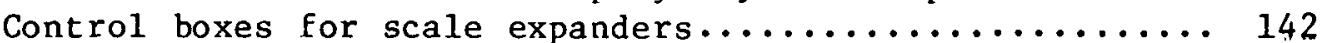
Scale expander wiring diagram................. 143 (continued)
2

\section{LIST OF TABLES}

Table 3-1 Table 3-2 Table 4-1 Table 6-1

Table 6-2
Mixcd/working standards for nutrient analyses........... Field replication experiment using natural seawater.......

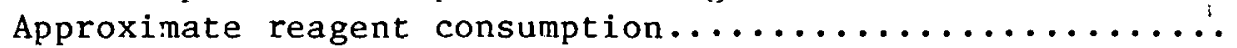
Knobelsdorff timer sampling rates and ratios for

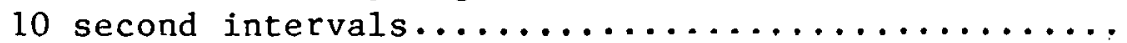
Knobelsdorff timer sampling rates and ratios for

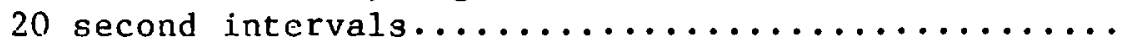

PA $\mathcal{G}^{\boldsymbol{P}}$ 


\section{THEORY AND MECHANICS OF AUTOMATED ANALYSIS}

Automated chemical analyses using colorimetric techniques fall into two basic categories, batch and continuous flow analyses. Several automated batch analyzers have been produced, the most recent of which is the Kem-0-Lab marketed by Coulter Electronics, Inc. This system incorporates a sample transport system, automatic sampling, reagent addition and mixing, incubation, colorimeter reading and printout of results. With 6 analyses about 40 samples can be analyzed per hour. A standard RS232C interface is available for computer interfacing. Currently incubation temperatures are not high enough to complete some chemical reactions and as a result the minimum concentration measured is reported to be about $1.4 \mu \mathrm{g}$-at ammonium- $\mathrm{N}^{-1}$.

Continuous flow analysis (CFA) techniques were developed to improve chemical analysis procedures by allowing a laboratory analyst to measure several parameters on a large number of small samples. Improvements have occurred in the analysis system but the basic operating principles remain the same. Sample and reagents are pumped into a manifold, mixed, and are segmented by air bubbles thus producing tiny discrete parcels of sample (often called slugs) that are separated to reduce sample mixing and drag. Between the samples distilled water washes are used to produce distinct "absorbance peaks" when each of the samples are measured in the colorimeter. The typical shape of a sample peak is a sharp rise from the initial distilled water baseline, then near the top of the peak the absorbance asymptotically approaches a steady state value which produces a plateau (Figure 1-1). The peak drops sharply as the distilled water wash enters the flow cell and the absorbance asymptotically approaches the initial baseline if-the wash time between sample peaks is sufficiently long. In some early AutoAnalyzer versions good sample peaks and

\section{PEAK 2}

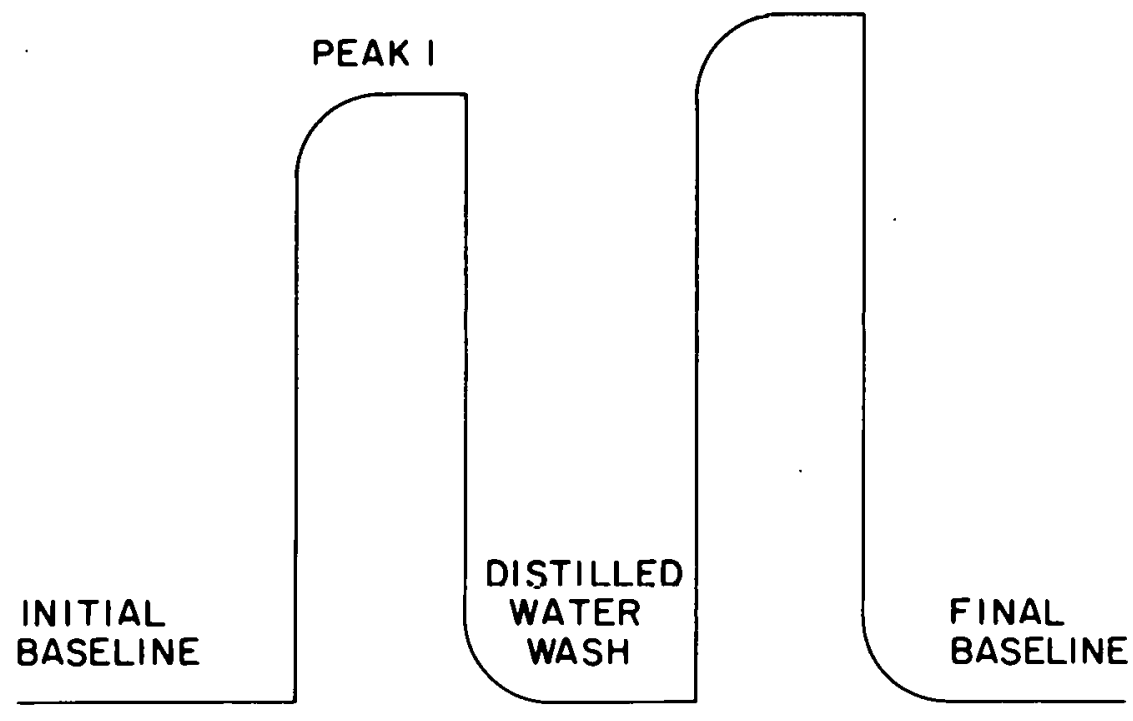

Figure 1-1. Raw AutoAnalyzer Data Showing Peaks 
baselines could be obtained but the sample analysis rate was very slow. As sampling rates increased the determination of peak heights became increasingly difficult so attention was focused on understanding the physics involved in continuous flow analysis systems.

A technique known as curve regeneration evolved from the early efforts to relate the shape of peaks observed by the detector of air segmented continuous flow analyzers (AutoAnalyzers) with elementry physical phenomena such as mixing and diffusion. About ten years after Skeggs introduced air segmented continuous flow analysis, Thiers and coworkers showed that the familiar rise and fall curves of CFA peaks were comprised of two parts, the lag phase and the exponential phase (Thiers and 01geby, 1964; Thiers, Cole and Kinsch, 1967).

The lag phase is characterized by a "damped exponential" or Poisson distribution which can be observed by constructing a histogram of concentrations caused by the leakage of the contents of one segment into those which follow via the thin film of liquid that wets the inside wall of the glass manifold tubing. This thin film deposited by one segment is overtaken and mixed into the next segment and so on. Suppose, for example, that a marker-dye (or sample) could be instantaneously injected into a single segment of the fllowing analytical stream in a CFA networks. After a time, by the process described above, the dye would have become incorporated into a number of the succeeding segments and the maximum concentration would not be found in the original dye containing segment, but in one of a number of segments downstream (Figure 1-2). Next suppose that the marker dye (or sample) was continuously pumped
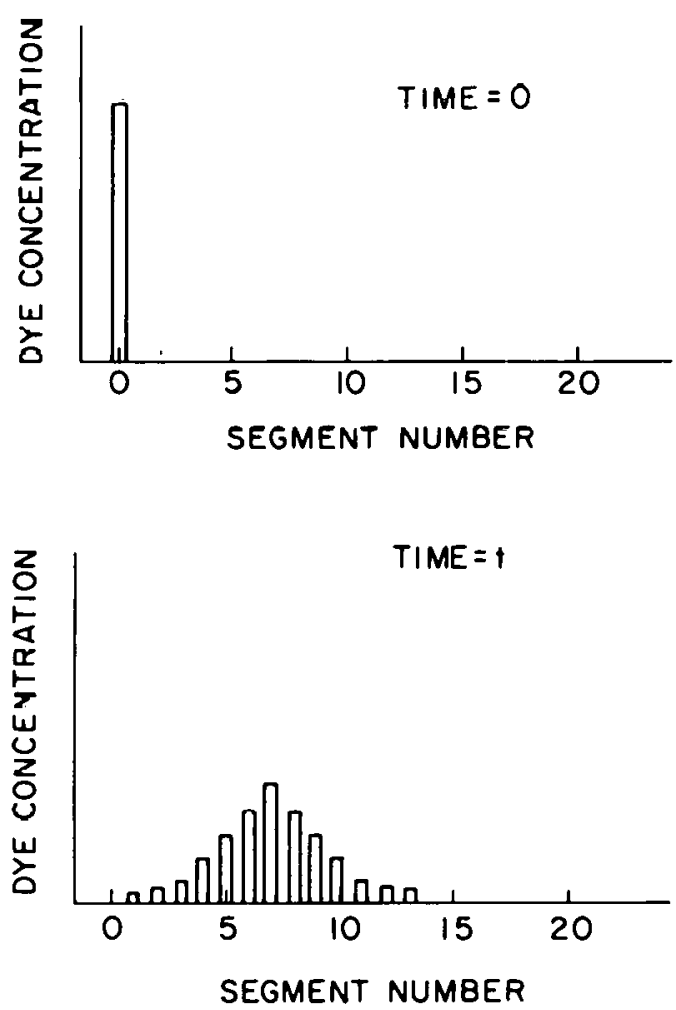

Figure 1-2. Dispersion Effect of a Single Segment of Dye 
into the manifold. The concentration of the dye in the liquid segments emerging from the manifold would approach a constant value and when the concentration from one segment to the next no longer varied with time, the system is said to be at steady-state (see Figure 1-3).

- The time required to attain steady state is a function of the amount of dispersion which occurs in the entire (sampler to detector) flow network. Thiers' group developed a mathematical model based on the above description and recently Theirs' model has been expanded to allow the prediction of dispersion in the CFA network in terms of experimental conditions. The amount of dispersion in the CFA network can be related to the inside diameter of the manifold tubing, liquid flow rate, bubble segmentation rate, residence time in the flow network, liquid viscosity, surface tension and the sample mass transfer coefficient. Usually the experimenter has control of only the first four variables since the others are largely fixed by the inherent properties of the sample and reagents. In general, dispersion decreases as the inside tubing diameter and dwell time decrease. By assigning values to tubing diameter and dwell time and holding all other variables constant, optimum values can be found for segmentation rate and liquid flow rate (Snyder and Adler, 1976). These types of calculations are useful in designing CFA networks with minimum dispersion.

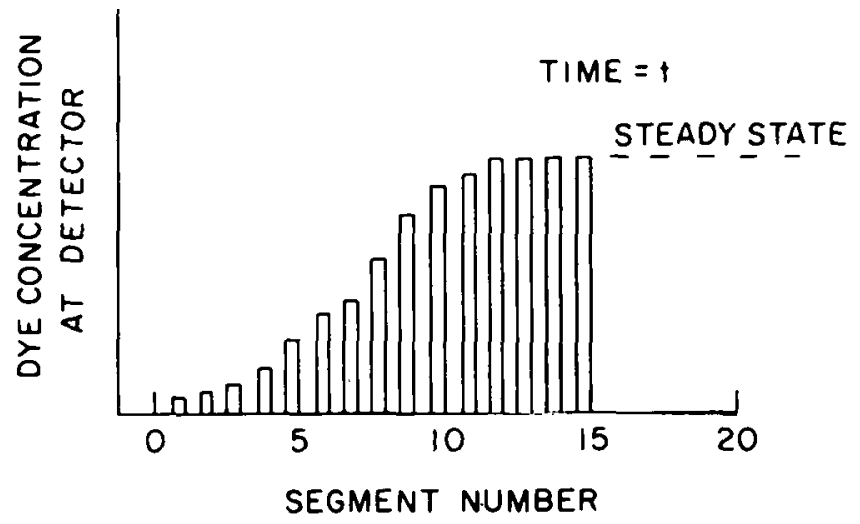

Figure 1-3. Dispersion Effect of a Continuous Input of Dye

The foregoing discussion assumes that the analytical stream is uniformly segmented at all times with gas (air) bubbles. This is not a good assumption since in conventional CFA analyzers, air bubbles must be removed from the analytical steam prior to its passage into the detector's flow cell in order to obtain a stahle nutput. signal. Under these conditions, the exponential phase becomes dominant. The Thiers group noted that with standard (debubbling) flow rellis a logarithmic plot of absorbance versus time (Figure 1-4) yielded a straight line, after an initial lag period (a). Walker and coworkers seem to have been the first to recognize that since the majority of points on the rise and fall curves were well behaved exponential functions 
over most of their range, the steady state detector response can be estimated from the rate of change of the detector using the equation:

$$
H_{S s}=H_{t}+B \frac{d H_{t}}{d t}
$$

where $\mathrm{H}_{\mathrm{SS}}$ is the steady state detector output, $\mathrm{H}_{\mathrm{t}}$ the detector output at any time $t$, and $B$ the exponential factor (the negative inverse slope of the line from a plot of $\ln \left(\mathrm{H}_{\mathrm{ss}}-\mathrm{H}_{t}\right)$ versus $t$ ) which is concentration independent (Walker et al, 1970; Walker, 1971; Walker et al, 1971). This steady state detector response can be generated to a very good approximation before it is physically achieved. The signal processing required for this transform can be performed in the analog or digital domain. At Brookhaven we convert analog detector signals to digital and regenerate the data in software using most of procedure described by MacAulay et al. (1976). A refinement was suggestan for thin technique in which the dispersion correction is made proportional to the powcr of the gradient (Begg, 1974) rather than the nondimensional length of the manifold. This change allows the dispersion coefficient to be empirically determined over a larger range than the technique suggested by Walker (1971). An alternate method of regeneration has been described by Font (1978) which has been used on both discrete samples and continuous underway data. This post-processing method is based upon obtaining a transfer function for the dispersion in the analysis system which is then used to transform the observed absorbances into regenerated data. We are not convinced that this method has any advantages over the MacAulay et al. (1976) procedure, but it has the disadvantage of post-processing the data hence a slower output rate.

RISE CURVE

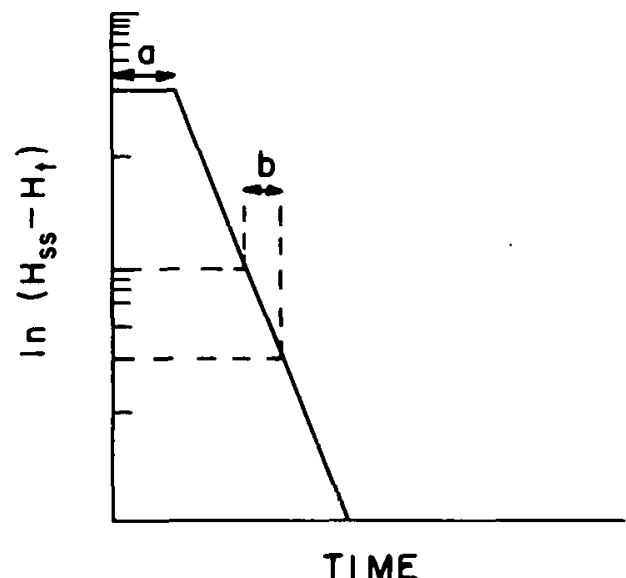

FALL CURVE

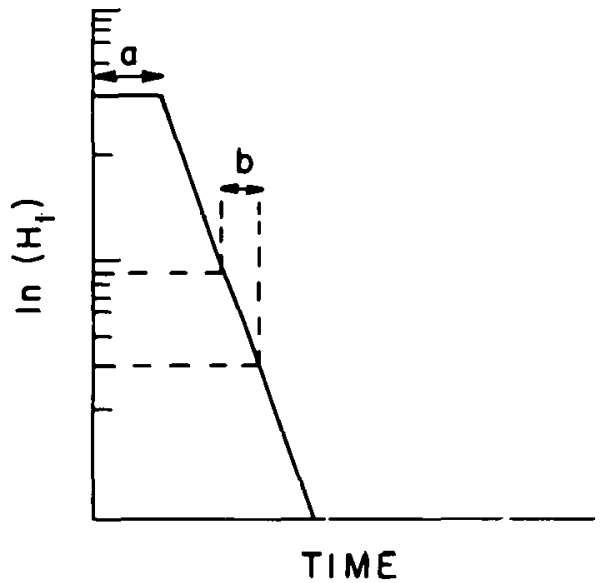

Figure 1-4. Exponential Lag Phases of Rise and Fall Curves of a Peak 


\section{CONTINUOUS FLOW SYSTEN DESCRIPTION}

The most serious problem in continuous flow analyses is sample dispersion which can be defined as mixing of a segmented sample stream that occurs along the wall of the tubing. Several factors influence the amount of dispersion of a sample including: 1) tube inside diameter, 2) liquid flow rate, 3) bubble segmentation rate, 4) liquid viscosity, 5) surface tension, 6) time in the flow network, and 7) a sample mass transfer coefficient. Several excellent papers that generally describe these factors are listed in the reference section among which are Snyder et al. (1976); Snyder and Adler (1976); Snyder (1976); Snyder (1980) and Van Den Berg et al. (1980).

For seawater analyses tube inside diameter, liquid flow rate, bubble segmentation rate and length of the flow network are the only variables that can be manipulated to minimize dispersive processes. The trend in Technicon instruments and manifold components has been to use smaller tubes, increase bubble segmentation rate, space bubbles at regular intervals and shorten the length of the flow system. Of course as the dispersion and the length of the systems decreased the sample analysis rate increased markedly. The result is that the AutoAnalyzer I system using $2 \mathrm{~mm}$ I.D. tubing would produce satisfactory results for nutrients in seawater at about 20 samples/hour. The AutoAnalyzer II system with $1.5 \mathrm{~mm}$ I.D. tubing and a pump III with an air bar can analyze seawater samples at 60-90 samples/hour, especially if peak regeneration processing of the raw data is used. The Technicon SMAC system has $1 \mathrm{~mm}$ I.D. tubing, no debubbling in the colorimeter flow cell, and computer control including peak regeneration which can do 150 samples/hour. Ultimately it has been calculated that 600 samples/hour can be analyzed if all dispersion processes are minimized, however, that analysis rate has not been approached by any operating system.

\section{General Component Description}

The automated chemical analyzer is basically composed of modules connected by tubing or electrical connections. The modules uscd in most systems in chronological order are: sampler, pump, manifold, colorimeter, recorder and data logger or computer. A basic description of these modules and their utility follows.

The sampler is basically a timer and sample changer which starts the sample through the analyzer system and alternates wash solution and samples to give separate "peaks" for each of the samples. The standard AutoAnalyzer sampler will hold 40 cups in the rotary tray. The length of sample time and wash time is governed by a mechanical timer with interchangeable cams. The total sample plus wash time period is set by the speed of rotation of the timer motor hence it is not changeable but the ratio of sample to wash time can be changed within that period of rotation. Several modifications of the standard AutoAnalyzer sampler are desirable to increase operator efficiency and reduce sample containination (e.g. adapting the sample tray to accept 2 ounce polythylene bottles instead of the small cups and a selectable electronic timer in which a large number of sample-wash combinations can be prograined). The sampler can also be operated remotely with the computer controlling both the sampling rate and the data logging. See the chapter on Computer Interfacing and Hardware Modifications for futher details. 
The pump (known as a peristaltic pump) is the work horse of the AutoAnalyzer system. A set of revolving rollers squash plastic tubing and pull sample reagents and air streams into the pump and push them into the manifold section. As in manual (hand) methods it is necessary to add different quantities of sample and various reagents to achieve the proper results. The different quantities are obtained by using various bore sizes for the pump tubes. The wall thickness of all the various pump tube sizes are identical so all the tubes are compressed equally and sealed by each of the rollers. Air is also pumped to generate the bubbles used to segment the sample stream. On most of the later pumps an air bar is used to produce more precise bubble spacings in the manifold. The air bar is a necessary fixture to obtain high quality analyses for a large number of samples. No modifications are necessary on the AutoAnalyzer pump unless a microflow system is desired.

The chemical reactions occur in the manifold where the sample is segmented with air, mixed with reagents, heated if necessary and then sent to the colorimeter. All the pump tubes are connected to small glass fittings or plastic blocks which divide the sample and inject the reagents and air into the sample stream. Small, circular glass coils are then used to mix the sample thoroughly. Several additions of other reagents may be made through platinum or glass injector connectors after the initial mixing. The number of turns in the mixing coils governs time delay before another reagent is added or the sample goes to the colorimeter. If a chemical reaction time is normally too long to come to completion at room temperature, the coils are heated to increase the reaction rate. Basically it is best if all parts of the manifold are constructed with glass which reduces back pressure and chemical reaction with the walls of the coils and allows you to see the sample stream. Another variable to be optimized in the manifold is the internal diameter of the glassware. Basically it is best to use the smallest tubing possible which minimizes mixing and contamination between samples and wash. Glass tubing of 1.5 and $1.0 \mathrm{~mm}$ internal diameter are being used on the relatively recent systems.

The AutoAnalyzer II single channel industrial colorimeter (SCIC) measures the transmittance (which is electronically converted to absorbance) of the sample stream after it has been debubbled. The latest models have sample and reference cells even though they are called single channel instruments. The reference cell is normally filled with air and serves to modulate variation in light filament intensity. Narrow pass interference filters are used with the sample and reference cells to produce the desired wavelength of light for spec1fic analysis. The sample stream with bubbles is pushed into the colorimeter. At the debubbler in the colorimeter the nonsegmented sample is pulled through the sample cuvet and back through the pump while the bubbles and a small fraction of the sample stream are vented to a waste 1 ine. Several flow cell lengths and diameters are available to optimize sensitivity and to alter sample residence and wash out times in the cuvet. Some problems are produced with smaller diameter flow cells such as a significant refractive index difference between distilled water wash and seawater samples. This refractive index error is normally corrected empirically as described in section 3 . The output of the colorimeter is both. $60 \mathrm{mv}$ and 5 volts full scale. Older versions of the colorimeter (AAI) use larger volumes and measure percent transmittance of the samples. The output of the older colorimeter nust be amplified using the recorder as provided by Technicon. It is also possible to build or buy a log-amplifier which will linearize the transmittance output of the AAI so it can be recorded on a standard chart recorder. 
The recorder receives the analog signal from the colorimeter so that the trace displays the absorbance of the samples as "peaks" and the distilled deionized wash water lowers the trace to separate the peaks from one another. The baseline absorbance obtained with reagents and distilled wash water represents zero concentration. The difference between the peak heights in absorbance units and the baseline absorbance represents the absorbance of the sample.

A data logger also can connect to the output of the colorimeters to digitize the analog output and print this output on paper tape. The data logger is also connected to the sampler to coordinate the sample times and it can be calibrated to display concentrations by inserting the appropriate factor. The data logger is deficient in that it will not correct baseline changes and refractive index corrections, and displays only to paper tape.

A computer is an optional data recording device (as is the data logger) which collects the absorbance values of baselines and sample peaks. The computer is interfaced to the analog output signal of the colorimeter by an analog to digital converter. Absorbance values of the sample peaks are stored in the computer. The computer does the tasks of the data logger but also can correct for baseline changes and refractive index, store data in formatted files, store data on mass storage media (magnetic tape or disks), print a formatted report, display formatted data in tabular or graphic form on a CRT, and calculate cheinical factors directly from standard solutions. Given the combination of capabilities that are currently available in the commercial narket it is possible to purchase a computer that performs these tasks for less cost than the data logging devices needed to operate five or six AutoAnalyzer channels. The software development of data logging from an automatic analyzer is not difficult if the computer has a high level language such as BASIC. Technicon Corp. is currently marketing an AutoAnalyzer IIC Data Handler and Controller system which is built around a microprocessor. The system description indicates that it produces data listings and can communicate with other computers but there are currently no graphics available with the system.

\section{Specific Component Description}

The autonated analysis system (Figure 2-1) has the capability of processing 8 channels but in practice only 6 analyses are implemented at the present time. The specific modules in the analysis system are:

1. AA II Sampler IV

2. AA II Single Channel Industrial Colorimeter (SCIC)

3. AA II Pump III with single speed

4. Honeywell dual pen recorders with multiple speeds and input spans.

5. Manifold modules constructed from a la carte components.

5. A to $D$ interface with $\mathrm{HP} 98132 \mathrm{~A}$ interface card. This device also has a DAC output port which controls the sampler.

7. HP $9845 \mathrm{~S}$ desktop computer with internal printer, CRT, real-time clock, I/O read only memory (ROM), GRAPHICS ROM and Mass Storage ROM.

HP System Description

A. HP 9845S: with 62,650 bytes of $R / W$ memory (option 203) graphics package (option 370, option 700) second tape drive (option 600)

integral thermal line printed - 8-1/2 paper (option 500) standard ASC II keyboard and printer (option 800) 


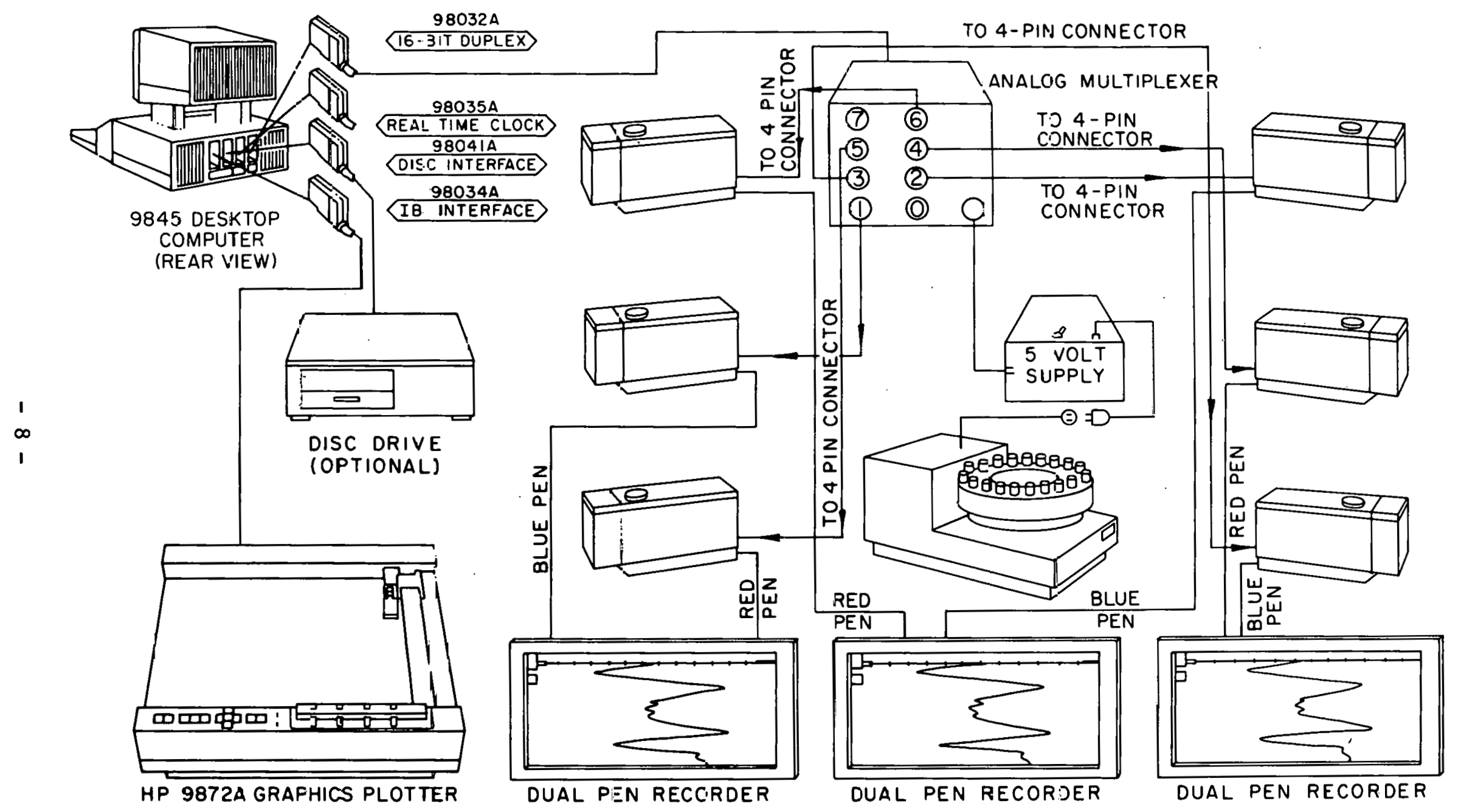

Figure 2-1. Schematic Diazram of Computer-AutoAnalyzer System 
$\begin{array}{lll}\text { B. ROMs : } & \text { mass storage } & 98431 \mathrm{~A} \\ & \text { graphics } & 98437 \mathrm{~A} \\ & \mathrm{I} / 0 & 98432 \mathrm{~A}\end{array}$

C. Peripherals: Flexible disk drive 9885M, option 045

Plotter 9872A, option 045

D. Peripheral Interface Cards:

Plotter interface (HP-IB) 98034A

Flexible disk interface 98032A, option 485

16-bit parallel I/0 98032A

Real time clock 98035A

RS-232-C interface 98036A, option 001

E. Other: Anderson Jacobson, mode1 A242, 300 baud modum Analog multiplexer constructed by Interscience Instrumentation

\section{Configuration}

The automated analysis system is operated in both shore-side and shipboard laboratories. The component modules have been configured to occupy a minimum of bench space but still allow easy access for troubleshooting (Figure 2-2). The 6 AutoAnalyzer channels require about 7 feet of bench space that is 3 feet wide and has $2-1 / 2$ feet of overhead clearance above the bench top. The computer requires another 3 feet by 3 feet area but it can be somewhat removed (a few feet).

The analysis system is transported as four separate modules that are attached to plywood bases. A dual channel recorder, 3 colorimeters and a pump are located on each end of the layout while a dual channel recorder and sampler are located in the center. The colorimeters are placed in aluminum frames that are attached securely to the top of the recorders (Figure 2-3). The colorimeters may be easily lifted out of the frames for repairs. The manifolds are attached vertically along the sides of the recorders (Figure 2-4). The pumps are located close to the sampler, reagents and colorimeters so that no long reagent lines are required. Heating coils for the phosphate, ammonium and urea channels are located on the back side of the manifold platens.

The component parts used to construct each of the analysis manifolds were purcliased mainly from Technicon. Some costs can be reduced by using parts manufactured by other vendors, however, the quality of these cheaper parts are often not good. Detailed lists of all component parts are located in

Appendix B.

As mentioned before all flow lines between the pump and colorimeters should be constructed from glass tubing to reduce back pressures. The glass segments are best joined using heavy walled $1 / 8$ inch tygon tubing. The ends of the glass segments should be butted against each other inside the joints. A11 reagent lines from the storage bottles to the pump should be small bore teflon or polyethylene tubing. This will reduce start up or shut down time. The small teflon tubing can be joined tightly to the pump tubes using small segments of old pump tubes. Small reagent lines from the pump to the manifold injector fittings can often be made using small teflon tubing. 


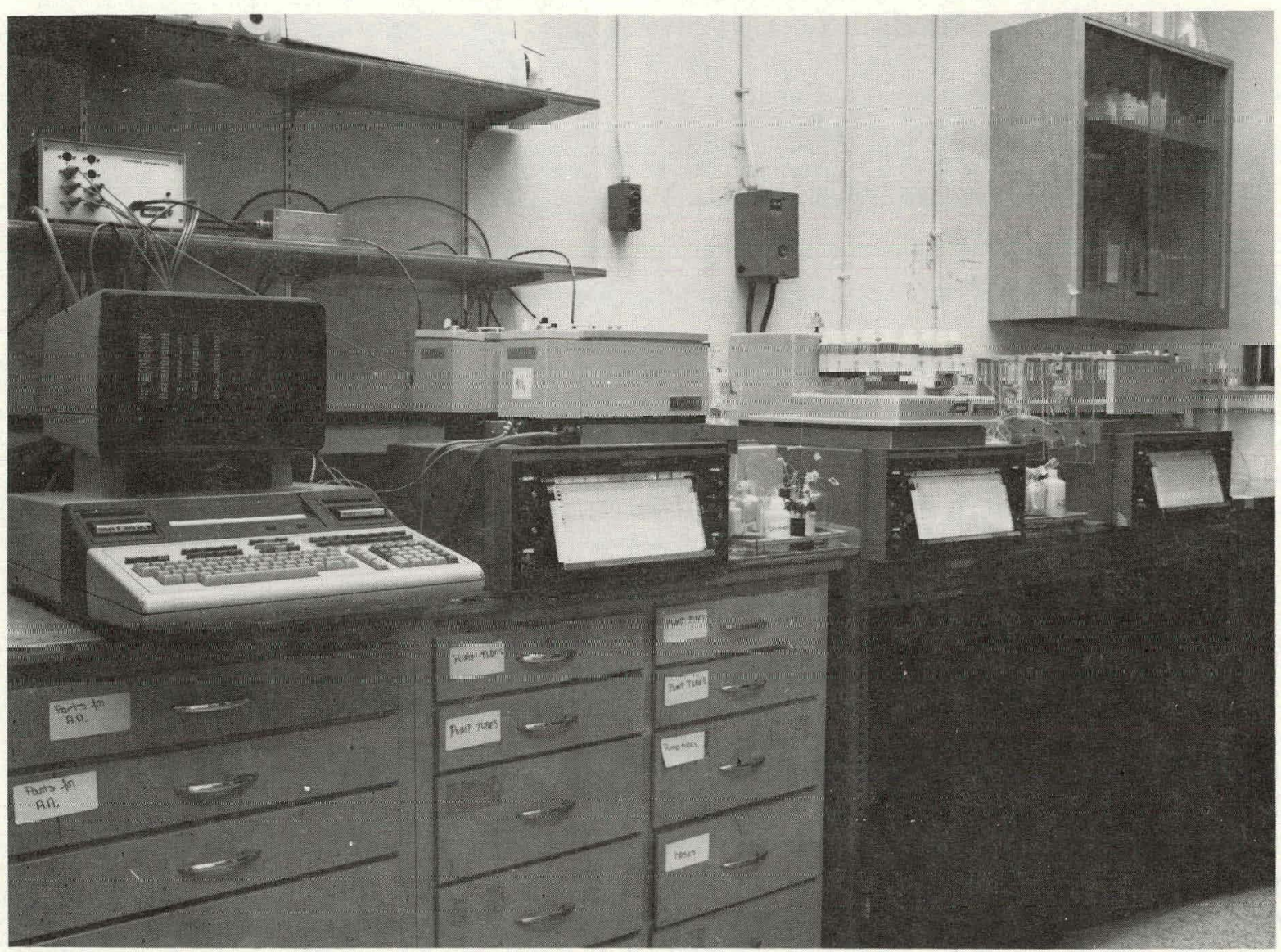

Figure 2-2. AutoAnalyzer on the Laboratory in a Sea-gning Configuration 


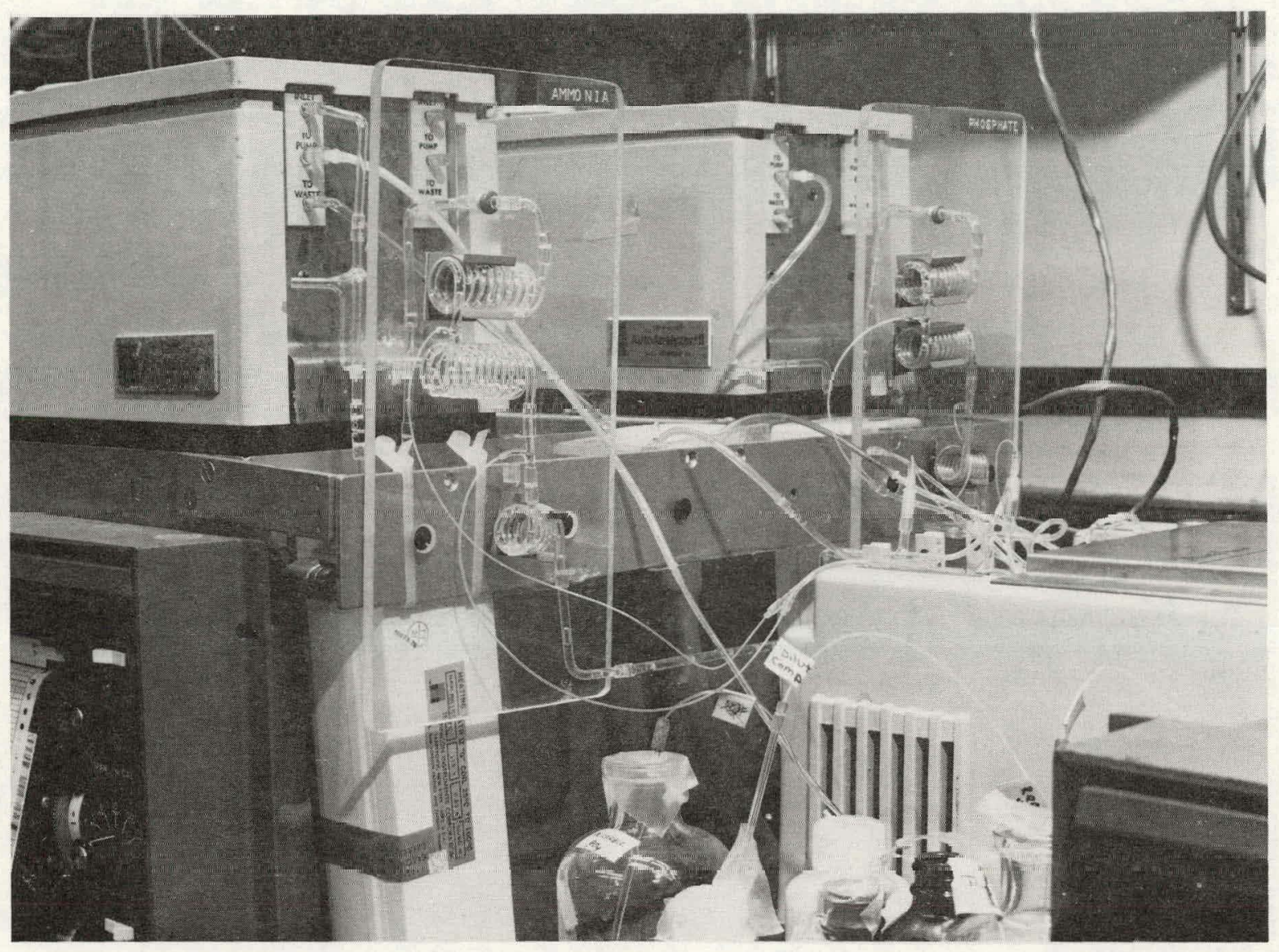

Figure 2-3. Ammonium Manifold Showing Vertical Orientation of Flow Stream and Heating Bath 


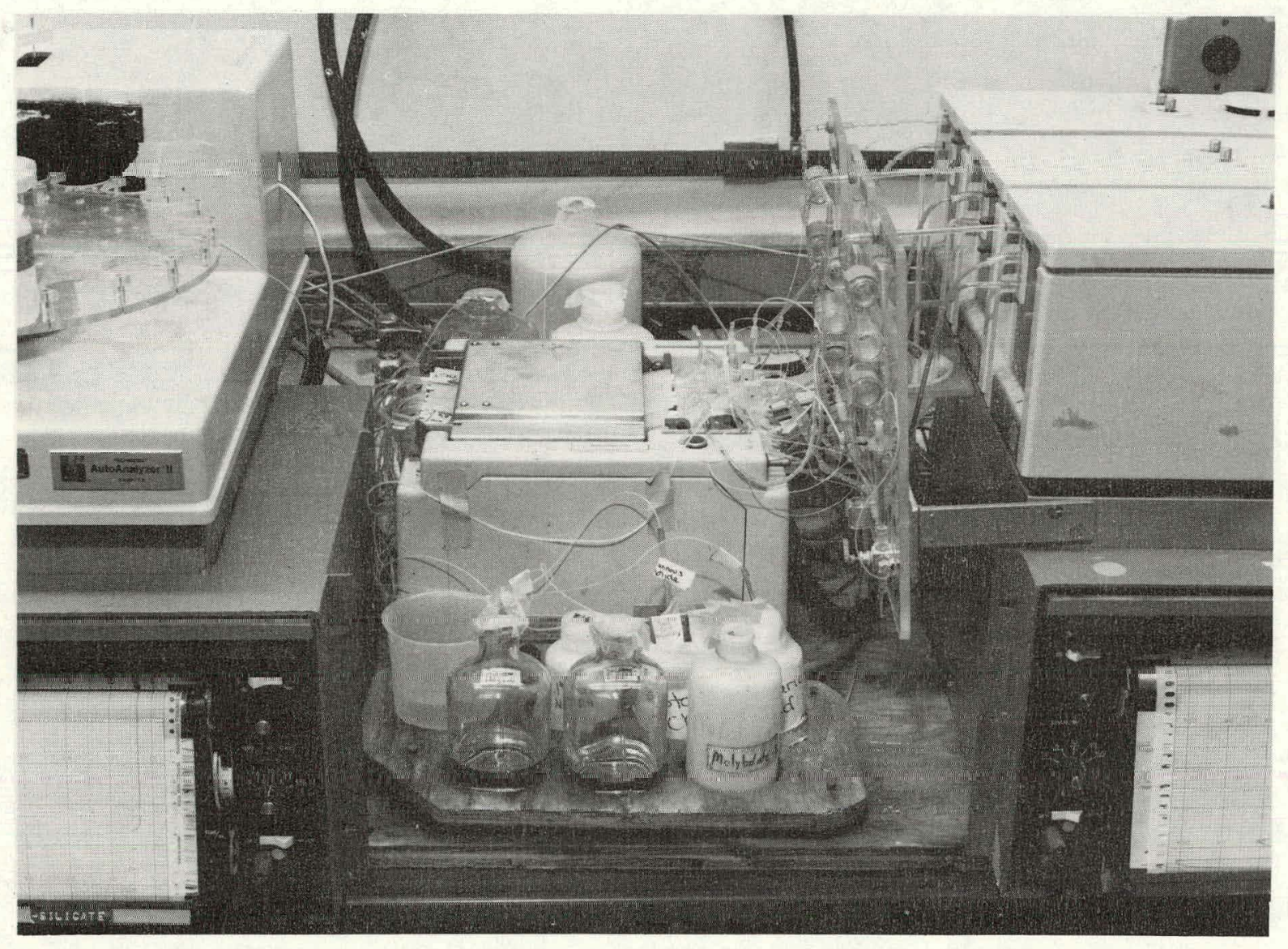

Figure 2-4. Arrangement of AutoAnalyzer Sampler, Pump and Colorimeters which Reduces the Total Length of the Flow System 


\section{OPERATION OF AUTOANALYZER SYSTEM}

Nutrient Analyses in the Field

Running nutrient samples onboard ship is required by projects which collect a large number of samples or desire the highest precision especially with an analysis like ammonium. Some problems may be encountered with shipboard automated nutrient analyses that are not often present in the shoreside 1aboratory. It is generally best if the shipboard nutrient analyzer is oriented along the starboard-port axis, located in an area with relatively constant temperature $\left(15^{\circ} \mathrm{C}\right)$ and near the centerline of the ship. The colorimeters are temperature sensitive so cold drafts in the middle of a run can increase colorimeter drift. The roll of a vessel produces the same angle of roll at the center line and the outside bulkheads however the vertical displacement is much smaller near the center of the vessel so the segmentation air bubbles are less likely to enter the colorimeter flow cell. The problems created by the tips of air bubbles which quickly dip in and out of flowcells during excessive ship roll are most severe with the $50 \mathrm{~mm}$ length flowcells used in ammonium and phosphate analyses.

In terms of operating the AutoAnalyzer at sea there are several additional problems that often arise. The quality of water that comes from ship evaporators can range from nearly perfect with no nutrients to practically straight seawater. It is always best to prepare for lousy shipboard water and bring extra ion exchange columns and several big polyethylene storage jugs.

To successfully analyze for micromolar quantities of nutrients in seawater it is imperative that very pure water is used in reagent and primary standard preparations. Distilled water produced in very good stills is usually contaminated with some nutrients, especially ammonium. Water produced by evaporators aboard ship can of ten be very pure but it is rarely pure enough to use without further treatment.

Mixed-bed ion exchange resins are most often used to further reduce the small amounts of nutrients conlained in distilled or evaporated water. The efficiency of the ion exchange columns is best when flow rates are relatively slow so it is best to fill large 20 to 40 liter polyethylene jugs that have spigots for easy use. The ion exchange columns change colors as the capacity of the resin beads are reached. A convenient method to get the entire use of a column is to connect two columns in series so that the first column pretreats the water for the second column. A flow rate of 200 to $400 \mathrm{ml}$ per minute can be easily obtained. Several brands of ion exchange columns are available and mounting racks can also be purchased. There seems to be no noticeable difference between the several best known brands (e.g. IONXCHANGE cartridges with duplex mounting fixture, Illinois Water Treatment Company, 840 Cedar St., Rockford, IL 61101).

Several spare columns should be taken to sea if good water onboard ship is vital. It is not uncommon for seawater to be accidentally admitted to the shipboard freshwater system. If this happens, a column can often be exhausted in processing 5 to 10 liters. Shipboard contamination and moisture condensation from overhead pipes can also bring disaster if a drop falls in the wrong place.

Another potential source of problems of nutrient samples collected at sea is mistakes in drawing samples from the water bottles especially if it is rough and people are tiol feeling too well. We have tound that it is best to 
have nalgene ( $2 \mathrm{oz} \cdot)$ nutrient sample bottles that are previously numbered with waterproof ink located in a rack under the water sampling bottles or carried in a plastic soda case if a rosette is used. The person who fills the nutrient sample bottles should be very attentive because it is easy to take water from the wrong sampling bottle. Before drawing the samples it is best to place the nutrient sample bottles in numerical order in the rack or sampling case. As each of the nutrient bottles are rinsed and filled they should be checked for proper order, and finally after all the nutrient bottles are filled the numerical order should be checked again while you have the chance to redraw the samples. If an error is made at this step it is nearly impossible to correct it later unless it is a simple error such as filling the bottles in reverse order. Another note of caution - a rosette sampler can collect up to 12 samples on a cast. It is critical that the chief rosette operator check on the number of sample bottles tripped and he should clearly mark the first sample bottle with a tag.

The AutoAnalyzer operator should start analyzing the samples immediately for best results. It a short-term delay 1s necessary, the samples slivuld be refrigerated in the dark to retard changes in the samples. He should place the nutrient bottles on the sampler tray in numerical order taking notice whether they were systematically arranged in the carrying case. It is important to analyze the surface samples first so that the data logging and later computer transfers can be carried out smoothly.

\section{Storage of Nutrient Samples}

The best policy is never store nutrient samples for extended periods -fresh ones are best There are times, however, when it is not convenient or possible to analyze the samples at sea. There are some differences of opinion on the best storage procedure of nutrient samples and there are a few papers that discuss freezing and pickeling (May, 1960; Proctor, 1962; Marvin and Proctor, 1965; Gilmartin, 1967; Thayer, 1970; Degobbis, 1973;). Generally we have had good results from trozen samples for phosphace, sll1cate, nlliale atud nitrite. Results arc sometimes poor on anmonium samples that have been frozen. We have obtalned the best results by collectling samples in nalgent (2 $o z$ ) bottles that are filled to the shoulder, the caps tightened and quick frozen in an upright position in a salt-ice bath. The samples freeze in 20-30 minutes and then are placed in a nutrient case in a freezer. The tops should be checked at this time to be certain that they are tight. The samples are thawed just minutes before analyzing by placing them upright in a sink with running cold water. A comparison of nitrate concentration in both fresh and frozen samples collected on a cruise indicated that the mean concentrations did not change significantly and the mean difference between all the fresh and frozen samples was -0.05 ugat $\ell^{-1}$ (Atwood et al., 1979).

Some speclal samples collected in muddy estuaries, from bottom water samples, or in very dense plankton blooms should be filtered before running the samples on the AutoAnalyzer. To filter such samples pour the sea water from the nalgene ( 2 oz.) sample bottle into a millipore stainless steel filter funnel that uses a prewashed $25 \mathrm{~mm}$ or $47 \mathrm{~mm}$ glass fiber filter (Reeve Angel, Gelman, or Whatman, etc.). The gravity flow of the sample through the filter can be used to rinse the sample bottle. After $1 / 2$ oz of sample is used for rinsing, the filter funnel mounted on the top of a bell jar is placed on a base plate (Fischer order No. 9-788) and a vacuum is applied to filter the remaining sample into the sample bottle. (Alternatively the Filter Funnel can 
be mounted on a bored rubber stopper which fits a glass side armed cup especially constructed to hold the sample bottle.) This process places the filtered sample back into the original sample bottle and removes any interfering particulate matter. For the smaller samples like pore water from cores it is often better to withdraw the sample into a 10 or $20 \mathrm{cc}$ glass syringe and filter through a previously rinsed $0.45 \mathrm{~m}$ membrane filter (Fischer No. 9-730-219) that fits directly on the syringe tip.

\section{Starting Up and Shutting Down}

1. Fill out AutoAnalyzer data sheet for the station.

2. Place samples in sampler tray in order listed on data sheet.

3. Start pumps with reagents if they have been previously shut down.

4. Turn on colorimeters and recorders and wait until stable baselines are established (approximately 20 minutes). Turn on the computer, the $A$ to $D$ interface box and the sampler control box. Load APILOT program into the computer.

5. The pump may be turned on to rapid pump to help flush the reagents thru. Be sure all reagent tubes are in the proper bottles and that all tubes are connected to the colorimeter etc. Turn on nitrate column.

6. Write on the recorder chart paper the ink color for each of the nutrients being run, the station number, the date and time and the investigator's name if they are special samples.

7. Turn sampler main power switch on.

8. Check distilled water and reagents every $1 / 2$ hour until the samples have all been run.

9. To shut down the A.A. move reagent straws to deionized water and if analyzing silicate leave tartaric acid straw in reagent bottle for 1-2 minutes after removing the other reagents before putting into distilled water. A blue precipitate will form if molybdate and $\mathrm{SnCl}_{2}$ are mixed without tartaric acid. The precipitate can be removed with a short flush of the manifold with $0.1 \mathrm{~N}$ sodium hydroxide.

10. Turn off nitrate column.

11. After thoroughly flushing all lines with water, turn off pump and release pump tube end blocks.

12. Turn off power of computer, A to D interface, sample box, sampler, recorders and colorimeters if analyses are completed for the day. While on shipboard the colorimeters are usually not turned off if more samples will be run within 4 to 8 hours.

\section{Standards}

\section{Frimary Standards}

Primary standards should be prepared from the best grade reagents available. Transfer a small quantity of these reagents to weighing bottles and dry in an oven for two hours at $100^{\circ} \mathrm{C}$. Store the dried reagents in a vacuum dessicator. Weightngs should be made to a tenth of a milligram on an analytical balance which has been recently calibrated. Bottles used to store standard solutions (and analytical reagents for that matter) should be initially acid 
rinsed with $10 \% \mathrm{HCl}$ and then rinsed three times with the solution they are to contain. Primary standards preserved with chloroform and stored in the refrigerator are usually stable for a month.

$$
\text { Ammonium - } 5 \text { micromole primary standard/ml }
$$

Dissolve $0.2674 \mathrm{~g}$ ( $5 \mathrm{~m} \mathrm{~mole}$ ) of $\mathrm{NH}_{4} \mathrm{Cl}$ in $\sim 800 \mathrm{ml}$ DDW in a 1 liter flask and dilute to the mark with DDW. Transfer to a $500 \mathrm{ml}$ poly bottle, add 3 drops of chloroform, and refrigerate.

Nitrate - 20 micromole primary standard/ml.

Dissolve $1.0111 \mathrm{~g}$ ( $10 \mathrm{~m} \mathrm{~mole}$ ) of $\mathrm{KNO}_{3}$ in $\sim 400 \mathrm{ml}$ DDW contained in a 500 $m l$ volumetric flask, dilute to the mark, add 3 drops of chloroform, and refrigerate.

Nitrite - 5 micromole primary standard/ml.

Dissolve $0.3450 \mathrm{~g}$ ( $5 \mathrm{~m}$ mole) of $\mathrm{NaNO}_{2} \mathrm{in}_{\mathrm{n}} \sim 800 \mathrm{~m} 1 \mathrm{DDW}$ contained in a 1 liter volumetric flask and dilute to the mark with DDW. Transfer to a $500 \mathrm{ml}$ poly bottle, add 3 drops of chloroform and refrigerate.

Orthophosphate - 5 micromole primary standard/ml.

Dissolve $0.6804 \mathrm{~g}$ ( $5 \mathrm{~m} \mathrm{~mole}$ ) $\mathrm{KH}_{2} \mathrm{PO}_{4}$ in $\sim 800 \mathrm{ml} \overline{\mathrm{D}} \overline{\mathrm{W}}$ and dilute to 1 liter with DDW. Transfer to a $500 \mathrm{ml}$ poly bottle, add 3 drops of chloroform and refrigerate.

Orthosilicic Acid - 20 micromole primary standard/m1.

Add $0.9403 \mathrm{~g}$ ( $5 \mathrm{~m} \mathrm{~mole}) \mathrm{Na}_{2} \mathrm{SiF}_{6}$ to a $500 \mathrm{~m} 1$ nalgene beaker containing $150 \mathrm{ml} \mathrm{DDW}$ and a teflon coated magnetic stirring bar. Stir magneticaliy at low speed for several hours to effect complete solution. Uuancicarively transfer this solution to a $250 \mathrm{ml}$ volumetric flask and dilute to the mark with DDW. Transfer to a poly bottle, add 3 drops of chloroform and retrigerate.

Urea - 5 micromole primary standard.

Dissolve $0.1502 \mathrm{~g}\left(2.5 \mathrm{~m}\right.$ mole) of $\mathrm{NH}_{2} \mathrm{CONH}_{2}$ in $\sim 800 \mathrm{~m} 1$ DDW in a 1 liter flask and dilute to the mark with DDW. Transter to a $500 \mathrm{ml}$ polybottle, add 3 drops of chloroform and refrigerate.

\section{Secondary Standards}

Secondary standards can be prepared individually or as a mixed standard containing an aliquot of each of the five primary standards. The mixed secondary standard approach is appealing because a single set of working standards prepared from a mixed secondary standard can be used to calibrate all six chemistries simultaneously. In order for this approach to be valid, however, one must assume that each primary standard is pure. In practice, this proves to be a rather poor assumption since the salts used to prepare the primary standards usually contain trace impurities which are often significant at the micromolar concentration range. 
For example, assume that the nitrate primary standard contained a small amount of phosphate impurity. It follows that when an aliquot of this nitrate standard was combined with an aliquot of the phosphate primary standard, the analytical concentration of phosphate in the resulting mixed secondary standard would be somewhat higher than its nominal concentration. This error often goes undetected because its only manifestation is a non-zero intercept for the Beer-Lambert calibration plot of absorbance versus nominal phosphate concentration.

For this reason, it is probably best to prepare an individual secondary standard and set of working standards for each analyte. Once this is done, however, the concentrations of the other four analytes in each of the five working standard sets can be determined and appropriate correction factors calculated to apply when mixed standards are used. These factors should remain constant as long as the concentration of the primary standards and their ratios to each other in the mixed secondary standards remain constant. It should be stressed that the errors which result from the use of mixed standards are small (usually $1-5 \%$ ), but this error source is one of which the analyst should be aware.

In our laboratory, we prepare two sets mixed/working standards combining those primary standards which experience has shown do not contain trace impurities of one another. To make five concentrations of mixed standard series number 1 equivalent to $5,15,25,35$, and $45 \mu \mathrm{g}$-at $/ 1$, pipet $25,75,125,175$, and $225 \mu \mathrm{l}$ each of primary nitrate and silicic acid into $100 \mathrm{ml}$ volumetric flasks. Dilute to the mark with DDW (Table 3-1). These standards constitute the "S-1" series. For work in the Bering Sea and other waters where higher concentrations of silicic acid are normally encountered, double the amount of silicate primary standard to $50,150,250,350$, and $450 \mu 1$ for this series and calculate the standard factor (see STAND) based on these greater values. If urea is to be analyzed it should be included in the "s-1" standard by adding $10,30,50,70$, and $90 \mu 1$ of the primary solution to obtain $0.5,1.5,2.5$, 3.5 , and $4.5 \mu \mathrm{g}-\mathrm{at} / 1$ urea standards.

Concentrations of $0.5,1.5,2.5,3.5$, and $4.5 \mu \mathrm{g}-\mathrm{at} / 1$ of $\mathrm{NH}_{4}, \mathrm{NO}_{2}$, and $\mathrm{PO}_{4}$ are obtained by pipetting $20 \mu \mathrm{l}$ in $200 \mathrm{ml}$ and $30,50,70$, and $90 \mu \mathrm{l}$ of the primary solutions per $100 \mathrm{ml} \mathrm{DDW}$ as indicated above. This group of mixed standards is designated as the "S-2" series (Tahle $3-1$ ).

With good quality chemicals, these two mixed/working standards eliminate the need to apply correction factors.

A synchronization standard designated as DO, is prepared by pipetting 225 $\mu \mathrm{L}$ of $\mathrm{NO}_{3}$ and $\mathrm{Si}(\mathrm{OH})_{4}$ primary standard and $90 \mu \mathrm{l}$ of $\mathrm{NO}_{2}, \mathrm{PO}_{4}, \mathrm{NH}_{4}$, and urea primary standard into $100 \mathrm{ml}$ distilled water.

There are definite salt effects in some of the analyses, e.g. ammonium. It is therefore highly recommended that if standards are prepared in distilled water, then spike standards in seawater should also be analyzed. This is best accomplished by making a standard addition of primary standard to a surface sample on selected low nutrient stations. With the present ammonium method and manifold (see Cookbook section), we have obtained consistently better reproducibility and linearity with working ammonium standards prepared in low nutrient seawater. The amnonium series run in distilled water yields reduced absorbances and deviation from linearity. We emphasize that these ammonium seawater samples should be utilized for calculating the standard factor.

The merits of preparing standards in distilled water can be debated among a group of seawater chemists for hours. There are difficulties with almost all the choices. Here are some of the arguments. 
Table 3-1

Mixed/Working Standarde for Nutrient Analysis

\begin{tabular}{|c|c|c|c|c|c|c|}
\hline ID & $\begin{array}{l}\text { Seandard } \mathrm{Se} \\
\left(\mathrm{NO}_{3}+\mathrm{S}_{\mathrm{i}}(\mathrm{c}\right. \\
\text { Primary/10 }\end{array}$ & $\begin{array}{l}\text { E NO. } 1 \\
\text { H) } 4 \text { ) } \\
\text { me DDW }\end{array}$ & $\mu g-a t / 1$ & ID & $\begin{array}{l}\text { Scandard Sei Nu. } 2 \\
\left(\mathrm{NO}_{2}+\mathrm{PO}_{4}+\mathrm{NH}_{4}\right) \\
\text { Primary/100 ml DDW }\end{array}$ & $\mu g-a t / 1$ \\
\hline$s-1-1$ & 25 & $50 *$ & 5.0 & $S-2-1$ & 10 & 0.5 \\
\hline$s-1-2$ & 75 & $150^{*}$ & 15.0 & $s-2-2$ & 30 & 1.5 \\
\hline$s-1-3$ & 125 & $250 *$ & 25.0 & $s-2-3$ & 50 & 2.5 \\
\hline$s-1-4$ & 175 & $350 *$ & 35.0 & $s-2-4$ & 70 & 3.5 \\
\hline$s-1-5$ & 225 & $450 *$ & 45.0 & $s-2-5$ & 90 & 4.5 \\
\hline \multicolumn{7}{|c|}{$\begin{array}{l}\text { If standards are prepared in sodium chloride or splked seawater instead of } \\
\text { DDW, "blanks" are designated as } 5-1-0 \text { and } 5-2-0 \text { respectively. }\end{array}$} \\
\hline
\end{tabular}

*Microliters of silicic acid in S-1 standard for Bering Sea work. Equivalent concentrations $10,30,50,70$, and $90 \mu \mathrm{g}$-at $51(\mathrm{OH})_{4} / 1$. 
A. Deionized water standards:

Advantages

1. The quality of the water is usually well known.

2. The quality of the water is not highly variable.

3. The prepared standards are relatively stable with time.

4. Large volumes of water are easily available.

Disadvantages

1. The chemical factors may be different than in salt solution (salt effect).

B. Deionized water-sodium chloride solutions:

Advantages

1. Salt effects on chemical factors are minimized.

2. Sodium chloride solution is easy to prepare and is not expensive.

Disadvantages

1. Ammonium impurity is quite large in sodium chloride.

2. Large quantities of sodiun chloride are sometimes required.

C. Artifical Seawater Solution:

Arguments are similar to sodium chloride solution. No known advantages over sodium chloride.

D. Low Nutrient seawater:

Advantages

1. Salt effects are eliminated.

2. In certain regions of the ocean 1 t is easily obtained. Disadvantages

1. Ir always contains sune nutrients.

2. If not used immediately it must be filtered to remove any particulate matter.

3. Often it is difficult to obtain when working in eutrophic waters.

4. Storage is difficult so large quantities are not easily obtained.

The choice of 1) low nutrient seawater when available or 2) deionized water standards for seawater nutrient samples was made because the ammonium analysis is very important in our scientific programs which are often studying highly variable eutrophic environments. Other choices may be made in oligotrophic waters.

The frequency of analyzing standards has increased in recent years as the analysis rate has increased. When 10 samples per hour was a good analysis rate, it was often difficult to run standards more than once a day, As the 
analysis rate has gone to 20,40 or even 60 samples per hour it is possible to analyze more standards. When the AutoAnalyzer is not busy running nutrient samples between stations, while at sea, it has been a regular procedure to run a set of standards ( $S 1$ and $S 2$ standards of 5 concentrations each for a total of 11 samples including the sync sample). We try to run a complete set of standards every six hours if the AutoAnalyzer is running around the clock. of course, one S1 and one S2 standard is placed at the beginning of each set of station samples which are used to check how well the AutoAnalyzer is operating.

\section{Running Standards}

The determination of nutrient concentration in seawater is a strictly empirical process, $i . e$. for each analysis chemical factors are calculater using prepared standard concentrations. There are several steps in preparing the standards which produces some uncertainty in the concentrations prepared. Tt. is therefore very advisable that an independent check of standards be made in some way. This is often accomplished by obtaining standard solutions from a commercial manufacturer, government agency, or another marine laboratory.

Several approaches in producing standards have been tried. A commercial firm (Sagami Chemical Research Center, Japan) has manufactured several concentrations of orthophosphate, nitrate, nitrite and silicic acid in solutions of sodium chloride which sell for about $\$ 5$ per vial. The orthophosphate, nitrate and nitrite are sealed in glass ampoules and silicate is placed in plasti.. vials. The solutions are normally only used immediately after opening so a calibration using 3 concentrations of the 3 nutrients would cost about $\$ 45.00$. The cost is rather high so these are used only occasionally as a check rather than the routine daily standards. There have heen snme negative comments about these standards from several laboratories because of possible inaccuracies.

Another approach has been to prepare and freeze standards which are used to compare to fresh standards while at sea. The institutions that use this method have carefully worked out the details of producing, freezing, and thawing the standards in order to obtain highly precise results.

Some distilled water standards can be obtained from government agencies in limited quantities for calibration purposes. The Environmental Protection Agency (EPA) has produced phosphate standards in the past.

Refractive Index Corrections

The Beer-Lambert law which defines the linear relationship between the absorbance of a species in solution and its concentration is valid only when refractive index (and a number of other solution variables) is constant. When seawater samples are determined relative to a distilled water baseline, this assumption is not satisfied. For this reason, some fraction of the total absorbance measured for seawater plus reagents will reflect refractive index rather than analyte concentration differences relative to the distilled water plus reagents baseline. The magnitude of the refractive index correction is a function of the Initial salinity of the sample and the amount of dilution the sample experiences in the manifold. Once determined, the refractive index corrections remain relatively constant if the salinity of the seawater samples remain constant to within $\sim \pm 2 \%$ provided that there is no change in either the manifold or the colorimeter's cell path length or standard calibration control. 
To determine refractive index corrections seawater or a sodium chloride solution which closely matches the salinity of the samples expected to be encountered is analyzed after one of the reagents necessary for the formation of the absorbing species in each analysis is omitted. The resulting change in absorbance relative to the distilled water baseline is therefore due only to refractive index changes. Thus the absorbance due to differences in analyte concentration $\left(A_{c}\right)$ is equal to the total absorbance $\left(A_{t}\right)$ of a sample minus the absorbance due to refractive index changes $\left(A_{r}\right)$.

$$
A_{c}=A_{t}-A_{r}
$$

The suggested reagent ommissions for each analysis is presented below. Note that for standards, the refractive index correction is included in the "blank" absorbance determined for the sodium chloride solution or seawater used in their preparation.

Determination of Refractive Index

Ammonium. Substitute $1 \mathrm{~g} \mathrm{NAOH}$ in $200 \mathrm{~m} 1 \mathrm{DDW}$ for reagent $\mathrm{B}$. All other reagents unchanged.

Orthosilicic acid. Substitute $80 \mathrm{ml} \mathrm{DDW}+120 \mathrm{ml} 10 \% \mathrm{v} / \mathrm{v} \mathrm{HC}$ for the molybdate reagent. All other reagents unchanged.

Nitrate + Nitrite, Nitrite. Substitute DDW containing Brij-35 wetting agent for the NNED reagent. All other reagents unchanged.

Orthophosphate. Substitute $10 \% \mathrm{v} / \mathrm{v} \mathrm{H}_{2} \mathrm{SO}_{4}$ containing sodium lauryl sulfate wetting agent for the molybdate reagent. All other reagents unchanged. Urea. Substitute $1.65 \mathrm{~m} 1 \mathrm{DDW}$ for the semicarbizide in the color solution.

Carryover Corrections

If dispersion is minimized in the continuous flow analysis channels by reducing the size of the manifold and increasing segmentation by injecting a lot of bubbles, then the peaks obtained will be sharp and will look like square waves. However, when several samples are run close together preceding samples may affect the height of following peaks. This effect is known as "carryover" (Walker et al., 1970; Snyder et al., 1976; Jacklyn et al., 1978) or "sample interaction" (Thiers and Oglesby, 1964; Thiers et al., 1967). Peaks are composed of fall curves and rise curves so carryover can be viewed as the height of the fall curve at the time when the next peak is formed (Walker et al., 1970). The extent of carryover can be calculated as: carryover $(C .0)=.E_{1} e^{-p / b}$

where $E_{1}$ is the height of the previous peak, $p$ is the interval between peaks (sample plus wash time) and $b$ is the slope of the exponential portion of the rise or fall curve.

In practice we do not correct for carryover in our determination of seawater nutrients. This is mainly the result of not finding a significant interactiaon between peaks. This was checked by alternately running two low samples and then two high samples.

Precision Testing of Peak Reading Program (APILOT)

The use of large numbers of periodic standards has the purpose of maintaining a high degree of accuracy of the results in the nutrient analyses. A further check on the precision of the results can be estimated by running a 
number of replicate determinations at high, medium, and low nutrient concentrations. As a result, Table 3-2 was constructed from a data set obtained at sea under normal working conditions. Each sample was individually collected in a separate bottle so the values should represent a "typical" degree of precision.

Table 3-2

Field Replication Experiments using Natural Seawater. Units are: $\mu g-a t$ liter ${ }^{-1}$

\begin{tabular}{|c|c|c|c|c|c|}
\hline & $\mathrm{PO}_{4}$ & $\mathrm{SiO}_{4}$ & $\mathrm{NO}_{3}$ & $\mathrm{NO}_{2}$ & $\mathrm{NH}_{4}$ \\
\hline \multicolumn{6}{|l|}{ Low Conc. } \\
\hline $\begin{array}{l}\text { No of replicates } \\
\text { Mean Concentration } \\
\text { Std. Dev. } \\
95 \% \text { Confid. Interval } \\
\text { Med. Conc. }\end{array}$ & $\begin{array}{l}11 \\
0.17 \\
0.02 \\
0.02\end{array}$ & $\begin{array}{l}10 \\
1.36 \\
0.06 \\
0.05\end{array}$ & $\begin{array}{r}8 \\
0.09 \\
0.01 \\
0.01\end{array}$ & $\begin{array}{l}\quad 17 \\
0.05 \\
0.01 \\
0.006\end{array}$ & $\begin{array}{l}17 \\
0.09 \\
0.01 \\
0.008\end{array}$ \\
\hline $\begin{array}{l}\text { No. of replicates } \\
\text { Mean Concentration } \\
\text { Std. Dev. } \\
95 \% \text { Confid. Interval } \\
\text { Iligh Conc. }\end{array}$ & $\begin{array}{r}20 \\
1.09 \\
0.03 \\
0.01\end{array}$ & $\begin{array}{r}20 \\
11.96 \\
0.12 \\
0.05\end{array}$ & $\begin{array}{r}20 \\
19.78 \\
0.10 \\
0.05\end{array}$ & $\begin{array}{l}\quad 11 \\
0.26 \\
0.009 \\
0.007\end{array}$ & $\begin{array}{r}8 \\
0.68 \\
0.03 \\
0.03\end{array}$ \\
\hline $\begin{array}{l}\text { No. of replicates } \\
\text { Mean Concentration } \\
\text { Std. Dev. } \\
95 \% \text { Confid. Interval }\end{array}$ & $\begin{array}{l}17 \\
3.21 \\
0.02 \\
0.02\end{array}$ & $\begin{array}{r}17 \\
178.23 \\
0.35 \\
0.17\end{array}$ & $\begin{array}{r}17 \\
42.97 \\
0.24 \\
0.13\end{array}$ & $\begin{array}{l}10 \\
1.28 \\
0.006 \\
0.005\end{array}$ & $\begin{array}{l}20 \\
6.38 \\
0.16 \\
0.08\end{array}$ \\
\hline
\end{tabular}

Comparison of Automated and Manual Data Logging

In addition to the replication tests described in the previous section a comparison of automated peak reading using the "APILOT" program was compared to the manual method of reading the analog strip charts. The natural seawater samples were run at three speeds $(20,40$ and 60 per hour) and were recorded with the "APILOT" program. The strip charts were read manually and the peaks were entered into files using the "MANDAT" program. A comparison of each of the sampling rates was made using the "A vs $M$ " program. The output on pages 24-33 were run at 20 samples per hour for both sets of samples, HA016 and HM016. The first page of output lists the absorbances read by the computer (HA016) and the data set 2 was read manually (HMO16). A table of differences for the nutrient channel and a plot of those differences versus sample number indicates that only one or two points deviated by more than .03 absorbance units for silicate while the majority of data for phosphate, silicate, nitrate and nitrite differed by 0.01 absorbance units.

Nutrient analyses at faster sampling rates do show divergence between manual and computer determined absorbances if the chemical aspects of the 
AutoAnalyzer methods are not optimum. If the nutrient channels are well designed and maintained, then analysis rates of 60 samples per hour produce results that are nearly as precise and accurate as 20 samples per hour.

\section{Comparison of Slow and Fast Sample Analysis Rates}

A series of natural seawater samples was analyzed at 20,40 and 60 samples per hour using the "APILOT" program. A comparison of each analysis was made for differences that occurred in going from 20 to 40 analyses per hour and 40 to 60 analyses per hour using the "A vs $M "$ program. The example data set (pages 34-39) shown is a comparison between 20 samples per hour (HY2-20) and 40 samples per hour (HY2-40). The analysis of the data indicates that the phosphate channels gave higher results at 20 samples per hour than 40 per hour which is probably related to some "carryover effect" in that channel. Silicate exhibited no trend while nitrate and nitrite were lower at the slow speed. Finally, ammonium was in need of some work because the differences were quite large and all tended to be high at the slow speed compared to the faster rate. 


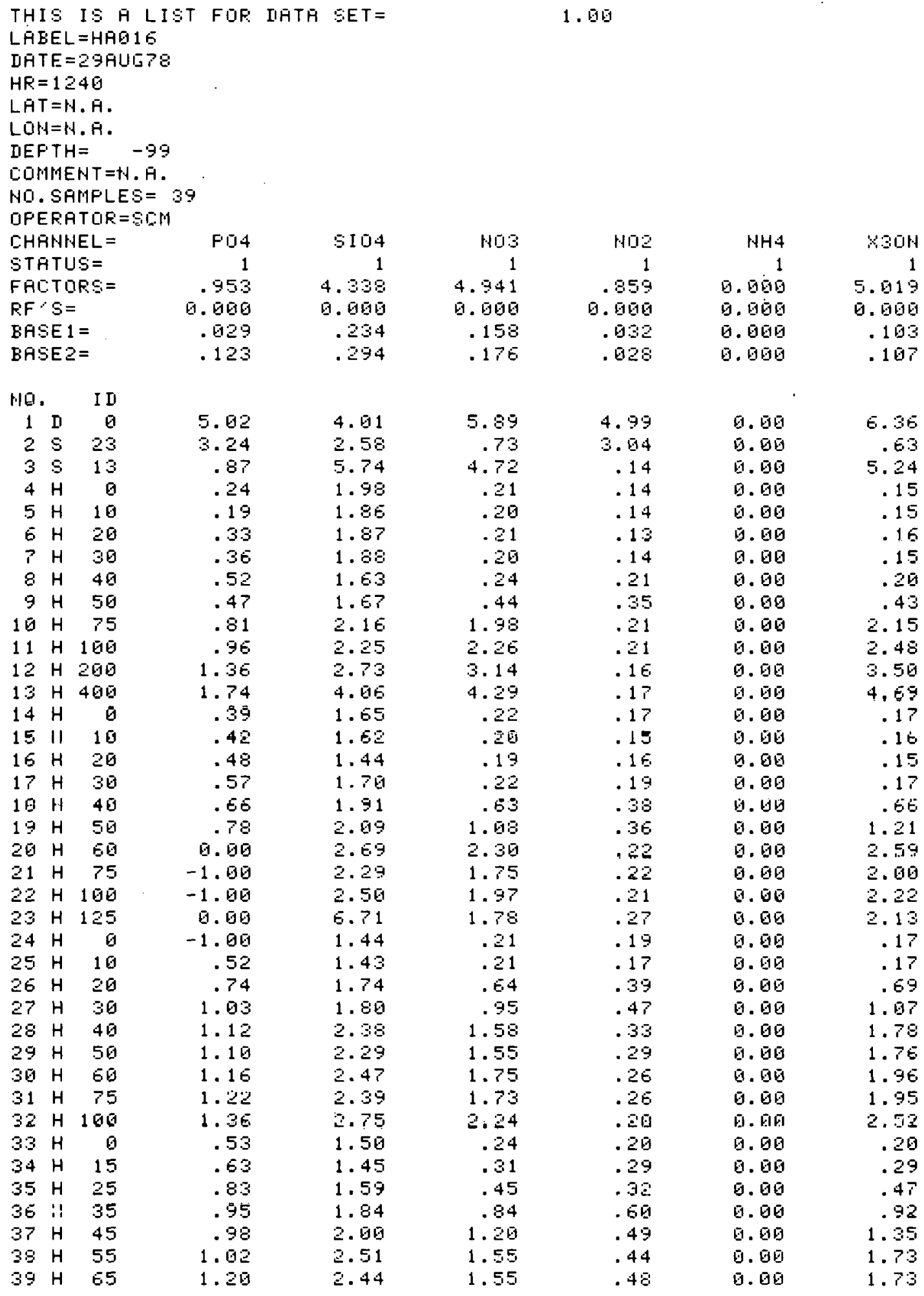




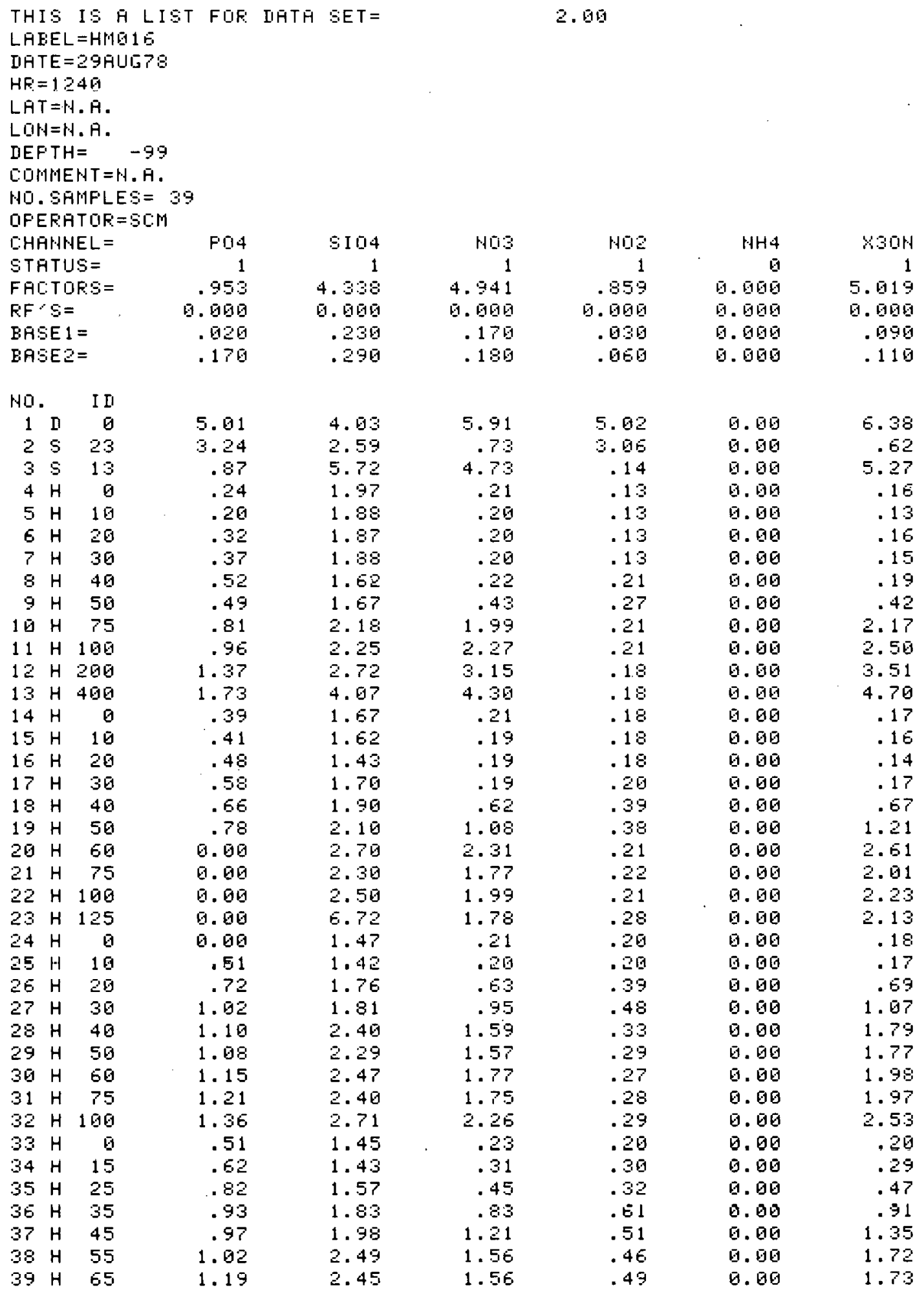


THIS IS A TAELE OF MANIJAL RHII COMFUTER RERI RESDRERHCE FOR FO4 $1=H A Q 1 G$

$2=H M 16$

PEAK HO

$\begin{array}{cc}1 & 5.92 \\ 2 & 3.24 \\ 3 & .87 \\ 4 & .24 \\ 5 & .19 \\ 6 & .33 \\ 7 & .36 \\ 8 & .52 \\ 9 & .47 \\ 16 & .81 \\ 11 & .96\end{array}$

$2 \mathrm{FO4}$

5. 01

3.24

.87

.24

.20

.32

.37

.52

.49

.81

.96

1.37

1.36

1. 74

.39

.42

.48

.57

.66

.78

0.00

$-1.06$

$-1.09$

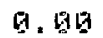

$-1.00$

.52

.74

1. 09

1.12

1.19

1.16

1. 22

1. 5

.53

.63

.83

.95

.98

1.02

1. 20

1. 73

.39

.41

.48

.58

.66

.78

6. 90

0.00

6.00

a. 00

0.00

.51

.72

1. 02

1. 10

1. 08

1.15

1. 21

1.38

.51

.62

.82

.93

.97

1.02

1.19

1-2

.91

.00

.00

$-.06$

$-.91$

.01

$-.01$

.60

$-.02$

.06

$-.00$

$-.01$

.01

$-.05$

.51

$-.00$

$-.01$

$-.00$

$-.00$

0.00

$-1.00$

$-1.00$

0.00

$-1.00$

. 1

.02

. 1

.62

.02

.01

.91

$=.00$

.02

. 01

.01

.02

.01

39

1. 19

$-.00$ 


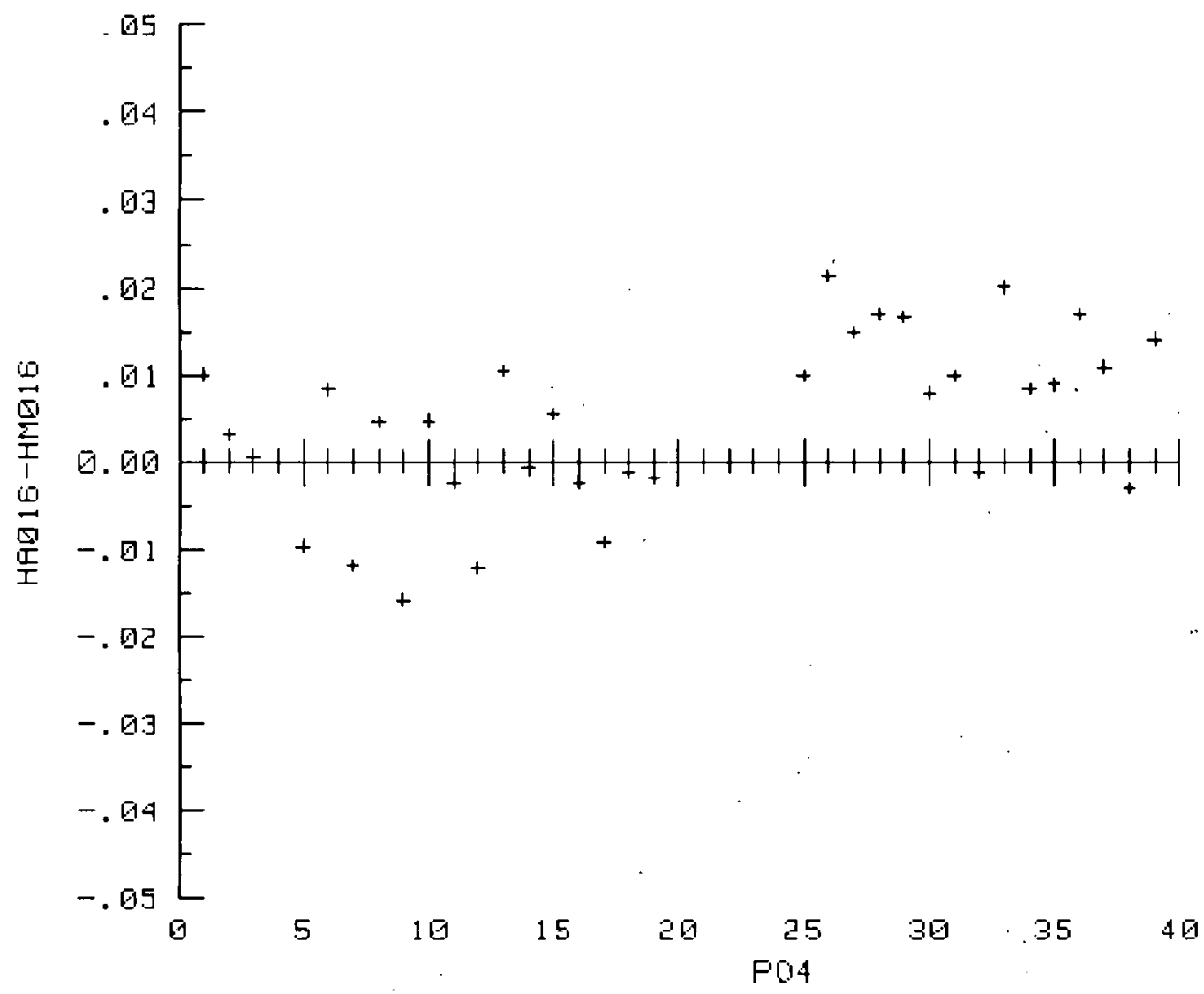




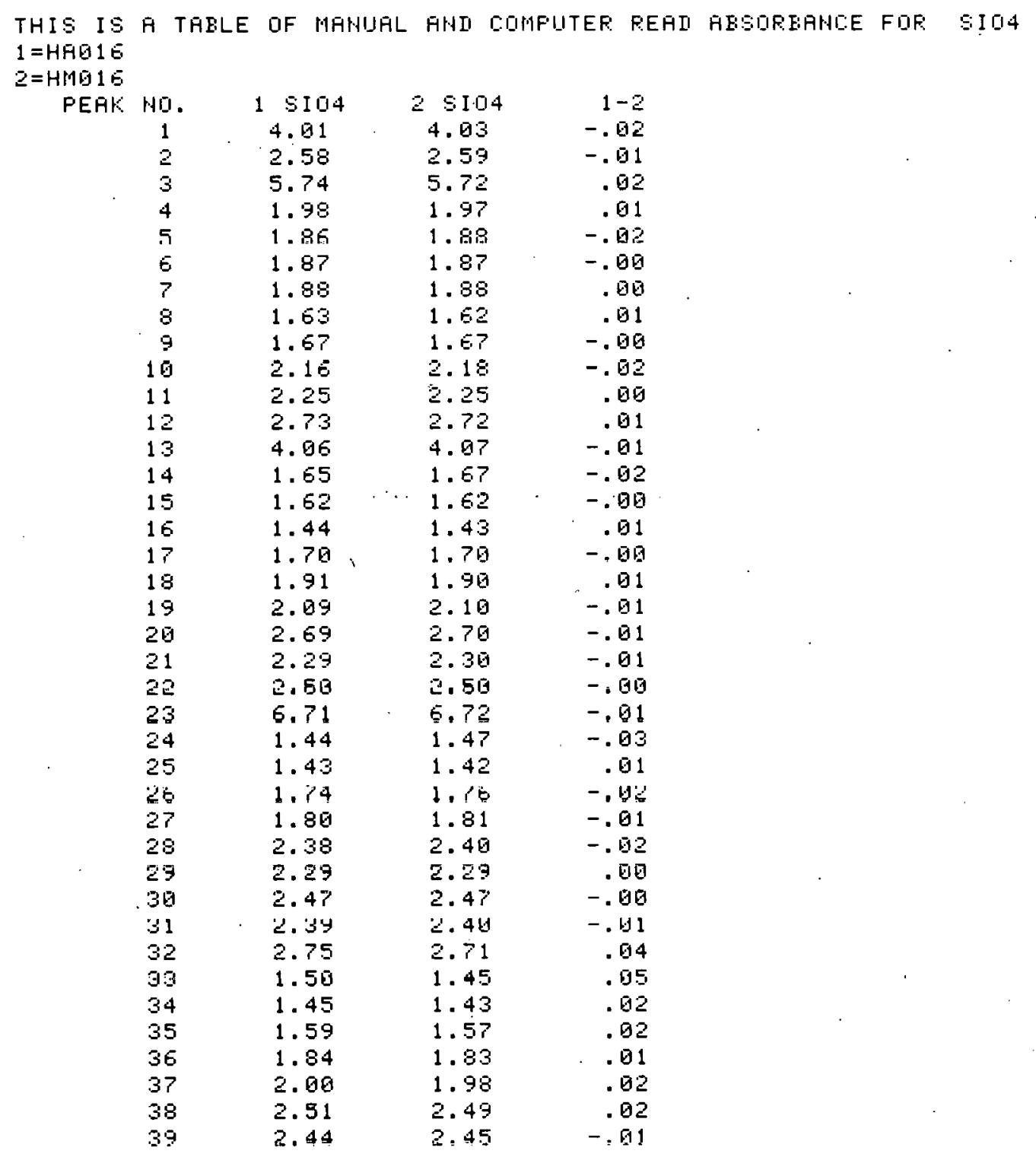




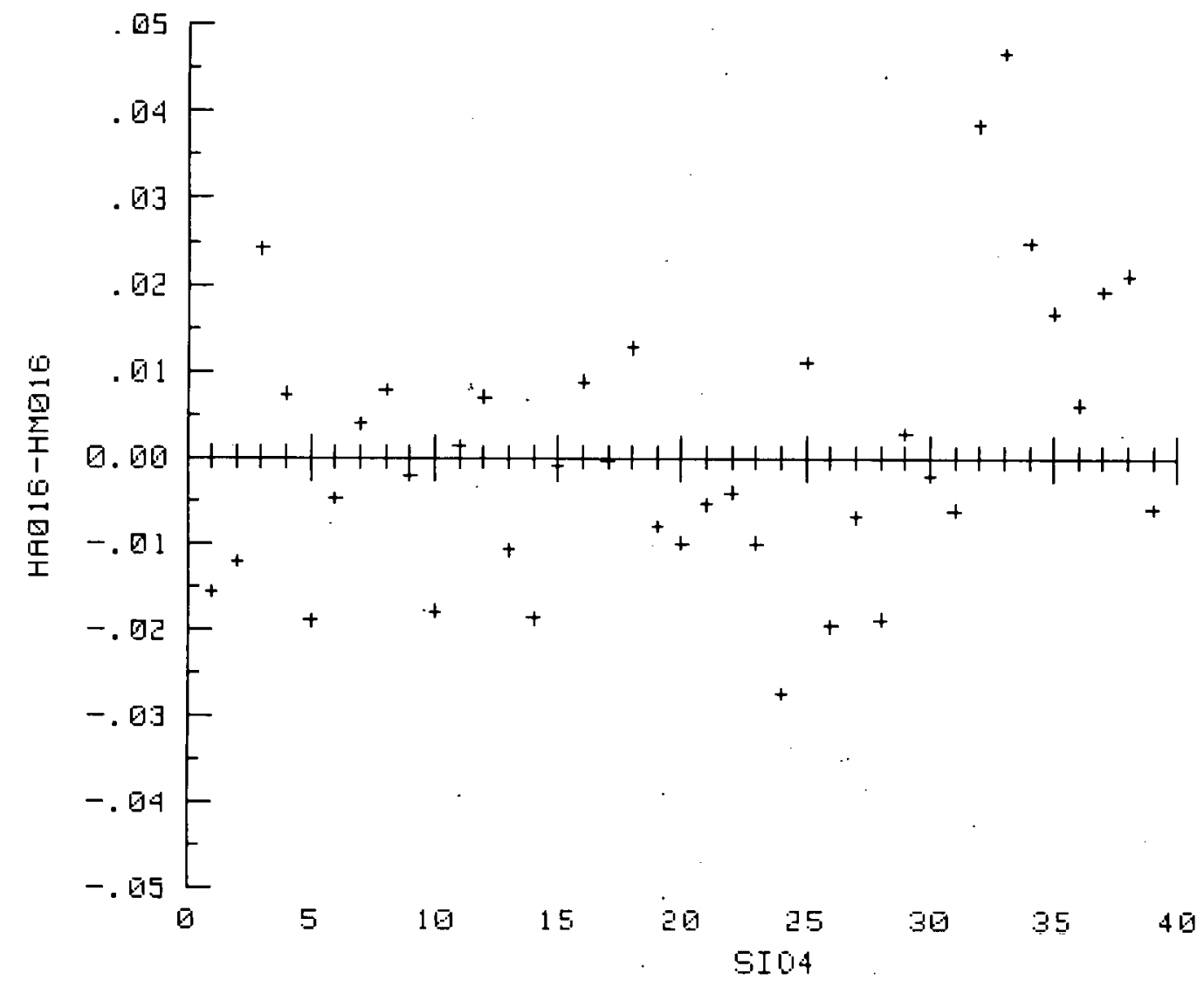




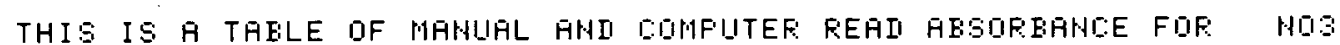
$1=H A G 16$

$2=H M 16$

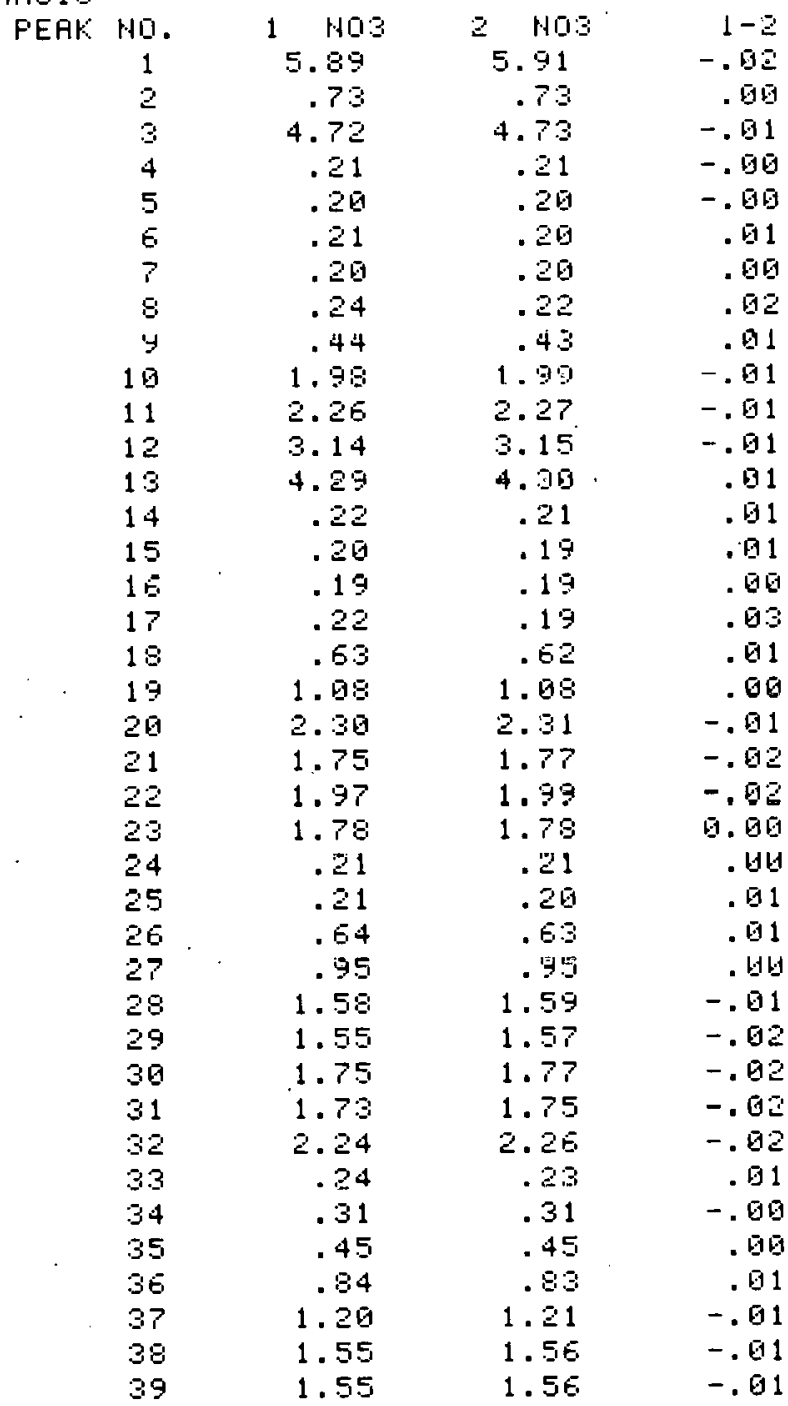




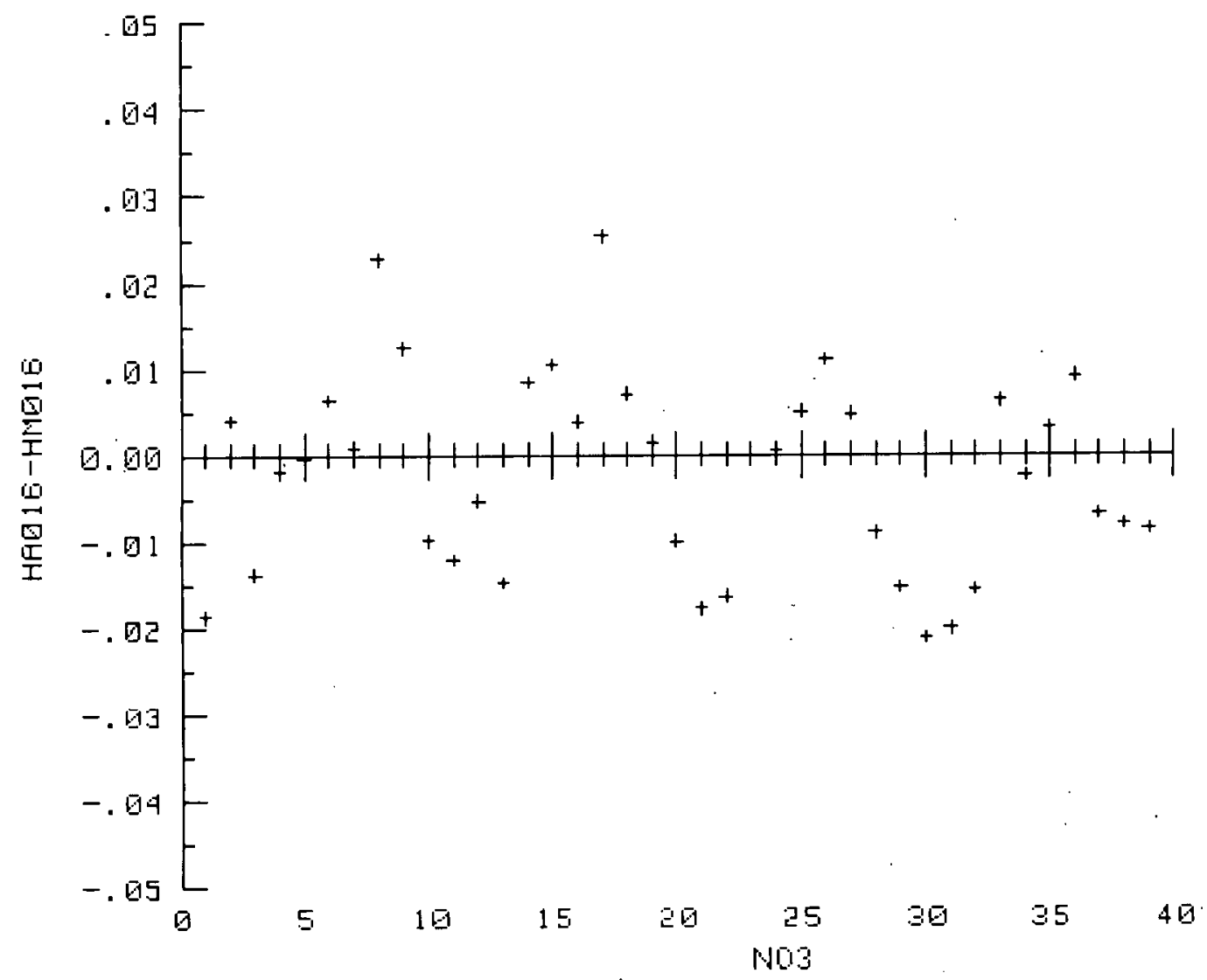




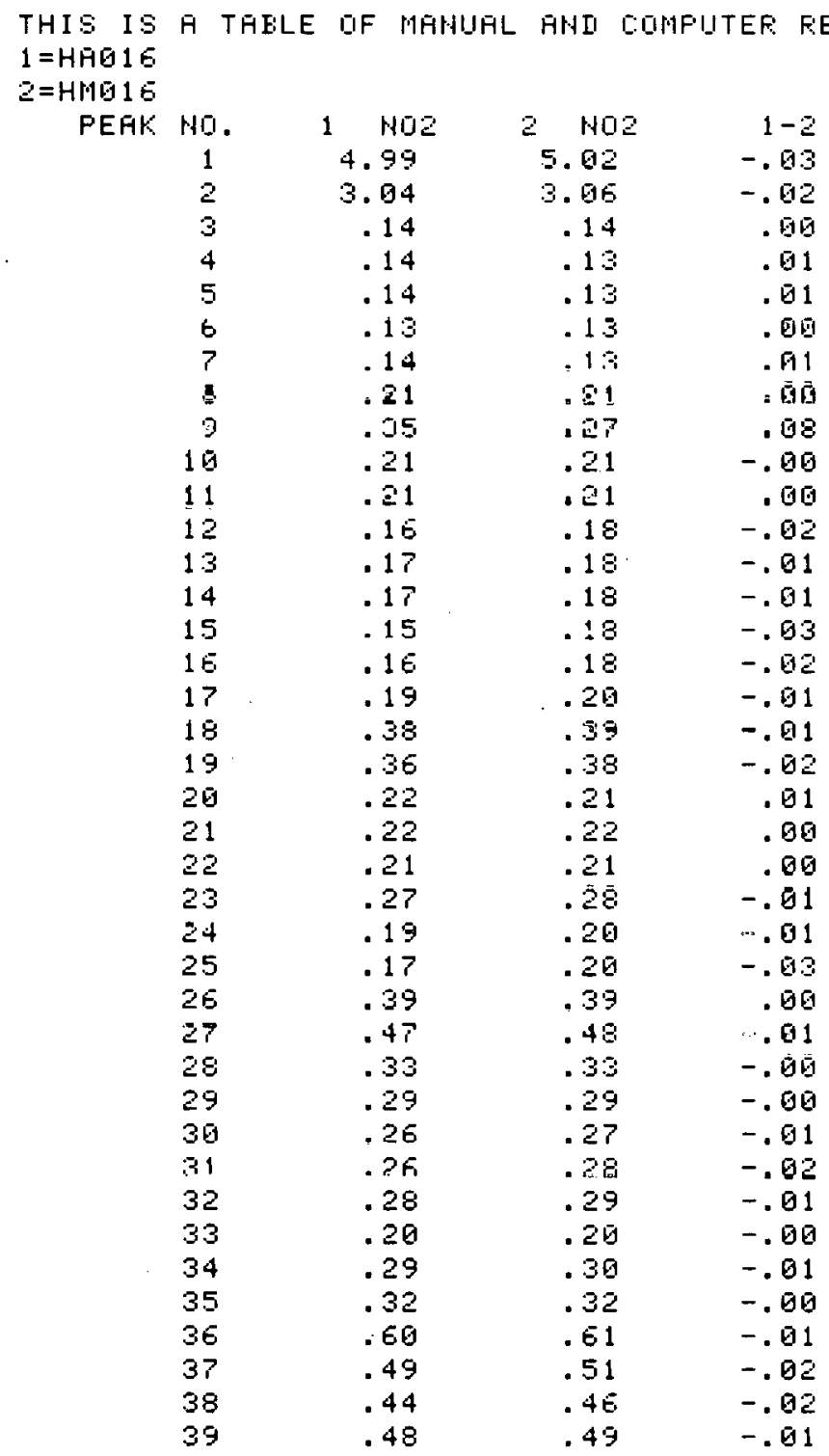




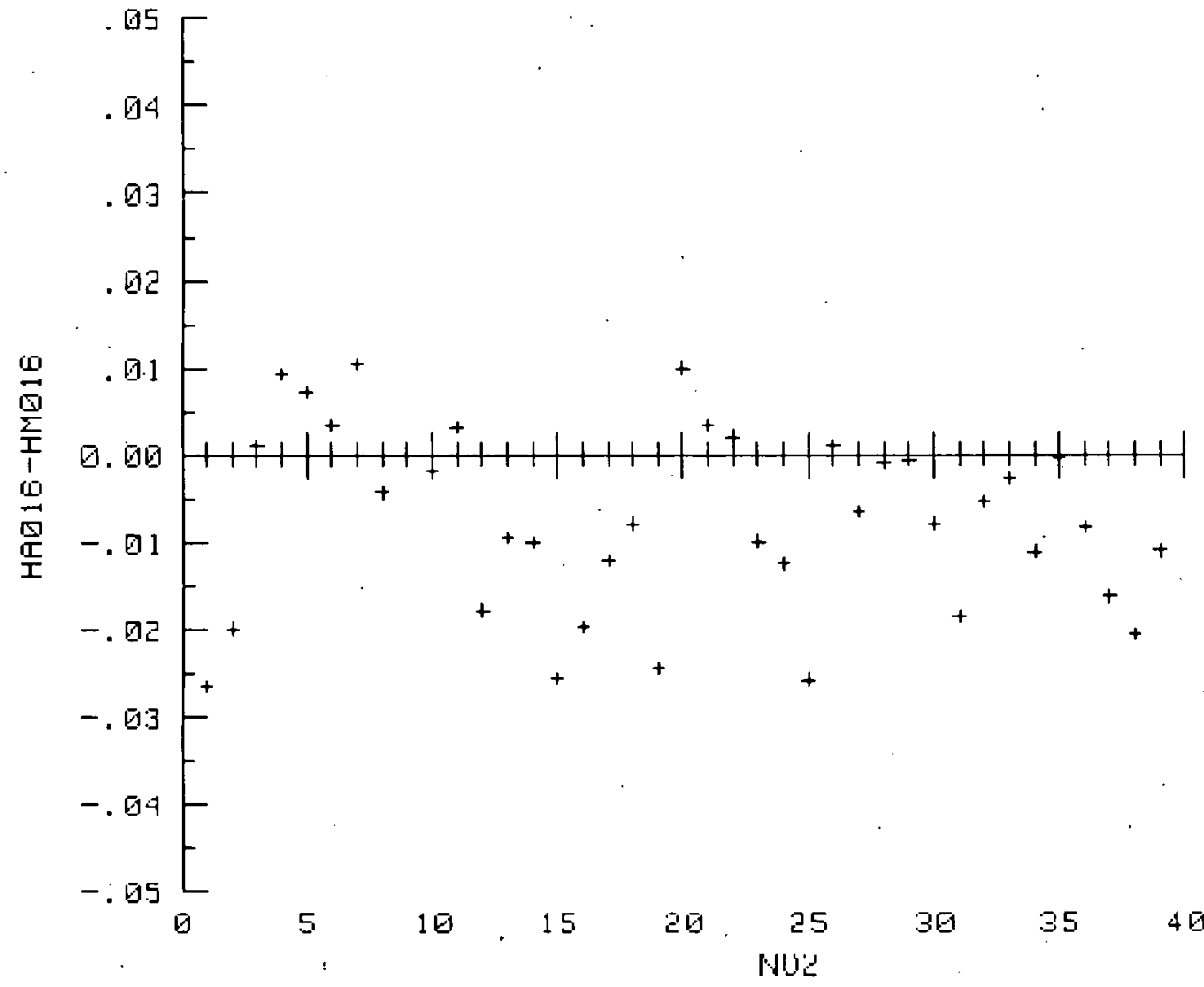


THIS IS H LIST FUR IIHTA GET=

LAEEL $=H Y Z-2 \mathrm{G}$

IIATE $=120 T: T P$

$H F:=0.5 .45$

$L F T=N . H$.

LOH. $=N . \bar{H}$.

IJEFTH $=\quad-9.9$

COMMENT $=$ H.

HO. SAMFLES=16

DFEF:ATOR: $=I F$

EHAHHEL $=$
STHTHS=

FALTUR: =

FF: $:=$

BASE $1=$

EASE: $=$

F

Fin

1. 244

6. 060

.090

.122

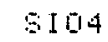

1

$4.76 ?$

‥ 960

.112

.131

N11.

1 II 11

2512

3522

$4 \mathrm{H}$

$5 \mathrm{H} 5$

E H 16

$7 \mathrm{H} 15$

B $\mathrm{H} 2 \mathrm{~B}$

$3 \mathrm{H} \quad 30$

3.55

.42

1. 71

.63

.65

. 6

.64

.62

.75

.94

$16 \mathrm{H} 4 \mathrm{G}$

7.35

2.35

.14

.37

.37

.38

.39

.45

1.28

2.17

THIS IS A LIST FOF IHTH SET=

LFEEL = HY $2-40$

IIATE = 120 OT TS

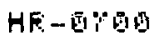

I. AT $=1 ! .9$.

LOH = H. R.

IIEFTH:= $-9.9$

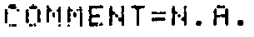

NO. $B$ AHFLES: $=10$

DFERATDR: $=$ :JF

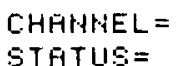

STFITUS=

FHัT TRE: $=$

$\mathrm{R} F \cdot \mathrm{S}=$

BAEE $1=$

BHSE: =

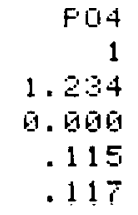

14

5104

4. 767

6. 1616

.127

.151

NO. II II

$\begin{array}{rrr}1 & \text { I } & 0 \\ 2 & 5 & 12\end{array}$

3532

$4 \mathrm{H}$

$5 \mathrm{H}$

E H 19

$7 \mathrm{H} 15$

E $H 20$

$9 \mathrm{H} \quad 3 \mathrm{~B}$

$10 \mathrm{H} 4 \mathrm{~B}$

$\begin{array}{rr}3.77 & 7.35 \\ .29 & 2.36 \\ 1.59 & .15 \\ .65 & .38 \\ .64 & .38 \\ .59 & .38 \\ .64 & .38 \\ .61 & .40 \\ .69 & 1.26 \\ .96 & 2.15\end{array}$

1. 90

\begin{tabular}{|c|c|c|c|}
\hline $1+199$ & 102 & $\mathrm{HH}_{4}$ & xom \\
\hline 1 & 1 & 1 & 1 \\
\hline 4.315 & 1.920 & 1. 900 & 1.61 \\
\hline 0.060 & 0.960 & 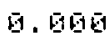 & \\
\hline .098 & .058 & . 196 & 8 \\
\hline .112 & .115 & $=1 E 1$ & 0. \\
\hline
\end{tabular}

7.6

2.95

.41

.11

.16

.65

.69

.11

.67

1. 25

2.69

2.45

5. 56

6. 610

9. 95

5. 50

回.

9. 0

5. 5

1. 34

6. 00

6. 615

1.12

1.38

(1. 00

.64

1.38

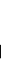




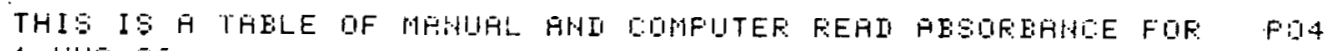
$1=4 Y 2-2=$ $2=H^{\prime} 2-45$

FEFK

\begin{tabular}{|c|c|c|c|}
\hline 怔。 & $1 \quad F 04$ & $\mathrm{FO}_{4}$ & $1-2$ \\
\hline 1 & 3.85 & 3.77 & .98 \\
\hline 2 & .42 & .29 & .13 \\
\hline 3 & 1.71 & 1.59 & .12 \\
\hline 4 & .83 & .65 & -.62 \\
\hline 5 & .65 & .64 & .00 \\
\hline 5 & .60 & .59 & .01 \\
\hline 7 & .64 &.$E 4$ & .81 \\
\hline 8 & .52 & .61 & .81 \\
\hline 9 & .75 & .69 & .91 \\
\hline 10 & .99 & .90 & G \\
\hline
\end{tabular}

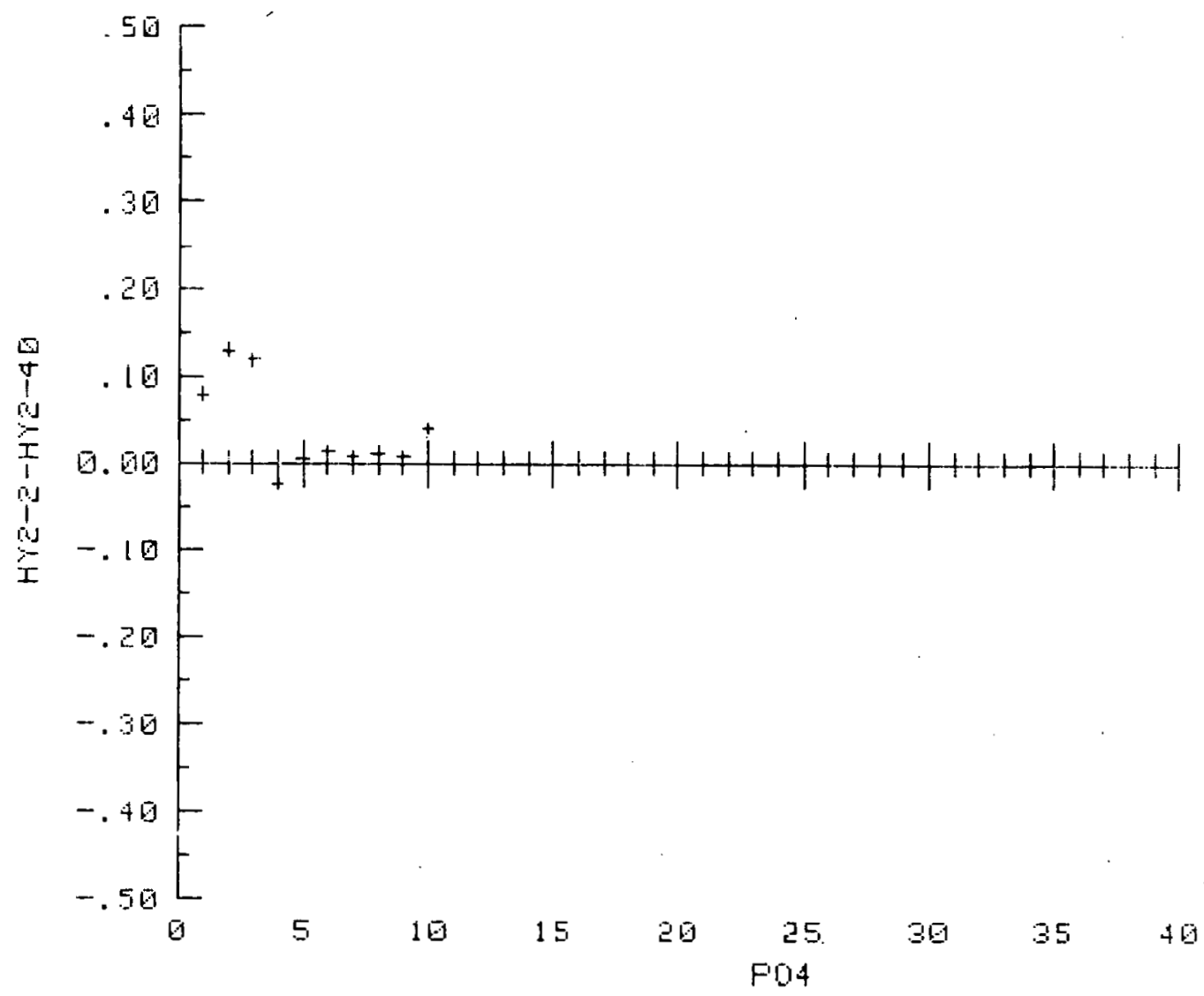




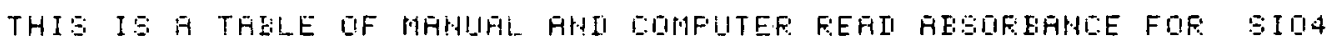
$1=H^{\prime}{ }^{\prime}-2-2$

$2=H \mathrm{H}-4 \mathrm{Q}$

$\begin{array}{cccr}\text { FEAK HD. } & 1.5104 & 2.5104 & 1-2 \\ 1 & 7.39 & 7.35 & .03 \\ 2 & 2.35 & 2.36 & -.00 \\ 9 & .14 & .15 & -.01 \\ 4 & .37 & .39 & -.01 \\ 5 & .37 & .35 & -.01 \\ 6 & .38 & .38 & -.00 \\ 7 & .39 & .39 & .01 \\ 9 & .49 & .46 & .00 \\ 9 & 1.29 & 1.25 & .02 \\ 19 & 2.17 & 2.15 & .02\end{array}$

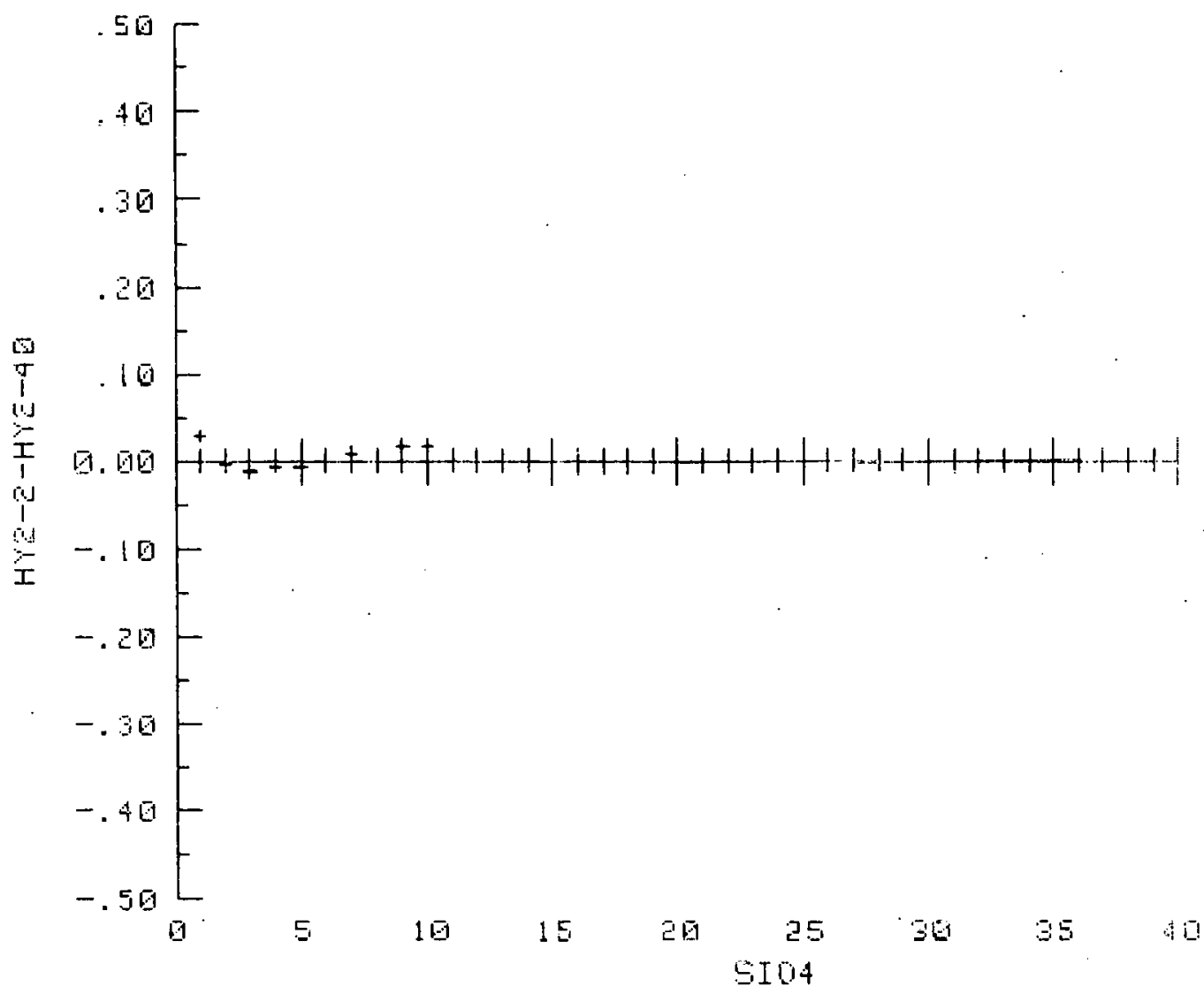




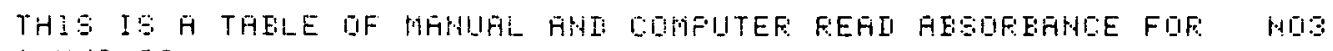
$1=H Y-29$ $2=H^{\prime} 2-4 \overline{9}$

\begin{tabular}{|c|c|c|c|}
\hline FEAY HI. & 110: & No: & $1-2$ \\
\hline 1 & 7.82 & E. 54 & .95 \\
\hline 2 & 2.95 & 2.78 & .17 \\
\hline 3 & .41 & .44 & -.03 \\
\hline 4 & .11 & .18 & -.07 \\
\hline 5 & .10 & .17 & -.67 \\
\hline$\theta$ & .59 & .15 & -.97 \\
\hline 7 & . 59 & .17 & -.63 \\
\hline 8 & .11 & .17 & -.60 \\
\hline 9 & .57 & .75 & -.03 \\
\hline 16 & 1.25 & 1.28 & -.03 \\
\hline
\end{tabular}

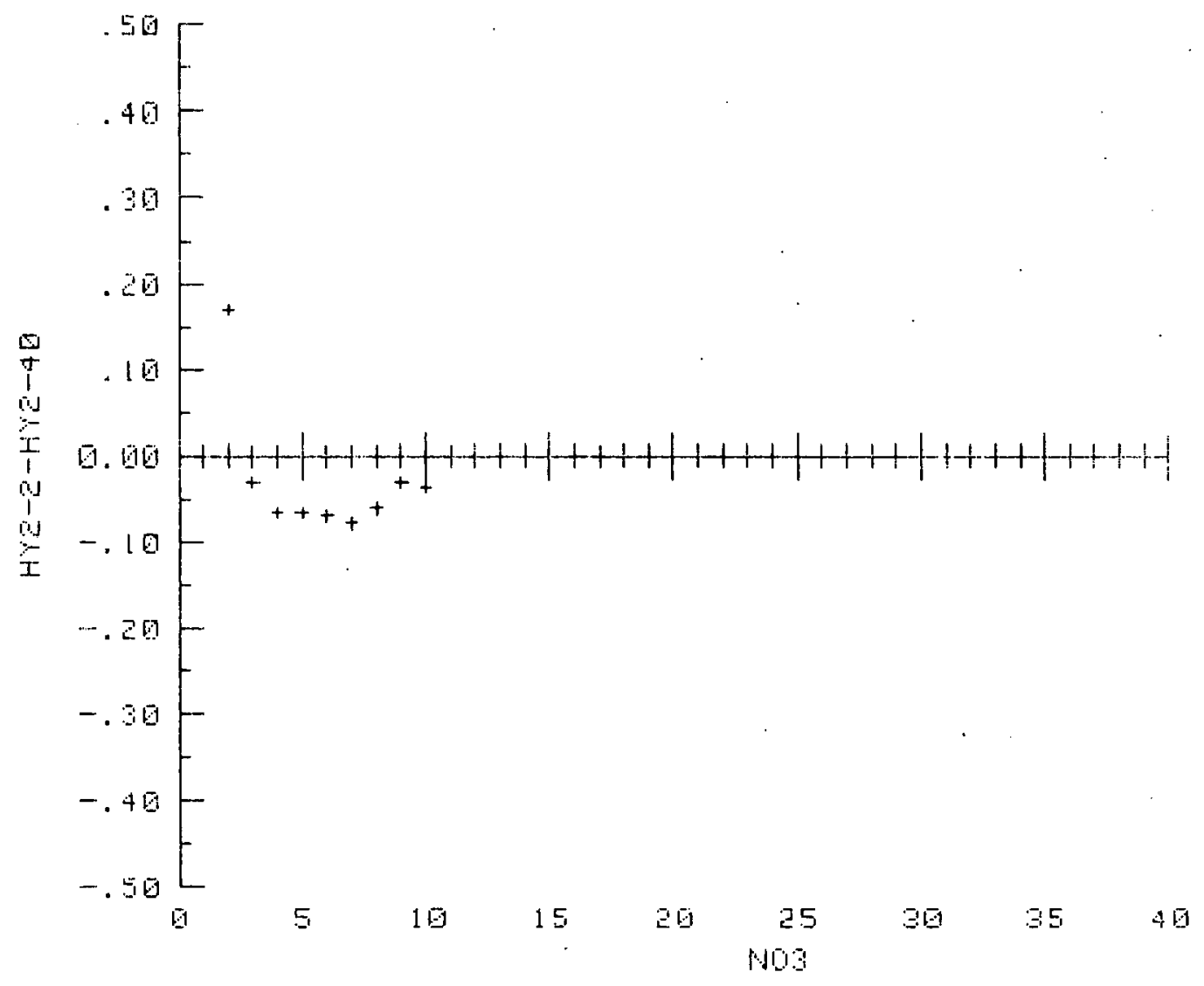




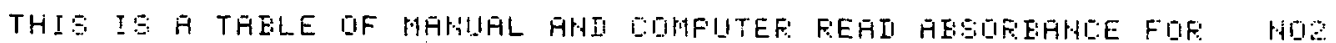
$1=H^{\prime} Z-2 B$ $2=H Y 2-40$

PEAK 10

$\begin{array}{rr}2.102 & 1-2 \\ 3.56 & -.05 \\ .14 & -.03 \\ 1.56 & -.01 \\ .22 & -.04 \\ .21 & -.03 \\ .22 & -.03 \\ .21 & -.03 \\ .21 & -.03 \\ .66 & -.01 \\ .98 & -.01\end{array}$

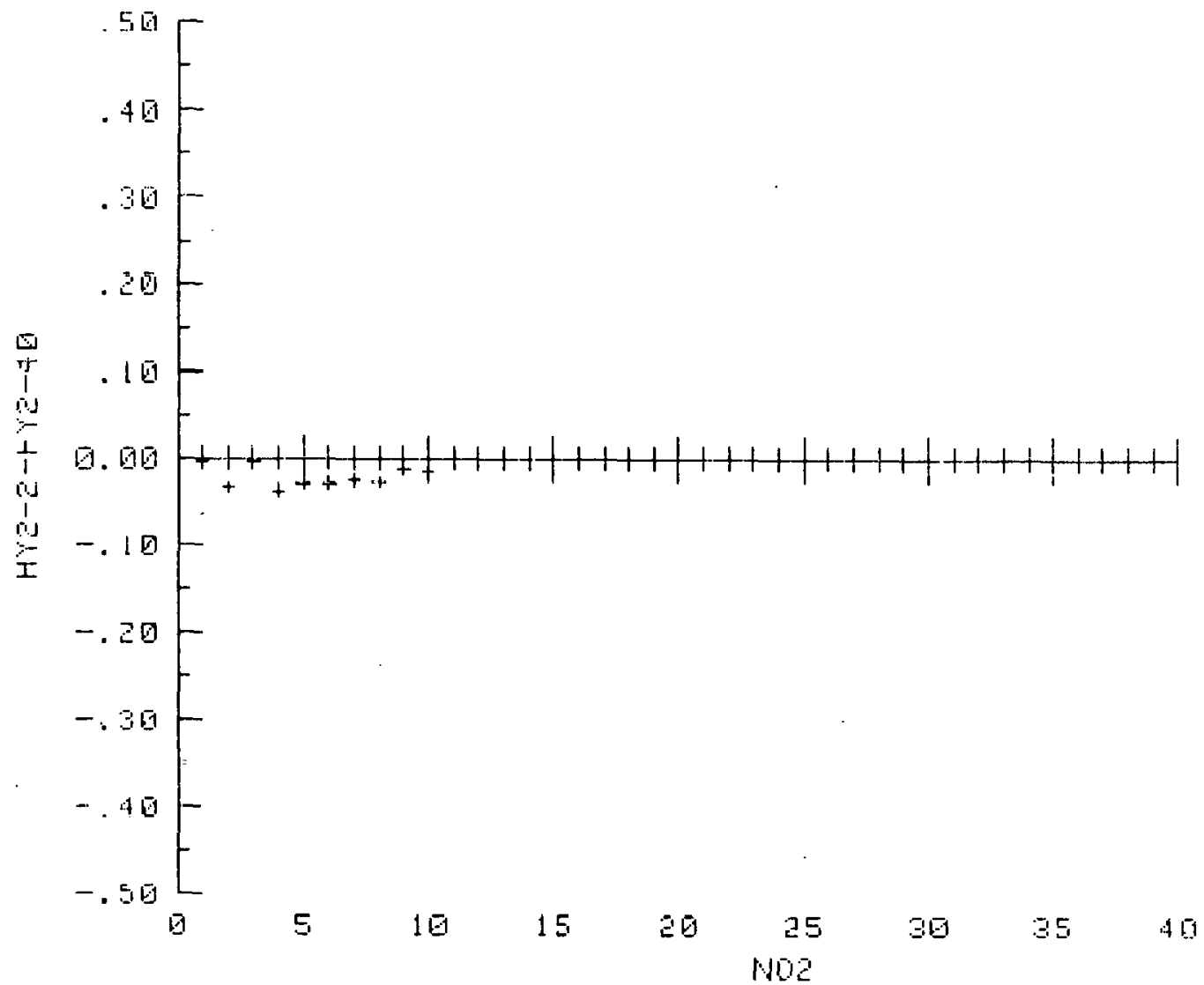




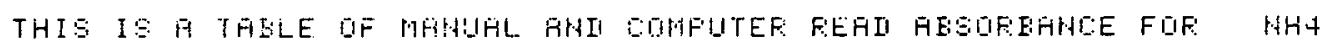
$1=H^{\prime} \mathrm{H} 2-2 \mathrm{~g}$

$2=\mathrm{H}^{\mathrm{T}} \mathrm{2}-4 \mathrm{G}$

\begin{tabular}{|c|c|c|c|}
\hline FERE: HO. & $\mathrm{HH}_{4}$ & $\mathrm{HH}_{4}$ & $1-2$ \\
\hline 1 & 2.40 & 5.17 & -2.77 \\
\hline 2 & .42 & 2.45 & $-2 \cdot 9$ \\
\hline 3 & 1. 02 & .45 & .56 \\
\hline 4 & .85 & .79 & .65 \\
\hline 5 & .82 & .96 & -.14 \\
\hline$E$ & $1 . \ddot{1} 1$ & .85 & $.1 E$ \\
\hline 7 & 1.34 & .55 & .43 \\
\hline 8 & 1.27 & .98 & .29 \\
\hline 9 & 1.12 & 1. 日7 & .515 \\
\hline 16 & 1.36 & .95 & .43 \\
\hline
\end{tabular}

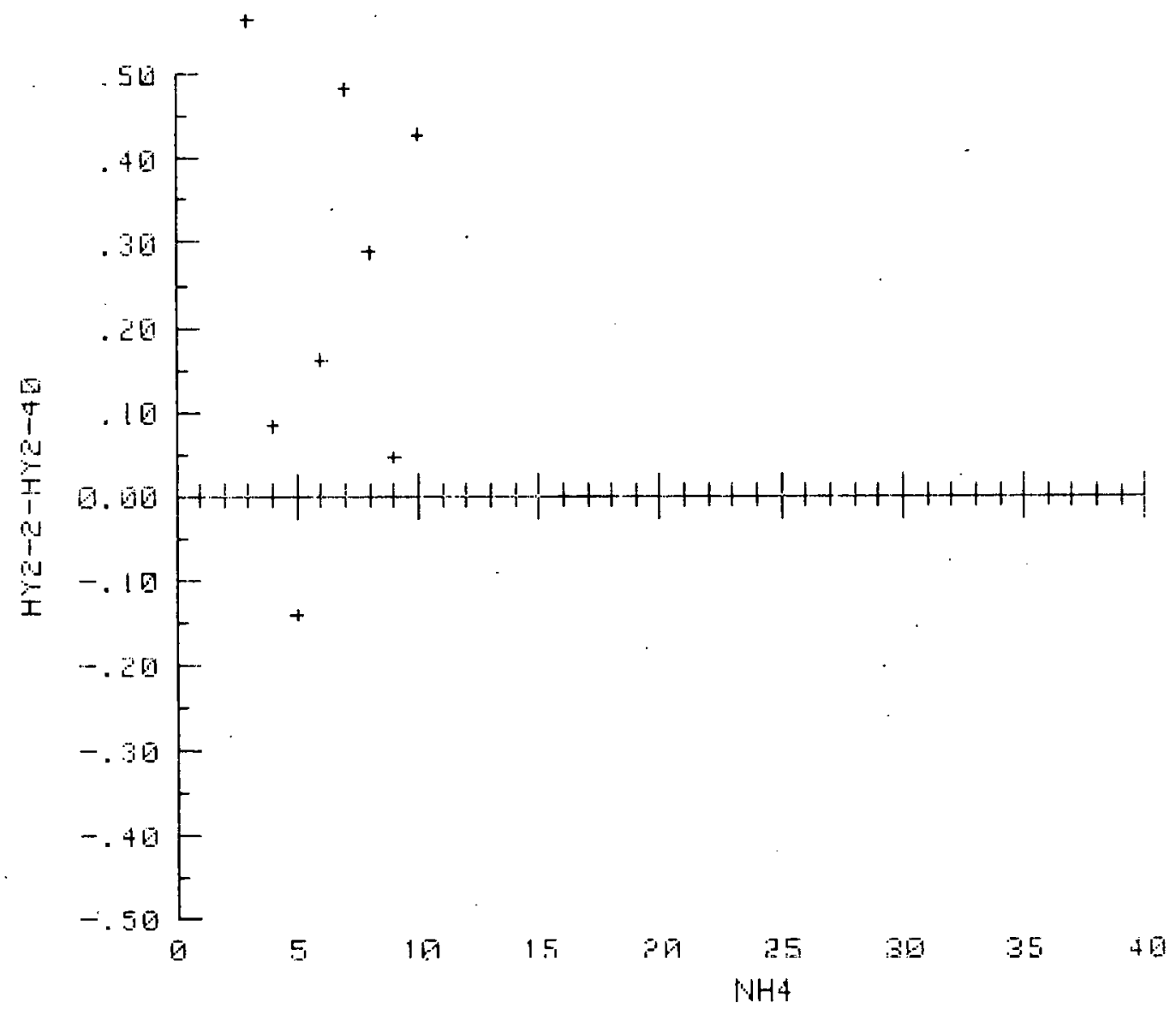


Underway Mapping

Underway nutrient mapping is a method of collecting continuous data as the ship steams a designated track. Two variations have been used in analyzing the sample stream that is pumped from a through-hull intake at 2-3 m depth to the ships' laboratory. One method uses a continuous sample with no washes to produce an absorbance analog that can easily be digitized with any scanning data logger (Kelly, Whitledge and Dugdale, 1974 and 1975). An alternate method pumps the sample stream into the wash cup of the sampler and deionized water is placed in the sample cups (Wiesenburg, Setser and Bottom, 1978). This approach produces peaks to be read but is not as adaptable to data logging and small scale variability in the data may be more difficult to observe.

The continuous sample method has been employed in most underway nutrient. mapping studies and is comparable to techniques normally used for mapping surface water temperature, salinity and chlorophyll fluorescence. A general flow diagram for the system is presented in Figure 3-1. Surface water is sampled continuously at a through-hull fitting and mixing tank assembly. In situ sensors can be installed in the mixing tank. Water is then pumped from the mixing tank to the wet laboratory sensor arrays and discrete samples may be collected for calibration puposes. The mixing tank is shown in Figure 3-2.

The through-hull fitting which feeds the mixing tank is usually located at a depth of approximately $3 \mathrm{~m}$. When a ship is underway, surface water is entrained in a slipstream at the bow and flows along the hull. The surface water may flow slightly downward, especially in conditions of appreciable roll. Thus, water sampled at the inlet can originate from anywhere in the upper $3 \mathrm{~m}$ of watcr.

At the outlet from the mixing tank, water is pumped through PVC piping to the ship's wet laboratories. Flow rates are on the order of $601 / \mathrm{min}$. The total residence time of water in the system has been estimated by injecting rhodamine-B at the inlet and timing the fluorometer response delay in the laboratory. Residence time is estimated as $15 \mathrm{sec}$. Water from this piping system is available for chemical, fluorometric and biological sampling in the ship's laboratories.

\section{Wet Laboratory System}

Water can be taken from the piping system by two methods. The first, and somewhat less successful technique, utilizes a standpipe of plastic tubing attached to the laboratory outlet. The standpipe is intended to prevent air bubbles from passing through the AutoAnalyzer or fluorometer array, but it performs unsatisfactorily due to considerable mixing during the long chamber residence time of the water. Exposure of the water to laboratory lighting also affects fluorescence determinations. The second technique employs a large latex tubing termination on the outlet, which is connected directly to the continuous-flow fluorometer. Water emerging from the fluorometer is drained directly to the sink. A small latex tube for the AutoAnalyzer sample is attached to a small " $T$ " connector in the fluorometer inlet tube. The flow through the fluorometer is kept as rapid as can be accommodated by drain facilities ( $401 / \mathrm{min}$ ) to minimize residence time in the piping system. The small latex tube feeding the AutoAnalyzer is connected to a CRC model $9350 / 305$ continuous dialysis block which contained a Millipore type HA $142 \mathrm{filter}$. The stream of water $(\sim 200 \mathrm{ml} / \mathrm{min})$ flows across the top of the filter membrane 


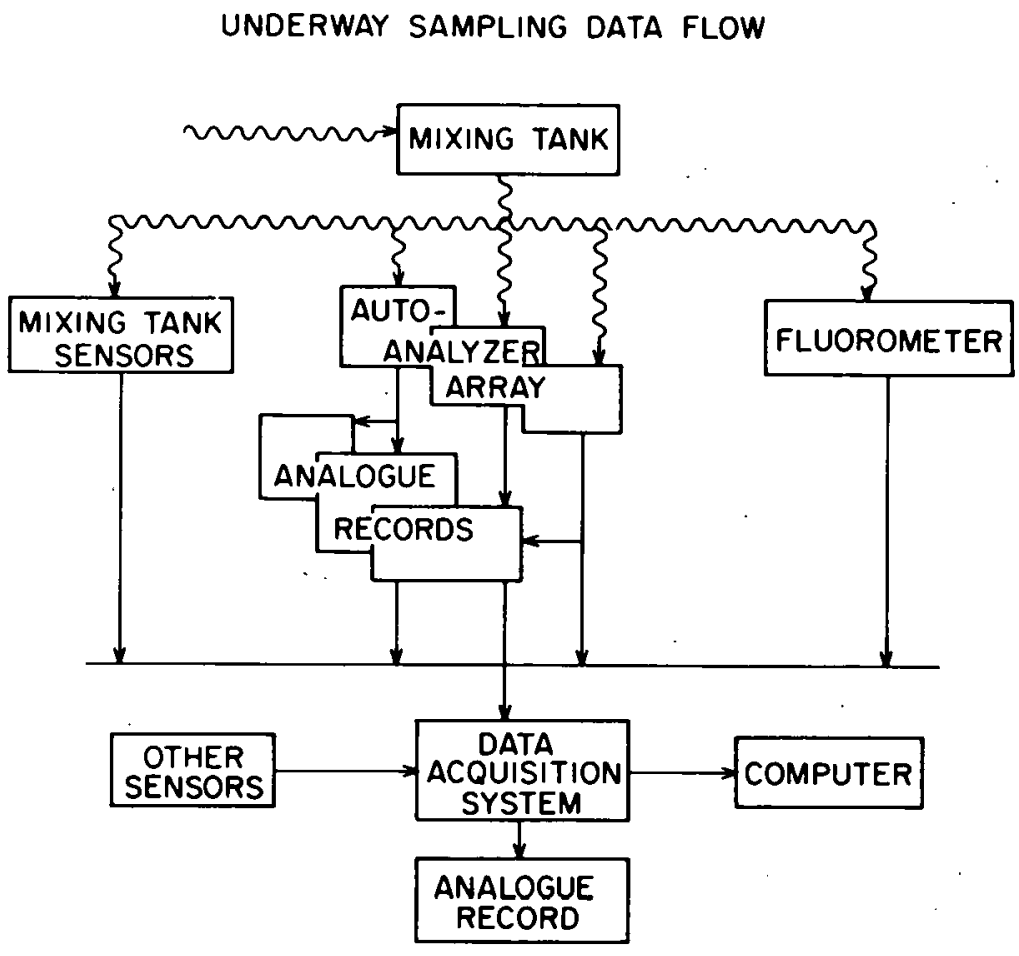

Figure 3-1. Flow Diagram of Total Sampling System. Wavy Lines Indicate Flow of Water, Straight Lines, Electronic Signals

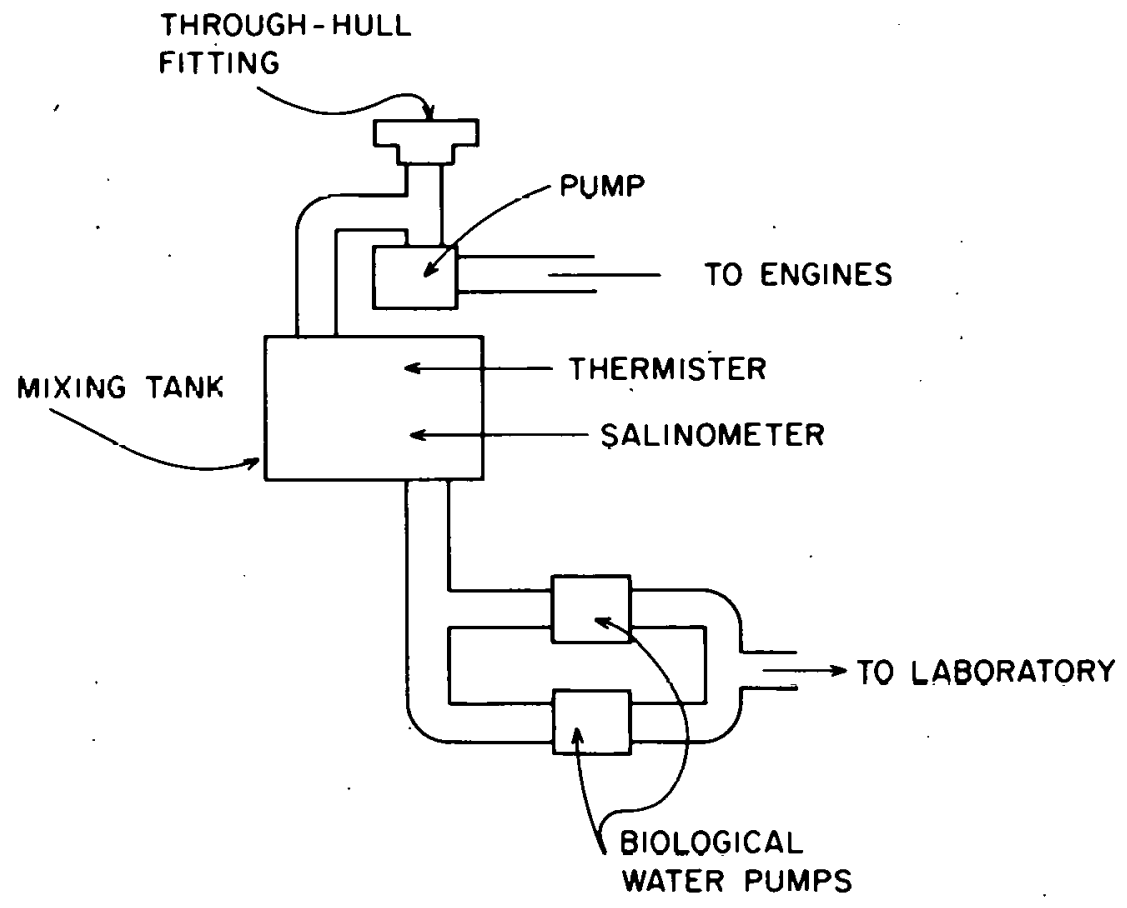

Figure 3-2. Diagram of Mixing Tank Arrangement 
while the AutoAnalyzer pumps a continuous sample stream through the filter membrane from a single nipple on the bottom of the dialysis block. A stream divider is used to split the sample stream to the various nutrient analysis manifolds. To prevent air contamination of the copper-cadmium column in the nitrate analysis, a debubbler is used to catch gas bubbles which form as the sample stream warms. A plug of glass wool in the nitrate sample stream helps speed the degassing process. Filtration measurably improved the quality of data in the phosphate and ammonium channels, but no change is noticed with filtered water in the nitrate and silicate analyses. Sample readings logged by a computer are normally collected at one minute intervals.

The continuous operation of an AutoAnalyzer array over long periods requires special considerations regarding operating procedures and monitoring personnel. For instance, the time should be marked on the analog strip charts every 15 minutes to aid in later data corrections. Depending somewhat on the stability of the AutoAnalyzer system at the time, a blank should be determined every 2 to 4 hours to establish baseline drift. Baseline drift may be large on long continuous runs because of reagent and instrument changes. A refrigerator has been used with some success to preserve reagents in our laboratory when runs cover several days or weeks. The timing of hlank values should be coordinated with the operation of the ship so that the data of least importance to the survey area is missed during the 10-15 minute period required for the blank determination. Mixed nutrient standards are run either before or after the survey commences. If the survey is longer than 8-12 hours, nutrient standards should be run both before and after the survey. The baseline drift is assumed to be linear, unless clues to the contrary become apparent on the analog output.

The sequence of events which makes up the underway data processing system is shown in Figure 3-3. Raw data from the underway scans are stored as a multivariate time series. The record is a two-dimensional array in which rows represent sequential scans and columns represent different variables. Raw data records can be printed and edited. Editing is especially important for the AutoAnalyzer channels which are subject to spikes and other spurious effeces, and is normally done both on the raw voltages from these channels and on the nutrlent concentrations calculated from them. All nther raw data are converted to correct units before they are entered into the file. AutoAnalyzer channels must be corrected for baseline drift and thus the conversion of these data is delayed until the system encounters a blank determination from which it can update the record. Blanks are flagged in the digital record by the AutoAnalyzer personnel. The raw data file is accessed by the time index as the primary index but initially the time index indicates the time at which the data were acquired rather than the time the ship encountered the water parcel. Some variables such as temperature, salinity, and the meteorologlcal variables are acquired in real-time; but delays due to residence time in the pumping system and the AutoAnalyzer analyses cause the inputs from the AutoAnalyzer channels and the fluorometer, and from any other instruments in the ship laboratories, to be acquired at a lag of several minutes from realtime. This asynchrony must be corrected by shifting certain columns in the array a number of rows equivalent to the delay in the acquisition for the variable. 


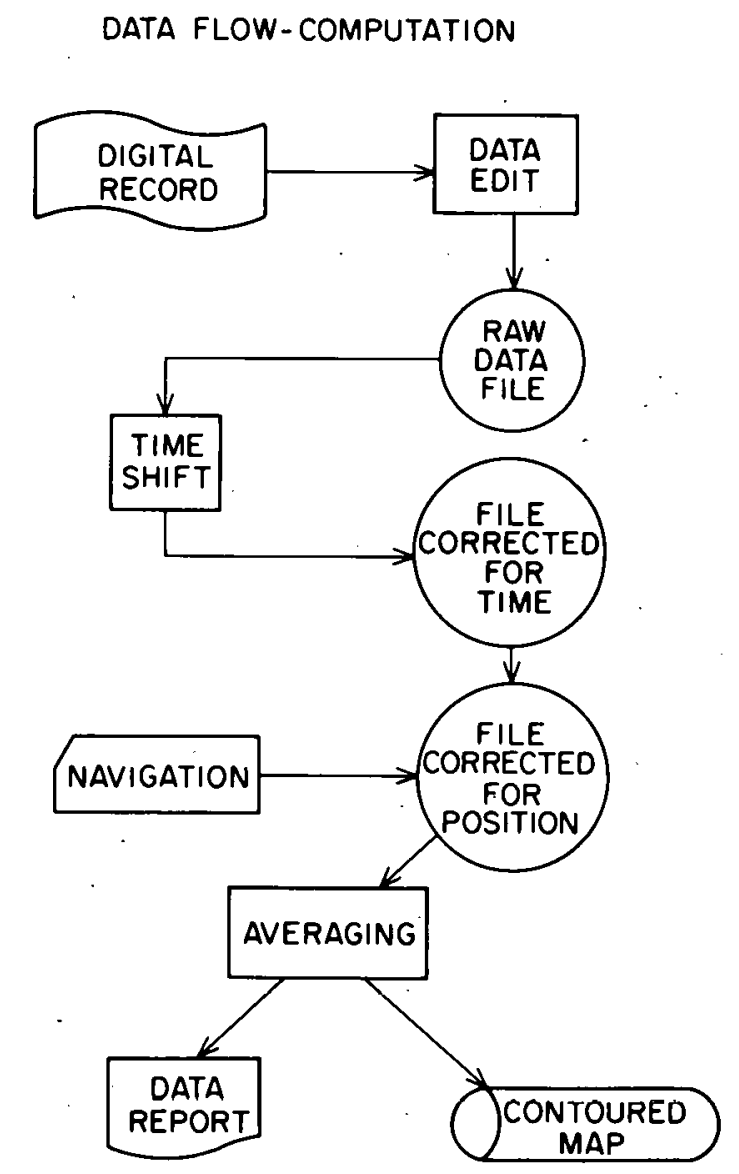

Figure 3-3. Flow Diagram of Computations 


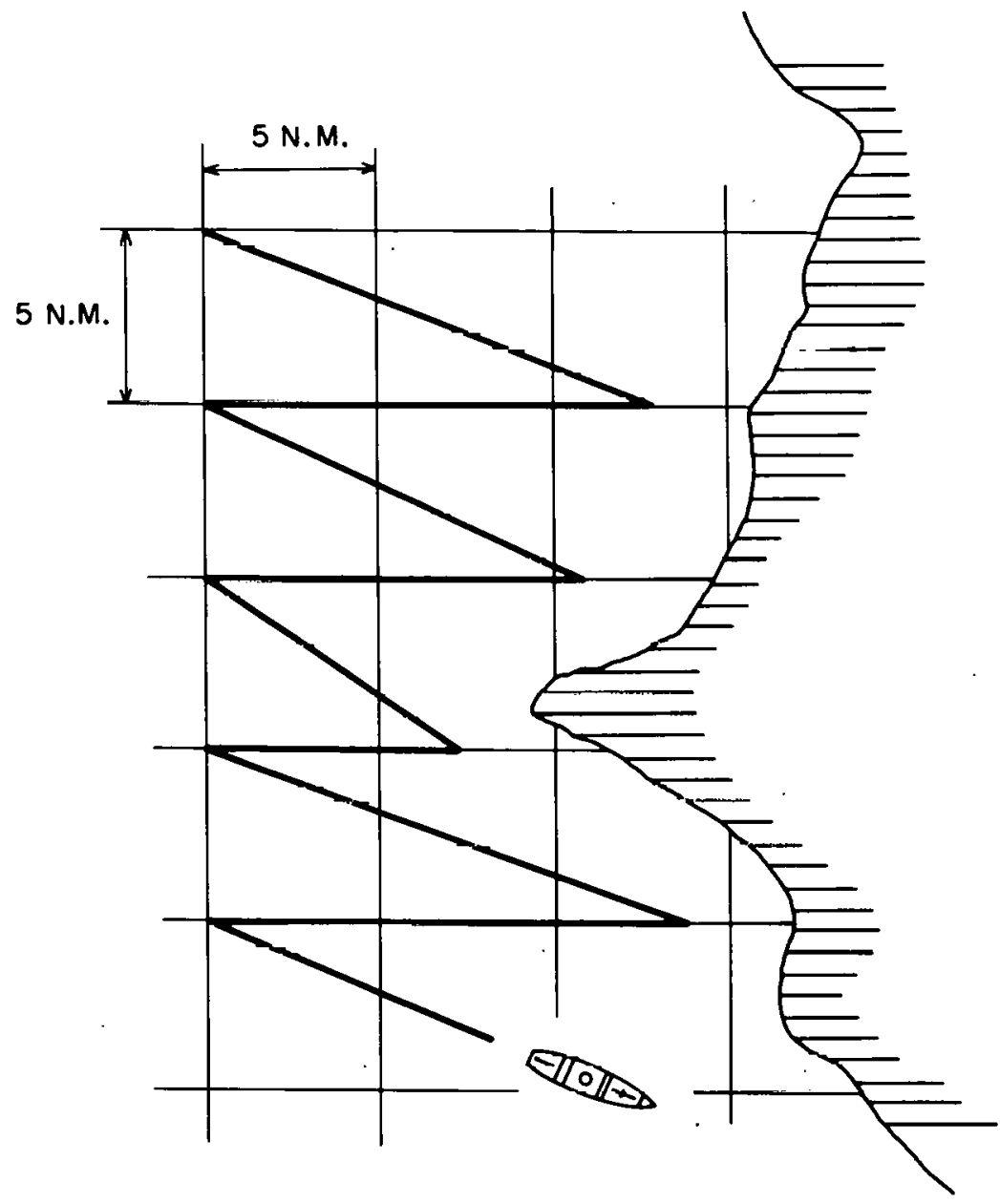

Figure 3-4. Example of Survey Grid and Mapping Pattern 
The multivariate time series also can be uniquely mapped into the $x, y, z$ space from which the samples are taken. For the surface sampling system depth, $z$ is assumed constant and equal to 3 meters, and $x$ and $y$ are the geographic coordlnates of the ship position. In the system described here, geographic positions are usually determined by entering fixes and their times and by interpolating linearly between them. The ship movement is assumed to be a straight line between fixed positions at a constant speed.

Once the file has been edited, the time shift effected, and navigational information included, the data can be presented in a number of ways. First, the contents of the file can be printed. The data in any single column can be plotted as a time series. Our method of presentation, which has proven quite useful, has been to plot the data in appropriate horizontal positions and contour them to produce a map of the geographic distributions of the measured varlables. These surface maps represent an approximation of the two-dimensional fields of the variables. When the data acquisition system is employed in this mapping activity the ship is deployed along a zig-zag course to cover the area of interest as uniformly as possible with a minimum of course changes. The ship typically steams this pattern over a standard grid (Figure 3-4) approximately 20 × 50 nautical miles in size and with a grid point spacing of 5 nautical miles. With the ship underway at 12 knots, scanning data channels once per minute yields a data point spacing of $370 \mathrm{~m}$ in the horizontal. This particulare sampling pattern is somewhat arbitrary, but it 'as evolved over a period of years. The contouring program uses a planar least squares interpolation from the randomly located data points to a square grid and contours the grid points. Several contouring methods have been investigated, but the grid interpolation scheme has been chosen because the goal of the contouring procedure was to define the total $x$, y field of the variables. Most schemes overemphasize the importance of individual data points and honor them exactly at considerable cost to the quality of interpolation to areas betwen data points. For some applications of automatic contouring techniques, such as topographic mapping, data points are often selected on the basis of their diagnosticity but in the application described here the locations of particular data points are totally fortuitous and the inclusion of a particular data point in the flle implies nothing about its relative importance for field definition. Additional discussion concerning underway nutrient mapping are given by Cruzado, 1971; Cruzado and Kelley, 1973; Cruzado, 1974; and in situ mapping by Bernhard and Piro, 1971. 


\section{THIS PAGE}

\section{WAS INTENTIONALLY LEFT BLANK}

$-46-$ 


\section{COOKBOOK OF CURRENT NUTRIENT METHODS}

This section gives a detailed account of the reagents, manifold configuration and operating instructions for the AutoAnalyzer II system that is currently being used for the analysis of orthophosphate, dissolved silicon (silicate), nitrate plus nitrite, nitrite, ammonium and urea nutrients. Analytical methods change with time as more is learned about the optimum conditions needed for the chemical. reactions to occur. As a result this section will need to be updated continually and the description presented here should be considered only our best effort at the time the material was written.

A large number of references are appended (Appendix A) to provide a convenient source of the past information available on manual and automated oceanographic nutrient analyses. Some of the most applicable clinical and analytical chemistry sources are included for completeness.

The chemicals and manifold components are detailed for each analysis in Appendix B. Technicon part numbers are listed for each manifold component and the manufacturers of chemicals are described. In some instances the purity of a few chemicals depends greatly on their source. 
Phosphate is determined as phosphomolybdic acid which in its reduced form in the presence of antinony has an absorption maximum at $880 \mathrm{~nm}$. The method reported here is basically an automated version of the Murphy and Riley (1962) procedure. The phosphate manifold is illustrated in Figure 4-1.

Reagents:

Molybdate solution. Dissolve $17.0 \mathrm{~g}$ of ammonium molybdate in 1 liter of DDW contained in a 2 liter volumetric flask. Add $200 \mathrm{ml}$ conc. sulfuric acid slowly and allow the solution to cool under running tap water. Next add 0.37 $g$ of potassium antimonyl tartrate (KAT) which has been previously dissolved in $20 \mathrm{ml}$ of DDW. Dilute to the mark with DDW, transfer to a nalgene bottle, and $2 \mathrm{ml}$ of a $15 \% \mathrm{w} / \mathrm{w}$ solution of sodium lauryl sulfate (SLS).

Ascorbic Acid Solution. Stock solution. Dissolved $6 \mathrm{~g}$ of ascorbic acid in $200 \mathrm{~m} 1$ of acetone and $200 \mathrm{ml} \mathrm{DDW}$. Store this stock solution in the refrigerator. To make the running solution, add $20 \mathrm{ml}$ stock ascorbic acid to $100 \mathrm{~m} 1 \mathrm{DDW}$. Prepare a fresh dilution daily if the autoanalyzer is not run continuously.

Dilution Water. Pipet $0.5 \mathrm{ml} \varepsilon L E$ in $1000 \mathrm{ml}$ DDW. Preparc daily.

\section{ORTHOPHOSPHATE \\ (RANGE: $0 \rightarrow 10 \mu g-$ of $\mathrm{PO}_{4} \equiv-P / \ell$ )}

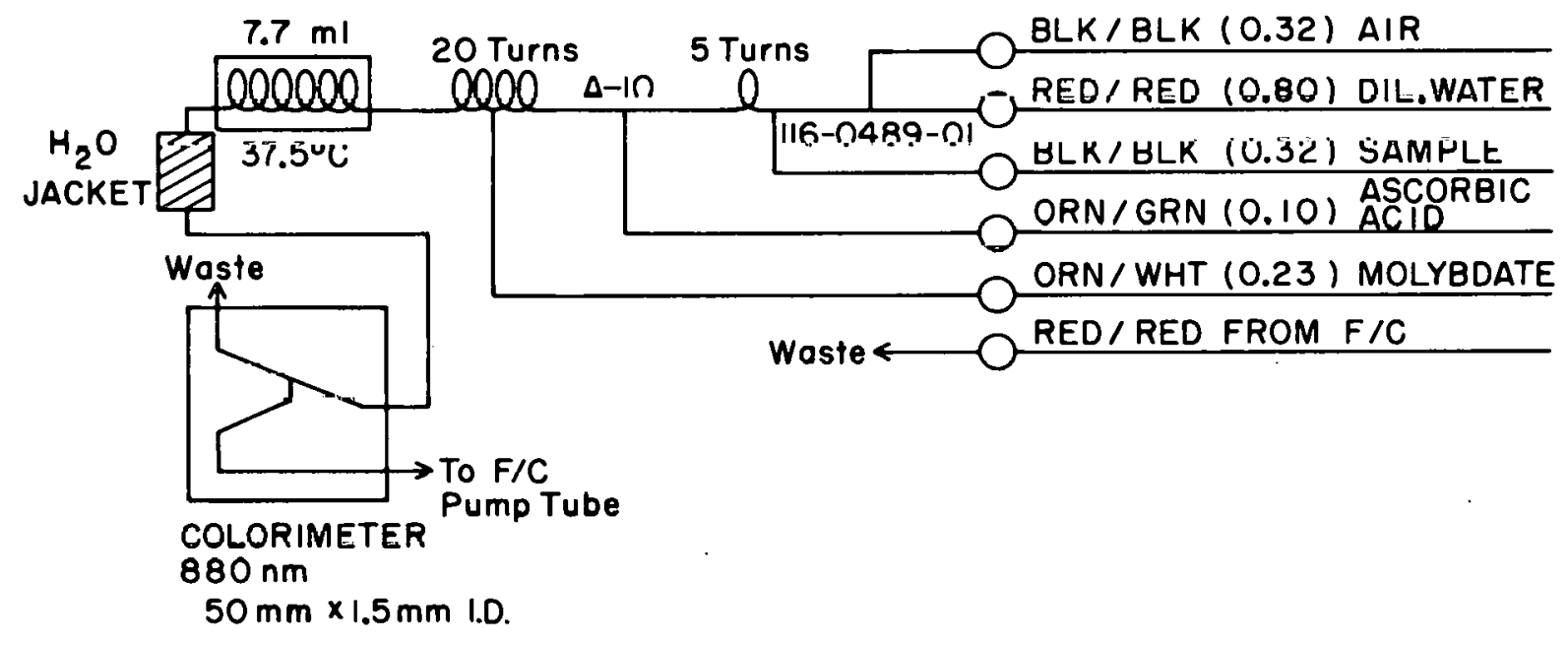

Flyure 4-1. Orthophosphate Man1fold fờ AutóAnàlȳèr 11 


\section{Orthosilicic Acid}

Orthosilicic acid is determined by its reaction with molybdate in aqueous acidic solution to form silicomolybdic acid. In this procedure, which is basically that of Arinstrong, Stearns and Strickland (1967), stannous chloride is used to reduce silicomolybdic acid to the heteropoly acid which has an absorption maximum at $820 \mathrm{~nm}$. The silicate flow diagran is shown in Figure 4-2. Reagents:

Molybdate. Dissolve $10 \mathrm{~g}$ anmonium molybdate in $800 \mathrm{ml}$ DDW and $2.8 \mathrm{ml}$

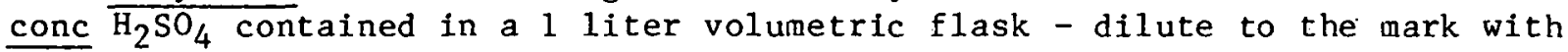
$\overline{\mathrm{DDW}}$ - transfer to a 1 liter poly bottle and add $1 \mathrm{~m} 1 \mathrm{SLS}$. DO NOT REFRIGERATE. Tartaric Acid. Dissolve $100 \mathrm{~g}$ of tartaric acid in $950 \mathrm{~m}$ DDW contained in a liter nalgene bottle and dilute to the mark. Add a few drops of Chloroform and store in the refrigerator.

Stannous Chloride.

a) Stock solution. Dissolve $40.0 \mathrm{~g}$ of stannous chloride in $50 \mathrm{ml}$ conc. $\mathrm{HCl}$, add $50 \mathrm{ml} \mathrm{DDW}$ and store in a small narrow-mouthed pyrex reagent bottle. Seal with a rubber stopper and store in the refrigerator.

b) Running solution. Add $0.5 \mathrm{ml}$ stock solution to $100 \mathrm{ml}$ of DDW contained in a small poly bottle. Prepare fresh daily.

ORTHOSILICIC ACIO

(RANGE: $\mathrm{O} \rightarrow 50 \mu \mathrm{g}-$ af $\mathrm{Si}(\mathrm{OH})_{4}-\mathrm{Si} / \mathrm{I}$ )

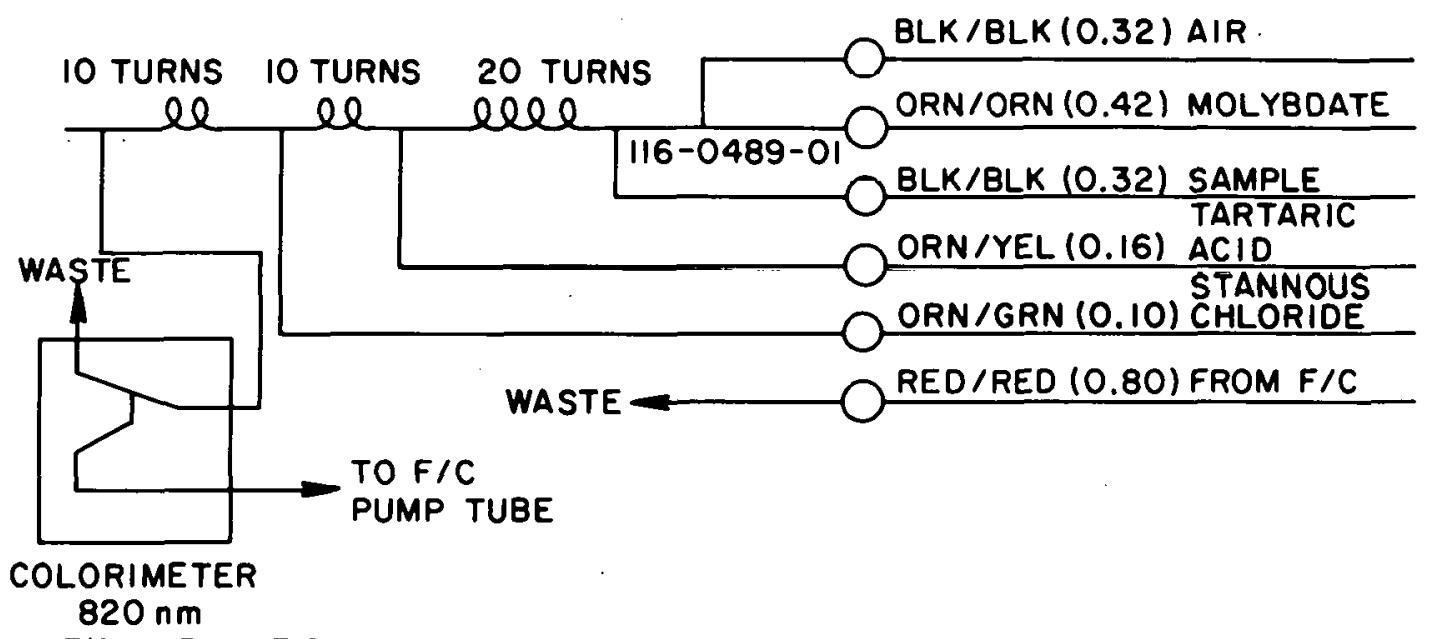

$15 \mathrm{~mm} \mathrm{F/C} \times 1.5 \mathrm{~mm}$ I.D.

Figure 4-2. Orthosilicic Acid (Silicate) Manifold

for AutoAnalyzer II 
Nitrate + Nitrite, Nitrite

Nitrite is determined by the Greiss reaction in which sulfanilamide and $\mathrm{N}$-(1-Naphthyl)ethylenediamine dihydrochloride (NNED) reacts with nitrite in aqueous acidic solution to form an intensely pink diazo dye with an absorption maximum at $540 \mathrm{~nm}$ (Bendschneider and Robinson, 1952). Nitrate, after it is reduced to nitrite by passage through a column containing copperized cadmium filings (Wood, Armstrong and Rlchards, 1967), is determined in an identical manner. Thus the sum of nitrate plus nitrite is determined in the nitrate procedure (Figures 4-3 and 4-4). Note that the cadmium column is quite small so that retention time and dispersive effects are minimized and no loss of efficiency is observed.

Reagents:

Ammonium Chloride. Dissolve $10 \mathrm{~g}$ of ammonium chloride in 2 liter of DDW. Sultanilamide. Dissolve $10 \mathrm{~g}$ sulfantlamide in a solution of $600 \mathrm{ml}$ DDW

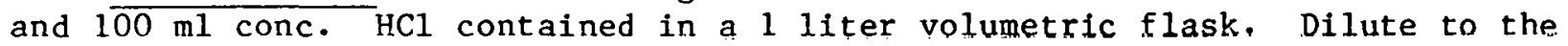
mark with DDW, transfer to a 1 1iter nalgene bottle, add $0.5 \mathrm{~m} 1 \mathrm{Brij-35}$ wetting agent and store in the refrigerator.

Nitrite Dilution Water. Add $0.5 \mathrm{ml}$ Brij-35 to 1 liter of DDW. N-(1-Naphthy1)ethylenediamine dihydrochloride (NNED). Dissolve $1.0 \mathrm{~g}$ NNED in $800 \mathrm{ml}$ DDW contalned in a l liter volumetric flask. Dilute to the mark with DDW, transfer to a 1 liter nalgene bottle, add $0.5 \mathrm{ml} \mathrm{Brij-35}$ wetting agent and store in the refrigerator. 

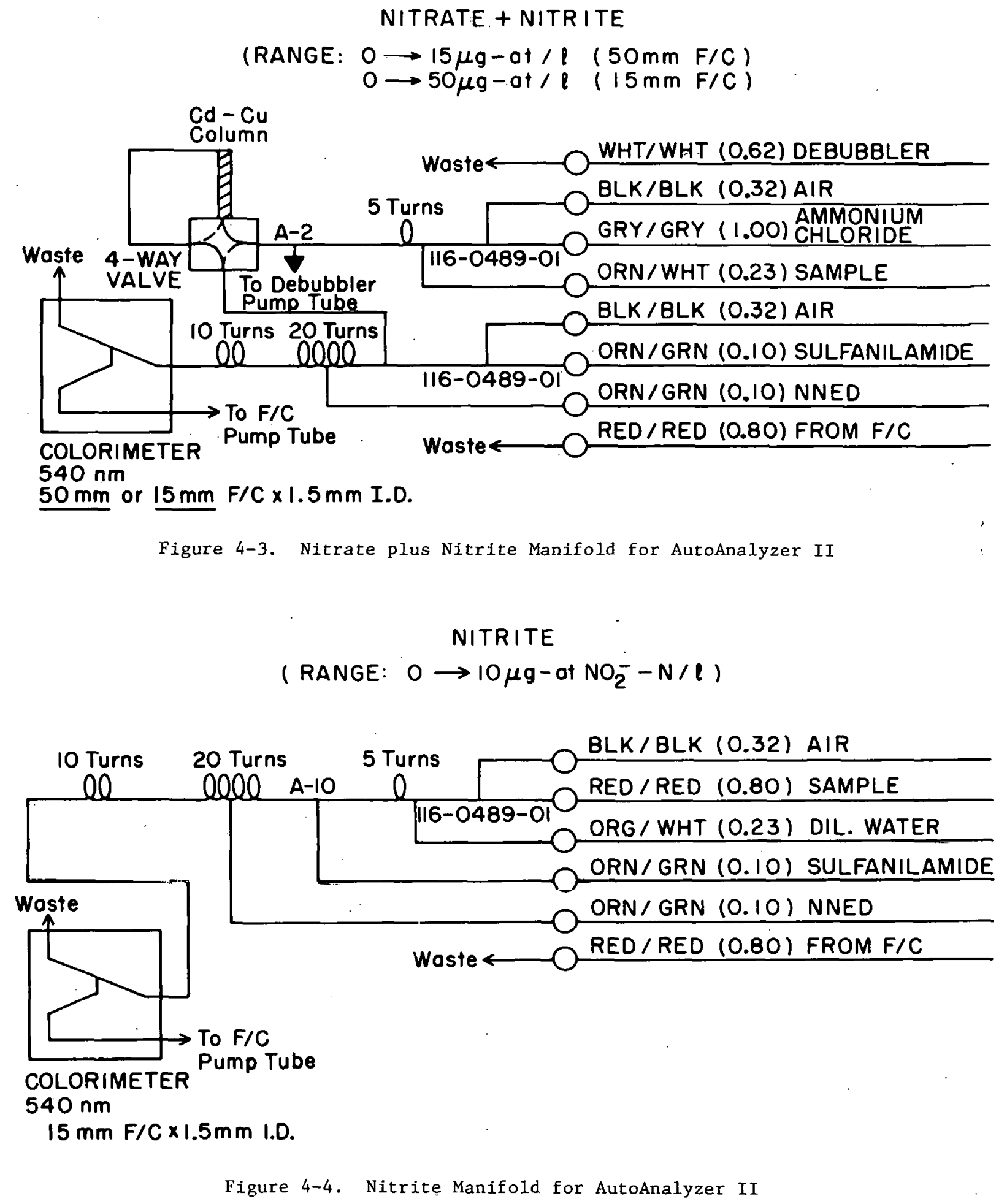
Preparation of Nitrate Reduction Column:

Copperized cadmium filings.

a) Filings are most easily prepared by holding a coarse file at a $45^{\circ}$ angle to a cadmium rod which is turned at slow speed on a lathe.

b) Seive the filings and retain the 30-60 mesh fraction.

c) Remove any ferrous metal from the seived filings with a magnet.

d) Next wash the filings with several portions of carbon tetrachloride and dry on filter papers.

e) Place the dry filings in a small glass beaker and cover with $75 \mathrm{ml}$ DDW.

f) Add conc. nitric acid drop-wise while stirring until redbrown nitrogen dioxide is evolved copiously. This pits the surface of the filings greatily increasing their curfacc area.

g) After about a minute, decant the liquid and rinse thoroughly (9-10 times) with DDW.

h) Rinse thoroughly with $10 \% \mathrm{v} / \mathrm{v} \mathrm{HCl}$.

i) Again rinse thoroughly with DDW.

j) Next treat the piepaled flilngs with $23 \mathrm{~mL}$ portions of $2 \% \mathrm{w} / \mathrm{v}$ copper sulfate solution. When the blue color fades from the solution, decant. it and add a fresh portion. Continue this procedure until the blue color does not fade (usually 8-10 times). The filings will appear charcoal gray and the supernatant liquid will be turbid at this stage. Rinse 8-10 times with DDW.

k) Rinse the filings in a $1 \% \mathrm{w} / \mathrm{v}$ ammonium chloride solution until they appear bright silver-gray and the supernant liquid is clear. The filings are now ready to be packed in the column.

1) Excess copperized cadminm filings should bo otored under seawate: containing ammonium chloride in a tightly sealed glaos jar where they are stable for at least 1 year.

Packing the column (Figure 4-5B)

a) WiLh the coluth (i5 um \& 4 แm OD pyrex tube with a constriction at one end) in place on the manifold, attas.h a small glass funnel to the top of the column by means of a tygon sleeve.

b) With the system pumping, open the 4-way valve to allow ammonium chloride to fill the column and partially fill the funnel.

c) Using a rigid wire push a small plug of glass wool to the bottom of the column.

d) Next add the copperized cadmium filings, a spatula tip full at a time. Tap the side of the column gently with the spatula to ensure proper packing. Continue this process until the filings alinost fill the column.

e) Insert a small plug of glass wool, remove the funnel, and insert an $\mathrm{N}-6$ nipple (Figure 4-5A).

f) Connect the top of the column to the 4-way valve with a short length of teflon tubing $(0.5 \mathrm{~mm}$ ID).

Note: If a large volume of air passes through the column it will have to be repacked. The filings, however, are unharmed, so simply empty them into a small beaker containing ammonium chloride solution and use them to repack the column. Add additional filings if necessary. 


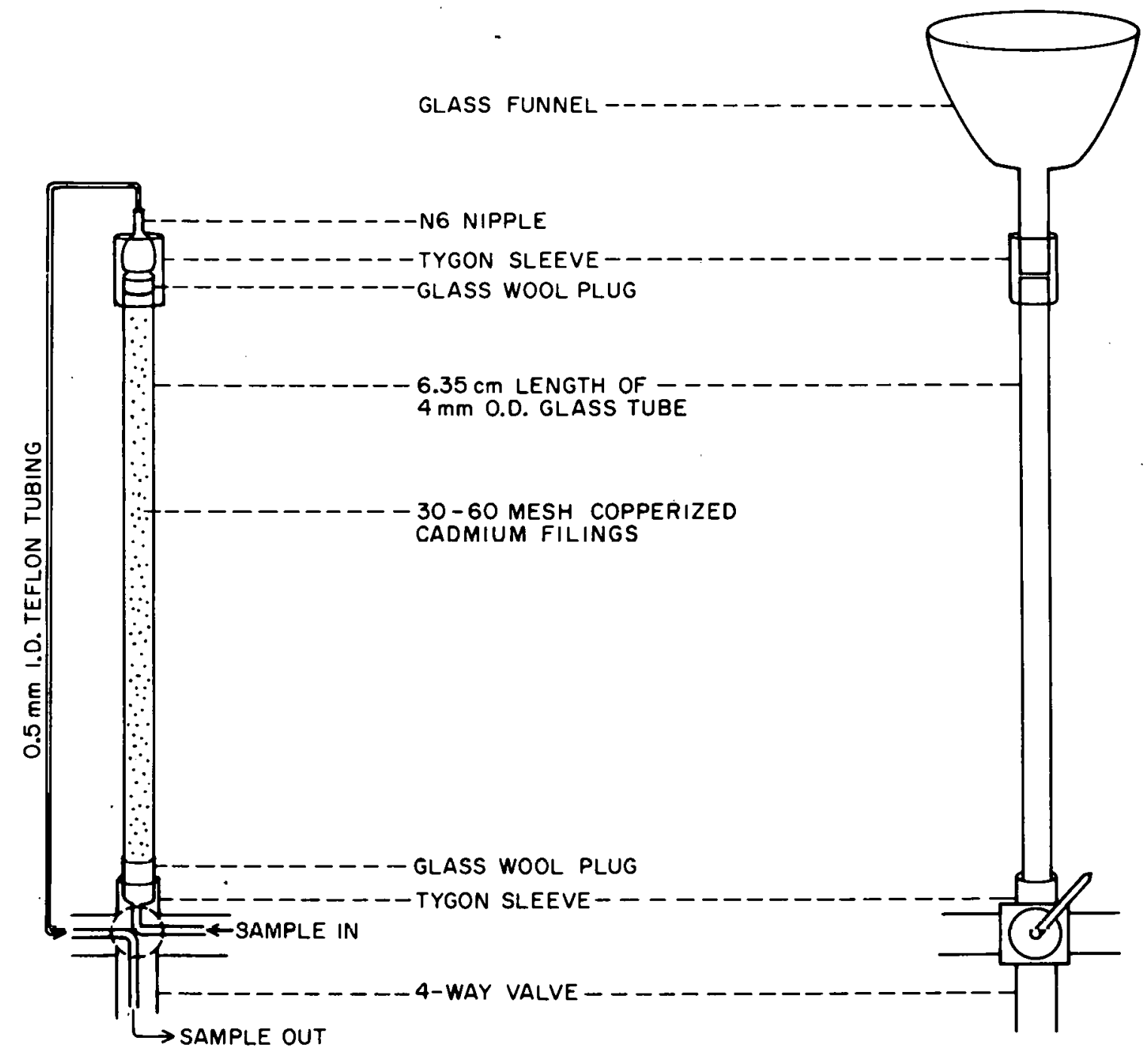

Figure 4-5. A) Cadmium Column for Nitrate plus Nitrite in Running Mode B) Column Ready for Packing with Cadmium Filings 
Ammonium is determined by the Berthelot reaction in which hypochlorous acid and phenol react with ammonium in aqueous alkaline solution to form indophenol blue, an intensely blue chromophore with an absorption maximum at $637 \mathrm{~nm}$. The method presented below is a modification of a procedure reported by Slawyk and MacIsaac (1972). Additional information on the kinetics of the reaction may be found in a paper by Patton and Crouch (1977). Figure 4-6 shows the flow diagran for this method.

Reagents:

Reagent A.

Stock Solution. Dissolve $35.0 \mathrm{~g}$ of phenol and $0.40 \mathrm{~g}$ of sodium nitroprusside dihydrate in $\sim 800 \mathrm{ml}$ of deionized distilled water (DDW) contained in a 1 liter volumetric flask. Dilute to the mark with DDW, transfer to a 1 liter nalgene bottle and store in the refrigerator.

Reagent $\mathrm{B}$. Dissolve $5.0 \mathrm{~g}$ sodium hydroxide in $800 \mathrm{ml}$ DDW contained in a 1 liter volumetric flask. Add $50 \mathrm{ml}$ Chlorox and dilute to the mark with DDW. Store in a 1 liter nalgene bottle in the refrigerator.

Dilution/Complex. Dissolve $140.0 \mathrm{~g}$ sodium citrate and $5.0 \mathrm{~g}$ sodium hydroxide in 1 liter $\mathrm{DDW}$ and refrigerate.

AMMONIUM

(RANGE: $\mathrm{O} \rightarrow 10 \mu \mathrm{g}-$ at $\mathrm{NH}_{3}-\mathrm{N} / \mathrm{l}$ )
SCRUBBER

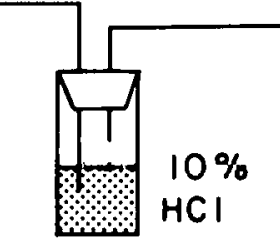

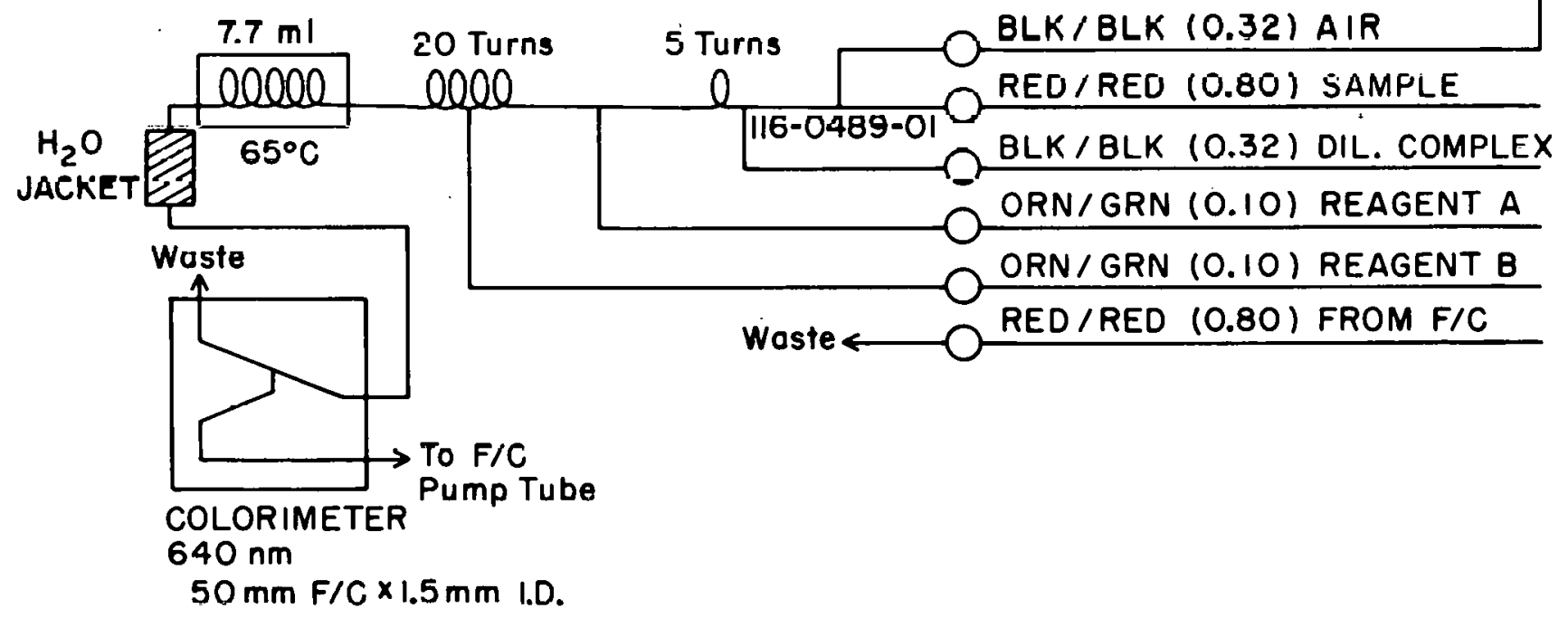

Figure 4-6. Ammonium Manifold for AutoAnalyzer II 
Urea

The urea analysis is based on the method of DeManche, Curl, and Coughenower (1973). The pink reaction product is measured at $520 \mathrm{~nm}$ after heating at $95^{\circ} \mathrm{C}$.

Reagents:

Sodium chloride solution. Dissolve $175^{\prime} \mathrm{g}$ of $\mathrm{NaCl}$ in $500 \mathrm{ml}$ DDW. Add 1 ml Brij-35.

Acid phosphate solution.

a) Stock solution. Dissolve $42.50 \mathrm{~g}$ of sodium phosphate, mono basic $\left(\mathrm{NaH}_{2} \mathrm{PO}_{4} \cdot \mathrm{H}_{2} \mathrm{O}\right)$ in $500 \mathrm{ml}$ conc. $\mathrm{H}_{2} \mathrm{SO}_{4} \cdot$

b) Working solution. Add $147 \mathrm{ml}$ of stock acid phosphate to about $100 \mathrm{ml}$

DDW in a $250 \mathrm{ml}$ volumetric flask. Cool under running tap water and make up to the mark with DDW.

Semicarbizide $\mathrm{HCl}$ stock. Dissolve $1.2 \mathrm{~g}$ semicarbizide $\mathrm{HCl}$ in $100 \mathrm{ml}$

DDW. Refrigerate the solution.

Manganous chloride and potassium nitrate solution. Dissolve $15.7 \mathrm{~g}$ $\mathrm{MnCL}_{2} \cdot 4 \mathrm{H}_{2} \mathrm{O}$ and $0.30 \mathrm{~g} \mathrm{KNO}_{3}$ in $100 \mathrm{~m} 1 \mathrm{DDW}$.

Color Reagent. Dissolve $1.65 \mathrm{~g}$ of diacetylmonoxime in $65 \mathrm{ml}$ hot DDW $\left(\sim 80^{\circ} \mathrm{C}\right)$ and then cool to room temperature. Add $1.65 \mathrm{ml}$ of semicarbizide stock and $33.3 \mathrm{ml}$ of $\mathrm{MNCl}_{2}+\mathrm{KNO}_{3}$ stock solution. Prepare a fresh solution daily.

UREA

(RANGE: $0 \rightarrow 10 \mu g-$ at UREA-N/ $/$

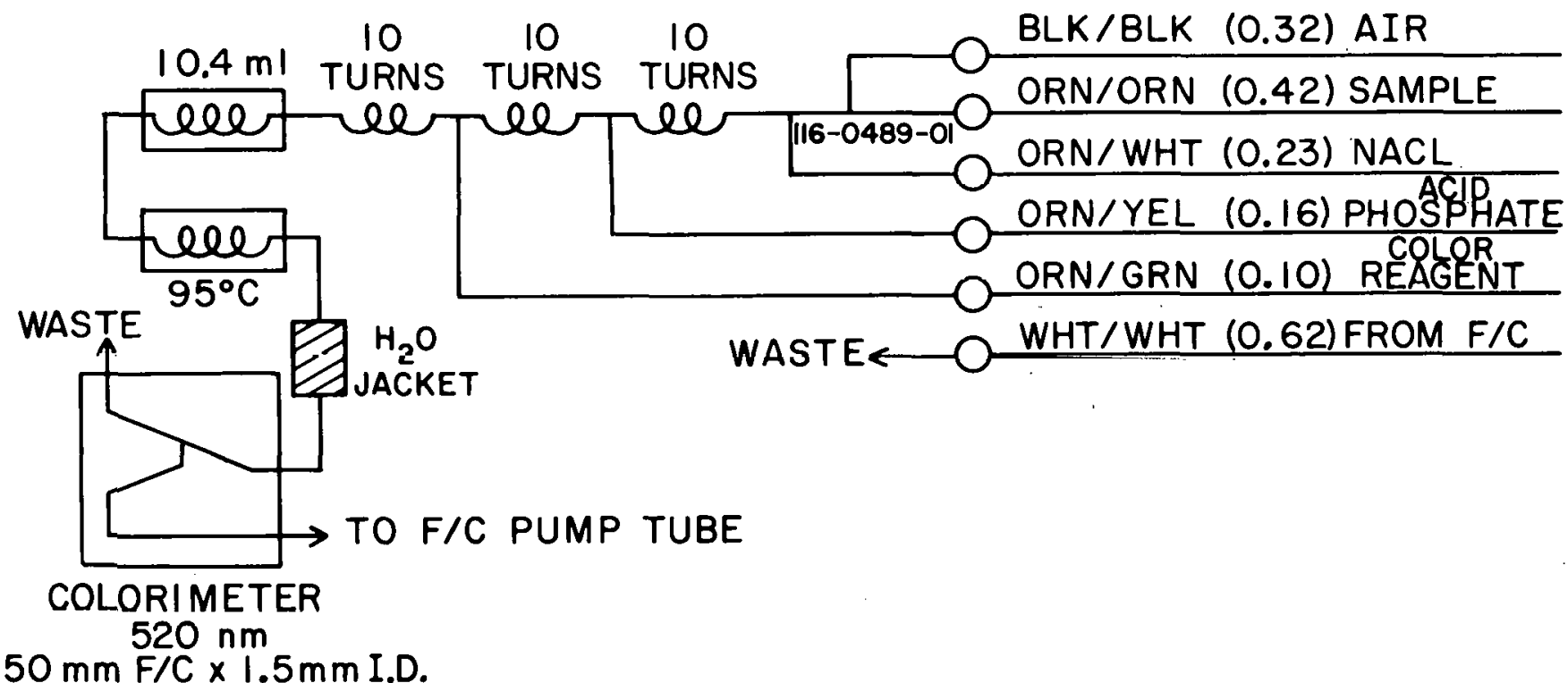

$50 \mathrm{~mm} \mathrm{~F} / \mathrm{C} \times 1.5 \mathrm{~mm}$ I.D.

Figure 4-7. Urea Manifold for AutoAnalyzer II 
Chemicals - Storage and Handling

a. Crystalline stannous chloride, ascorbic acid, and phenol may deteriorate rapidly at room temperature, so these bulk reagents should be refrigerated. We have obtained the best results with the chemicals suggested in the appendix.

b. Keep prepared reagent solutions refrigerated at all times. Transfer only the amounts of reagents expected to be used in one day of operation to small pyrex of plastic bottles for use at the AutoAnalyzer bench. Table 4-1 below can be used to estimate reagent consumption.

c. Wipe reagent straws dry with a tissue before placing them in reagent bottles. Seal the top of the reagent bottles with parafilm after the reagent straw is in place. Never release the platten until reagent straws are removed from reagent bottles. These measures prevent cross contamination of reagents.

d. Wetting agents are essential for proper flow in the AAII system. Brij-35 seldom causes problems. Sodium lauryl sulfate (SLS) on the other hand will precipitate if stored at too low a temperature. Simply place the bottle containing SLS in warm water to redissolve.

Table 4-1

Approximate Reagent Consumption

\begin{tabular}{cccc}
\hline & Pump Tube & \multicolumn{2}{c}{ Consumption (ml) } \\
Color-code & Flow-rate (ml/min) & per 8 hrs. & per 24 hrs. \\
\hline ORN/GRN & 0.10 & 48 & 144 \\
ORN-YEL & 0.16 & 77 & 231 \\
ORN/WHT & 0.23 & 110 & 330 \\
BLK/BLK & 0.32 & 154 & 462 \\
ORN/ORN & 0.42 & 202 & 606 \\
WHT-WHT & 0.62 & 298 & 894 \\
RED/RED & 0.80 & 384 & 1152 \\
GRN/FR.N & $2.0 n$ & 960 & 2880 \\
\hline
\end{tabular}

Glassware

a. Use only "Type A" pipettes and volumetric flasks. We use continuously adjustable microliter pipettes with disposable plastic tips instead of glass pipettes for mixed standard preparation.

b. Clean glassware periodically with a mild detergent solution. Always rinse glassware with dil. HCL and DDW just prior to use.

Plumbing

a. When the flow stream is unsegmented, use small ID nonwettable tubing such as teflon or polyethylene. Keep the lines as short as possible and use low dead-volume connectors (e.g., stream dividers). Use the same type of tubing to connect reagent straws to punp tubes. Reagent pump tubes are connected to the manifold with extensions made from old pump tubes of matching ID. 
b. Air segmentation of the flow stream and addition of the first reagent should be accomplished in an injector fitting (Technicon 116-0489-01). Subsequent reagent additions should be made either through the platinum side arms provided in some mixing colls or through A-10 fittings. Once the flow stream is segmented use $2 \mathrm{~mm}$ ID $\times 3.6 \mathrm{~mm}$ OD glass tubing for transmission to manifolds and colorimeters.

\section{Pump Tubes}

a. Only flow-rated pump tubes should be used.

b. Silicon rubber tubing should be used underneath the air bar.

c. New pump tubes should be sprayed lightly with a silicone lubricant. This will greatly extend their useful life time. Once a week spray the platten with this same lubricant. Wipe off the excess with a tissue.

d. Install new pump tubes after $300 \mathrm{hrs}$. of operation or sooner if necessary. 
THIS PAGE

WAS INTENTIONALLY

LEFT BLANK

$-58-$ 


\section{AUTOMATED ANALYZER AND DATA ANALYSIS SOFTWARE}

The tasks of using a computer to collect store and process AutoAnalyzer data requires a hardware interface from the colorimeters and software packages to handle the data. The interface hardware will need to be selected for compatibility with the system software on the particular computer used. In our case the Hewlett-Packard $9845 \mathrm{~S}$ has an interface card (HP98032A 16 bit parallel I/O card) which was connected to an eight channel analog to digital converter ( $A D C)$. A single digital to analog converter (DAC) is also utilized simultaneously through the interface card to control the sampler. A specific description of the interface operation can be found in Section 6, Computer Interfacing and Hardware Modifications.

The software written in BASIC language uses nearly all of the techniques described for peak regeneration by MacAulay et a1. (1976). In general, peak regeneration calculates the mixing characteristics of an AutoAnalyzer channel and empirically derives coefficients to calculate what a sample reading should be if dispersion did not exist (or at least ideally minimized).

The following short description will acquaint an unfamilar reader with the purpose and utility of the software operating procedures.

a. STAND program. This program takes data read by the computer with the APILOT program and calculates chemical factors for each of the analysis channels. After the factors are calculated the absorbances and concentrations of the standards may be plotted. The chemical factors must be manually entered in the APILOT program.

b. APILOT program. This program reads peaks while samples are being run on the AutoAnalyzer. An initial input of header information, the number of samples being run and an I.D. code for each sample is needed before the run can begin. The program will control the sampler, set initial and final baselines and will log the peak heights using a software peak regeneration routine. Additional features of this program allows a continuous logging of data points which is used in the BFIND program to calculate factors for peak regeneration. After a sample run is completed table lists of absorbances, concentrations, time between samples and confidence interval of all samples, data edit to correct errors, data save on cassette tape and data fetch from cassette tape can be made. Regenerated peaks may also be observed on the CRT while the data are collected.

c. MANDAT program. This program allows manual data entry into a file structure identical to APILOT program. This program also features the table lists, data edit, data save on cassette tape and data fetch from cassette tape.

d. BFIND program. This program reads a continuous data tape of standards logged with the APILOT program and calculates "B" factors used in the peak regeneration subrouting in APILOT during samples analyses. The routine collapses the raw data and plots both raw and regenerated sample peaks.

e. CLOCK program. This program sets the time on the real time clock that triggers the interrupt commands that the computer uses to operate the sampler and log the raw data. 
f. AvsM program. This program compares manually read absorbance values in chart units to automatic computer read absorbance values. The manually read raw peaks, baselines and factors are entered via the MANDAT program and saved on cassette tape. The computer read absorbances are generated by the APILOT program and saved on cassette tape. The AvsM program calls both files, tabulates the differences and plots the results of the differences between the two methods.

g. PLOT program. This program plots the station concentrations of nutrients in an $X-Z$ plot. The input data are taken from the stored station values on cassette tape. The nutrient to be plotted, concentration scales and depth scales of plots are chosen interactively by the operator.

h. SECS program. This program plots sections or time series stations. The operator requests the stations in the proper order and the program will store all values in memory. Station positions are read trom the nutrient file header for proper placement along the tranact line. The values for each nutrient wan be witten at their proper distance and depth along the transect for later hand contouring. Automatic machine contouring with or without numbers is another option available. Contour intervals are selected interactively by the operator. Ratios of nutrients may also be plotted. Integrated concentrations over an operator-selected depth range can be printed and plotted along the transect. 
STEPS FOR USING STAND - Regression of Standards

1. Insert Autoprogram tape into tape drive 15 .

2. Type Load "STAND" and then press Execute.

The step loads the program into the computer's memory. When the small square of light at the lower right hand corner of the cathode ray tube (CRT) is extinguished, the program is fully loaded and ready for use. Remove program tape and put data dape in drive 15 .

3. Press RUN. CRT displays HELLO FROM REGRESSION OF STANDARDS, "VARIABLE NAMES ARE P04, SI04, N+N, NH4, X30N. At the bottom of the screen, CRT prompts you with FILE WANTED.

4. Type in your standard run file name and press CONT. Computer finds and reads your standard file. CRT displays file and prompts "DO YOU WANT A COPY OF "THE LIST? Y/N."

5. If you want copy of the list type "Y". Thermal printer gives you a hard copy of the list and CRT "DO YOU WANT A COPY OF THE LIST?

$\mathrm{Y} / \mathrm{N}$ ". Again, Type "N" and press CONT. CRT displays REGRESSION SECTION at top of screen and prompts with "VARIABLE NAME".

6. Type one variable name: $\mathrm{P} 04, \mathrm{SIO4}, \mathrm{N}+\mathrm{N}, \mathrm{NO}_{2}, \mathrm{NH}_{4}$, or URE and press CONT. Typing an incorrect variable yields incorrect variable BAD CHOICE TRY AGAIN.

CRT displays TABLE OF DATA FOR REGRESSION

Label = station name

NUTRIENT = nutrient chosen

$\mathrm{N}=$ number of sample, ID - identification, CONC = concentration $\mathrm{ABS}=$ absorbance and prompts DO YOU WANT TO DELETE? Y/N

7. If you want to delete a bad point, type $Y$ and press CONT. CRT prompts WHICH SAMPLE IS TO BE DELETED? NO.

8. Type in sample number to be deleted and press CONT. If there are several numbers to be deleted, eliminate them in descending order. CRT displays standard table as in 6 above minus deleted sample(s) and "DO YOU WANT DELETE? Y/N" If you delete until the number of sample is $<2$, an "ERROR IN REGRESSION $\mathrm{N}=$ " appears. Regression analysis is invalid.

9. If you do not wish to delete, type "N" and press CONT. Computer performs least squares regression on your data. CRT displays TABLE OF DATA FOR REGRESSION as in 6 including calculated INTERCEPT, SLOPE, $R * R$, and FACTOR, and prompts DO YOU WANT A LIST OF THE TABLE? $\mathrm{Y} / \mathrm{N}$

10. If you want a 1ist, type $Y$ and press CONT. Thermal printer gives hard copy and CRT displays "DO YOU WANT A PLOT? Y/N"

11. If you do not want a list of the table, press $\mathrm{N}$ and then CONT. CRT displays DO YOU WANT A PLOT? Y/N (Go to 12 or 14)

12. Type " $Y$ " and then press CONT if you desire a plot of the regression. CRT plots data. Press CONT. CRT prompts DO YOU WANT A HARD COPY OF THE PLOT? Y/N

13. Type $Y$ for the hard copy and then CONT. Hard copy is output to thermal printer. Computer program returns to step 6 .

14. Type "N" and press CONT. CRT and computer go back to STEP 6 and prompts for new variable name.

15. If you desire another standard data file, press CONTROL/RESET simultaneously and then RUN to restart STAND. 


\section{STAND PROGRAM - USER DEF INED PARAMETERS}

These are program lines that may need to be changed occasionally by doing a program edit of the designated lines.

Lines

220 Variable names: Order of variable is constant. Channel 6, URE is the experimental channel, however, the name may be changed if so desired.

690' Channel labels: Same as 111 above.

710 Maximum sample concentration for each channel: For Bering Sea, set channel 2 which is silicate to 100 .

940 Concentrations of standards: For Bering Sea work set channel 2 which is silicate to $10 \mathrm{i}$.e. $0,5,5,0,0,5$ becomes $0,10,5,0,0,5$

950 Same as 750 . Set channel 2 to 30 i.e. $0,15,15,0,0,15$ becomes 0,30 , $15,0,0,1.5$

960 Same as 750 . Set channel 2 to 50 i.e. $0,25,25,0,0,25$ becomes 0,50 , $25,0,0,25$

970 Same as 750 . Set channel 2 to 70 i.e. $0,35,35,0,0,35$ becomes 0,70 , $35,0,0,35$.

980 Same as 750 . Set channel 2 to 90 i.e. $0,45,45,0,0,45$ becomes 0,90 , $45,0,0,45$ 


\begin{tabular}{|c|c|c|c|c|c|c|c|}
\hline \multicolumn{8}{|c|}{$\begin{array}{l}\text { LHEEL }=5 \text { THHA } \\
\text { IIATE = } 2 \text { J JHHS } 1\end{array}$} \\
\hline \multicolumn{8}{|c|}{$L \bar{H} T=H . \bar{H}$. } \\
\hline \multicolumn{8}{|c|}{ LDH= H. H. } \\
\hline \multicolumn{8}{|c|}{ DEF'TH $=\quad-99$} \\
\hline \multicolumn{8}{|c|}{ CODMEHT = WIIFKIHE STAHIIAFIS: } \\
\hline \multicolumn{8}{|c|}{ ND.SHMFLES= 11} \\
\hline \multicolumn{8}{|c|}{ DFEF'ATOR: = IMW } \\
\hline \multicolumn{2}{|c|}{ EHAHHEL $=$} & $\mathrm{PO} 4$ & $5 \square \square 4$ & $\mathrm{H}+\mathrm{H}$ & +10 & $\mathrm{NH}_{4}$ & IIRE \\
\hline \multicolumn{2}{|c|}{ STATUS= } & 1 & 1 & 1 & 1 & 1 & 6 \\
\hline \multicolumn{2}{|c|}{ FHI:TORE: = } & 1.039 & 5.720 & 4.520 & .945 & 1.016 & 1. 0019 \\
\hline \multicolumn{2}{|c|}{$\mathrm{F} F: S=$} & 0.060 & 0.000 & 0.000 & 0. 00 & Q. 010 & 0. 960 \\
\hline \multicolumn{2}{|c|}{ BASE $1=$} & 9.006 & .190 & .379 & .307 & .218 & 日. \\
\hline \multicolumn{2}{|c|}{$\mathrm{BASE} 2=$} & 0.000 & .183 & .391 & .308 & .220 & 日. \\
\hline \multicolumn{8}{|l|}{$N[1}$. \\
\hline $1 \mathrm{II}$ & 0 & 6. 906 & E.064 & 10.000 & 4.884 & 5.159 & 0. 108 \\
\hline 25 & 11 & 9. 060 & 1.245 & 1.716 & .327 & .450 & Q. \\
\hline 35 & 12 & 6. 606 & 2.985 & 3.629 & .367 & .6 .42 & 9. 600 \\
\hline 45 & 13 & 0.005 & 4.749 & 5.776 & .301 & .444 & 0. 0100 \\
\hline 55 & 14 & 日. 006 & $E .514$ & ㄱ. 964 & .960 & .426 & 6. 0100 \\
\hline 65 & 15 & 9.000 & 5.217 & 9.996 & .296 & .429 & Q. 050 \\
\hline 75 & 25 & 6. 0100 & .189 & 1.251 & .198 & $4.8 E 1$ & 0. 150 \\
\hline 85 & 24 & 0.000 & .178 & .994 & .567 & 4.691 & Q. \\
\hline 95 & 23 & 0.000 & .170 & .820 & 3.002 & 2.731 & 6. 6日a \\
\hline 105 & 22 & 1. 090 & .178 & .651 & 1.960 & 2.069 & 0. 010 \\
\hline 115 & 21 & 0.000 & .173 & .482 & .875 & .960 & Q. 010 \\
\hline
\end{tabular}



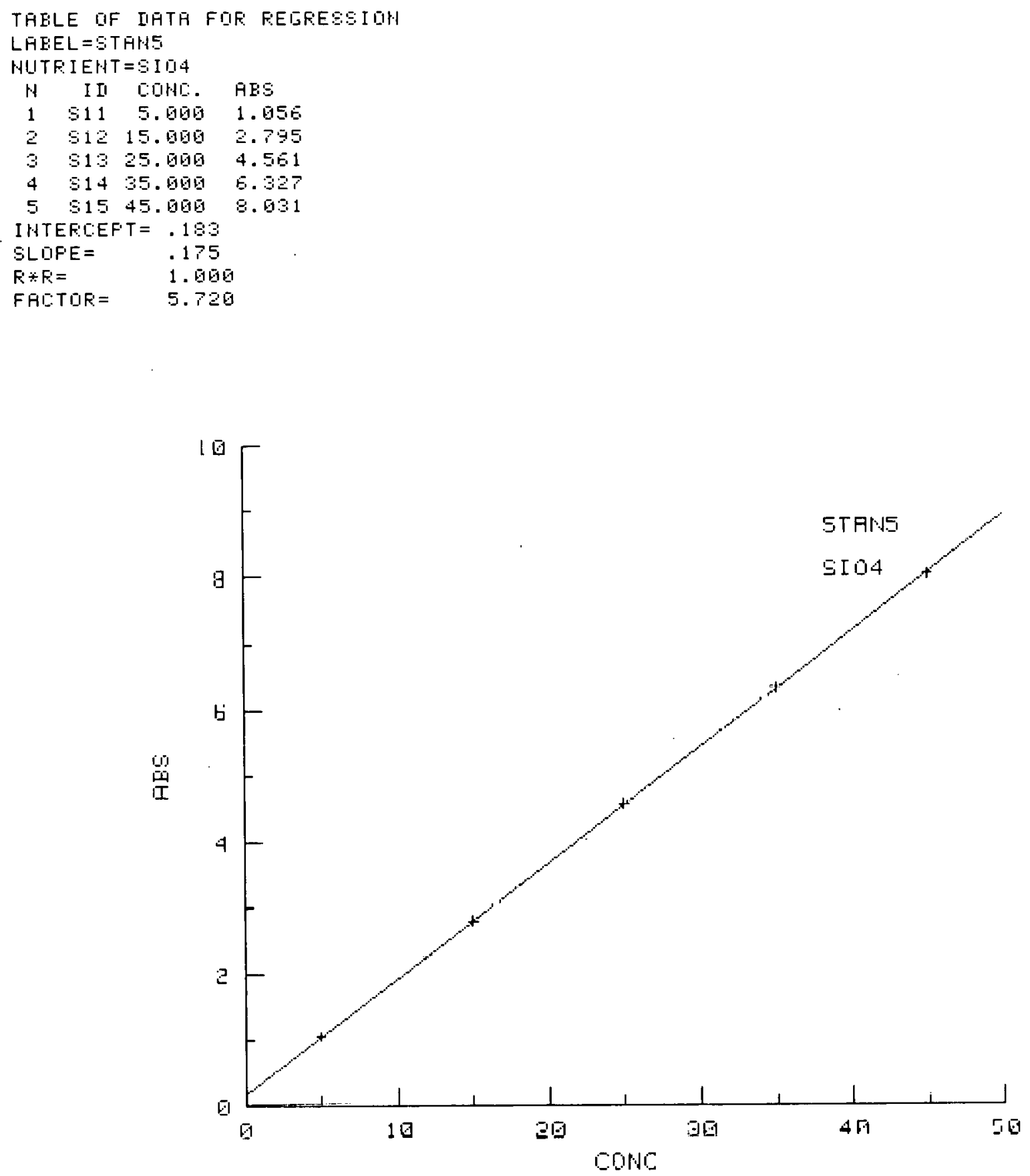
THELE DF IATA FOF REGEESSIDH

LAEEL $=$ STHAS

HIITRI IEHT $=H+H$

H II COHC: HES

$151215.056 \quad 3.248$

$251325.060 \quad 5.394$

$3514 \quad 35.096 \quad 7.526$

$451545.000 \quad 9.611$

$5 \quad 525 \quad 4.560 \quad .565$

$6 \quad 524 \quad 3.5010 .697$

$7 \quad 523 \quad 2.500 \quad .432$

$8 \quad 522 \quad 1.500 \quad .262$

$9 \quad 521.500 \quad .092$

INTER CEF T $=-.072$

SLDPE $=\quad .216$

$R * R=\quad 1.090$

FALTOR $=4.620$

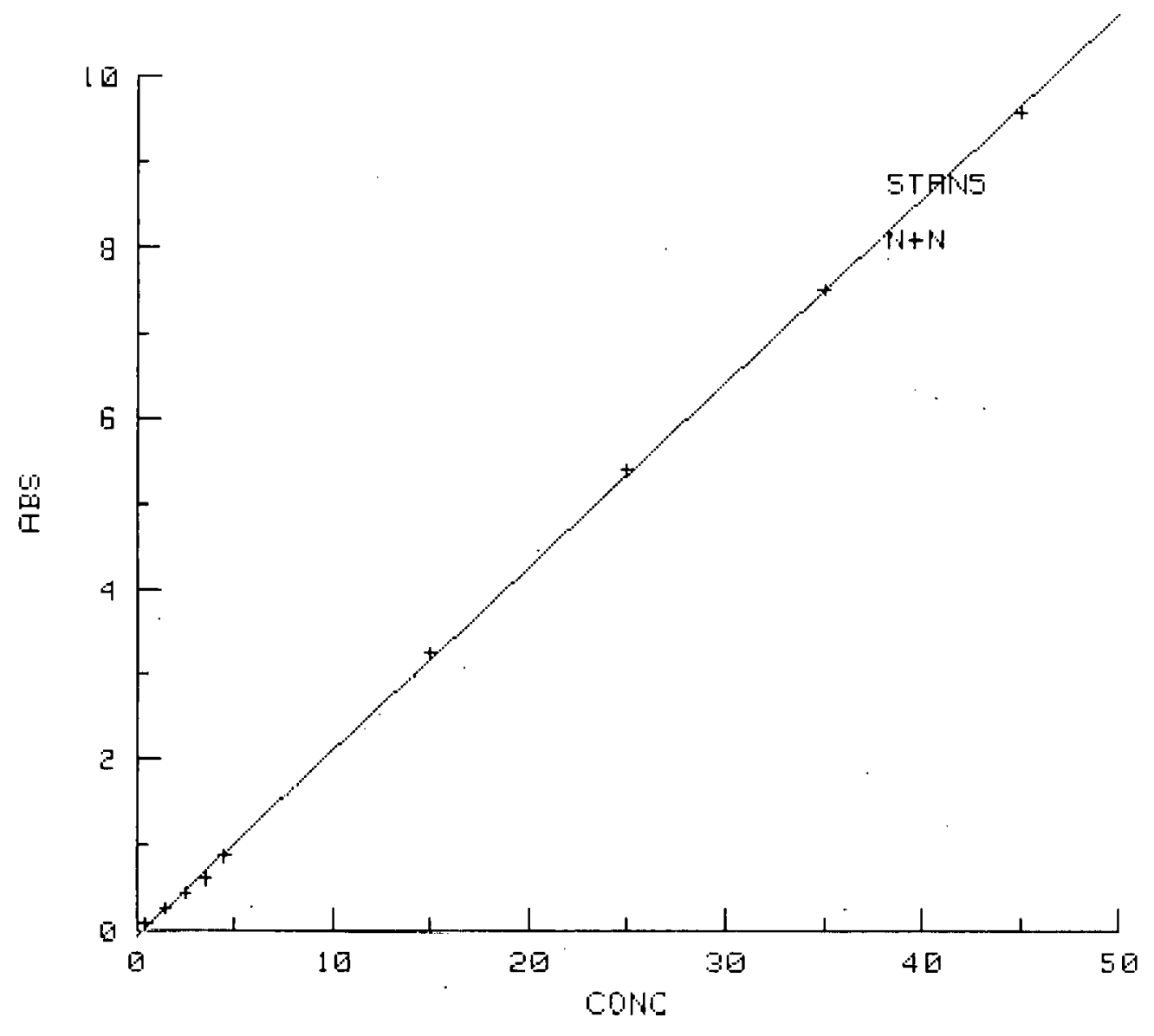


THELE IIF IIATA FOF FELEESSIOH LAEEL $=5$ THHS

NUTE I EHT $=1+102$

N I II EIHC. AES

15232.5692 .594

25221.5001 .652

$3521.560 \quad .567$

IHTEREEFT $=.143$

SLOFE $=1.063$

$\mathrm{R} \div \mathrm{R}=\quad$ 1. 100

FHLTOK $=\quad .946$

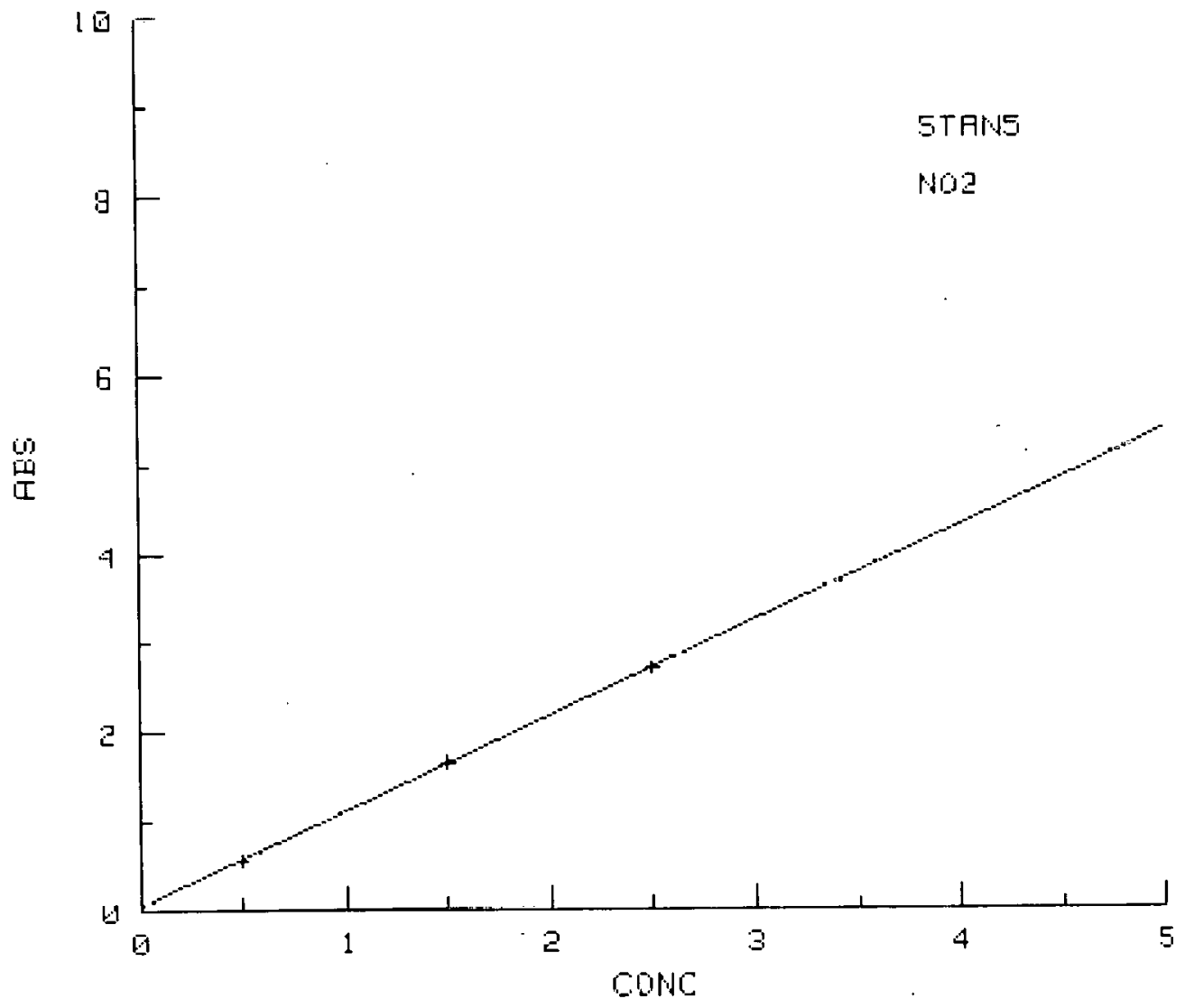


THELE DIF IIATTA FOF FEIFESSION LAEEL = STAHS.

NITTE IEHT $=\mathrm{HH} 4$

N II EOHE RES

15254.5054 .541$.

25243.569382

$35232.500 \quad 2.511$

45221.5601 .349

5521.506 .240

IHTEF:CEFT $=.271$

SLOFE =

$R \div F:=$ .974

FALTUR= 1.027

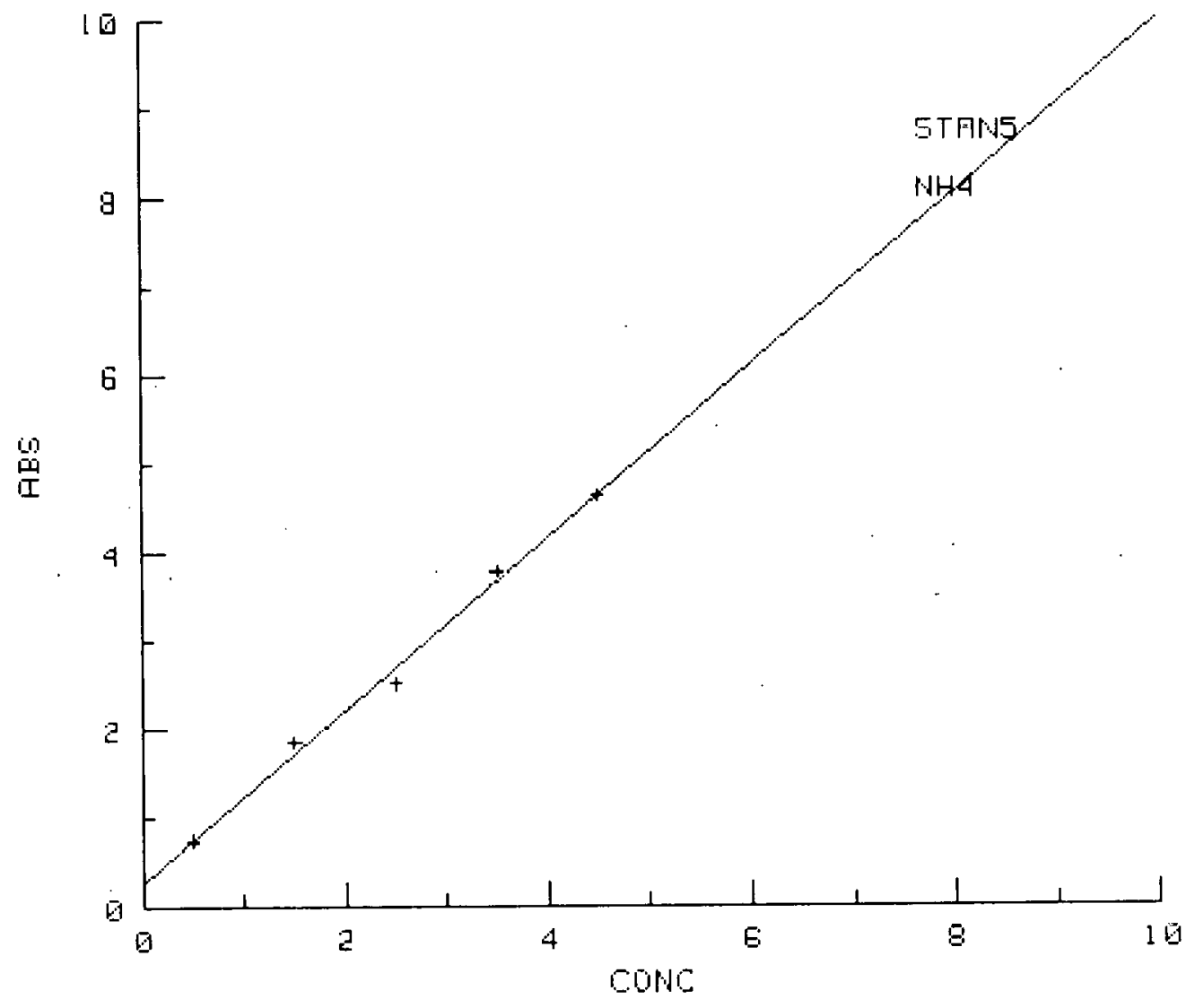




\section{INSTRUCTIONS FOR THE AUTOMATIC PEAKING FINDING ROUTINE KNOWN AS "APILOT"}

1. Have AutoAnalyzer log sheet filled out with station number, date, time, latitude, longitude, sonic depth, sync standard, calibration standards, nutrient sample numbers, and the sample depths from the hydrographic or productivity log sheets. See sample log sheet at the end of this description of APILOT

2. Insert the Auto program tape into tape drive 15.

3. Type LOAD "APILOT" and then press Execute. This step loads the program into the computer's memory. When the small square of light at the lower right hand corner of the cathode ray tube (CRT) is extinguished, the program is fully loaded and ready for use.

Press $\mathrm{K}_{7}$ to rewind the Autoprogram tape. After rewinding the tape, remove and place in protective case. Place an Initialized data tape in tape drive 15.

4. Press RUN. CRT displays "He.11n From Auto Pilot". "I HAVE RUN OFF TO GET THE TIME BACK IN 20 SEC." After pause, "CLOCK TIME IS correct time." CRT then prints "IS DATA FROM IIAPE? Y/N"

5. Press " $\mathrm{N} "$ " and then CONT

Display prints "DO YOU WANT TO SAVE DATA FII.E ON TAPE? Y/N"

6. Press " $\mathrm{N}$ " and then CONT. Thermal printer writes on

$\begin{array}{lll}\text { KEY } & 0 & \text { INIT } \\ \text { KEY } & 1 & \text { LIST } \\ \text { KEY } & 2 & \text { PEAK } \\ \text { KEY } & 3 & \text { EDIT } \\ \text { KEY } & 4 & \text { SAVE } \\ \text { KEY } & 5 & \text { FINI } \\ \text { KEY } & 6 & \text { FE'I'CH }\end{array}$

"When in doubt, press CONTINUE, something will happen" CRT displays flashing "WAITING FOR COMMAND". At this point you must set up table for leceivlug the peaks.

7. Press $K_{O}$. CRT displays "HELlo FROM INITIALIZE" LABEL [6]? Enter station number as 001,002 , e.tr. Yny may wieh to identify statiui type as Hydro, Productivity, Interface, Pump, Benthic, Zooplankton, or Miscellaneous sample run as $H, P, I, Q, Z$ or $M$ respectively. For example $\mathrm{HOOl}$ indicates station No. 1 is Hydro. Station label cannot contain more than 6 characters - hence [6] after LABEL. (See examples at the end of this section that show the several klnde of tables.)

8. Press CONT after entering the label. CRT displays "DATE [7]?"

9. Type in date as day number (2 characters), month ( 3 characters), year ( 2 characters).

$$
\text { Examples: n1MAR79 21APR79 }
$$

10. Press CONT after entering date. CRT displays "TIME [4]". Type in the time ( 4 characters using 24 hour clock)

$$
\text { Examples: } 0014 \quad 2341
$$

Press CONT. CRT displays "LAT? 12A or [CONT]" Enter Latitude (Maximum 12 characters) if available.

$$
\text { Examples: } 4020.1 \quad 5601.1
$$

Press CONT. CRT displays "LON? 12A or [CONT]" Enter Longitude (maximum 12 characters) if available.

Examples: $70 \quad 29.6 \quad 150 \quad 02.1$


Press CONT. CRT displays "STATION DEPTH? FLOAT or [CONT]" Enter depth if available.

$$
\text { Examples: } 26 \quad 1046
$$

Press CONT. CRT displays "COMMENT? 50A or [CONT]" Enter your comment (maximum 50 characters).

$$
\text { Example: TIME SERIES STATION I }
$$

11. Press CONT. CRT displays "OPERATOR [6]?"

12. Enter your initials or name up to 6 characters.

$$
\text { Example: TEW }
$$

13. Press CONT. CRT displays "NO. SAMPLES?"

14. Type in the number of samples (including the three standards) for this run and press CONT. CRT displays "DO YOU WANT TO CHANGE THE TABLE? Y/N"

(NOTE: Each individual hydro station should be a separate run, i.e. never set up a tray with 2 or more hydro stations or a hydro and prod station in same run. This prevents a lot of extra work in data processing later.)

15. Press "Y" and then CONT. If you have a mistake in the completed table, type $\mathrm{N}$ which takes you back to Step 7. Type in correct parameter and press CONT again and again until computer and you return to step 14 - "DO YOU WANT TO CHANGE THE TABLE? Y/N"

16. Press "N" and then CONT. CRT displays "ENTER SAMP $\sim$, ID OPTIONS $=$ EXIT and LIST)". "NO; ID?"

17. TYPE in sample sequence number, a comma, sample ID, and depth or sample number if it is an experimental sample.

Examples:

\begin{tabular}{ll}
\multicolumn{1}{c}{ 4, H0 } & (seq. no. 4 - hydrography sample, 0 meters) \\
$15, \mathrm{H} 120$ & (seq. no. 15 - hydrography sample, 120 meters) \\
$19, \mathrm{P} 5$ & (seq. no. 19 - productivity sample, 5 meters) \\
21, I19 & (seq. no. 21 - interface sample, 19 meters) \\
22, Q10 & (seq. no. 22 - pump sample, 10 meters) \\
23, Z250 & (seq. no. 23 - Zooplankton experiment sample, \\
& bottle no. 250 ) \\
24, B101 & (seq. no. 24 - Benthic sample, bottle no. 101) \\
25, M12 & (seq. no. 25 - Miscellaneous sample, bottle no. 12).
\end{tabular}

NOTE: The first 3 bottles of any run are standards.

Bottle No. 1 is 1, DO

Bottle No: 2 is 2,81

Bottle No. 3 is 3 , s2

DO is a mixed synchronization standard for all channels.

S1 and $\mathrm{S} 2$ are calibration standards. The is a number, 1 to $\overline{5}$, corresponding to the standard concentration (discussed section 3 under standards).

18. Press CONT and repeat Step 17 until all bottle sequences and ID's have been entered. (Note it is very important to run bottles in numerical sequence to avoid data processing problems later).

19. Press " $T$ " and then CONT after entering last sample. CRT displays "HELLO FROM LIST" "1=ABS 2=UG-AT"

20. Press " 1 " and then CONT to obtain a list of your entered material. CRT displays "DO YOU WANT A HARD COPY? Y/N"

21. If table is correct, press " $N$ " and CONT. CRT displays "ENTER SAMP No., ID, OPTIONS = EXIT or LIST)

22. Press "E". CRT displays "INITIALIZE FINISHED" "WAITING FOR COMMAND" in flashing characters. (Go to Step 24.) 
23. If table is incorrect, press " $\mathrm{Y}$ " and CONT. CRT displays "ENTER SAMP No., ID (OPTION = EXIT OR LIST)" "NO., ID?" Type in correct sequence number and ID and press CONT. (Go to Step 19.)

2.4. Press $K_{7}$ to enter check. CRT displays check In check, the time and absorbances for all si $\bar{x}$ channe $\overline{l s}$ are displayed. Examine CRT value and strip chart values to see if they correspond. If they are not the same, adjust zero knob on recorder until value is in agreement with CRT value. NOTE: The above adjustment assumes recorder has been checked previously against colorimeter to assure full scale is being used.

25. Press $\mathrm{K}_{7}$ to exit "check". CRT displays "WAITING FOR A COMMAND" in flashing type.

26. Press $K_{2}$ if all the channels are ready to run samples. The sampler is controlled by the computer and the channel delay times are entered into the program so the baselines are set automatically for each channel 30 seconds before the first sample reaches the colorimeter.

So sit back and relax as the peaks are read.

27. At any time you can ohtain a tahle "riate of the peakc on the CnT by pressing $\mathrm{K}_{11}$.

28. When all peaks have been read and baselifnes have flattened, the baselines will automatically be set about one sample time after the last peak. CRT displays "Waiting for Command" in flashing characters.

29. Press $\overline{\mathrm{K}}_{1}$ to obtain list. CRT prints "HELlO FROM LIST" " $1=\mathrm{ABS}$, 2=TIME, 2=DELTA TIME, 4=AG-AT, 5=CONF ID"

30. Press 1 and then CONT to obtain list of absorbances on CRT. CRT displays also "DO YOU WANT A HARD COPY?"

31. Press "Y" to obtain thermal printer hard copy. CRT displays "WAL'I'LNG FUR COMMAND"

32. Press $K_{1}$ to obtain 1ist. CRT prints "HELLO FROM LIST" " $1=A B S$, 2-TIME, 3=DELTA TIME, 4=UG-AT, 5=CONF ID"

33. Press 4 to nhtain a list in UG-AT. CRT dioplays also "DO YOU WANT A HARD CŌPY, Y/N?"

34. Press "Y" to obtain a hard copy of list in UG-AT. CRT displays "WAITING FOR COMMAND" in flashing characters.

35. Press $\mathrm{K}_{4}$ to save the file. CRT displays "HELlO FROM SAVE" "DO YOU WANT TO SAVE THE FILE, Y/N?"

36. Press "Y" and then CONT. CRT Aisplay "TAPE DRIVE 14 or 15"

37. Type 15 and then CONT. When file has been save, CRT prints "FILE HA3 BEEN SAVE ON $T: 19 "$

38. To set up for another run, press CONTROL and RESET simultaneously and then RUN. Go to Step 4.

Regenerated peaks may be viewed on the CRT after the peak reading routine has been started. The channel number of the analysis you want to view must be entered:

Cplot $=3$ Execute will display $\mathrm{N}+\mathrm{N}$ channel then press $\mathrm{K}_{9}$. The plot will appear on the screen. To exit, repress $K_{9}$. 
In the event that the sampler control system fails, it is possible to easily utilize the Knobelsdorf electronic timer using the following steps.

1. Check line 5300 in "APILOT" program for sample: wash time increments. Set the Knobelsdorf timer and "APILOT" program for identical sample and wash times.

2. Set up file structure in "APILOT" in the usual manner and load samples in sample tray. Load a distilled water bottle at the beginning of samples in front of the sync sample but do not enter in computer file. Put turn-off pin next to the last sample bottle.

3. Push key 7 and go into "check" mode.

4. Turn sampler "of $f$ " and "on" to start Knobelsdorf timer.

5. When timer goes into the first bottle which is dionized water, turn off "check" and turn on "check" again using key 7 .

6. When using a 120 second sample and 60 second wash, exit "check" with key 7 when the counter on the CRT reaches 600 .

7. In about $10-15$ seconds the sampler will go into a wash cycle. When the needle leaves the sample bottle of deionized water press "PEAK FINDER," key 3, to start data logging.

8. The complete set of readings will be automatically taken. No further instructions are necessary until "WAITING FOR A COMMAND" appears on the CRT after which the data is processed normally. 


\section{APILOT PROGRAM - USER DEFINED PARAMETERS}

In most of the programs associated with the computer assisted AutoAnalyzer, there are lines which should or can be edited by the user. These user defined parameters (factors are most frequently changed) are entered immediately after a program has been loaded into the computer's memory.

1. To change a user defined parameter, press EDIT LINE. Type in the line number and press EXECUTE. The CRT will display this line with the blinking cursor to the right of it. Move the cursor to the parameter to be changed and edit it.

2. Press STORE. The edited line is now in the computer's memory. If you don't press STORE the original line will not be retained.

3. Press CONTROL/RESET simultaneously and then RUN. Your edited program is now ready for use.

The common user defined parameters for each sutodnalyecr program ari Listed below by ine number.

5260 The data in this statement indicate whether a channel is on or of . An active channel is " 1 " while " 0 " is inactive. If an analysis is not being performed or if a channel is shut down for some reason, change the status to " 0 ". Operating a non-active channel in the on mode can result in cross talk with an active channel.

5300 This line lists the regression factors as determined in STAND. The factors should be updated and changed periodically as the standard runs dictate.

5320 The refractive index for each channel is usually determined at the beginning of each cruise, stored in the program, and not altered thereafter unless the manifold is modified.

5340 Th1s line lists the B factors calculated in the BFIND program. These numbers, used to determine the regenerated peak hcights, are also determined at the initiation of a cruise and remain constant if no changes are made in the manifold colorimeter and the sample and wash times.

5360 These six numbers are the times at which the initial baseline is set for each channe1. These baseline numbers are set about 15 seconds before the sample stredul enters the flow cell. 'l'hey represent the number of seconds required for a sample to be aspirated, traverse the manifold, and just reach the colorimeter with the present system. If the diameter of the sample pump tube is changed by substitution or the sample line from the smpler to the manifold is significantly lengthened or shortened, the initial baseline time should be redetermined.

5380 The second and third numbers in this sequenre arr the sample and waoh times, respectively. Standard rates for the present manifold configurations are 120 seconds of sample and 60 seconds of distilied water wash -approximately 20 samples per hour. If a faster rate is desired, 60 seconds sample and 30 seconds of wash is satisfactory. When recording data on tape for use in BFIND, sample for 180 seconds and wash for 60 seconds.

In addition, some of these user defined parameters can be altered once a program is engaged. They are Refractive index, Factors, and Baselines.

1. Refractive index is defined by the Mnemonic $R f(*)$. To change the refractive index of channel No. 3, type, $\operatorname{Rf}(3)=v a l u e$ calculated for this channel and press EXECUTE. Follow the same procedure for the other channels if needed. This statement will change the value of 
$\mathrm{Rf}(3)$ for the file at hand and must be reentered for succeeding files. $\operatorname{Rf}(3)$ will not be changed on the program tape using this statement.

2. Factor is defined by the Mnemonic $F(*)$. To change the factor for channel No. 2, type $F(2)=v a l u e ~ c a l c u l a t e d$ for this channel and press EXECUTE. Follow the same procedure for the other channels if needed.

3. Baselines

a. Initial or beginning baseline is defined by the Mnemonic $B 1\left(^{*}\right)$. To change the initial baseline for channel No. 4, type $\mathrm{Bl}(4)=v a l u e$ determined from strip chart and press EXECUTE. Repeat as needed for the other channels.

b. Final or end baseline is defined by the mnemonic $B 2(*)$. To change the final baseline for channel No. 5, type B2(5)=value determined from strip chart and press EXECUTE. Repeat as needed for the other channels.

4. Sample Specification

a. Sample identification is defined by the mnemonic $\operatorname{Id\$ (*)}$ and is used to correct minor listing errors.

Example: Sample 10,H18 is incorrectly listed as 10,B18. Type $\operatorname{Id} \$(10)=" H "$. Press Execute.

b. Sample code is defined by the mnemonic $\operatorname{ICODE}(*)$ and is also used to correct listing errors.

Example: Sample 13,H425 is incorrectly listed as 13,H5425. Type $\operatorname{ICODE}(13)=425$. Press execute.

Using these two mnemonics the operator does not have to re-initialize a file in order to correct listing errors.

5. Header Information

The complete list of header mnemonics (see APILOT No. 8-13) for any file are:

$$
\begin{array}{ll}
\text { L\$ } & =\text { "Label" (file name) } \\
\text { Da\$ } & =\text { "Date" } \\
\text { Hr\$ } & =\text { "Hour" } \\
\text { Lat\$ } & =\text { "Latitude" } \\
\text { Lon\$ } & =\text { "Longitude" } \\
\text { Mess } \$ & =\text { "Comment" } \\
\text { Depth } & =\text { Depth } \\
\text { Nsamp } & =\text { No. samples } \\
\text { Op\$ } & =\text { "Operator" }
\end{array}
$$

Note that mnemonics followed by " $\$$ " require quotes while others do not.

To change any part of the header simply type the mnemonic LS = $"$ " and press Execute.

Examples: LS = "BIRD" Execute. Mess\$ = "MESA STATION 23" Execute.

The depth and opcrator changes to not require the use of parentheses. Hence it is correct to type Depth $=45$. Execute.

6. Columi Heading

The column headings for the six autoanalyzer channels are defined by the mnemonic $\mathrm{A} S\left(^{*}\right)$ and presented as $\mathrm{PO}_{4}, \mathrm{SiO}_{4}, \mathrm{~N}+\mathrm{N}$, $\mathrm{NO}_{2}, \mathrm{NH}_{4}$, and URE. The sixth channel for urea is not routinely run. Thus it is available for other data. For example, should 
you wish to use this column for chlorophyll, type $\mathrm{A} \$(6)=$ "CHL". Press Execute. Likewise A\$(6) = "SAL" indicates that the column is reserved for salinity values. The chlorophyll data can be entered manually under the Edit subprogram of APILOT or in MANDAT.

Additional capabilities such as edit, list, tape write and tape read may be performed in APILOT. For detailed instructions of these tasks go to MANDAT program description. 


\begin{tabular}{|c|c|c|c|c|c|c|c|c|c|}
\hline \multicolumn{2}{|c|}{ Investigator } & & & \multicolumn{3}{|c|}{ Experiment } & & & \\
\hline $\begin{array}{l}\text { Vessel } \\
\text { Crutse } \\
\end{array}$ & ب... & \multicolumn{2}{|c|}{$\begin{array}{l}\text { Station } \\
\text { Run No. }\end{array}$} & \multicolumn{2}{|c|}{ سـ., } & $\begin{array}{l}\text { Tlme } \\
\text { Date }\end{array}$ & & & $\begin{array}{l}\text { Page } \\
\text { of }-\end{array}$ \\
\hline Analysts & sis Code & Factor & $\begin{array}{l}\text { Std } \\
\text { Cal }\end{array}$ & \multicolumn{2}{|c|}{ Blank I } & 8 lankII & \multicolumn{2}{|c|}{$\begin{array}{l}\text { Refract. } \\
\text { Index }\end{array}$} & $\begin{array}{l}\text { Reagent } \\
\text { klangtar } \\
\text { for }\end{array}$ \\
\hline \multirow{5}{*}{$\begin{array}{ll}- & \mathrm{PO4} \\
- & \mathrm{S} 104 \\
- & \mathrm{N}+\mathrm{N} \\
- & \mathrm{NO2} \\
- & \mathrm{NH4} \\
- & \text { Urea }\end{array}$} & 09 & رـــــــ & ـ & \multirow{2}{*}{\multicolumn{2}{|c|}{ ســـــــ }} & \multirow{2}{*}{ 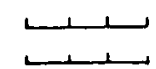 } & \multirow{2}{*}{\multicolumn{2}{|c|}{$\bar{\square}$}} & 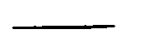 \\
\hline & 10 & 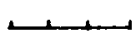 & 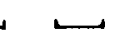 & & & & & & \multirow{2}{*}{$\bar{\square}$} \\
\hline & 11. & بــــــــ & $+\sqcup$ & \multirow{2}{*}{\multicolumn{2}{|c|}{ ב, }} & \multirow{2}{*}{ } & \multicolumn{2}{|c|}{$\longrightarrow$} & \\
\hline & 12 & 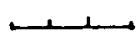 & $\smile$ & & & & & & $=$ \\
\hline & $\begin{array}{l}13 \\
27 \\
8 \quad\end{array}$ & . & ب & \multicolumn{2}{|c|}{ L. L } & Lـ. & & & $\bar{\square}$ \\
\hline Seq. & Depth & Bottle & Ident. & $\mathrm{PO4}$ & Sin4 & $\mathrm{N}+\mathrm{N}$ & Nก2 & $\overline{\mathrm{NH} 4}$ & U rea \\
\hline 1 & - & $D \phi$ & SYN & & & & & , & \\
\hline 2 & - & $s-1-$ & STD & & & & & & \\
\hline 3 & $\overline{-}$ & $\mathrm{s}-2-$ & STD & & & & & & \\
\hline 4 & & & & & & & & & \\
\hline 5 & & & & & & & & & \\
\hline 6 & & & & & & & & & \\
\hline 7 & & & & & & & & & \\
\hline 8 & & & & & & & & & \\
\hline 9 & & & & & & & & & \\
\hline 10 & & & & & & & & & \\
\hline 11 & & & & & & & & & \\
\hline 12 & & & & & & & & & \\
\hline 13 & & & & & & & & & \\
\hline 14 & & & & & & & & & \\
\hline 15 & & & & & & & & & \\
\hline 16 & & & & & & & & & \\
\hline 17 & & & & & & & & & \\
\hline 18 & & & & & & & & & \\
\hline 19 & & & & & & & & & \\
\hline $20^{\circ}$ & & & & & & & & & \\
\hline 21 & & & & & & & & & \\
\hline 22 & & & & & & & & & \\
\hline 23 & & & & & & & & & \\
\hline 24 & & & & & & & & & \\
\hline 25 & & & & & & & & & \\
\hline 26 & & & & & & & & & \\
\hline 27 & & & & & & & & & \\
\hline 28 & & & & & & & & & \\
\hline
\end{tabular}




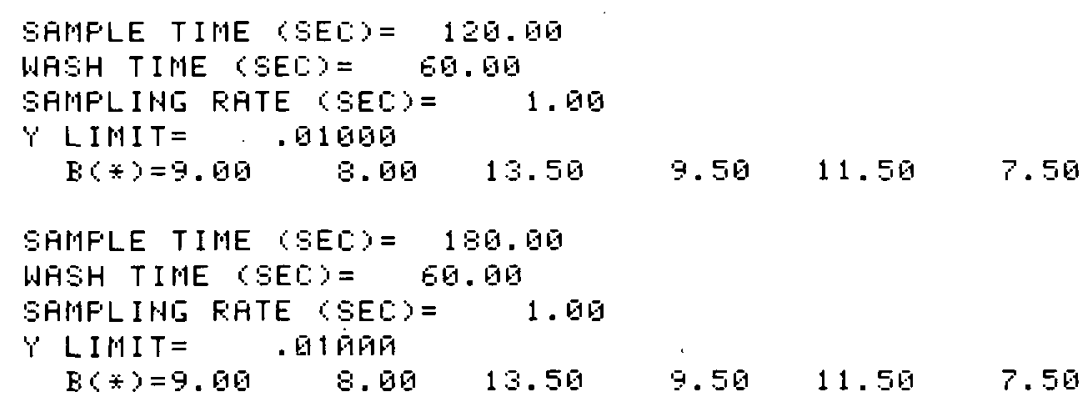

LFEEL = EF INII

IATE $=9 \mathrm{FEES} 1$

$H F:=1600$

LAT I TUDE = N. H.

LOHEITUDE = N. F.

COHNEHT =H. H.

IJETH $\quad-99$

HO. SAMPLES= 11

DPERATOR: TEW

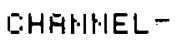

STATUS:

FAL:TORS=

F.F $S=$

$\operatorname{EASE} 1=$

BASE2=

$\begin{array}{rrr}\text { HU. } & & 1 \text { D } \\ 1 & \text { II } & 0 \\ 2 & 5 & 15 \\ 3 & 5 & 14 \\ 4 & 5 & 13 \\ 5 & 5 & 12 \\ 6 & 5 & 11 \\ 7 & 5 & 25 \\ 8 & 5 & 24 \\ 9 & 5 & 23 \\ 11 & 5 & 2 ? \\ 11 & 5 & 21\end{array}$

rō

1. 599

.140

‥

$-9.990$

AES

0.000

4. $v b 4$

0.000

0.000

0. 000

1.000

0.009

6. 0100

9. 000

1.. 500

0.000
5104

4.911

.090

.531

.580

RES

9. 173

b. ‥ 43

E. 874

5. 351

3.394

1. 735

.565

.562

.575

.577

.577

$\begin{array}{rr}1111 & 102 \\ 1 & 1 \\ 5.996 & 1.923 \\ .030 & .049 \\ .327 & .217 \\ .333 & .210\end{array}$

HES

AES

9.955

7.954

5.995

3.784

2.516

1. 194

1.659

.798

. 605

.417
5. 140

.238

.234

.225

.230

1. 514

5. 160

4.163

3.017

2. 371

.926

\begin{tabular}{rr} 
HH4 & \multicolumn{1}{c}{ UFE } \\
1 & 0 \\
3.498 & 1.000 \\
.150 & 0.000 \\
.227 & 0.000 \\
.210 & -9.990
\end{tabular}

FES

4.848

.479

.354

.431

.332

.313

4.865

4.298

2. 751

1. 1947

1. 141
AES

0. 000

0.000

0.000

b. 500

0. 050

1. 006

0. 000

0. 500

6. 050

1.. 906

ด. ธุตูอ 


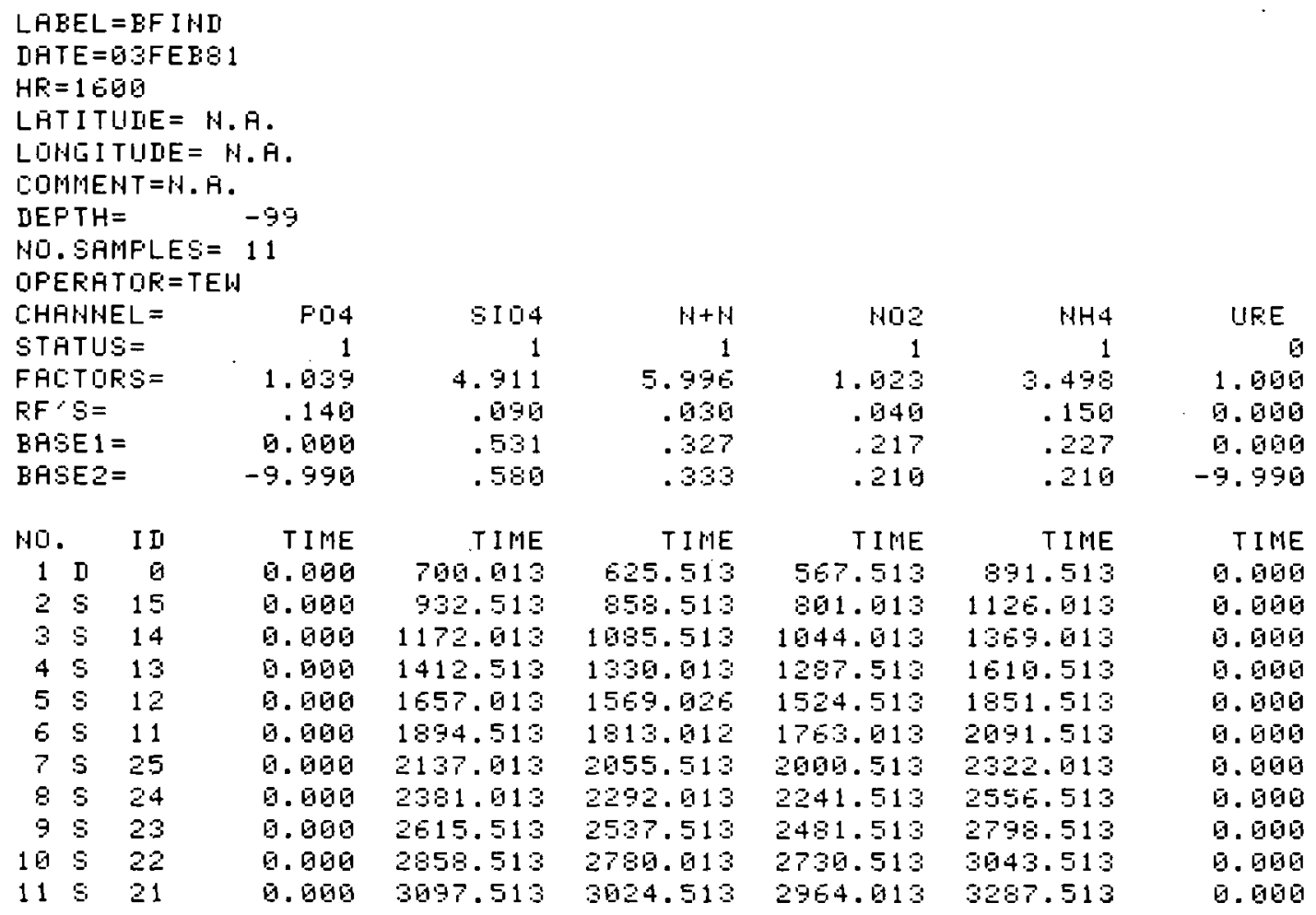

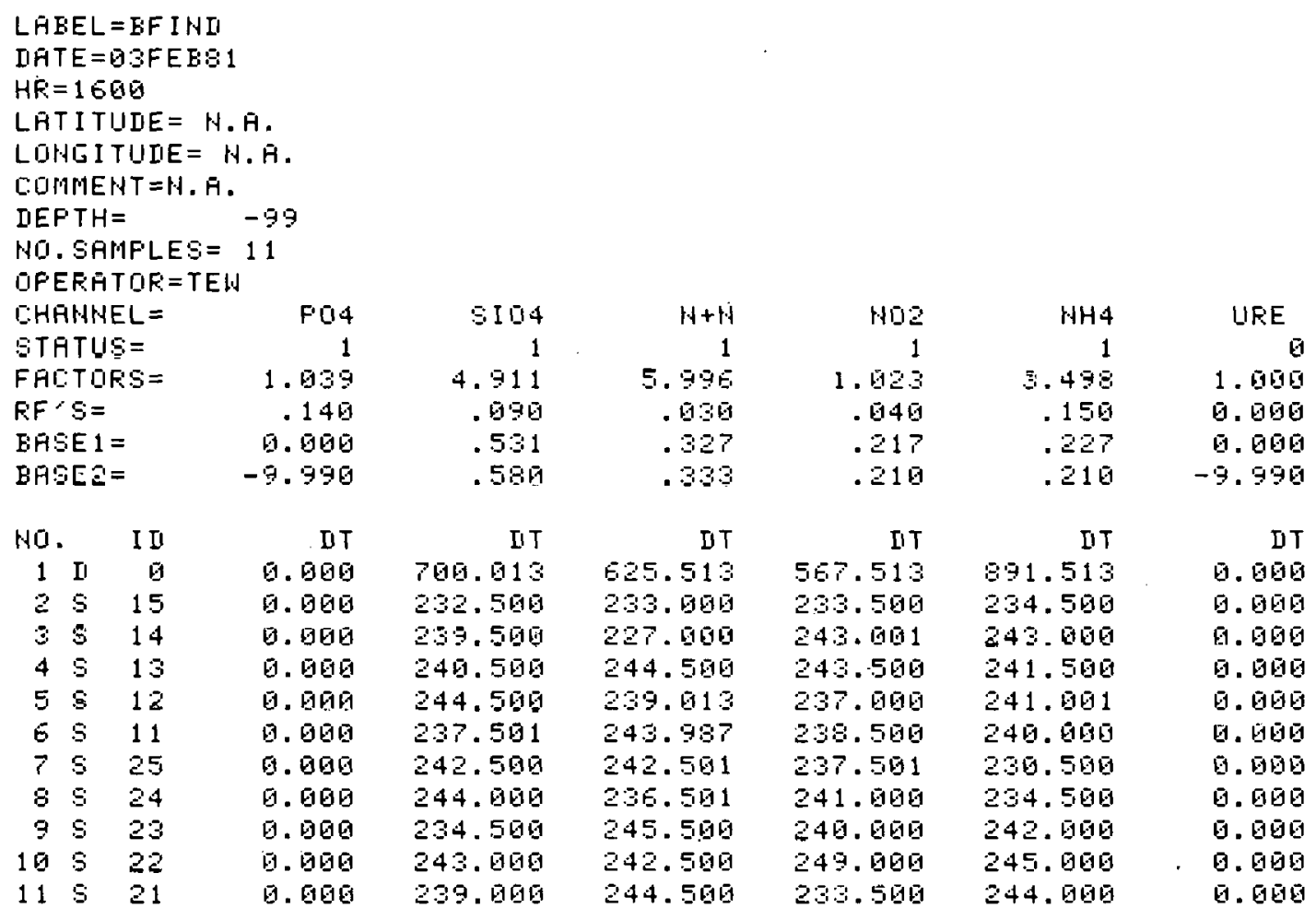




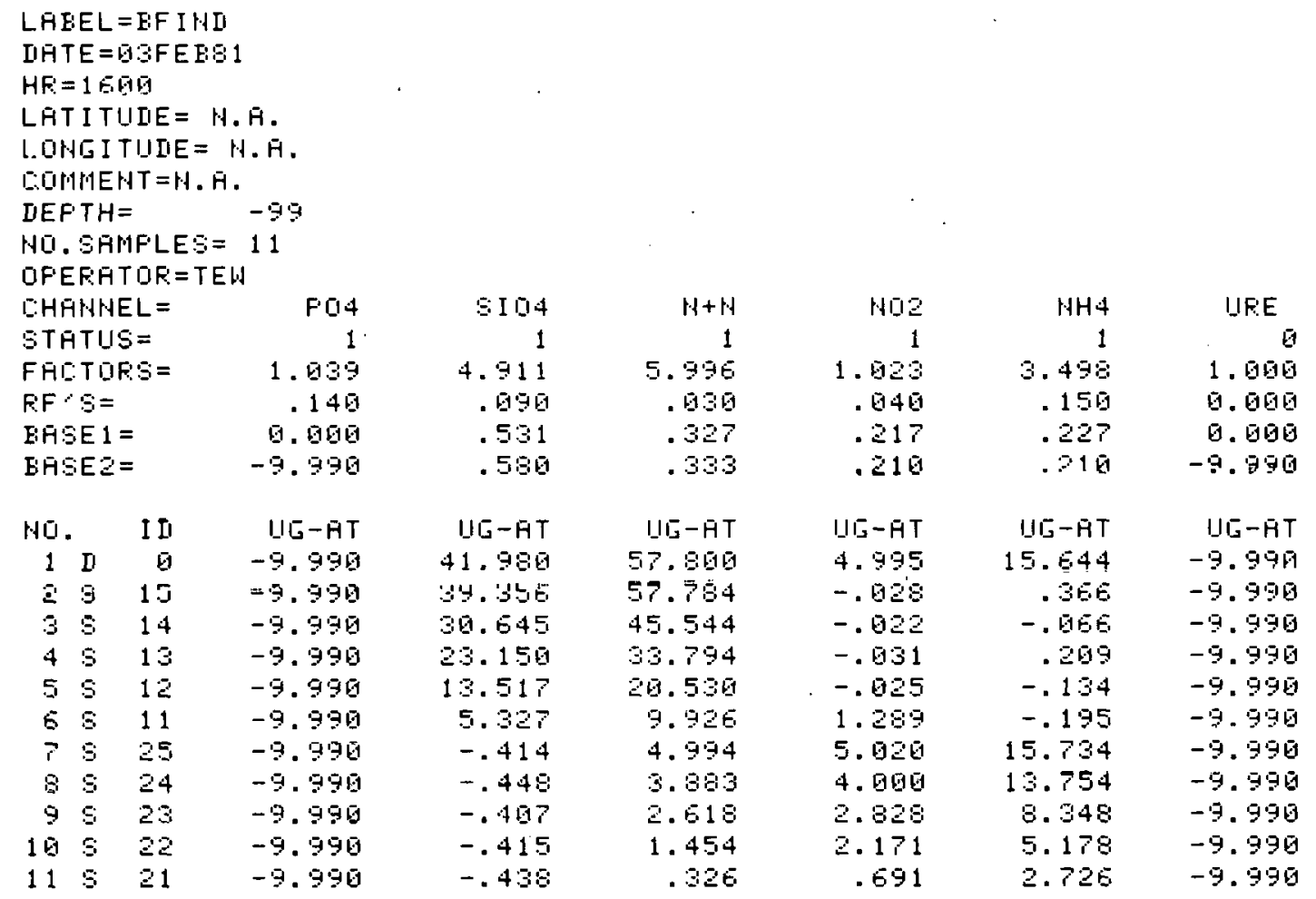

\begin{tabular}{|c|c|c|c|c|c|c|c|}
\hline \multicolumn{7}{|c|}{$\begin{array}{l}\text { LHEEL =EF IHI } \\
\text { IHTE = GEOFEEG } \\
\text { HFE }\end{array}$} & \\
\hline \multicolumn{8}{|c|}{ HF - 1 EBQ } \\
\hline \multirow{2}{*}{\multicolumn{4}{|c|}{$\begin{array}{l}\text { LOHEITUDE }=\text { H. } \mathrm{H} . \\
\text { EOMNENT }\end{array}$}} & & & & \\
\hline & & & & & & & \\
\hline \multicolumn{8}{|c|}{ IIEPTH $=\quad-99$} \\
\hline \multicolumn{8}{|c|}{ NOI. SAMFLES= 11} \\
\hline \multicolumn{8}{|c|}{ DFEF:ATQF $=$ TEW } \\
\hline \multicolumn{2}{|c|}{ Г:HANNEL = } & FOM & (1) & $N+N$ & Hug & $\mathrm{HH} 4$ & UFEE \\
\hline \multicolumn{2}{|c|}{ STATUS= } & 1 & $\dot{1}$ & 1 & 1 & 1 & G \\
\hline \multicolumn{2}{|c|}{ FACTDKS= } & 1.039 & 4.911 & 5,996 & 1.920 & 3.435 & 1. 1516 \\
\hline \multicolumn{2}{|c|}{$\mathrm{RF}: \mathrm{S}=$} & .140 & .096 & .696 & .040 & .155 & 6. 106 \\
\hline \multirow{2}{*}{\multicolumn{2}{|c|}{$\begin{array}{l}\text { EASE1 }= \\
\text { BASE2 = }\end{array}$}} & 0.005 & $.5: 31$ & .327 & .217 & .227 & 6.566 \\
\hline & & -9.990 & .586 & .333 & .210 & .210 & -9.990 \\
\hline$N O$ & I D & CONF & GIIAF & cotsf & EOHF & COHF & COHF \\
\hline 1 II & 0 & -.990 & .0166 & .001 & .962 & .863 & -.950 \\
\hline 25 & 15 & -.990 & .008 & .001 & .001 & .001 &,- 990 \\
\hline 30 & 14 & -.996 & .065 & .655 & .086 & . 152 & -.996 \\
\hline 45 & 13 & -.990 & .005 & .005 & .000 & .061 & -.990 \\
\hline 58 & 12 & -.990 & .002 & .613 & . E⿹ 1 & .001 & -.990 \\
\hline 65 & 11 & -.990 & .002 & .062 & .000 & .462 & -.990 \\
\hline \multirow{2}{*}{$\begin{array}{ll}7 & 9 \\
8 & 9\end{array}$} & 25 & -.995 & .001 & .002 & .504 & .8155 & -.990 \\
\hline & 24 & -.990 & .012 & .061 & .002 & . 102 & -.990 \\
\hline 9 & 23 & -.990 & .462 & .619 & . 191 & .062 & -.990 \\
\hline \multirow{2}{*}{$\begin{array}{l}105 \\
115\end{array}$} & 22 & -.990 & .062 & .001 & .001 & .0103 & -.990 \\
\hline & 21 & -.996 & .51 & .693 & .678 & .663 & -.990 \\
\hline
\end{tabular}


1. Insert Autoprogram tape into tape drive 15.

2. Type LOAD "MANDAT" and press EXECUTE.

This step loads the program into the computer's memory. When the small square of light at the lower right hand corner of the cathode ray tube (CRT) is extinguished, the program is fully loaded and ready for use.

3. Press RUN. CRT displays HELLO FROM MANDAT and prompts with flashing WAITING FOR A COMMAND in lower left hand corner of the screen. KEY specifications are output to thermal printer. These are the special Function Keys at upper right hand side of Keyboard.

KEY $0=$ INITIALIZE

KEY 1 = LIST.

KEY 2 = INPUT DATA

WHEN IN DOUBT PUSH CONTINUE,

KEY $3=$ EDIT SOMETHING WILL HAPPEN

KEY 4 = SAVE DATA

KF.Y 5 = FINISHED

KEY $6:=$ FETCH

\section{INITIALIZE}

4. Press $\mathrm{K}_{\mathrm{O}}$. CRT displays HELLO FROM INITIALIZE and promps for LABEL [6]? Type label for this data up to six characters. Press CONT.

5. CRT prompts for DATE [7]? Type date number as day, month, and year i.e. 06JAN80. Press CONT.

6. CRT prompts for TIME [4]? Type time for 24 day i.e. 1146, 2205. Press CONT. CRT prompts for LAT, LON, DEPTH and COMMENT. Enter as described in step 10 of APILOT program.

7. CRT prompts for OPERATOR [6]? Type name or initials of the AutoAnalyzer operator up to six characters i.e. SCM, PATTON. Press CONT.

8. CRT prompts for NO. SAMPLES? Type number of samples to be entered. Press CONT.

9. CRT prompts BEGIN BASE LINE [6 NO. 5]. Type in the beginning baselines for all six channel.

Example: $0.75,1.1,0.32,0.41,0.2,1.3$ Press CONT.

10. CRT prompts FINAL BASE LINE? [6 NO. 5]. Type in the final baseline for all six nutrients. Press CONT.

11. CRT displays list of the parameters entered and prompts DO YOU WANT TO CHANGE FACTORS? Y/N (Go to if you want to change Factors, type $Y$ and press CONT.

12. CRT displays LIST FINISHED and prompts for FACTOR? [6 NO. 5]. Type in the six nutrient factors previously determined in STAND. Press CONT.

13. CRT prompts IS THE TABLE CORRECT? Y/N. Type Y and Press CONT. CRT displays iNITIALIZE FINISHED and prompte WAITING FOR A COMMAND.

14. If the table is incorrect, type $N$ and press CONT. Computer program returns to step 4 and prompts for LABEL [6]? Press CONT until you arrive at incorrect parameter. Correct it and press CONT to step to through INITIALIZE to step 13. 
15. Press $\mathrm{K}_{2}$ to input data.

CRT displays HELLO FROM MAKE and prompts SAMPLE NO., LIST OR EXIT?

16. Type 1 and press CONT. CRT displays SAMPLE NO $=1.00$ and prompts ID, NUT 1 , NUT 2 , NUT 3 , NUT 4 , NUT 5 , NUT 6 ?

17. Type in identification of sample usually an $\mathrm{H}$ or $\mathrm{P}$ followed by a numeral to Indicate a Hydro sample or Productivity sample and its depth. Follow the identification with the absorbances of the six nutrients separated by commas as recorded on the strip charts. Press CONT.

18. CRT again prompts for SAMPLE NO., LIST OR EXIT? Repeat the steps above for each sample and press CONT.

19. Type L for List and Press CONT to obtain a complete listing of the input data. CRT prompts for OUTPUT TYPE: 1=ABS, $2=U G-A T / L$.

20. Type 1 and press CONT. CRT displays a table of data and prompts DO YOU WANT A HARD COPY, Y/N?

21. Type $Y$ and press CONT to obtain a hard copy of data in absorbance units. CRT again prompts for SAMPLE NO., LIST or EXIT. Repeat steps 19-20 for hard copy in ug-at/1.

22. Type E for exit and press CONT. CRT displays BYE FROM MAKE and prompts in flashing letters WAITING FOR A COMMAND.

\section{SAVE}

23. Press $\mathrm{K}_{4}$ to save the file. CRT displays HELLO FROM SAVE and prompts DO YOU WANT TO SAVE THE FILE, Y/N?

24. Type $\mathrm{Y}$ and press CONT. CRT prompts TAPE DRIVE WANTED? 14 nr 15 ?

25. Type 15 if data tape is in that drive and press CONT. Your data is saved ull Lape 15 and C'K'l displays FILE HAS BEEN SAVED ON T15. BYE FROM SAVE and prompts WAITING FOR A COMMAND.

26. Press $K_{5}$. FINI FINISHED AND PROGRAM IS FNDED-BYE is printed in flashing letters over the screen. To enter another run press CONTROL/RESET.

\section{FETCH}

27. If data file has been saved previously, retrieve it using FETCH Press $K_{6}$ - CRT prompts FILE WNNTED.

28. Type file name and press CONT. CRT prompts TAPE DRIVE WANTED? 14 or 15 ?

29. Type 14 or 15 wherever tape is, press CONT. Your file is read and CRT displays FINISHED READING FILE and prompts WALl'LNG FOR A COMMAND.

$$
\text { VI. LIST }
$$

30. If WAITING FOR A COMMAND is flashing, then press $\mathrm{K}_{1}$ and CRT prompts OUTPUT TYPE: $1=\mathrm{ABS}, 2=\mathrm{UG}-\mathrm{AT} / \mathrm{L}$. Obtain a hard copy as in steps 19-20. 
VII. EDIT DATA

Edit Functions

Should errors be discovered in your data after it has been entered manually, you can correct it using the edit functions.

31. CRT prompts WAITING FOR A COMMAND. Press $\mathrm{K}_{5}$. CRT displays HELLO FROM EDIT and prompts ENTER EDIT OPERATION LETTER Add, Replace, Delete, Exit, List.

A. To Replace.

32. Type $R$ and press CONT to replace a value in the data matrix. CRT prompts ROW, COLUMN?

33. Type respective row and column, press CONT. CRT prompts VALUE REQUIRED. VALUE.

34. Type corrected absorbance value and press CONT. CRT displays COMMAND Is letter, run, column, absorbance and prompts DO YOU WANT TO EXECUTE, $\mathrm{Y} / \mathrm{N}$.

35. Press $Y$ and press CONT. Computer returns to step 32. Repeat 32-35 as needed. Go to step 42 .

B. To Delete.

36. Type $\mathrm{D}$ and press CONT to delete a value in the data matrix CRT prompts ROW, COLUMN.

37. Type respective row and column, press CONT. CRT prompts ROLL REQUIRED. Y/D?

38. Type D and press CONT. (Entire data column above point of deletion will be moved down one position.) or type $U$ and press CONT. (Entire data column below point of deletion will be moved up one space.) CRT prompts ENTER EDIT OPERATION LETTER, ADD, REPLACE, DELETE, EXIT, LIST. Repeat $36-38$ as needed. Go to step 42 .

C. To Add

39. Type $A$ and press CONT to add a value in the data matrix. CRT prompts ROW, COLUMN?

40. Type respective row and column, press CONT. CRT prompts ROLL REQUIRED. U/D?

41. Type D and press CONT. (Entire data column will be moved down one space place below point of addition). Or type $U$ and press CONT. (Entire data column will be moved up one space above the point of addition.) CRT prompts ENTER EDIT, OPERATION LETTER, ADD, REPLACE, DELETE, EXIT, LIST. Repeat $39-41$ as needed. Go to step 42.

42. To obtain a display of the edited data, type $\mathrm{L}$ and press CONT. CRT prompts DUTPUT TYPE: $1=\mathrm{ABS} \overline{\mathrm{S}} 2=\overline{\mathrm{UG}-\mathrm{AT}} / \mathrm{L}$.

43. Type 1 or 2 press CONT. CRT displays data and prompts DO YOU WANT A HARD COPY, Y/N?

44. Type $Y$ and press CONT. Hard copy is output to thermal printer. or type $\mathrm{N}$ and press CONT. CRT prompts ENTER EDIT OPERATION LETTER, ADD, REPLACE, DELETE, EXIT, LIST.

D. To exit edit mode

45. Type E and press CONT. CRT displayed EDIT FINISHED and prompts with WAITING FOR A COMMAND.

46. To save this edited file, type PURGE "file name" and press EXECUTE. Follow steps $23-25$ of SAVE. 
2030 Channel labels: The only label which should be changed is "URE." For example, if chlorphyll is being run on channel 6, change URE to CHL.

2050 Channel status.

2090 Factors: Enter the factors as determined in stand for each channel.

2110 Refractive index: Enter the refractive $\overline{\text { index }}$ determined for each channel. 


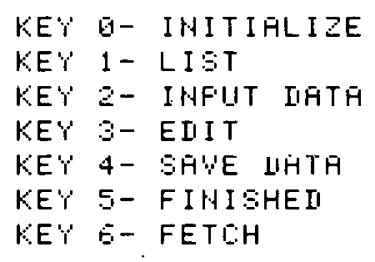

WHEN IH IOULT PUSH DOHTIHUE, SOMETHIHI HILL HAFFEH 
LAEEL $=H 41 \mathrm{GZ}$

IIHTE $=$ G S JIIHEG

$H E=2245$

$L F T=54 \quad 52.5$

LQH=167 5.

IJEFTH $=1527$

COMMEHT = HEFOSS SHELF TFEHSELT

NO. SAMFLES= 14

DFER:ATQF:=TEW

\begin{tabular}{|c|c|c|}
\hline \multicolumn{3}{|c|}{$\begin{array}{l}\text { CHAHHEL = } \\
\text { STATIS= } \\
\text { FACTURS= } \\
\text { RF S S } \\
\text { EASE }= \\
\text { BASEZ= }\end{array}$} \\
\hline +10. & & I II \\
\hline 1 & II & Q \\
\hline 2 & 5 & 15 \\
\hline 3 & 5 & 25 \\
\hline 4 & $H$ & 9 \\
\hline 5 & $H$ & 10 \\
\hline$\varepsilon$ & $\mathrm{H}$ & 20 \\
\hline 7 & $H$ & 30 \\
\hline$\theta$ & $H$ & 40 \\
\hline 9 & $\mathrm{H}$ & 50 \\
\hline 10 & $\mathrm{H}$ & 100 \\
\hline 11 & $\mathrm{H}$ & 250 \\
\hline 12 & 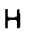 & 500 \\
\hline 13 & & 000 \\
\hline & & \\
\hline
\end{tabular}

F 14

5104

$\begin{array}{rr}1 & 1 \\ .69 & 9.996\end{array}$

$.190 \quad .029$

.431

.176

.225

.418

$\mathrm{H}+\mathrm{H}$

4.959

.030

.454

.534

AES

HES

1. 50

4.63

E. 99

5.85

.20

2.04

1.23

2.09

1.45

2.31

1.87

2.47

2. 05

2.67

2.14

2.29

2.94

3.20

3.95

3.76

E. 15

4.84
5.25

9.49

5.22

18.11

AES

8. 24

9.41

1. 26

2. 33

2. 79

3.36

3.55

3.77

3.97

5.51

6.42

8.87

9.55

9.29

$+10$

1
.746

.240

.278

.299

HHA

IJFE

1
.975

1. 960

.196

1. 906

.604

西. 96

.572

9. 900

\section{AES}

5.25

.34

AE:

AES

6. 09

.86

.04

.85

.89

.93

.90

1. 17

. 65

.59

.59

5.09

Q. 6

.81

Q. 515

4.64

1.04

6. 60

1.20

1. $: 0$

b. ㄴ.1

1. 97

6. 0

2.43

3.16

1.13

.99

1. 07

.99

.59

1. 6

6. 010

9. 010

9. 50

Q. 96

9. 96

9. 56

6. 50

6. 6

\section{LAEEL $=H 41$ Q}

IIATE= GISIINSE

$H F=294$

$L F T=5452.5$

LEH=167 52.7

IJEFTH $=1527$

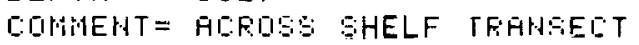

HO. SHMFLES= 14

DFEF:HTOF: =TEW

\begin{tabular}{|c|c|c|}
\hline EHA⿵冂卄川 & $\mathrm{PO} 4$ & $=114$ \\
\hline STATUS= & 1 & 1 \\
\hline FПETORS= & . E9y & 9.930 \\
\hline RF : $:=$ & .190 & .826 \\
\hline BASE $1=$ & .431 & .176 \\
\hline BASEZ= & .418 & .22 \\
\hline
\end{tabular}

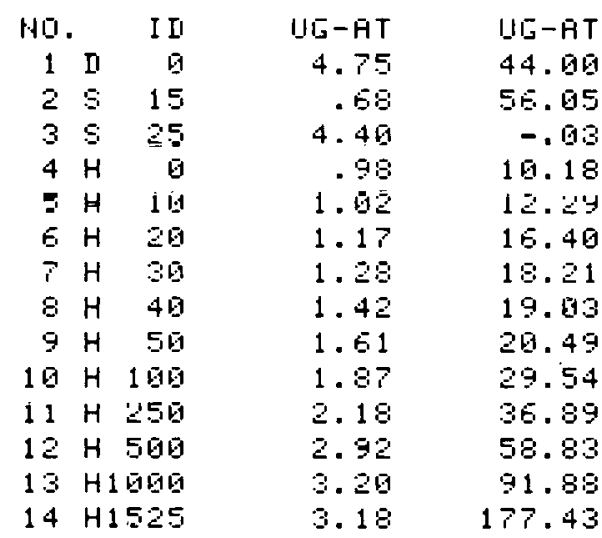

$H+H$
1
4.969
.030
.454
.534

102
1
.740
.240
.278
.299

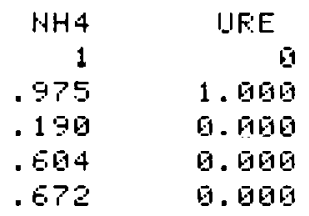

$$
\begin{array}{r}
11-A T \\
38.59 \\
44.36 \\
3.78 \\
9.95 \\
11.26 \\
14.16 \\
15.54 \\
16.97 \\
17.96 \\
24.64 \\
29.21 \\
41.38 \\
44.71 \\
43.37
\end{array}
$$

UI-AT

リए̈-म̈T

3.56

$-.17$

4. 13

9. 60

4. 12

-. 1

0. 010

25

.23

.24

.27

.29

.27

3.7

日. 60

อ.

.37

.46

6. 6

1. 11

1. 56

2. 27

. 20

.14

.99

.04

. 04

.22

.14

ด. 90

‥

0. 010

a. 50

อ. 00

a. 00

ด. 50

0. 50

.14

0. 00 
The BFIND progran calculates "B" factors from standards that are run on the AutoAnalyzer channels with the APILOT program. New "B" factors should be determined when changes are made which could affect the amount of dispersion in any of the channels (e.g. addition of an extra mixing coll or debubbler).

1. In order to save the data in the APILOT program a file must be created on the tape or disk. The number of records needed for the file can be calculated as follows:

1. A 180 second sample and a $60 \mathrm{~second}$ wash $=240 \mathrm{sec} / \mathrm{sample}$.

2 . One sync sample plus five $S 1$ standards and five $S 2$ standards $=11$ samples.

3. Eight values are recorded per second.

4. There are 4 Bytes per value and 256 Bytes per tape record.

The number of records needed to record 11 peaks plus initial and final baselines ( 2 peaks each) gives a total equivalent to about 15 peaks.

File Length $=15$ samples $\times 240 \mathrm{sec} / \mathrm{sample} \times 8$ values $/ \mathrm{sec} \times$

4 Bytes/value $\times 1$ record/256 Bytes

$\mathrm{F} . \mathrm{L} .=450$ records

So a file is created on tape 15 by: Create "TEST", 450 Execute.

2. After the file has been created and the data have been saved on the tape using the APILOT program, insert the AUTO program tape in tape 15.

3. Type LOAD "BFIND" and then press Execute to load the program.

4. Press RUN. CRT displays "ENTER CHANNEL No." Type in the channel number desired and push CONTINUE. Phosphate=1, Silicate=2, Nitrate plus Nitrite $=3$, Nitrite $=4$, Ammonium $=5$ and Urea $=6$.

5. CRT displays "MAX NO. OF POINTS." For all eleven peaks enter 2500 and press CONTINUE. For 4 or 5 peaks use 1600 points.

6. CRT displays "FILE NAME." Type TEST and press CONTINUE.

7. CRT displays "FILE DEVICE." Type 2 and press CONTINUE.

8. CRT displays "SAMPLE TIME." Type 180 and press CONTINUE.

9. CRT displays "WASH TIME." Type 60 and press CONTINUE.

10. Raw data will be plotted on the CRT and a cursor displayed. Move cursor between the sync sample and the first peak, press CONTINUE. Now move cursor between peaks 5 and 6 , press CONTINUE. This produces a collapsed data set which will automatically be plotted on the CRT.

11. The rnllapsed data is plotted on the CRT with the cursor near the first peak. Position cursor to a position about 5 seconds after the initial rise of the first peak and press CONTINUE. Position cursor further up the rise but still in the exponential portion of the peak. This position of the cursor is usually very close, therefore 11ttle if any movement is necessary, press CONTINUE. Select rise points for all peaks in the same manner. After the last rise is selected, press KO to exit.

12. The cursor will again appear but as a horizontal line this time. Select the peak heights for each peak and press CONTINUE. After the last peak height has been selected, press KO to exit.

13. CRT displays "DO YOU WANT A HARD COPY OF THE GRAPH? Y/N" Enter Y or $\mathrm{N}$ and press CONTINUE.

14. A segment table is displayed on the CRT along with "DO YOU WANT TO CHANGE THE E'S?" Enter "N" and press CONTINUE.

15. CRT displays "DO YOU WANT A HARD COPY? Y/N" If the table is desired enter "Y" and press CONTINUE. 
16. CRT displays regression plot of $\ln (\mathrm{E}-\mathrm{H})$ versus time. The regression lines should be linear for each of the segments chosen. If the lines are curved then the rise points were chosen incorrectly.

17. CRT displays "DO YOU WANT A COPY OF REGRESSION PLOT? Y/N" If a hard copy is desired enter " $\mathrm{Y}$ " and press CONTINUE.

18. CRT displays regression table with intercept, slope, $B$ value and no. of points and a mean "B" value is calculated.

19. CRT displays "DO YOU WANT A HARD COPY? Y/N" Enter "Y" and press CONTINUE.

20. Three notes are listed on the CRT describing the effects of the "B" value on peak regeneration.

21. CRT displays "B VALUE FOR REGENERATION?" For a first approximation take the mean " $B$ " value from regression and subtract one. Enter the $B$ value minus 1 and press CONTINUE.

22. CRT will display regenerated peaks using the "B" value entered.

a) If the regenerated peaks have a sharp spike at the beginning, they are probably over-regcncrated thus you should lower the "B" value.

b) If the peaks are rounded like the raw tata, the peaks are probably under-regenerated, thus you should raise the " $B$ " value.

c) The tops of the peaks and the valleys should be flat.

23. CRT displays "DO YOU WANT TO DUMP PLOT? Y/N" If a hard copy is desired enter " $Y$ " and press CONTINUE.

24. CRT displays "DO YOU WANT TO TRY REGEN AGAIN? Y/N" If you want to try another " $B$ " value enter " $Y$ " and press CONTINUE.

25. Enter the best " $B$ " value into APILOT program.

26. To determine the " $B$ " value for another channel, press STOP and then press RUN which will return you back to step 4 . 


\section{REQUIREMENTS FOR BFIND PROGRAM}

1. Must achieve true steady state

a. requires long sample and wash times 180 seconds and 60 seconds, respectively.

2. 3 stds (low, medium, high - i.e. s-1, s-3, s-5) are sufficient.

Inf ormation

1. "B" $\equiv$ exponential phase constant

"B" = - 1/slope of a plot of ln $(E-h)$ versus time

"B" tells you how fast the system approaches steady state. The

longer the system takes to reach steady state, the larger "B" will

be. Likewise, B reflects the amount of segment to segment mixing

(longitudinal dispersion) which occurs in the manifold and

colorimeter flow cells. As longitudinal dispersion decreases, $B$ decreases.

2. "A" $\equiv$ lag phase constant

"A" = y intercept of a plot of ln (E-h) versus time

"A" indicates (in seconds) the period of time before the rise curve begins to approach steady state exponentially. A is largely

influenced by the dwell time of the CF systems. Manifolds with

dialyzers and heating baths have longer lag phase than those without. 


\section{COLLFPGEII CHANNIEL - 3}

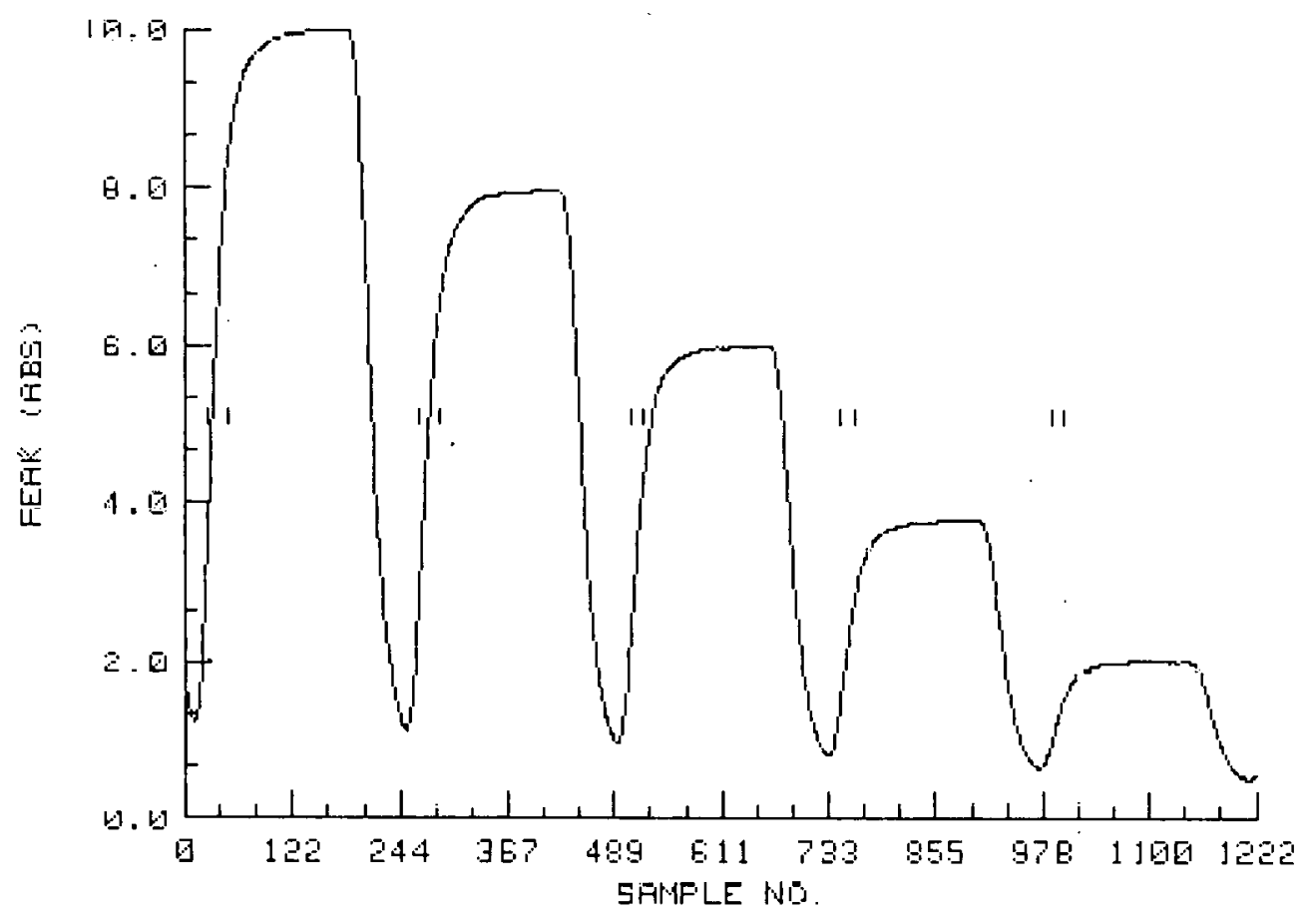


SELMENT TFELE

$\begin{array}{rrrr}\text { FEFK } & \text { TE } & \text { TF } & \text { E } \\ 1 & 26 & 49 & 9.99026 \\ 2 & 266 & 200 & 7.97902 \\ 2 & 506 & 521 & 5.99019 \\ 4 & 746 & 761 & 3.89930 \\ 5 & 986 & 1.091 & 2.02205 \\ 6 & 1226 & 0 & 2.92205\end{array}$




\section{REGFESSION}

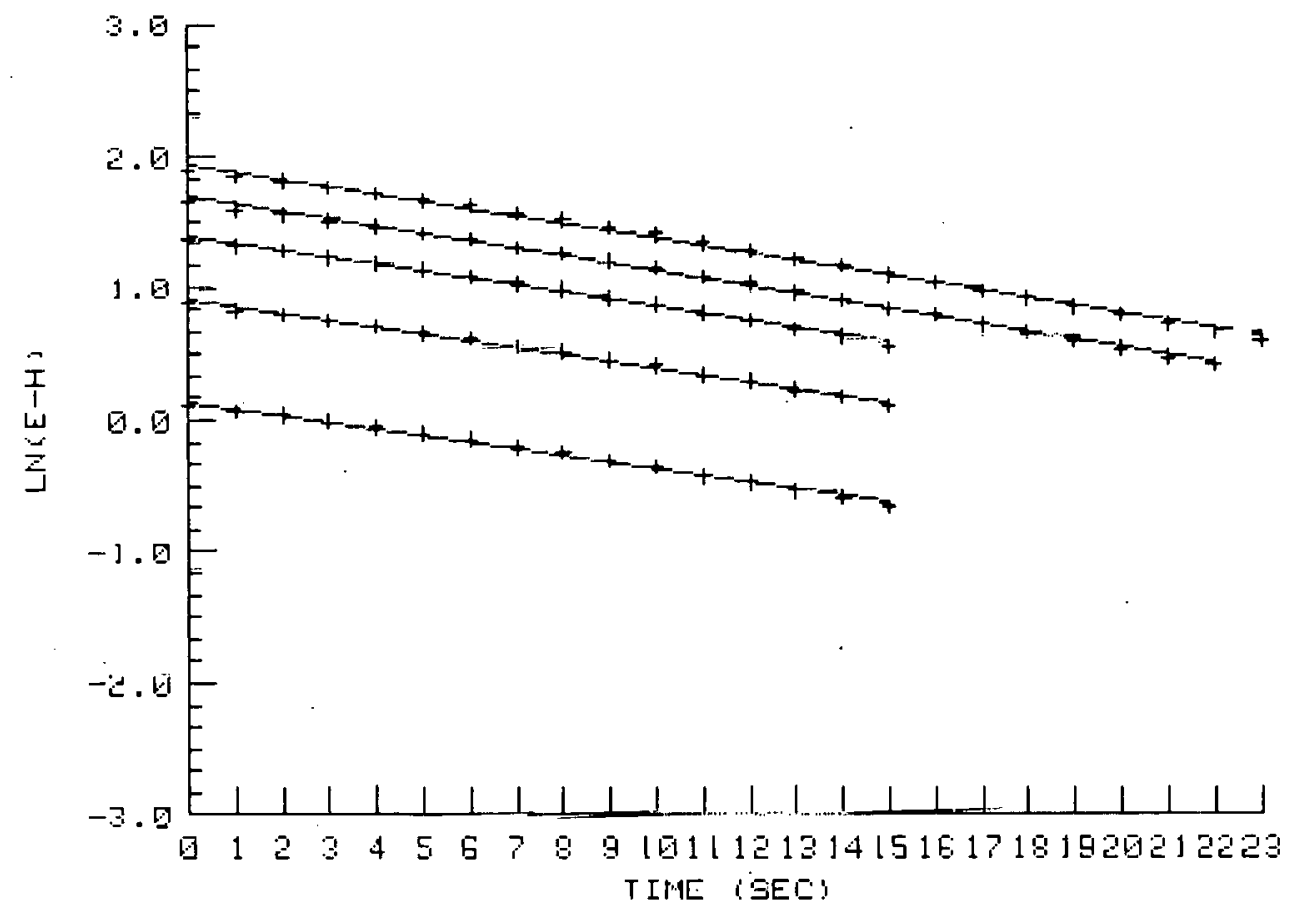


REIFESSION THELE

$\begin{array}{rrrrr}5 E & \text { INTE } & \text { SLOPE } & \text { E } & \text { NO. } \\ 1 & 1.94465 & -.05719 & 17.48469 & 24 \\ 2 & 1.68395 & -.05656 & 17.68958 & 23 \\ 3 & 1.36489 & -.05928 & 15.75985 & 16 \\ 4 & .89830 & -.05078 & 19.69321 & 16 \\ 5 & .14061 & -.05111 & 19.56438 & 16 \\ 6 & 0.00009 & 0.00000 & & \end{array}$

15.59212 
FEGEN CHANNELI B- 14.50

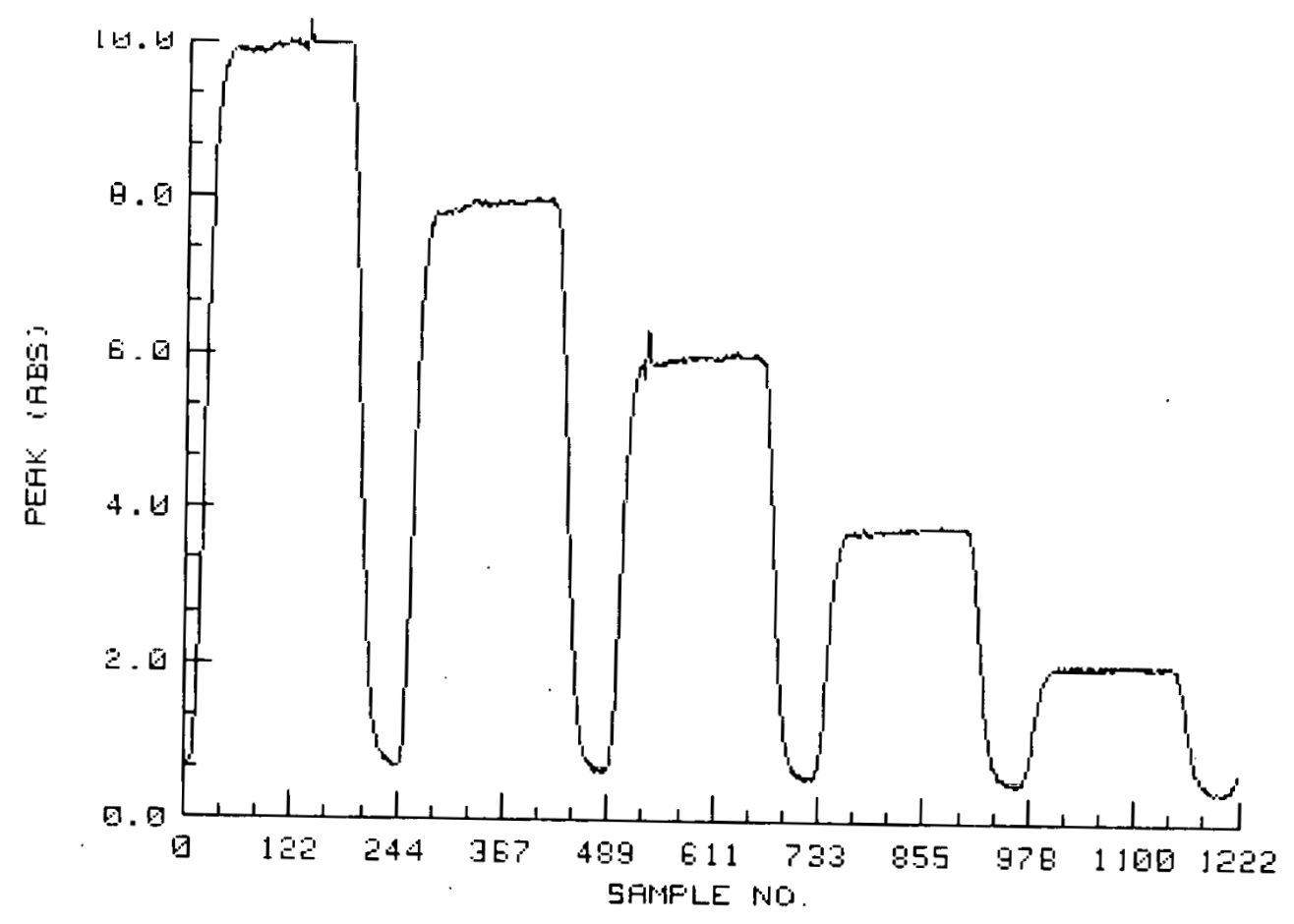


REGEN CHANNEL 3 E- 15.50

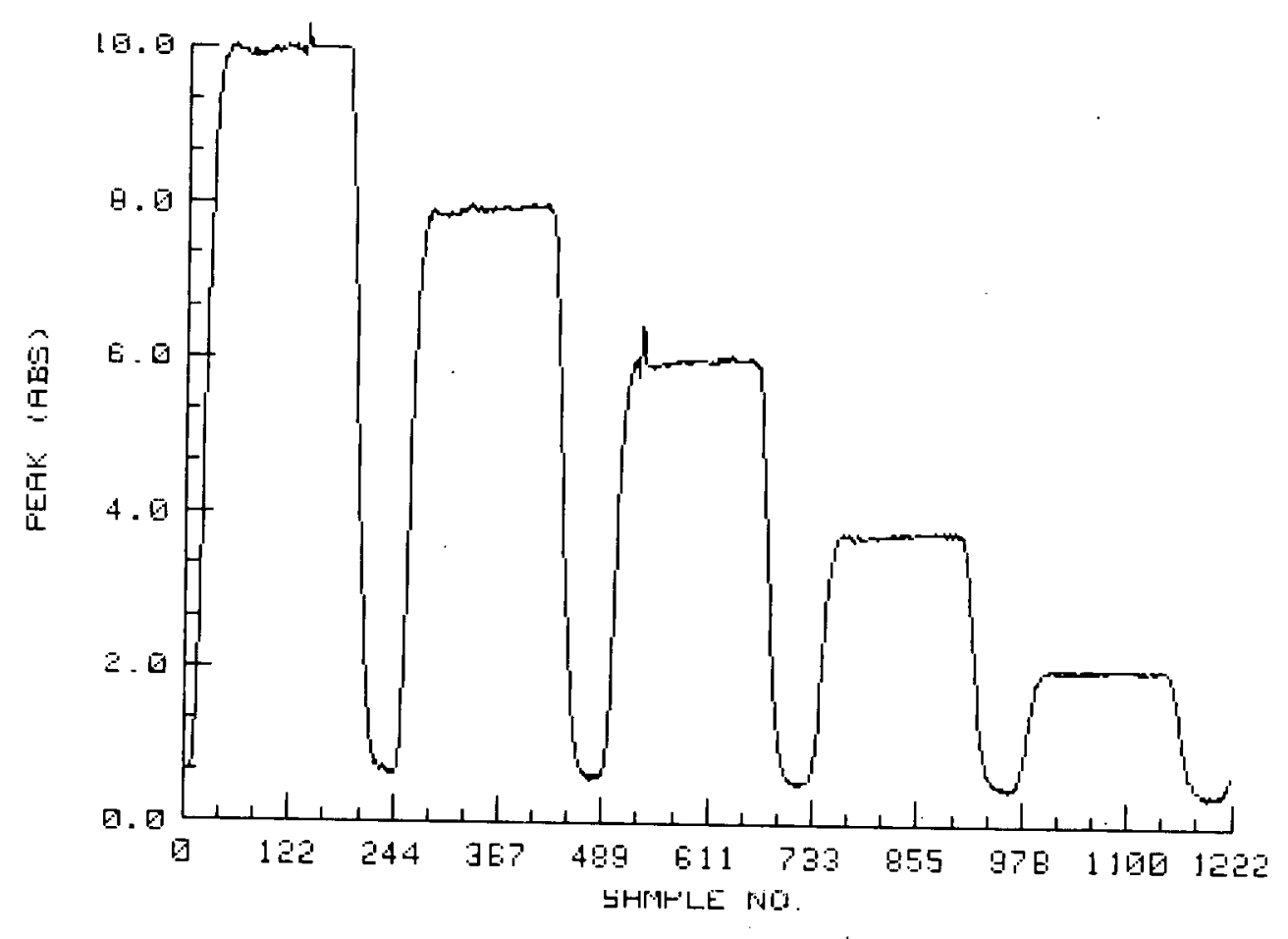


FEGEN CHANNËL:

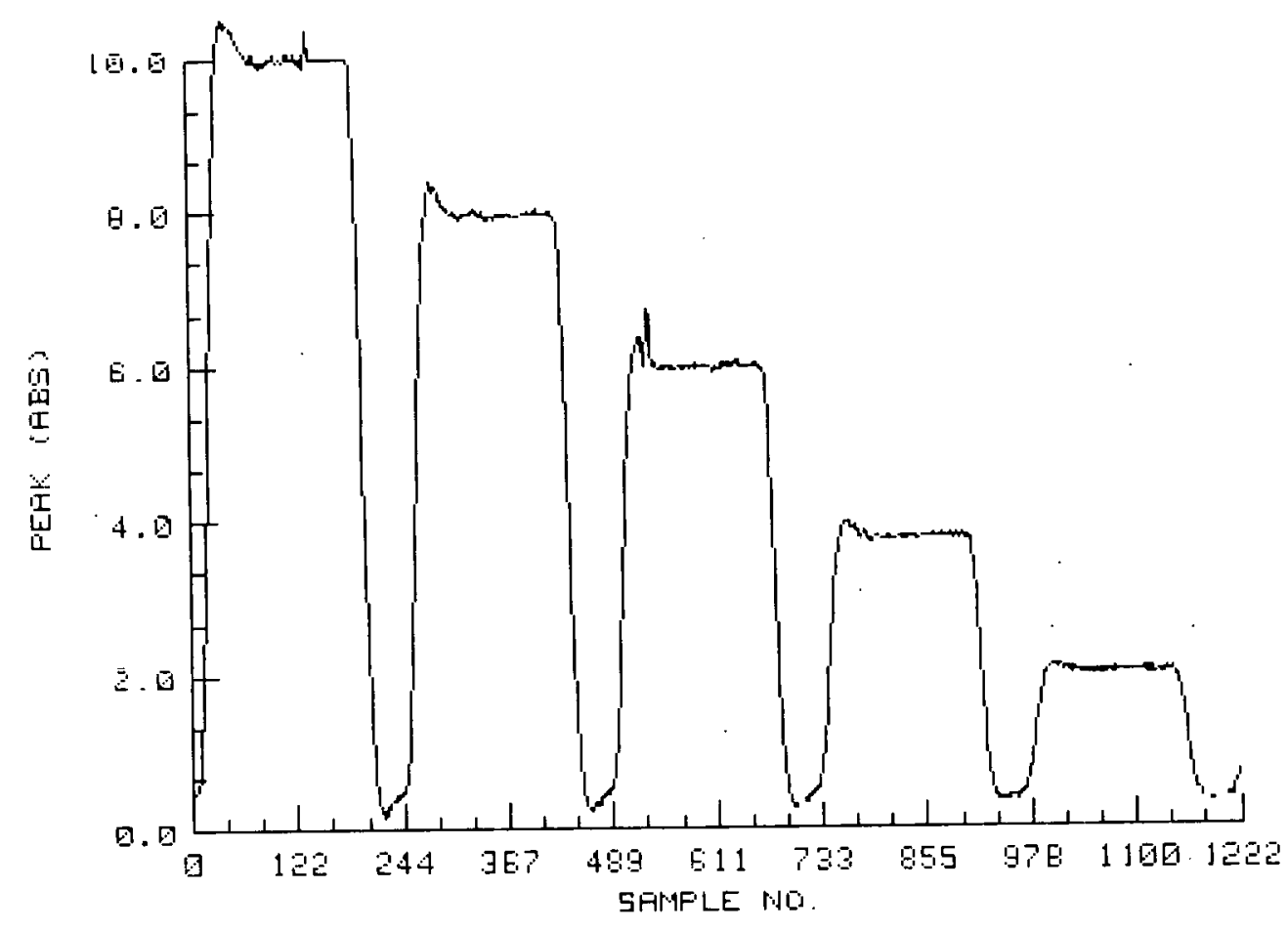


FEGGN CHANNELO G- 13.50

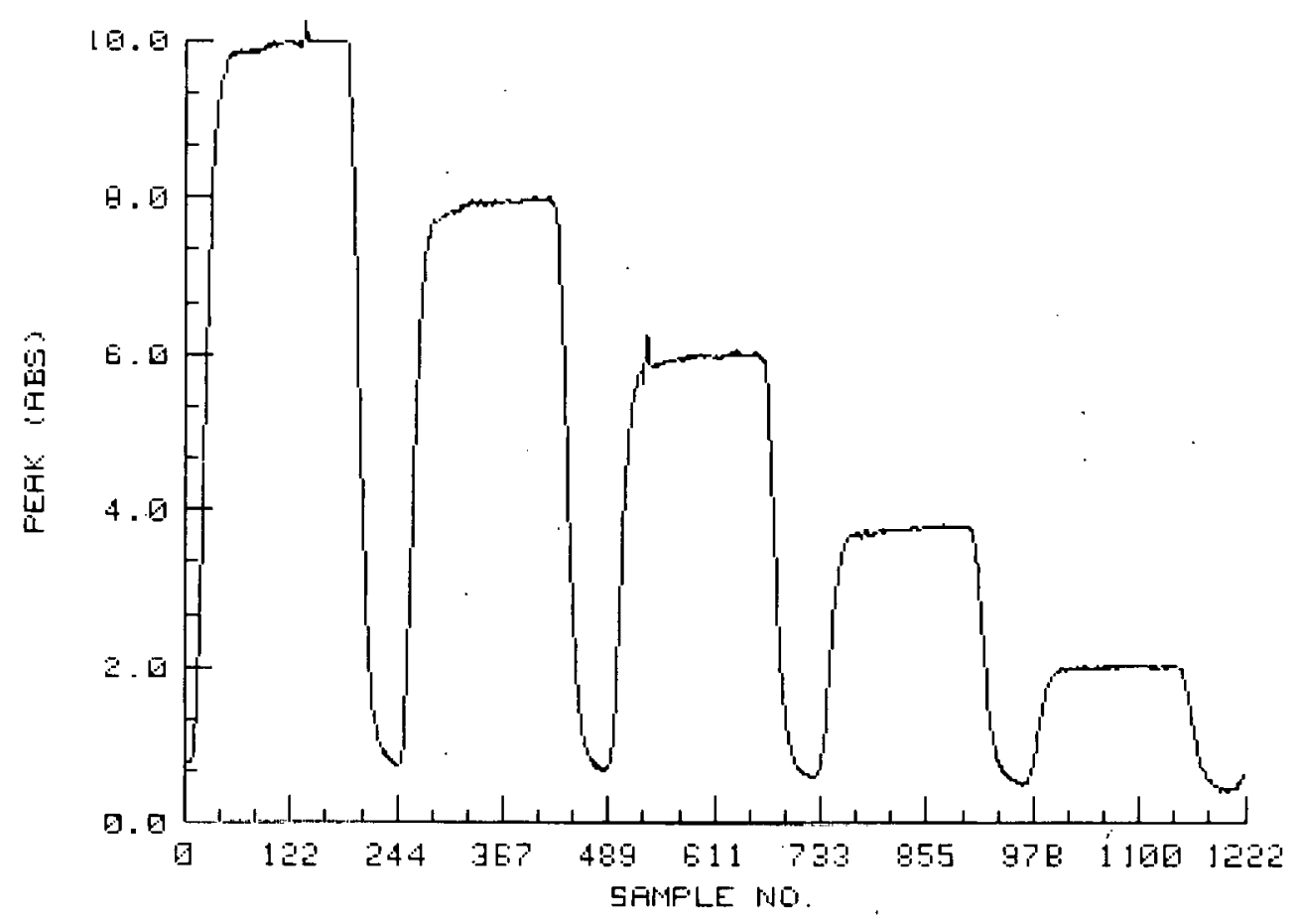


REGEN CHANNEL 9 E- 10. E10

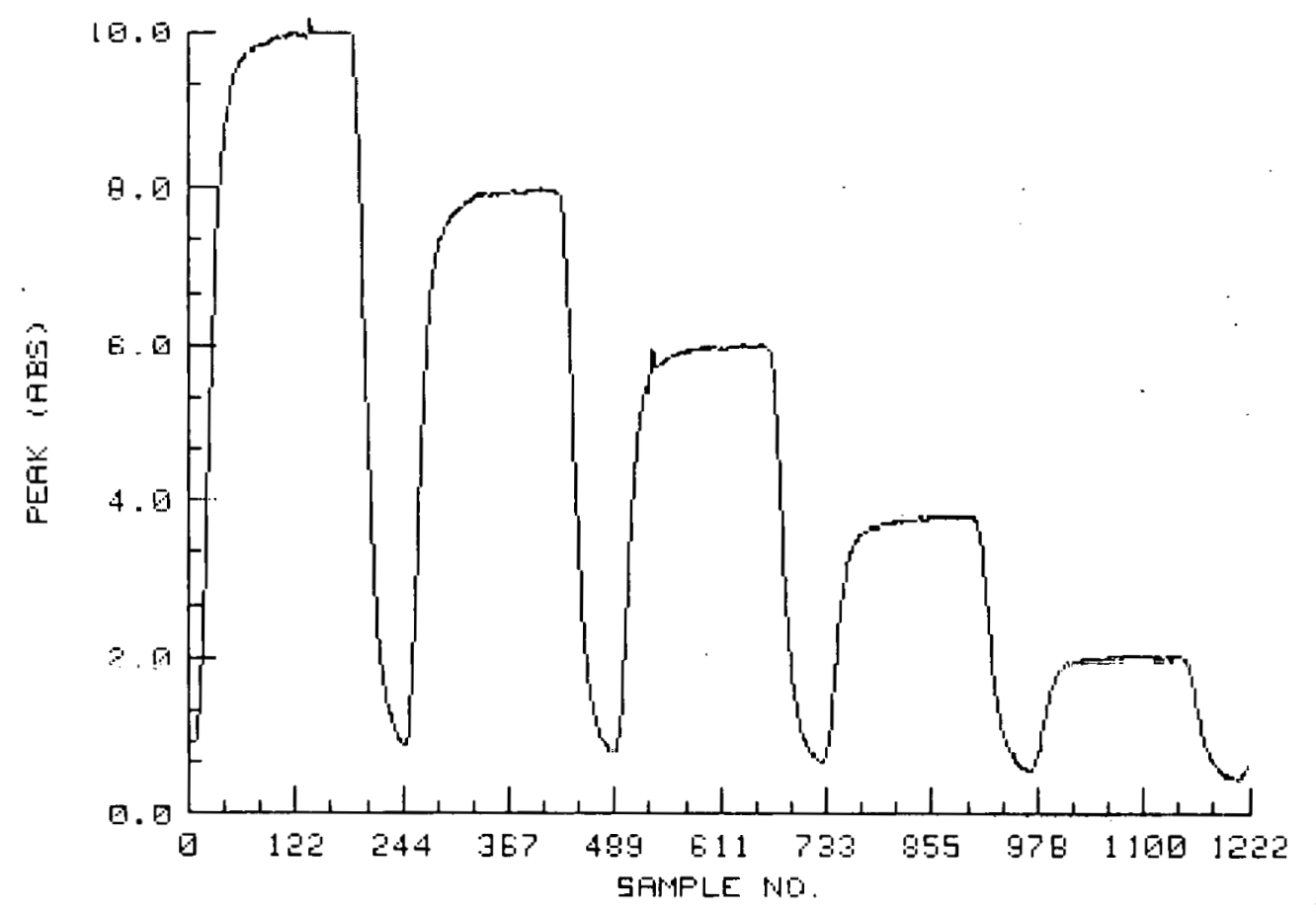


OLLFPSED CHAHNEL - ב

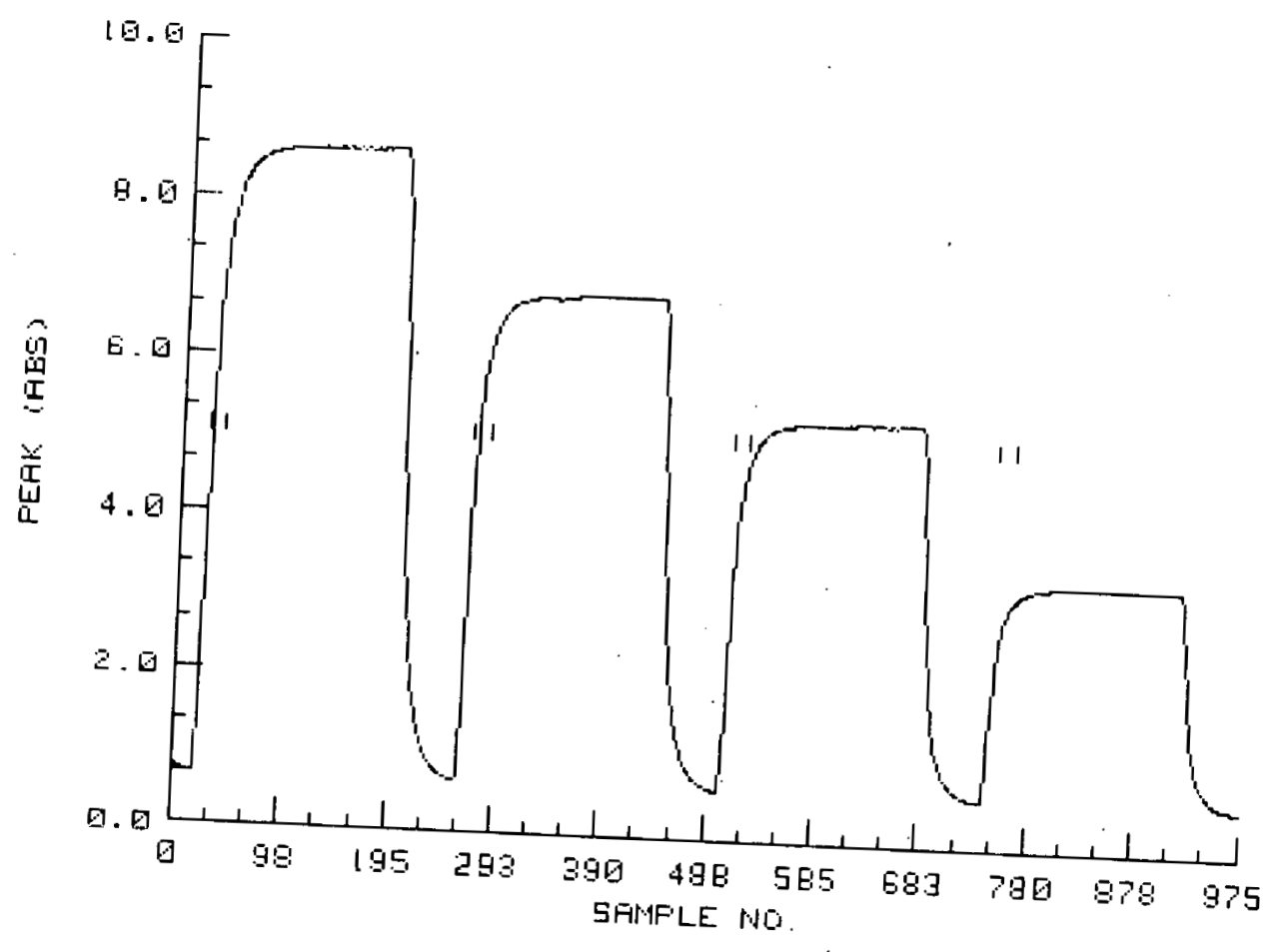




\section{SEGMEHT THELE}

$\begin{array}{rrrr}\text { FEAK } & \text { TE } & \text { TF } & E \\ 1 & 23 & 38 & 5.67662 \\ 2 & 266 & 291 & 6.86997 \\ 3 & 593 & 518 & 5.38239 \\ 4 & 74 E & 761 & 3.27267\end{array}$


REGFESGION

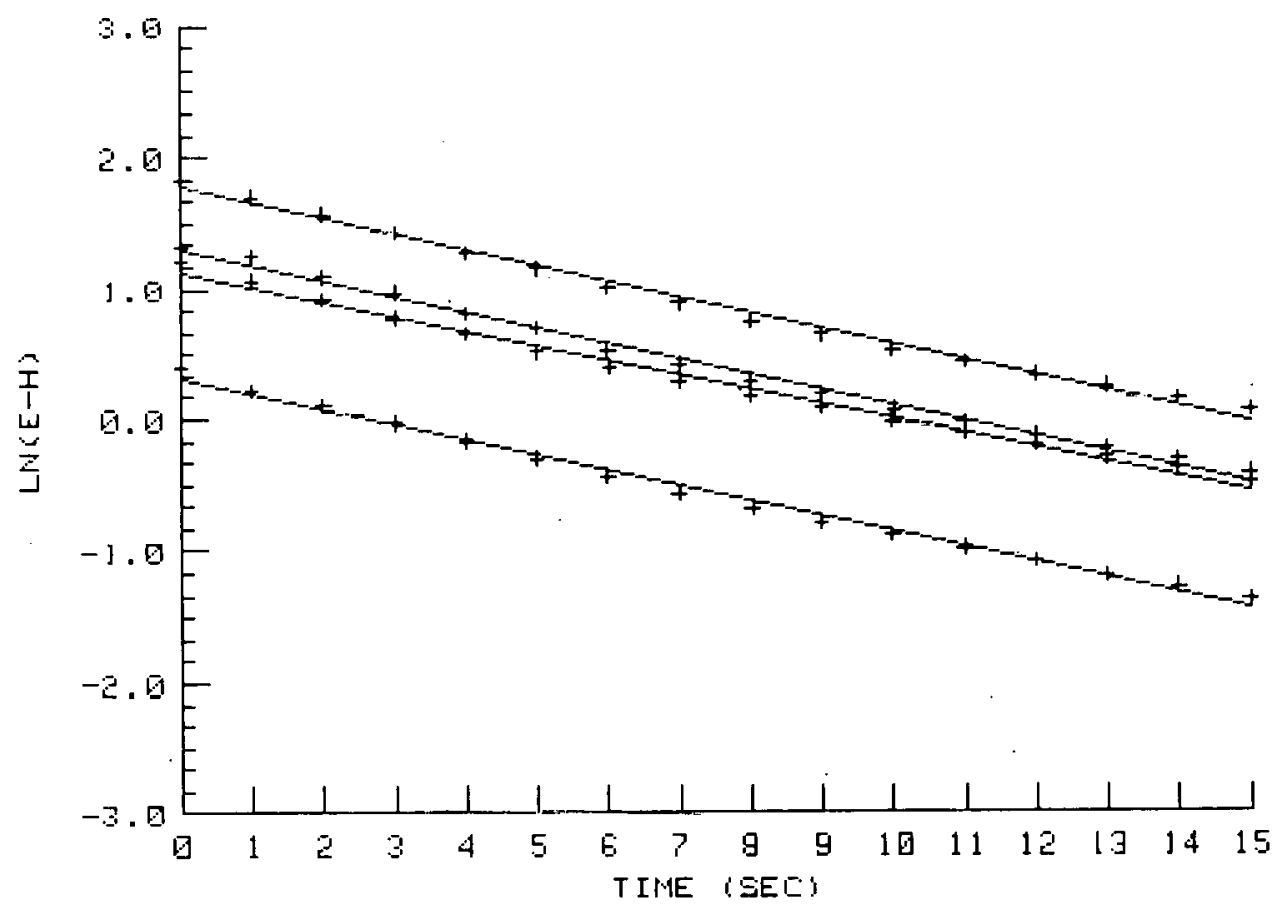




\section{RELEESSI IH THELE}

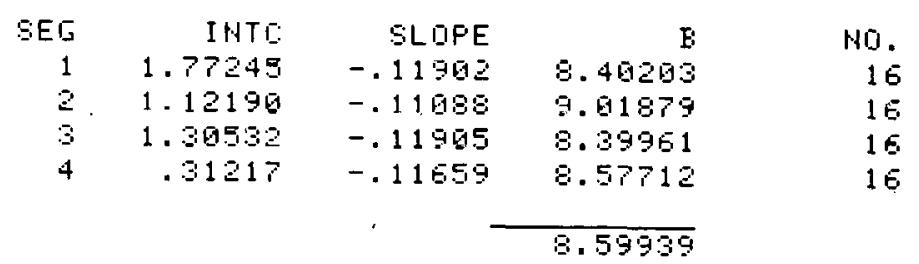


REGEN CHANNELE E- P.50

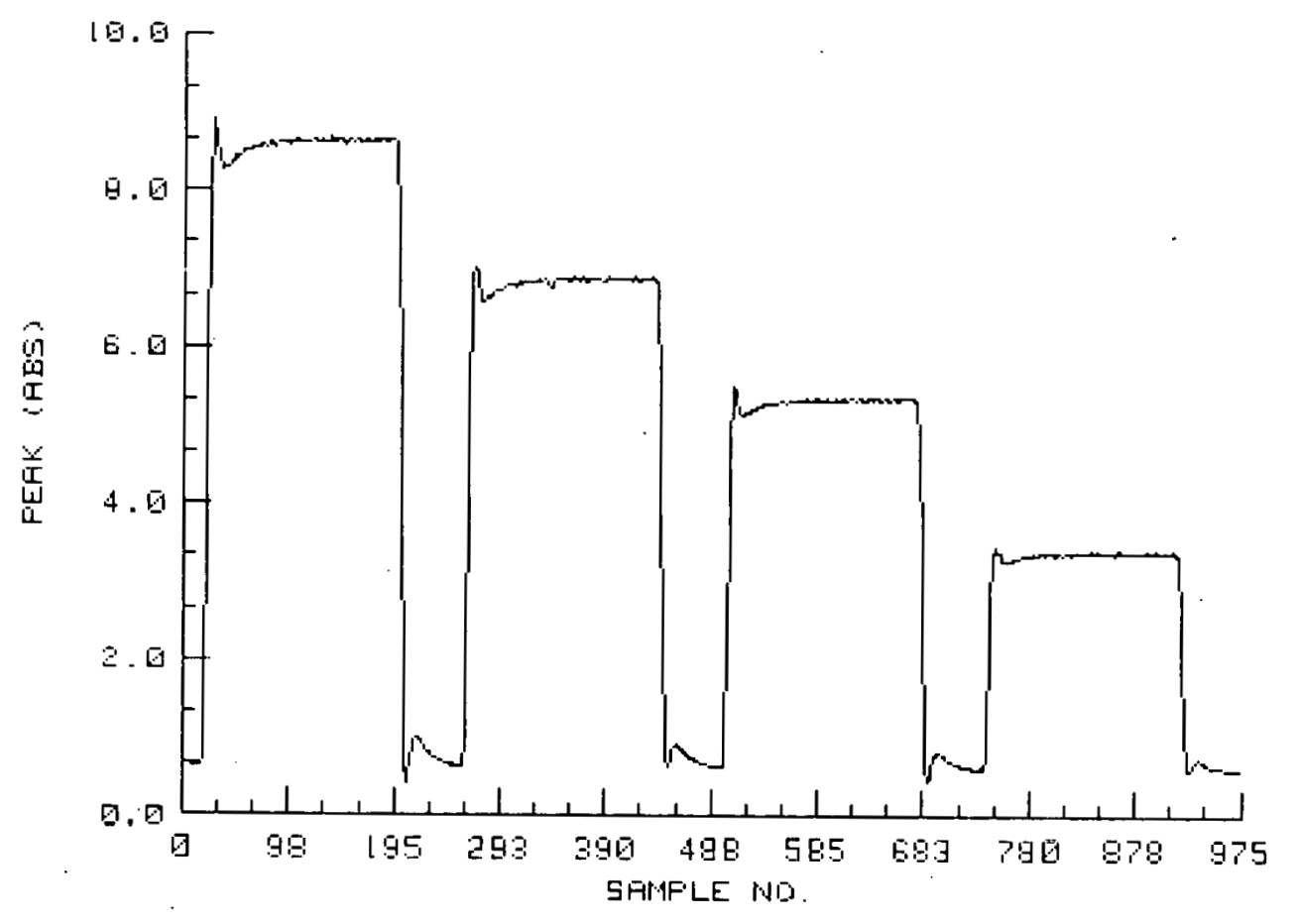


REGEN CHANALLO B- E.5Q

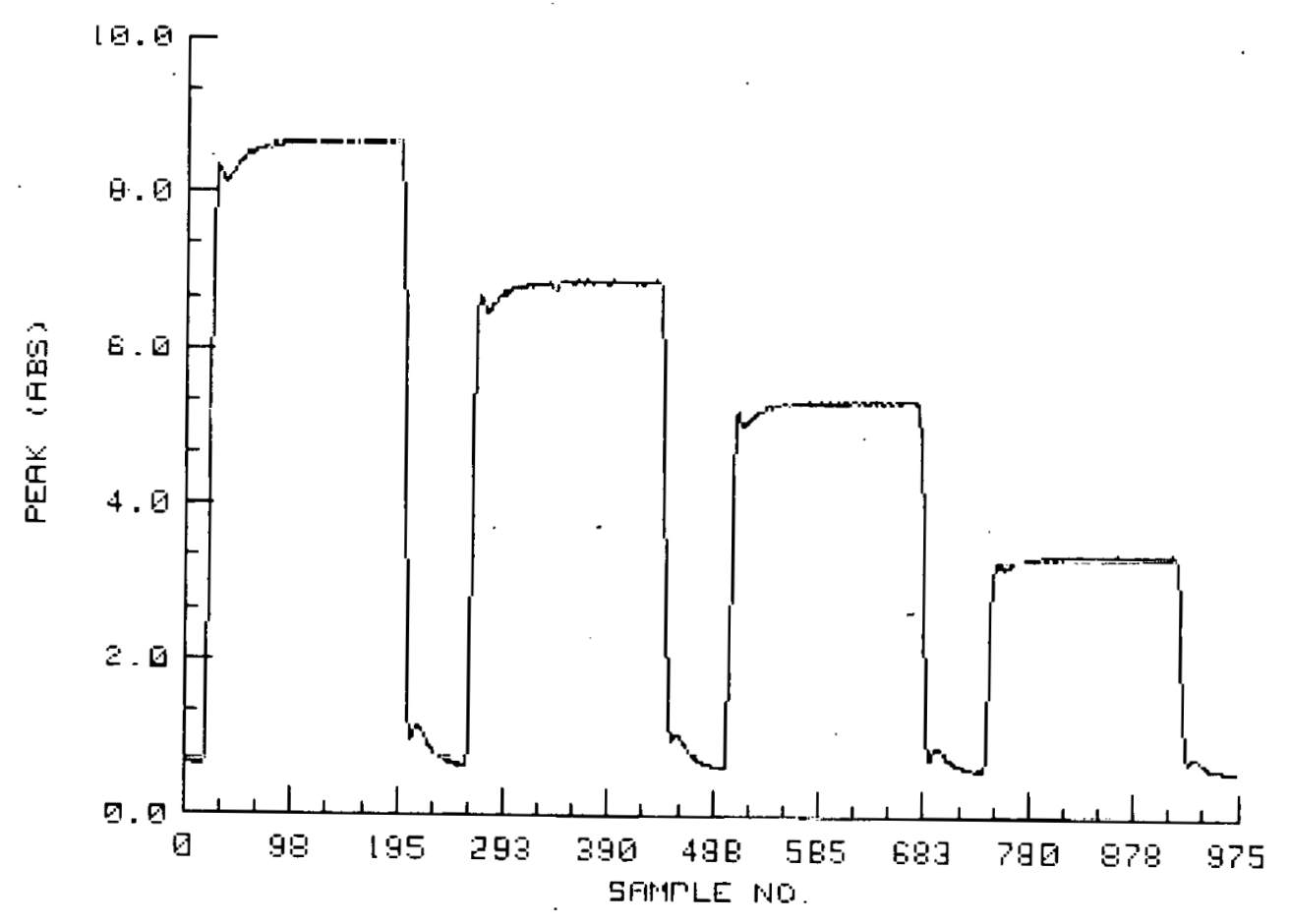


FEGEN CHANNLL E- 9.50

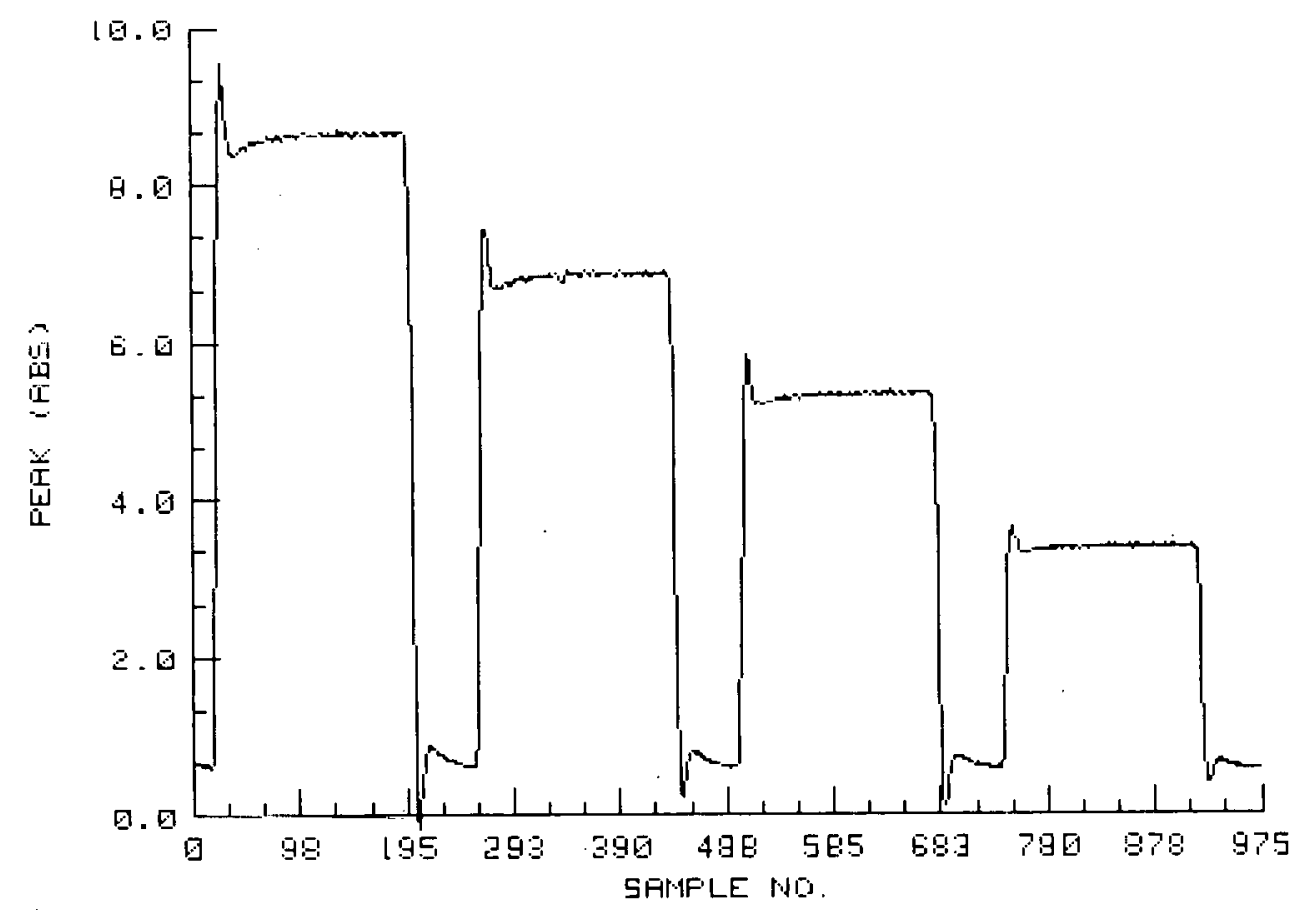


1. Insert Autoprogram tape into tape. drive 15. Type LOAD "CLOCK" and then press EXF.CITE.

This step loads the program into the computer's memory. When the small square of light at the lower right-hand corner of the cathode ray tube (CRT) is extinguished, the program is fully loaded and ready for use.

2. Press RUN, the CRT will display "HELLO FROM PROGRAM CLOCK. I AM LOOKING FOR THE TIME BACK IN 20 SEC".

3. The CRT will display "AT THE TIME OF THE TONE IT WAS" • DO YOU WANT TO CHANGE IT? $\mathrm{Y} / \mathrm{N}$ " Enter " $\mathrm{Y}$ " or " $\mathrm{N}$ " and push CONT. If $" \mathrm{~N}$ " then "CLOCK IS FINISHED" will be displayed. If "Y" then the CRT will ask for input of month, day, hour, minute, and second. Enter each as 2 digits and push CONT.

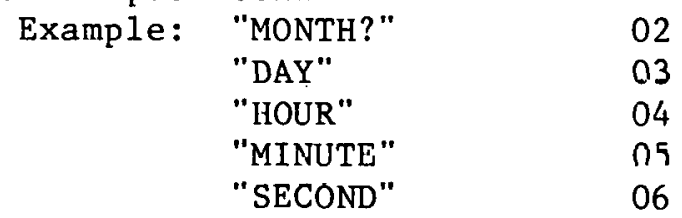

for February 3, 0405 hour, 6 seconds

4. The CRT will display "THE TIME YOU SET IS" "DO YOU WANT TO SET IT? Y/N". Enter " $\mathrm{Y}$ " or "N" and push CONT. If "Y" then clock will be set at the time you entered while the CRT displays "WORKING AT SETTING CLOCK". After setting the clock is completed the CRT will display THE TIME HAS BEEN SET IT IS ". "CLOCK IS FINISHED". 


\section{INSTRUCTIONS FOR USE OF AvSM PROGRAM}

1. Insert Autoprogran tape into tape drive 15. Type Load "AvsM" and then press EXECUTE.

This step loads the program into the computer's memory. When the small square of light at the lower right-hand corner of the cathode ray tube (CRT) is extinguished, the program is fully loaded and ready for use. Remove the Autoprogram tape and insert your data tape into tape drive 15.

2. Press RUN, CRT prompts "FILE WANTED?" for first data file to be read.

3. Type in the name of the file desired and press CONT. Computer finds and reads your data file from tape and writes table on CRT. CRT displays "DO YOU WANT HARD COPY, $\mathrm{Y} / \mathrm{N}$ ?" Enter " $\mathrm{Y}$ " or "N" and press CONT. If " $\mathrm{Y}$ " then the table will be written by printer.

4. CRT displays "FILE WANTED?" for second data file to be read.

5. Type in name of the second file desired and press CONT. The table will be displayed on CRT and you will be asked if you want a hard copy as in step 3 .

6. CRT displays "CHANNEL WANTED IN PLOT?" Enter channel number and press CONT. (Note: Usually the channels are: $1=\mathrm{PO}_{4}, 2=\mathrm{STO}_{4}, 3=\mathrm{NO}_{3}+$ $\mathrm{NO}_{2}, 4=\mathrm{NO}_{2}, 5=\mathrm{NH}_{4}, 6=$ UREA).

7. A table of absorbances for variable and the differences between absorbance values for the two data files will be listed on the CRT. You will be prompted by "DO YOU WANT A HARD COPY OF THE TABLE? Y/N". If a hard copy is wanted enter " $Y$ " and press CONT.

8. If "N" is entered to the hard copy then a graph of the differences between the absorbances will be plotted versus peak number in the AutoAnalyzer run.

9. The CRT will display "DO YOU WANT A HARD COPY OF THE GRAPH? Y/N". If "Y", the printer will produce a copy of the graph and iff " $N$ " then the. program will return to step 6 and ask for channel number. If a new set of files are desired, then push STOP and RUN which will start the programs with step 2 . 


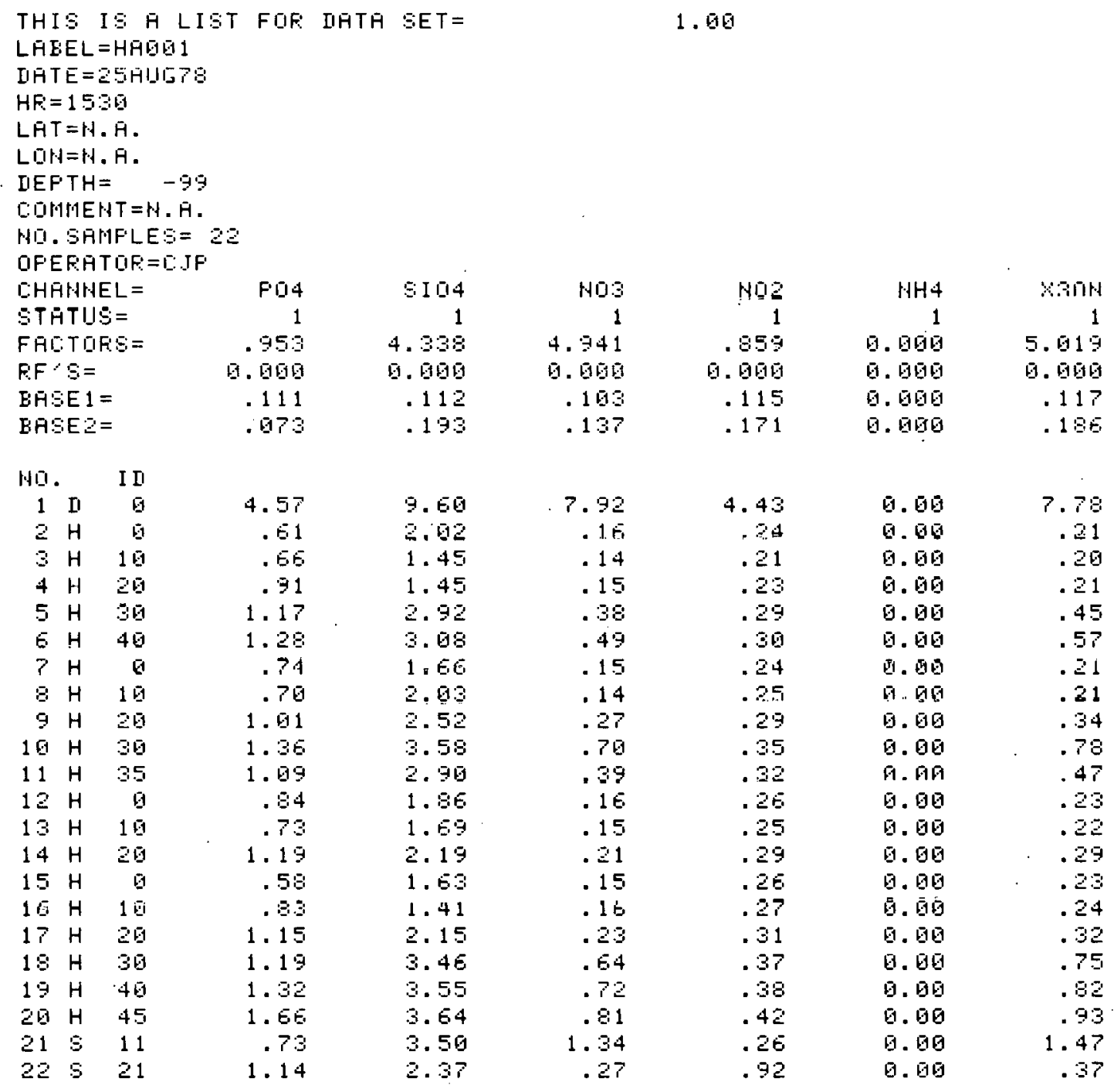


THIS IS A LIST. FOF IIATH SET= $\angle A E E L=H M O Q 1$

IATE $=28$ AUL7

$H K=1530$

$L A T=N . A$.

LOH $=N . A$.

IIEFTH $=\quad-99$

HO. SAMPLES $=22$

OFERATOR = C JP

CHAHNEL $=$

STATUS=

FAC:TORS=

$R F \cdot S=$

BASE $1=$

BHSE2 =

HO. II

150

$2 \mathrm{H}$

$3 \mathrm{H} 10$

$4 \mathrm{H} 2 \mathrm{O}$

$5 \mathrm{H} 3 \mathrm{G}$

$6 H 40$

$\begin{array}{rrr}7 & H & 0 \\ 8 & H & 10\end{array}$

$9 \mathrm{H} 1 \mathrm{G}$

$10 \mathrm{H} \quad 30$

$11 \mathrm{H} 35$

$12 \mathrm{H}$

$13 \mathrm{H} 10$

$14 \mathrm{H} 2 \mathrm{O}$

$15 \mathrm{H}$

$16 H \quad 10$

$17 \mathrm{H} 20$

$18 \mathrm{H} 30$

$19 \mathrm{H} 4 \mathrm{a}$

$20 \mathrm{H} \quad 45$

21511

22521

$\begin{array}{rr}\text { P04 } & 5104 \\ 1 & 1 \\ .953 & 5.579 \\ .180 & .940 \\ .110 & .110 \\ .090 & .187\end{array}$

4.58

.60

.64

.89

1. 16

1. 28

.73

.69

1.90

1.34

1.07

.82

.71

1.18

.57

.81

1.13

1.18

1.31

1. 66

.72

1.14
9.62

2.93

1. 47

1. 47

2.94

3.11

1. 58

2.03

2.52

3.10

2.90

1. 89

1. 69

2.21

1. 61

1. 45

2.19

3.47

3.57

3.62

3.55

2.38
2.96

$\begin{array}{rr}\text { HH4 } & \text { HOF } \\ 1 & 1 \\ 0.050 & 5.019 \\ .100 & 0.0100 \\ 0.000 & .120 \\ 0.056 & .180\end{array}$

0.0

5.56

9. 00

0.05

‥ 90

0.00

0.00

0. 00

0.09

0.05

6. 90

0.09

0.00

5.58

0.06

0.00

0.00

0.00

0.00

0. 0

0.00

0.00

7.81

.22

.20

.22

.47

.57

.21

.25

.35

.79

.47

.22

.22

.30

. 22

.24

.32

.73

.81

.92
1.35

.28 


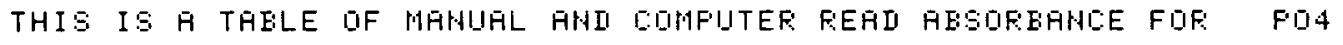
$1=\mathrm{HAB} 1$

$2=$ HMEG 1

FEFK HO

\begin{tabular}{|c|c|c|c|}
\hline 1 & 4.57 & 4.58 & -.01 \\
\hline $\bar{z}$ & .81 & $.6 \overline{1}$ & .91 \\
\hline 3 & .66 & .64 & .03 \\
\hline 4 & .91 & .89 & .613 \\
\hline 5 & 1.17 & 1.16 & .51 \\
\hline$\epsilon$ & 1.28 & 1.28 &.$\overline{a E}$ \\
\hline 7 & .74 & .73 & .01 \\
\hline 8 & .70 & .69 & .01 \\
\hline 9 & 1.01 & 1.518 & .51 \\
\hline 10 & $1.3 E$ & 1.34 & .02 \\
\hline 11 & 1.09 & 1.07 & .62 \\
\hline 12 & .84 & .82 & .02 \\
\hline 13 & .73 & .71 & .02 \\
\hline 14 & 1.19 & 1.10 & .01 \\
\hline 15 & .58 & .57 & .01 \\
\hline 16 & .83 & .81 & .52 \\
\hline 17 & 1.15 & 1.13 & .02 \\
\hline 15 & 1.19 & 1.15 & .01 \\
\hline 19 & 1.32 & 1.31 & .01 \\
\hline 26 & 1.66 & 1.60 & . \\
\hline 21 & .73 & .72 & . \\
\hline 23 & 1.14 & 1.14 & \\
\hline
\end{tabular}




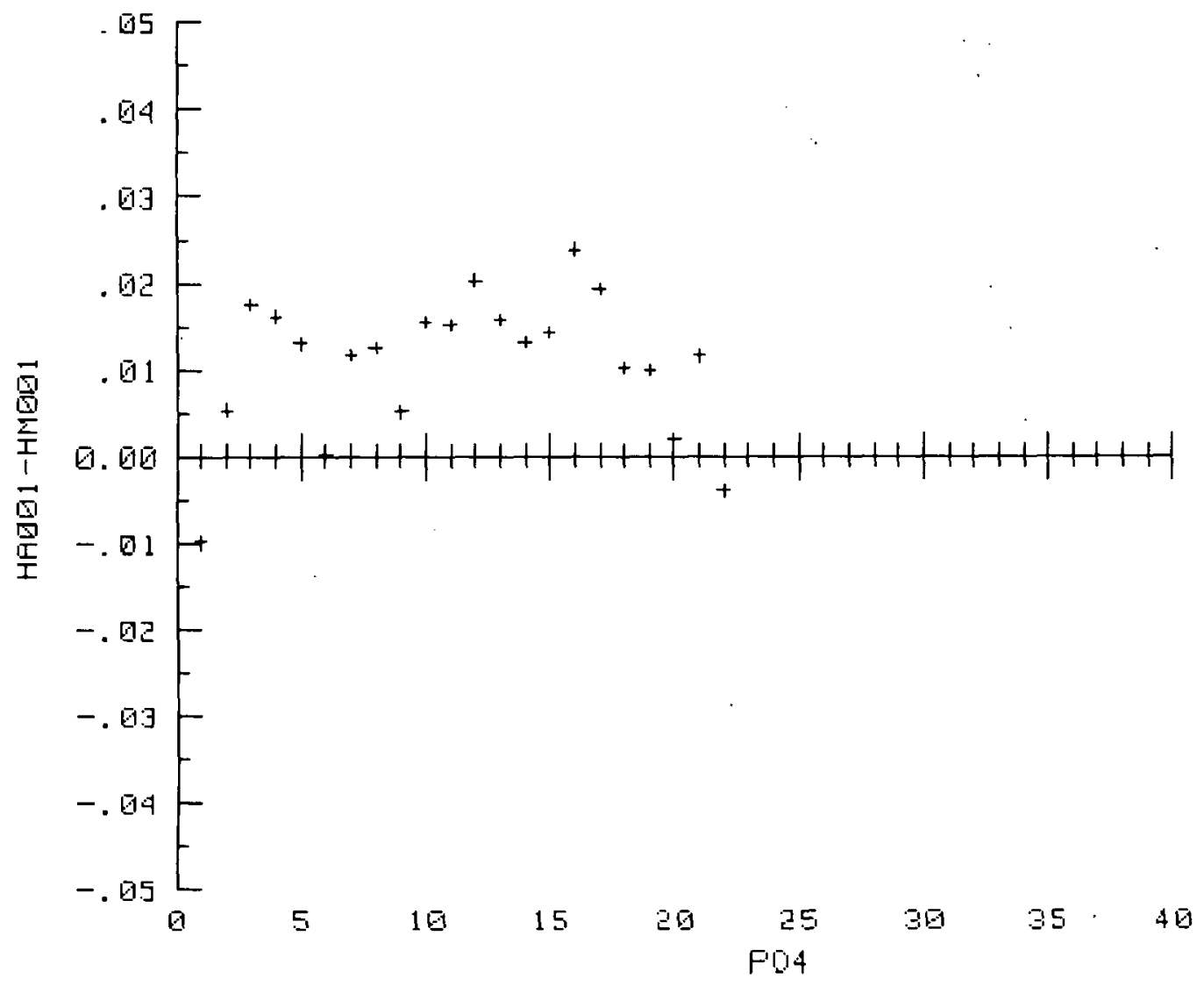




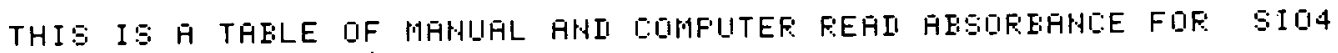

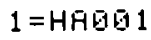

$2=H M 101$

\begin{tabular}{|c|c|c|c|}
\hline AKK HO. & 18104 & 25104 & $1-2$ \\
\hline 1 & 9.68 & 9.62 & -.02 \\
\hline 2 & 2.02 & 2.03 & -.01 \\
\hline 3 & 1.45 & 1.47 & -.02 \\
\hline 4 & 1.45 & 1.47 & -.92 \\
\hline 5 & 2.92 & 2.94 & -.02 \\
\hline$E$ & $3 . \overline{60}$ & 3.11 & -.03 \\
\hline 7 & $1.6 \theta$ & 1.58 & .08 \\
\hline 8 & 2.03 & 2.03 & .00 \\
\hline 9 & 2.52 & 2.52 & -.00 \\
\hline 10 & 3.58 & 3.16 & .48 \\
\hline 11 & 2.90 & 2.90 & -.015 \\
\hline 12 & 1.86 & 1.89 & -.03 \\
\hline 13 & 1.69 & 1.09 & -.00 \\
\hline 14 & 2.19 & 2.21 & -.92 \\
\hline 15 & 1.63 & 1.61 & .02 \\
\hline 16 & 1.41 & 1.45 & -.04 \\
\hline 17 & 2.15 & 2.19 & -.94 \\
\hline 18 & 3.46 & 8. 17 & -.01 \\
\hline 19 & 3.55 & 3.57 & -.02 \\
\hline 20 & 3.64 & 3.62 & .92 \\
\hline 21 & 3.50 & 3.55 & -.0 .5 \\
\hline 2 & 2.37 & 2.38 & -.6 \\
\hline
\end{tabular}

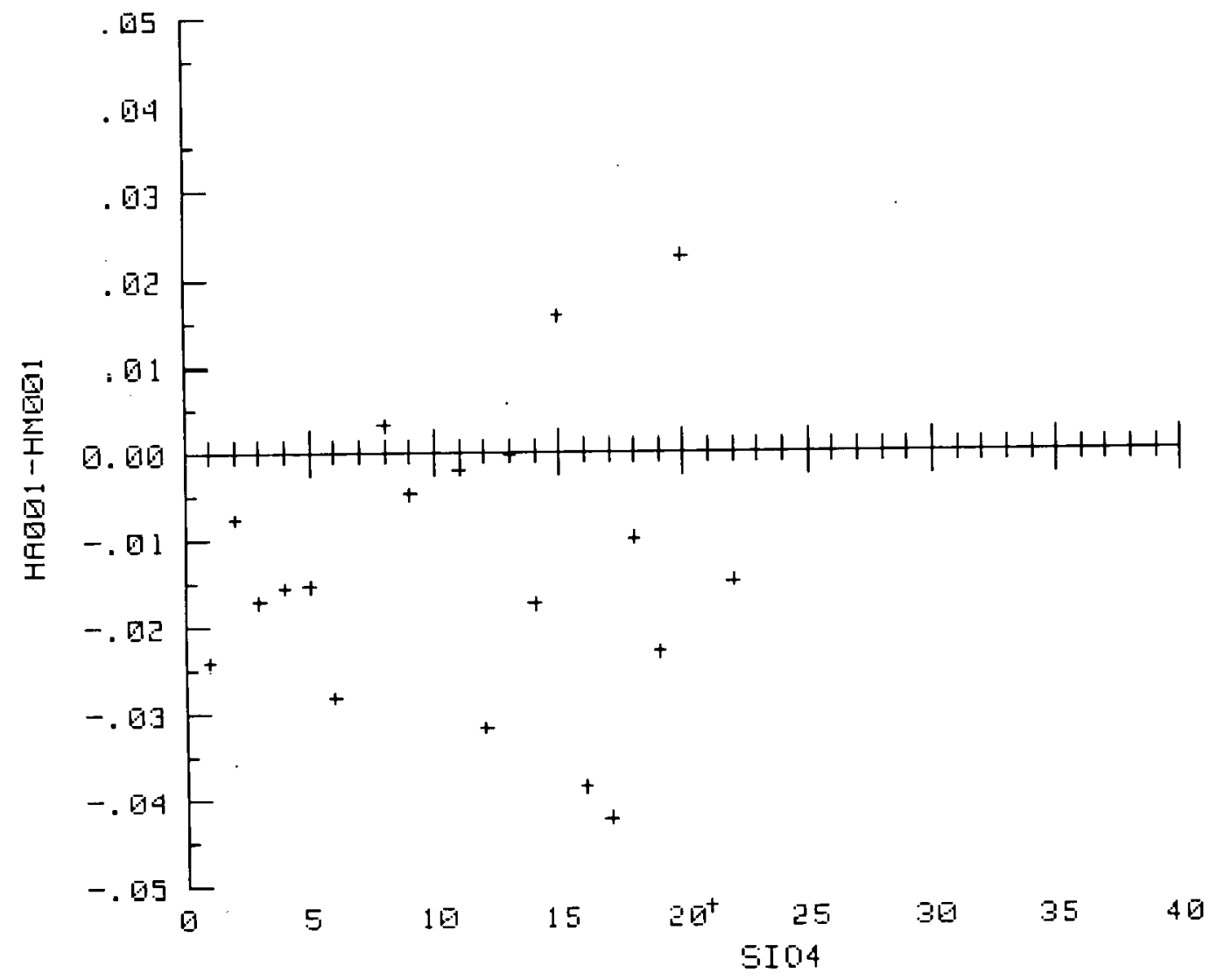




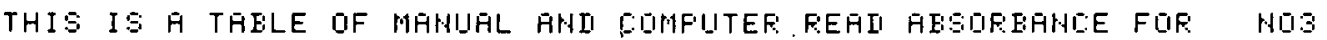
$1=H \bar{G} \mathbf{1} 1$

$2=H M \overline{0} 1$

\begin{tabular}{|c|c|c|c|c|}
\hline FEAK & MI. & NDO & Ho & $1-2$ \\
\hline & 1 & 7.92 & 7.94 & -.62 \\
\hline & 2 & .15 & .17 & -.61 \\
\hline & 3 & .14 & .13 & . 11 \\
\hline & 4 & .15 & .14 & .01 \\
\hline & 5 & .38 & .39 & -.011 \\
\hline & 6 & .49 & $.5 \overline{10}$ & -.6 \\
\hline & 7 & .15 & .13 & .52 \\
\hline & 8 & .14 & .13 & .8 \\
\hline & 9 & .27 & .27 & -.0 \\
\hline & 10 & .70 & .70 & -.0 \\
\hline & 11 & .39 & .39 & -.0 \\
\hline & 12 & .16 & .15 & .5 \\
\hline & 13 & .15 & .15 & $\cdot E$ \\
\hline & 14 & .21 & .21 & $\cdot 6$ \\
\hline & 15 & . 15 & .16 &.$- \square$ \\
\hline & 16 & .16 & .17 &.$- \bar{E}$ \\
\hline & 17 & .23 & .22 & .8 \\
\hline & 18 & .54 & .55 & -.0 \\
\hline & 19 & .72 & .71 & .5 \\
\hline & 20 & .81 & .81 &. \\
\hline & 21 & 1.34 & 1.35 & -.0 \\
\hline & 22 & .27 & .28 & -.02 \\
\hline
\end{tabular}

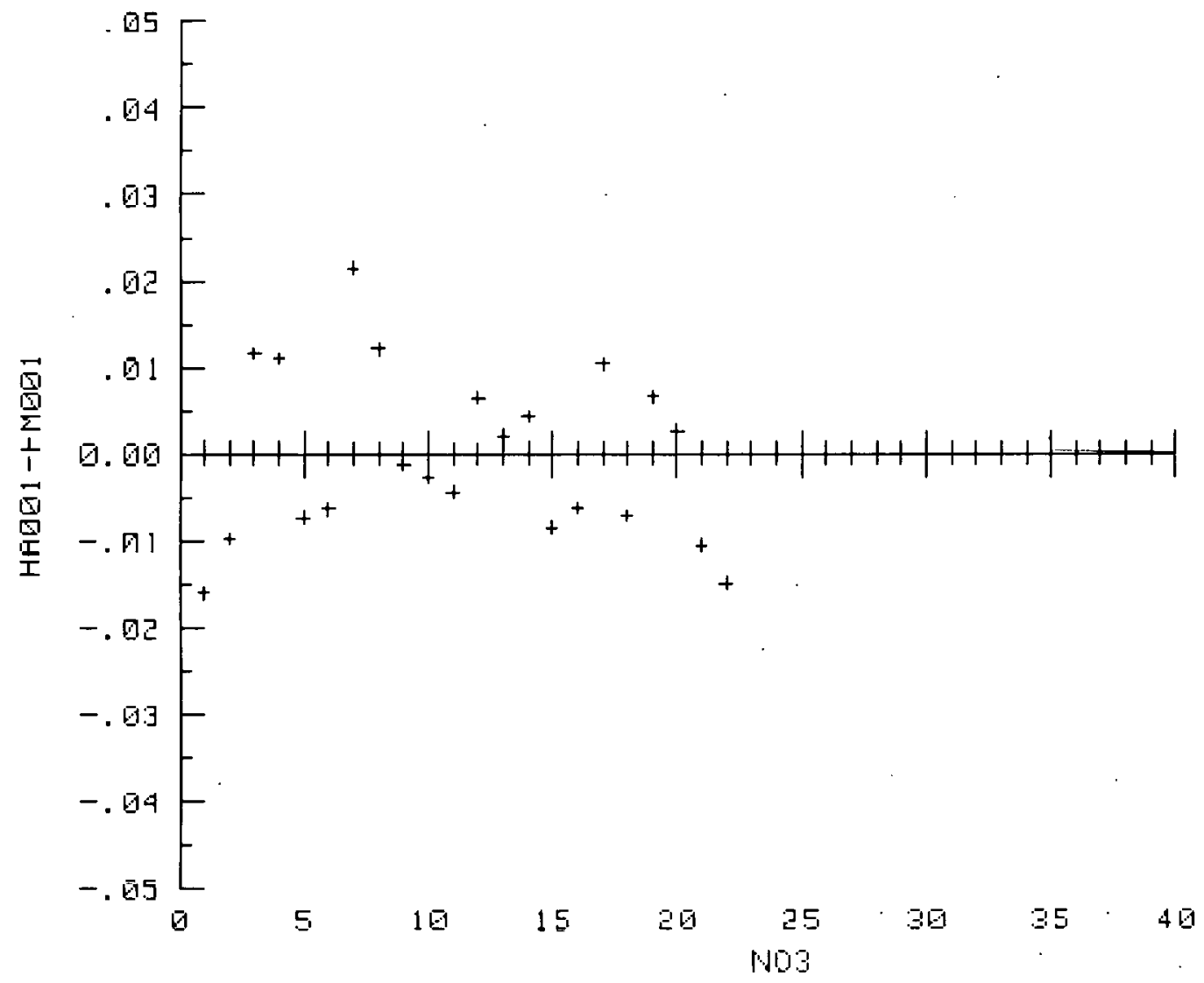




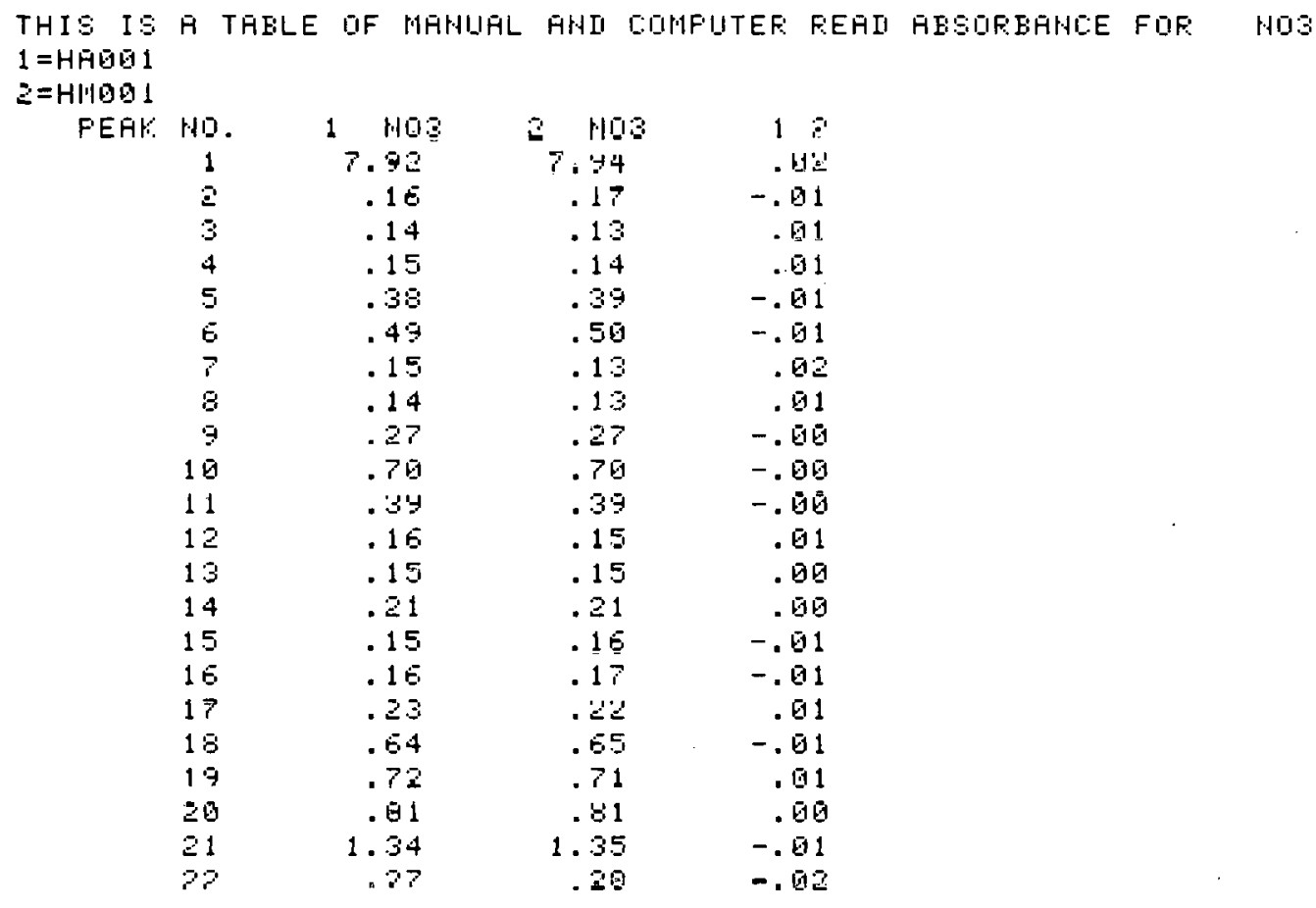




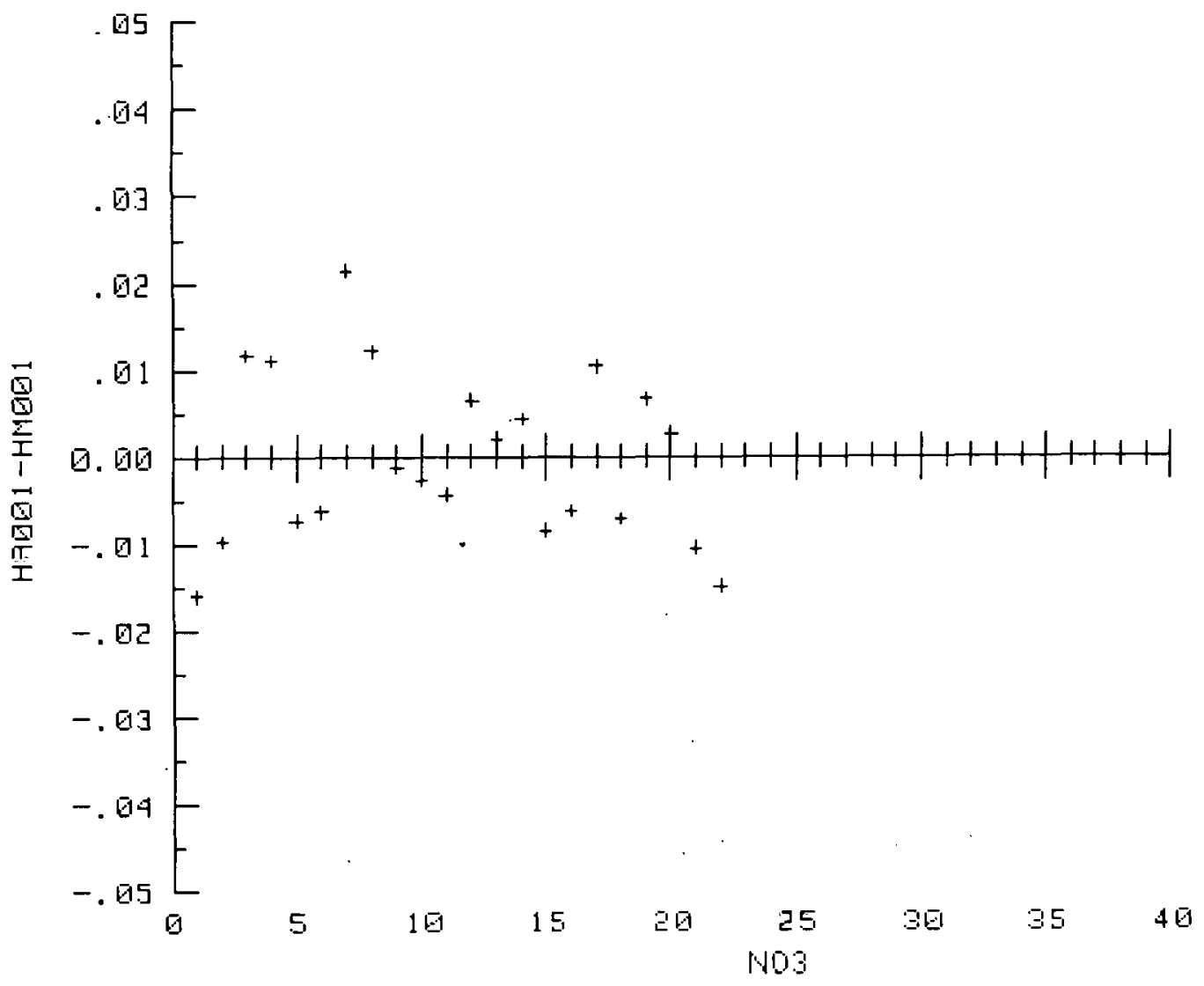




\section{INSTRUCTIONS FOR USE OF PLOT PROGRAM}

1. Insert Autoprogram tape into tape drive 15. Type IOAD "PIOT" and then press EXECUTE.

This steps loads the program into the computer's memory. When the small square of light at the lower right-hand corner of the cathode ray tube (CRT) is extinguished, the program is fully loaded and ready for use. Remove the Autoprogram tape and insert your data tape into tape drive 15.

2. Press RUN. CRT displays HELLO FROM PLOT USING STANDARD FILE. Variable names are PO4, SI04, N+N, NO2, NH4, URE. CRT prompts EILE WANTED at lower left-hand corner of the screen.

3. Type in the name of the file desired and press CONT. Computer finds and reads your data file from tape. CRT displays "FINISHED READTNG FILE" and prompts OUTPUT TYPE: $1=A B S$

$$
\text { 2-UG-AT/L }
$$

4. Type 1 if you desire à listing in ahsnrhanre units or type 2 if you desire a listing in $\mu g$-at/liter. Because you will need to know the nutrient concentrations in $\mu g-a t / 1 i t e r$ for the plotting routine, it is wise to select 2 . Press CONT.

CRT displays data file and prompts DO YOU WANT HARD COPY, Y/N?

5. Type $Y$ and press CONT. A hard copy is output to the thermal printer. CRT prompts again, DO YOU WANT HARD COPY, Y/N?

6. Type $N$ and press CONT. CRT displays LIST FINISHED and prompts DO YOU WANT A PI.OT?, Y/N.

7. Type $Y$ and press CONT. CRT prompts for VARIABLE NAME.

8. Type the variable desired; $\mathrm{PO} 4, \mathrm{SI04}, \mathrm{N}+\mathrm{N}, \mathrm{NO} 2, \mathrm{NH} 4$, or URE and press CONT. If variable name is incnrrert, CRT displaye incorrcct variable name IS A BAD CHOICE TRY AGAIN. Type correct name and press CNNT.

9. $\overline{\mathrm{CR} T}$ prompts XMIN, XMAX? Type range of concentration desired for this variable, press CONT.

1U. C'K' prompts DEPTH MIN, DEPTH MAX. Type range of depths desired for this variable. press CONT.

11. CRT plots data for this nutrient variable and prompts $\mathrm{n}$ Y YOU WANT $A$ HARD COPY OF THE PLOT? Y/N.

12. Type $Y$ and then press CONT to ubtalu a copy of the plot on the thermal printer. CRT prompts again DO YOU WANT A HARD COPY OF THE PLOT? Y/N.

13. Type $\mathrm{N}$ and press CONT. CRT prompts DO YOU WANT A NEW STATION? Y/N.

14. Type $N$ and press CONT and program returns you step to 9 for new variable or type $Y$ and press CONT. Program returns you to step 4 for the selection of a new station.

\section{PLOT PROGRAM - USER DEFINED PARAMETERS}

120 Varlable names: Urder of variables is constant. Channel 6, URE, is for experimental work. Change URE to the analysis at hand. For example, change URE to CHL if chlorophyll is heing determined.

550 'Type of sample: For hydro samples, this line specifies that these "H" samples will be plotted. To plot samples identified in the data base by any other letter, enter its I.D. letter here. For example, to plot productivity identified in the data by the letter $P$, substitute " $P$ " for "H". Only productivity samples will then be plotted when PLOT is called.

The following three pages are output examples of "PLOT". 


\begin{tabular}{|c|c|c|c|c|c|c|c|}
\hline \multicolumn{8}{|c|}{$\begin{array}{l}\text { LHEEL }=H 4091 \\
\text { DATE }=21 M A 190 \\
H R=2350\end{array}$} \\
\hline \multicolumn{8}{|c|}{ LAT $=54 \quad 52.0$} \\
\hline \multicolumn{8}{|c|}{ LOH $=16753.0$} \\
\hline \multicolumn{8}{|c|}{ DEFTH $=1527$} \\
\hline \multicolumn{8}{|c|}{ CDMMENT = TR:AHSELT STAT I DHA } \\
\hline \multicolumn{8}{|c|}{ HO. SAMFLES= 14} \\
\hline \multicolumn{2}{|c|}{ L:HANNEL = } & $\mathrm{FO4}$ & $5 I 04$ & $H+H$ & 102 & $\mathrm{HH} 4$ & UIEE \\
\hline \multicolumn{2}{|c|}{ STATUS= } & 1 & 1 & 1 & 1 & 1 & 0 \\
\hline \multicolumn{2}{|c|}{ FHI:TOF:S= } & $.8 B 1$ & 10.401 & 4.E13 & .609 & .855 & 1.006 \\
\hline \multicolumn{2}{|c|}{$\mathrm{RF} \cdot \mathrm{G}=$} & .150 & .136 & .619 & .030 & .180 & 0.006 \\
\hline \multicolumn{2}{|c|}{ BASE $1=$} & .369 & .427 & .215 & .375 & .322 & Q. 166 \\
\hline \multicolumn{2}{|c|}{ EAT:EZ = } & .474 & .860 & .515 & .356 & .331 & -9.996 \\
\hline $\mathrm{NO}$. & I I I & $\| \Xi-B T$ & UE-AT & $\mathrm{UG}-\mathrm{AT}$ & Uら-AT & $U G-A T$ & تال \\
\hline $1 \mathrm{II}$ & E & $5.1 \mathrm{~B}$ & 96.92 & 45.40 & 3.17 & 7.47 & 0.06 \\
\hline 25 & 15 & .73 & 94.79 & 43.96 & .02 & .10 & 0.00 \\
\hline 35 & 25 & 4. 29 & -.89 & 4.23 & 4.44 & 4.44 & 0.06 \\
\hline $4 \mathrm{H}$ & Q & 1.76 & 46.38 & 21.95 & .38 & .95 & 0.00 \\
\hline $5 \mathrm{H}$ & 10 & 1.86 & 45.51 & 21.53 & .35 & .90 & 0.00 \\
\hline$E H$ & 25 & 1.94 & 51.30 & 24.13 & .35 & .99 & 0.00 \\
\hline $7 \mathrm{H}$ & 30 & 2.01 & 50.89 & 25.34 & . 35 & 1.06 & 0.00 \\
\hline $8 H$ & 46 & 1.99 & 40.87 & 25.12 & .35 & .99 &.$\overline{0.0}$ \\
\hline $9 \mathrm{H}$ & 50 & 2.60 & 43.13 & 25.27 & .37 & .97 & 0.00 \\
\hline $10 \mathrm{H}$ & 160 & 2.09 & 53.92 & 26.71 & .39 & 1.06 & 0.06 \\
\hline $11 \mathrm{H}$ & 156 & 2.28 & 64.06 & 29.82 & .38 & .72 & 0.90 \\
\hline $12 H$ & 200 & 2.33 & 62.17 & 30.41 & .44 & .83 & 0.08 \\
\hline $1: H$ & 300 & 2.59 & 78.75 & $35 .: 31$ & .22 & .75 & 19.00 \\
\hline $14 \mathrm{H}$ & 11524 & 3.25 & 193.99 & 42.54 & .17 & .79 & 0.00 \\
\hline
\end{tabular}




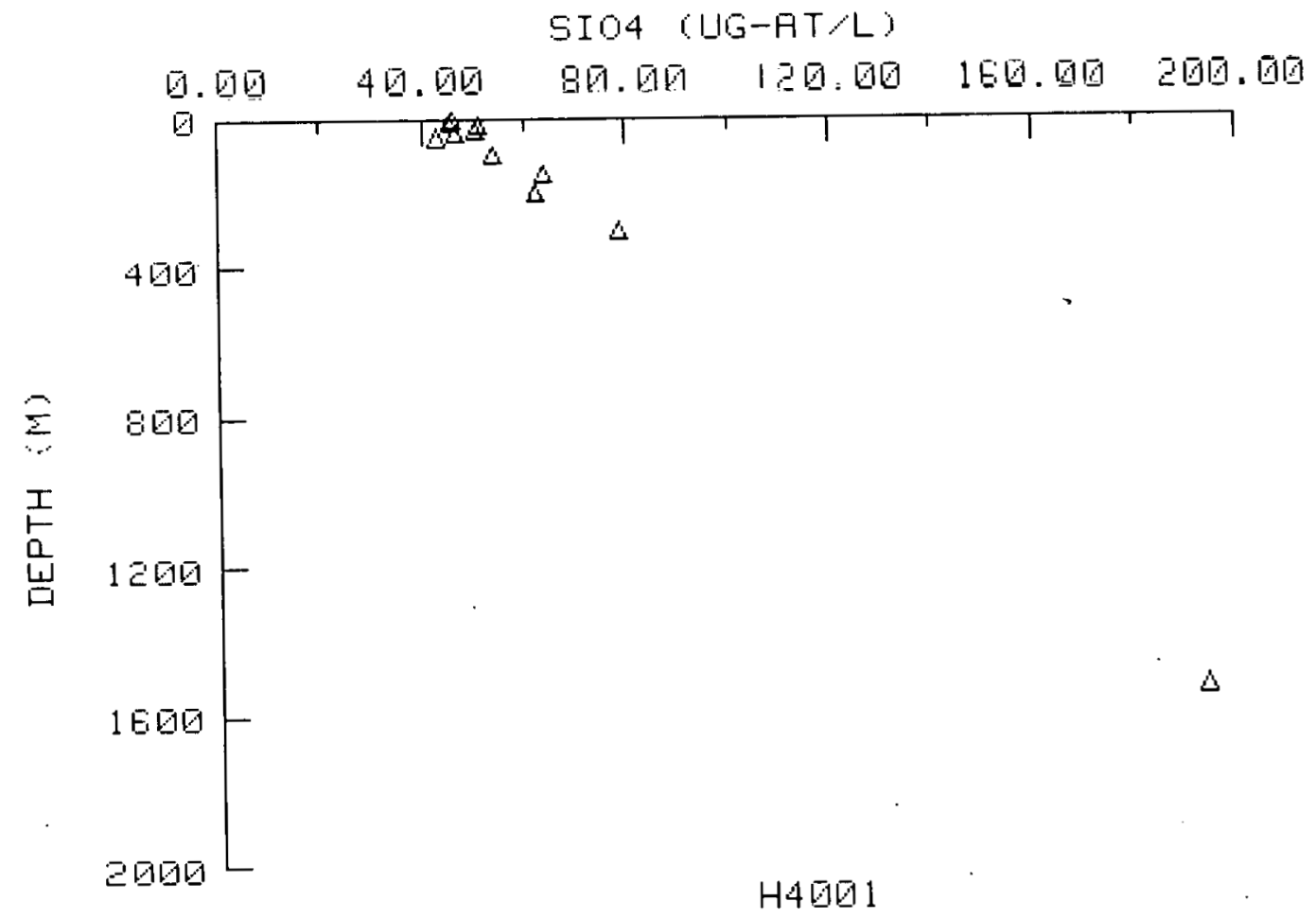




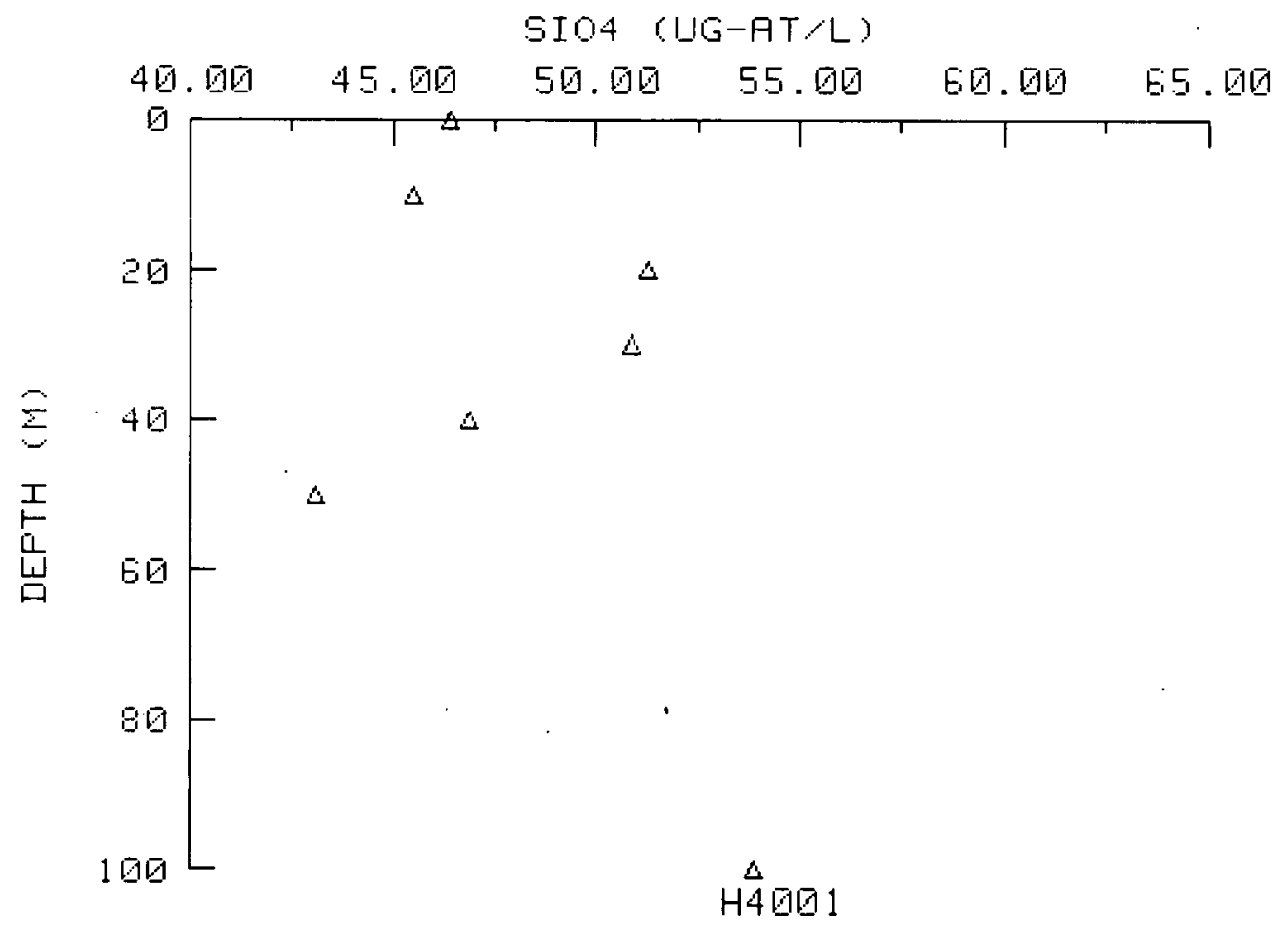




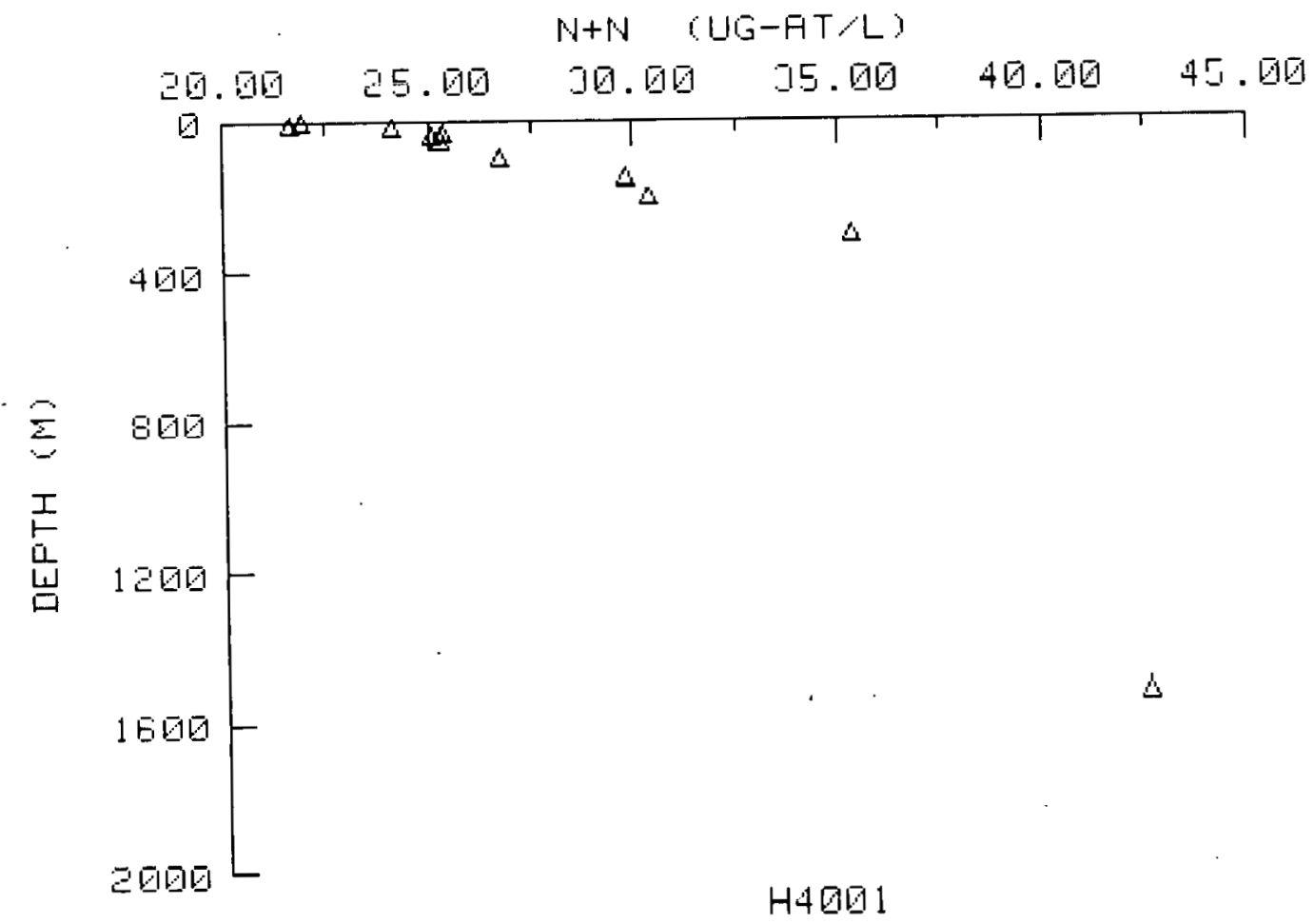


1. Insert Autoprogram tape into tape drive 15. Type LOAD "SECS" and then press EXECUTE.

This step loads the program into the computer's memory. When the small square of light at the lower right-hand corner of the cathode ray tube (CRT) is extinguished, the program is fully loaded and ready for use. Remove the Autoprogram tape and insert your data tape into tape drive 15.

2. Press RUN, CRT prompts "ENTER FILE NAME, STA NO.? TYPE EXIT TO QUIT". Enter file names that are stored on data tape and Station numbers to be used for each station in the section, push CONT. (Note: Be certain the stations are entered in their proper order in the transect). A maximum of 25 stations with 40 depths on each station and 6 channels are the upper limit of storage capacity in the computer.

$$
\begin{array}{ll}
\text { Example: HY2001, } 1 & \text { file "HY2001" is called station } 1 \\
\text { HY2002, } 3 & \text { file "HY2002" is called station } 3 .
\end{array}
$$

The file name is checked for each request on tape 15 and if not found "INPUT ERROR IN (file name) TRY AGAIN" will be displayed. Type "EXIT" and push CONT to quit requesting files.

3. The CRT will display "DO YOU WANT A HARD COPY?" Y/N" Enter "Y" or "N" and push CONT.

4. The CRT will display "DO YOU WANT TO RUN? $\mathrm{Y} / \mathrm{N}$ " Enter " $\mathrm{Y}$ " or "N" and push CONT.

If " $Y$ " 1 s answered to question then the computer will sequentially retrieve the files from the tape and store them in a 3-dimensional matrix of stations, depths and channel numbers. As the files are stored in the computer the CRT displays that the file has been found.

5. After the last file has been stored, the section length in $\mathrm{km}$ will be written on the CRT. This is calculated from the latitude and longitude fixes from each station file. The distance represents the cumulative distance calculated as a great circle between each of the stations. As a result, the cumulative distance between stations may be different than the distance between the two transect end stations.

6. The CRT will then ask for "VARIABLE NAME?" Enter the three or four letter name of the nutrient wanted, press CONT. Other options are: integrations, enter " $I$ " and ratios, enter " $R$ "

7. The CRT will request "SECTION LENGTH?" Enter desired length in $\mathrm{km}$ of the section while taking note of the actual length in step 6 above, press CONT.

8. The CRT will request "MAXIMUM DEPTH PLOT?" Enter the deepest depth for the vertical scale desired, press CONT. Note that you do not have to $\mathrm{plot}$ all values. If $100 \mathrm{~m}$ is requested then all values deeper than $100 \mathrm{~m}$ will be disregarded. Bottom depths will be drawn for all or part of the stations if the requested depth is chosen large enough.

9. The CRT will request "lype of Plot $1=$ numbers, 2 = numbers + contours, 3 = contours." If you want only number with no lines enter 1 and press CONTINUE. However, you can obtain numbers and contours or just contours by pressing 2 or 3 followed by a conTINUE. If contours are requested the CRT will display "Contour level value or E to exit." Enter each contour concentration followed by a CONTINUE. Enter $E$ and press CONTINUE to start plot. 
10. The section will be drawn from left to right. The bottom contour will be added to the figure automatically if sonic depths have been entered into the files.

11. The CRT will display "DO YOU WANT A HARD COPY OF THE PLOT? Y/N" Enter " $\mathrm{Y}$ " or "N" and press CONT.

12. The CRT will display "DO YOU WANT ANOTHER VARIABLE ON THIS SECTION? $\mathrm{Y} / \mathrm{N}$ ". Enter "Y" or "N" and press CONT. If "Y" then go to step 7. If " $N$ " then the program ends. To do another section push STOP and RUN, then start at step 2 .

\section{INTEGRATION}

To obtain integrated values in a transect respond to CRT with an "I" and press CONTINUE when "VARIABL.F. NAMF? [ $\mathrm{KA}] "$ is displayed.

1. CRI will request "WHAT IS THE INTEGRATION MIN?" Enter dept.h and press CONTINUE.

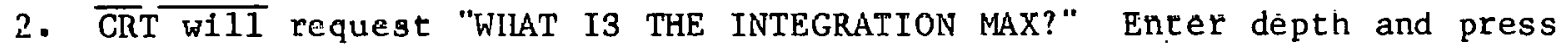
CONTINUE.

3. CRT wi11 request "DO YOU WANT A HARD COPY OF THE INTEGRATED VALUES? $\mathrm{Y} / \mathrm{N}$ " Enter " $\mathrm{Y}$ " and press CONTINUE for a printout of all integrated values in the transect.

4. CRT will request "SECTION LENGTH?" Enter length of $\mathrm{x}$-axis in km and press CONTINUE.

5. CRT will request "MAXIMUM INTEGRATED CONC?" Fnter maximum value of $\mathrm{y}$-axis and press CONTINUE.

6. The plot will commence but the CRT will request "VARIABLE MASK? [6 No.'s]" Enter 6 numbers separated by commas for the nutrient channels desired in the plot.

Examples: $0,1,1,0,0,0$ will plot only shannels ? and $\mathbf{3}$ ( $\mathrm{SiO}_{4}$ and $\mathrm{N}+\mathrm{N})$.

$$
\begin{array}{ll}
1,0,1,0,1,0 & \text { will plot channels } 1,3 \text { and } 5\left(\mathrm{PO}_{4}, \mathrm{~N}+\mathrm{N},\right. \\
\left.\mathrm{NH}_{4}\right) . &
\end{array}
$$

If you simply press CONTINUE without entering numbers, all channels will be plotted unless you had previuusly changed the mask.

\section{RATIOS}

To obtain ratios of variables in a transect respond to CRT with an " $R$ " and press CONTINUE when "VARIABLE NAME? [6A]" is displayed.

1. CRT will request "SECTION LENGTH?" Enter length in $\mathrm{km}$ and press CONTINUE.

2. $\overline{\text { CRT will }}$ request "MAXIMUM PLOT DEPTH?" Enter depth in $m$ and press CONTIINUE.

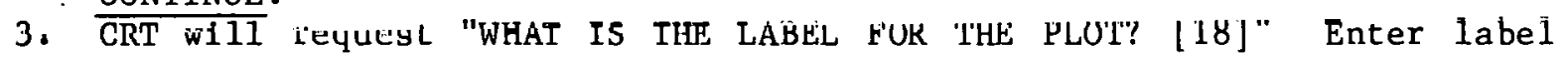
from keyboard (maximum of 18 characters) and press CONTINUE.

Example: N03/SI04.

4. CRT will request "TYPE OF PLOT $1=$ NUMBERS, $2=$ NUMBERS + CONTOURS, 3 = CONTOURS." Enter desired number and press CONTINUE. If contours are requested, enter contour levels and press CONTINUE. Enter "E" and press CONTINUE to start the plot.

(Note: For ratios other than $\mathrm{NO}_{3} / \mathrm{SIO}_{4}$ the coding must be altered in SECS program 1 ines 3210 and 3220. ) 


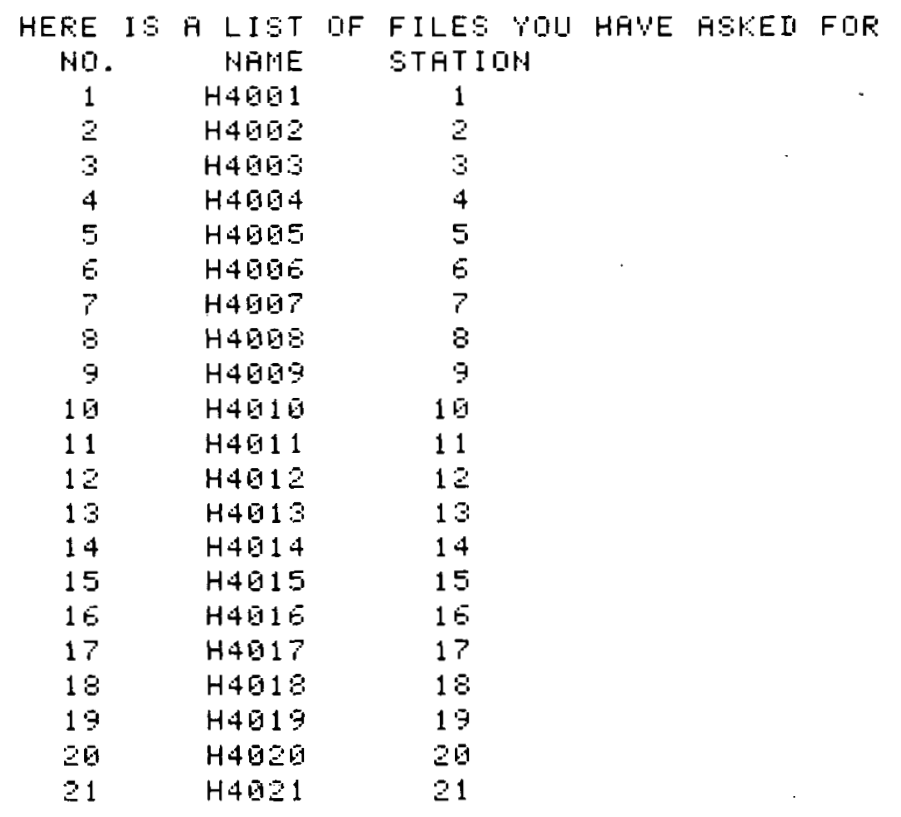




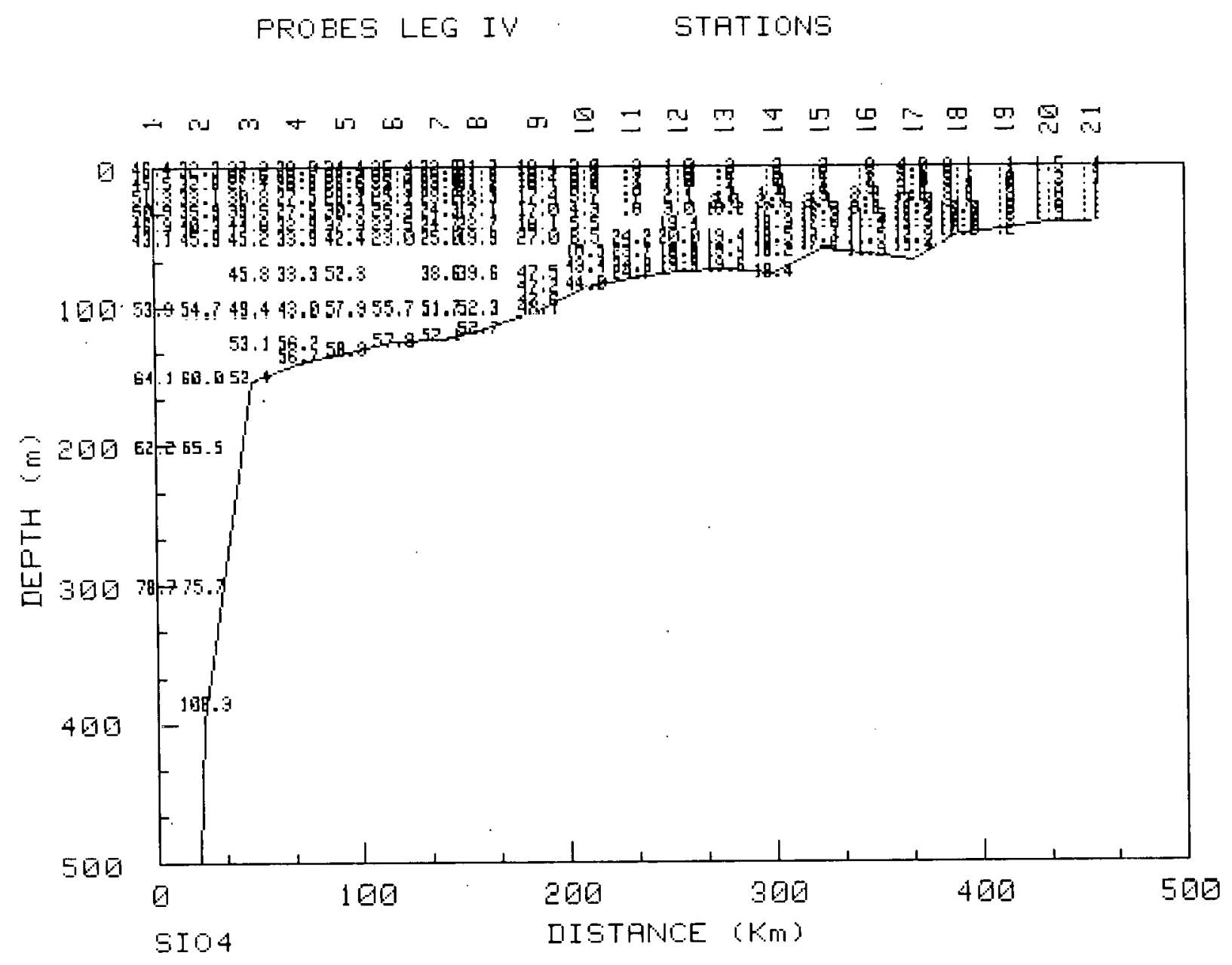




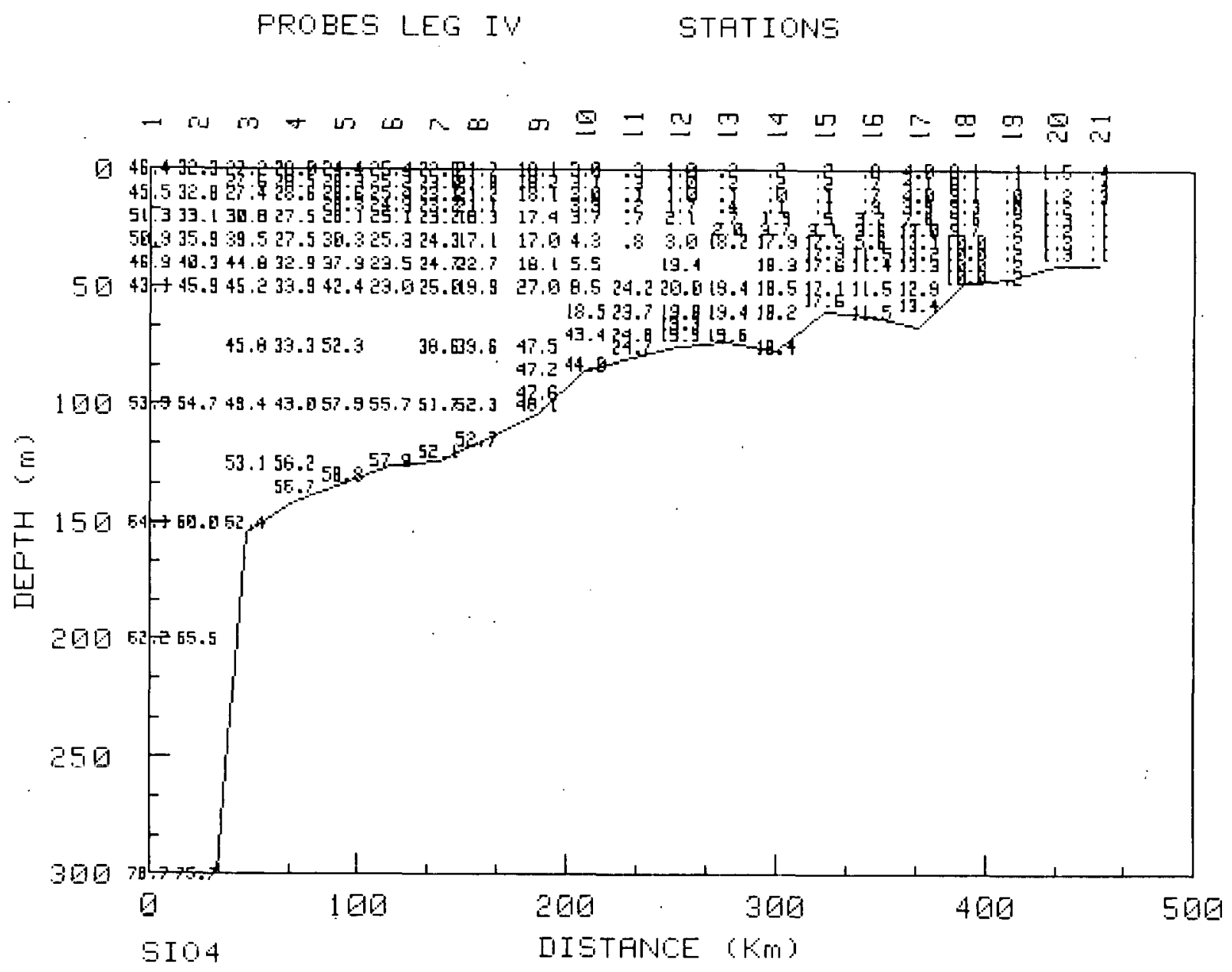




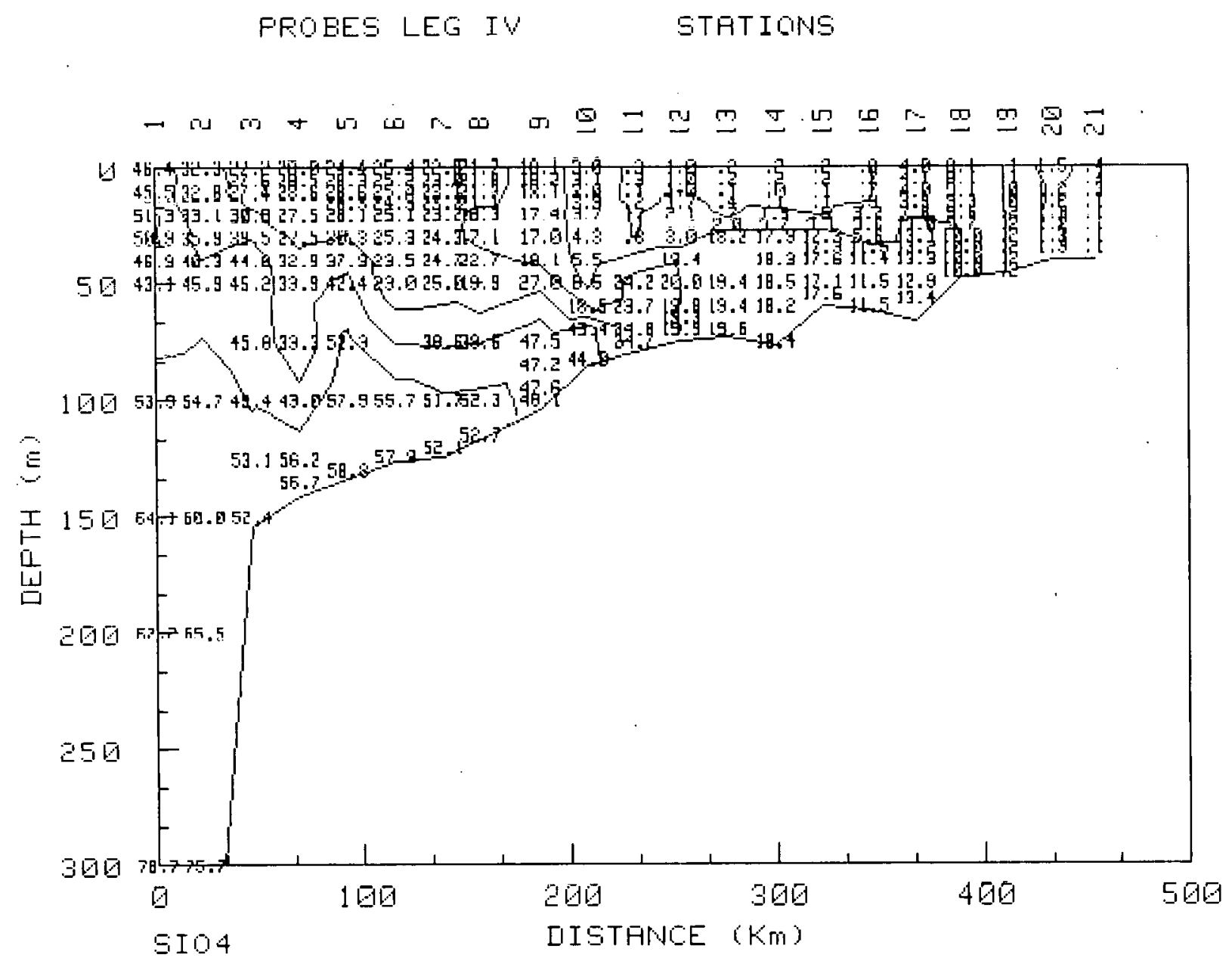




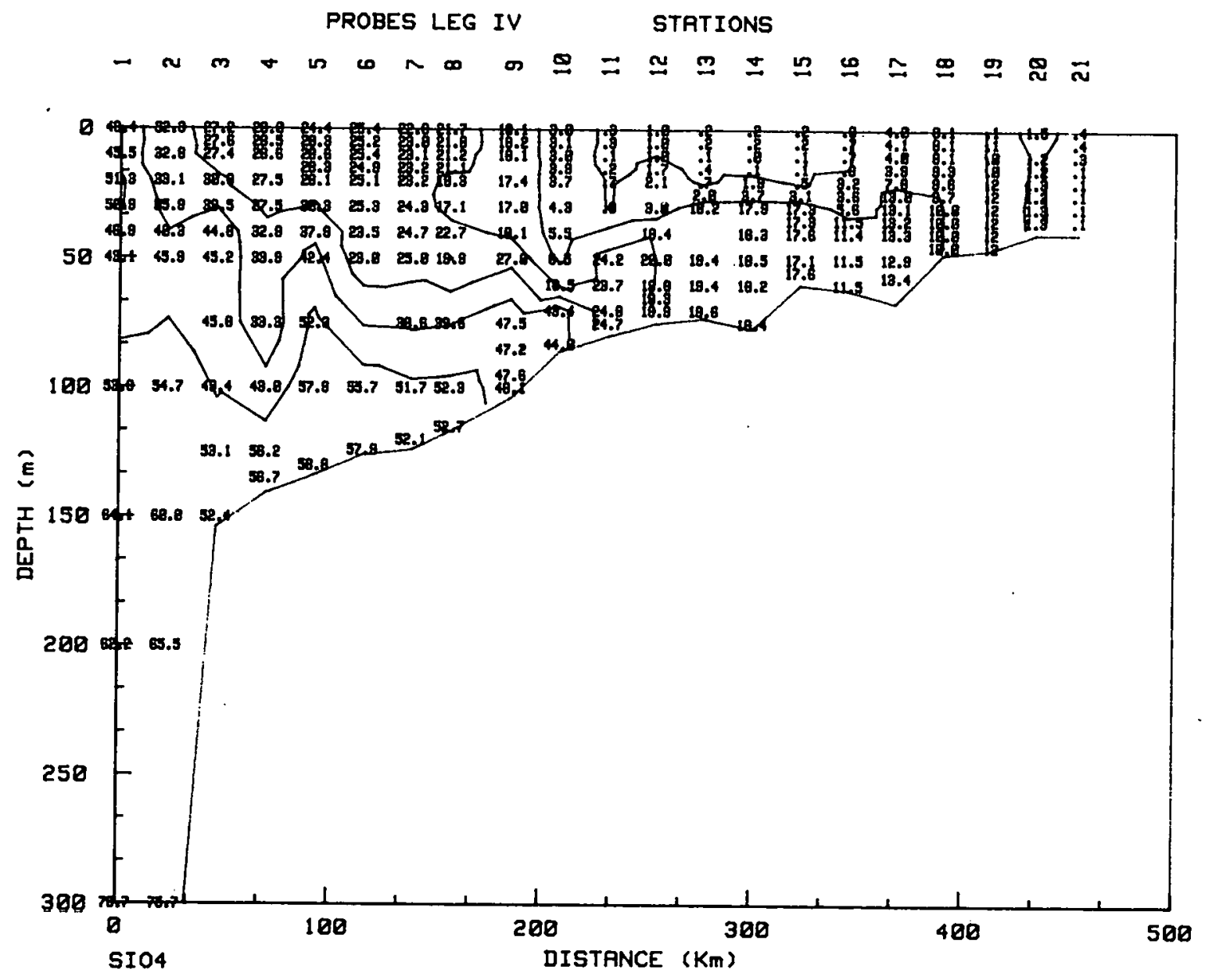




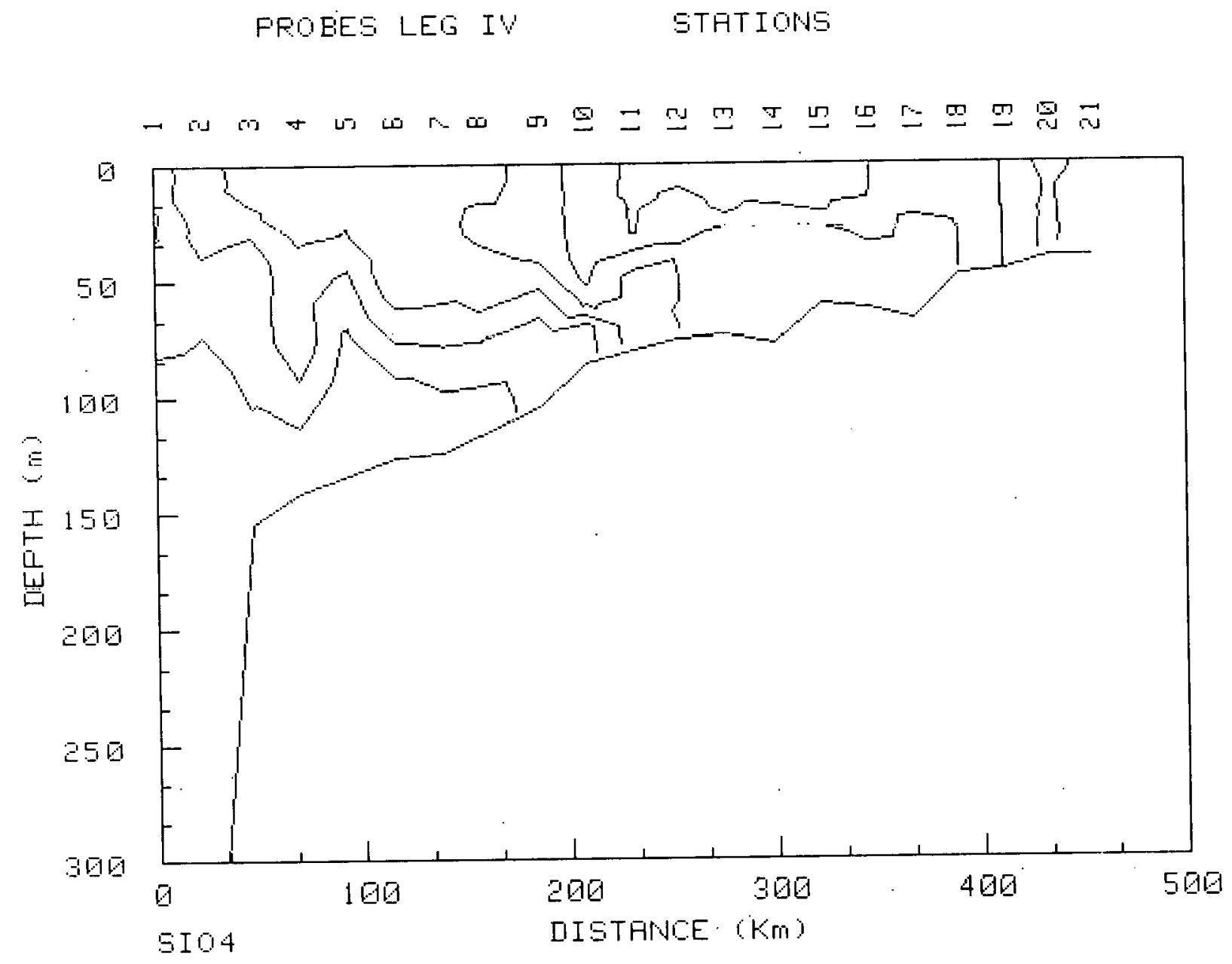




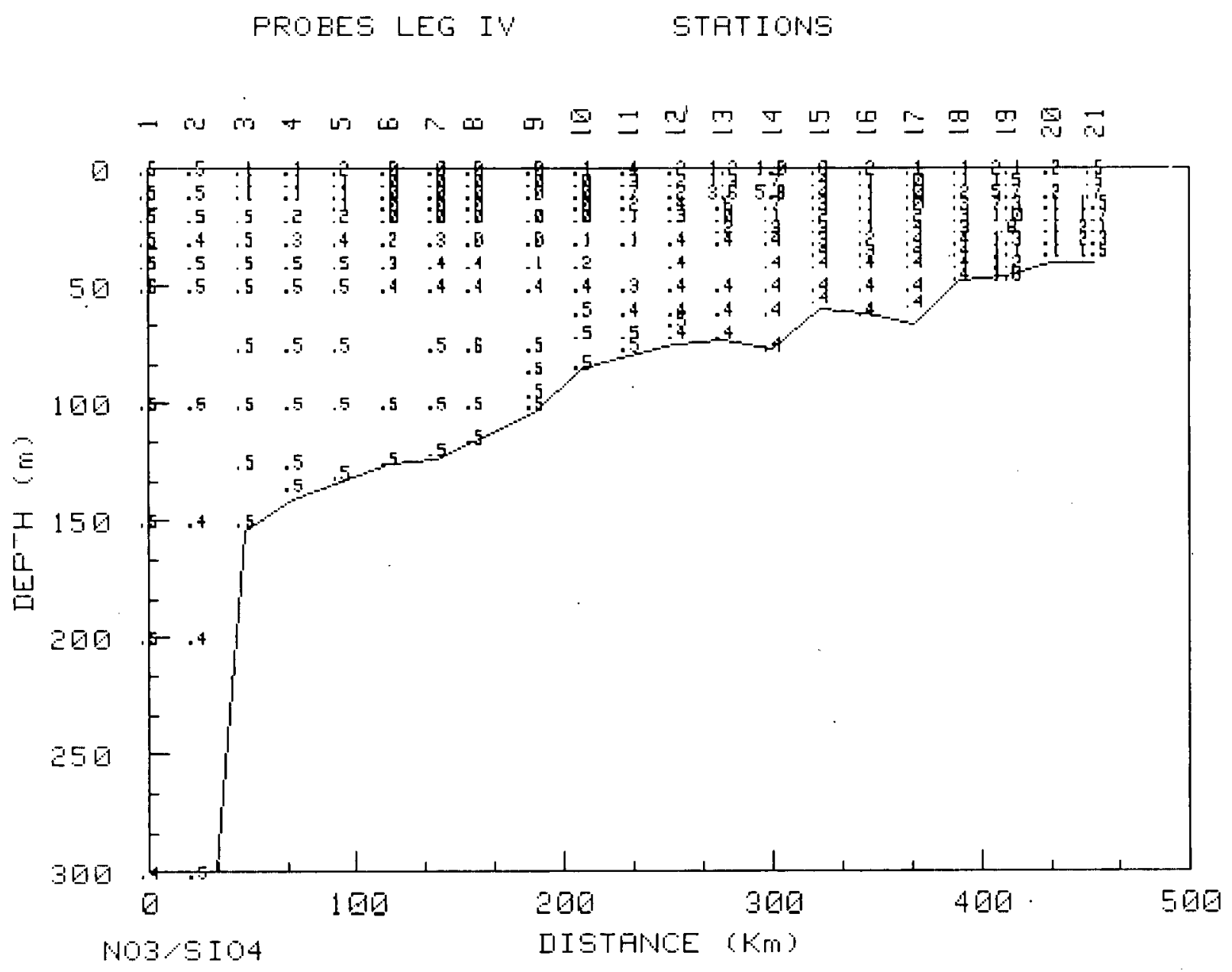




\begin{tabular}{|c|c|c|c|c|c|c|}
\hline \multicolumn{7}{|c|}{ IHTEGRATEI DOHCEHTRETIOHS ML-AT/MF:Z) } \\
\hline & & CHTEGEATE & ROAN & $T 0 \quad 40 \mathrm{~m}$ & & \\
\hline STA N口. & $\mathrm{F} 04$ & 5104 & $\mathrm{H}+\mathrm{H}$ & HOZ & $\mathrm{HH}_{4}$ & EHL \\
\hline 1 & TE. .1 & 1943.12 & 946.29 & 14.24 & 39.14 & 159.84 \\
\hline 2 & 56.84 & 1381.19 & 606.28 & 16.24 & 47.65 & 159.94 \\
\hline 3 & 53.16 & 1330.60 & 517.37 & 13.61 & 82.15 & 183.15 \\
\hline 4 & 39.36 & 1141.13 & 273.12 & 10.78 & 63.96 & 183.15 \\
\hline 5 & 43.19 & 1191.24 & 328.03 & 12.12 & 72.15 & 176.29 \\
\hline$\epsilon$ & 30.62 & 1006.45 & 98.24 & 8.40 & 43.77 & 214.07 \\
\hline 7 & 32.46 & 943.62 & 137.50 & 8.19 & 67.99 & 0.00 \\
\hline$\theta$ & 25.29 & 797.00 & 64.20 & 7.69 & 56.35 & 192.84 \\
\hline 9 & 22.17 & 705.95 & 17.35 & 6.14 & 32.69 & 141.52 \\
\hline 10 & 14.56 & 156.07 & 14.87 & 8.44 & 35.19 & 158.77 \\
\hline 11 & 10.46 & 21.54 & 3.09 & 5.22 & 25.65 & $1 \in 7.14$ \\
\hline 12 & 17.75 & 163.79 & 55.09 & 6.21 & 39.21 & 187.80 \\
\hline 13 & 25.28 & 244.51 & 106.17 & 3.09 & 52.29 & 209.21 \\
\hline 14 & 0.00 & 255.89 & 105.95 & $P .49$ & 48.48 & 197.79 \\
\hline 15 & $26.1 \mathrm{e}$ & 238.03 & 85.70 & 7.34 & 44.84 & 201.12 \\
\hline 10 & 20.23 & 162.31 & 35.30 & $E .44$ & 44.75 & 201.12 \\
\hline 17 & 22.32 & 338.65 & 98.56 & 8.68 & 12,01 & 251.12 \\
\hline $1 \varepsilon$ & 26.81 & 373.66 & 105.90 & 10.50 & 32.52 & 216.34 \\
\hline 19 & 18.87 & 5.50 & 8.11 & 6.26 & 20.26 & 216.34 \\
\hline 20 & $28.4 \theta$ & 50.59 & 7.65 & 5.85 & 18.51 & 244.56 \\
\hline 21 & 26.81 & 7.31 & 7.56 & 5.24 & 15.88 & 252.32 \\
\hline & & EES LE & 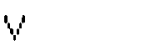 & GTATI & & \\
\hline
\end{tabular}

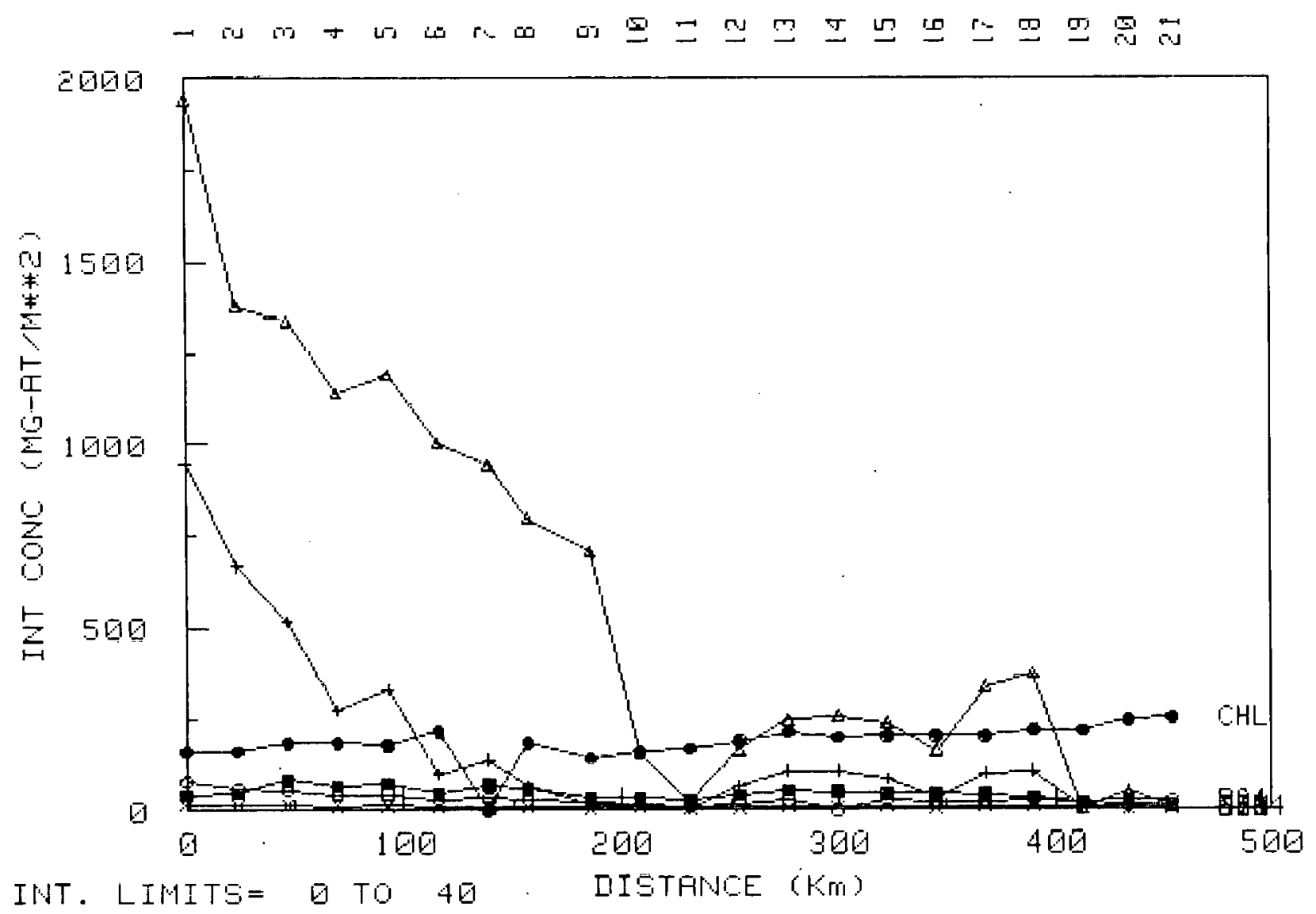




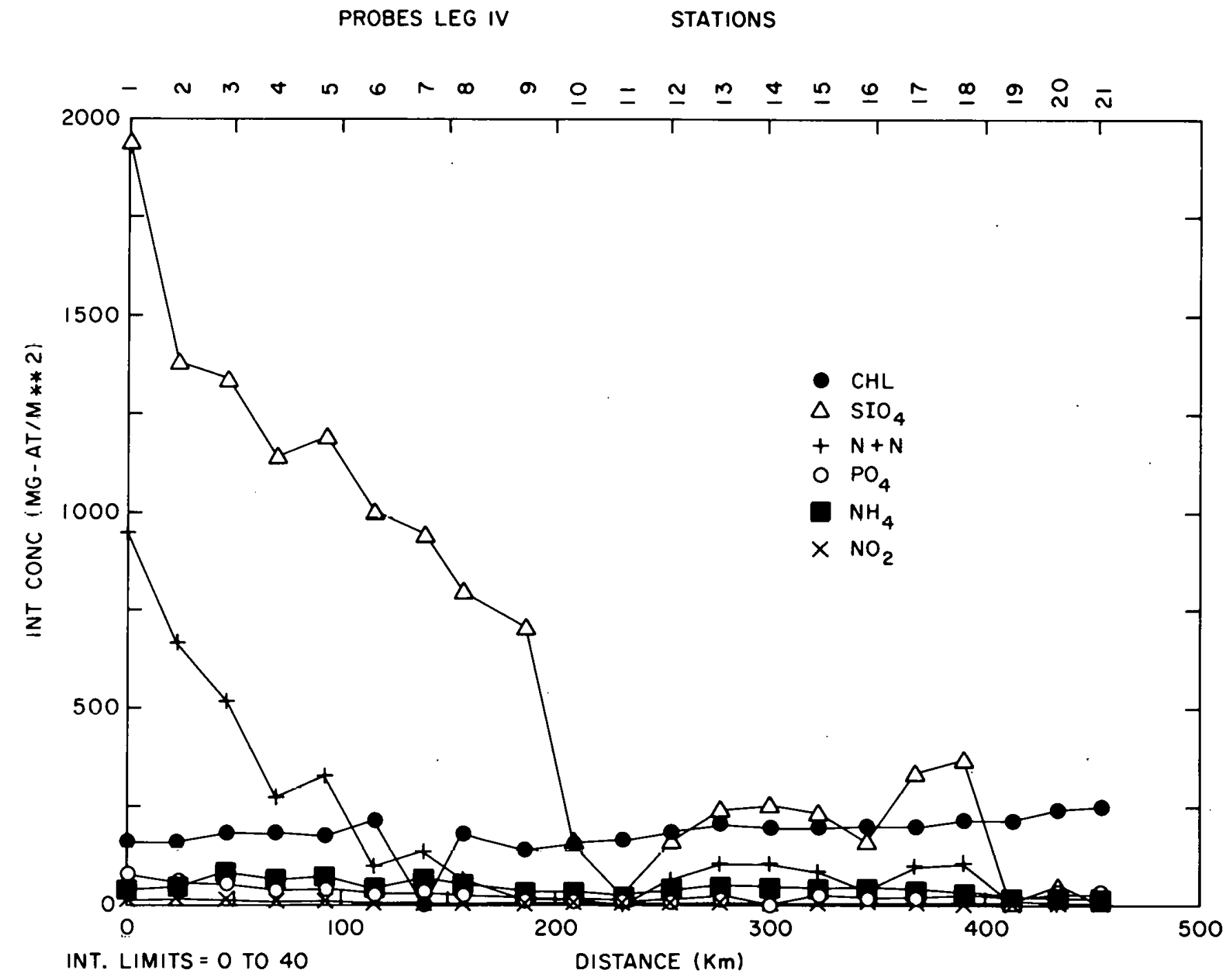




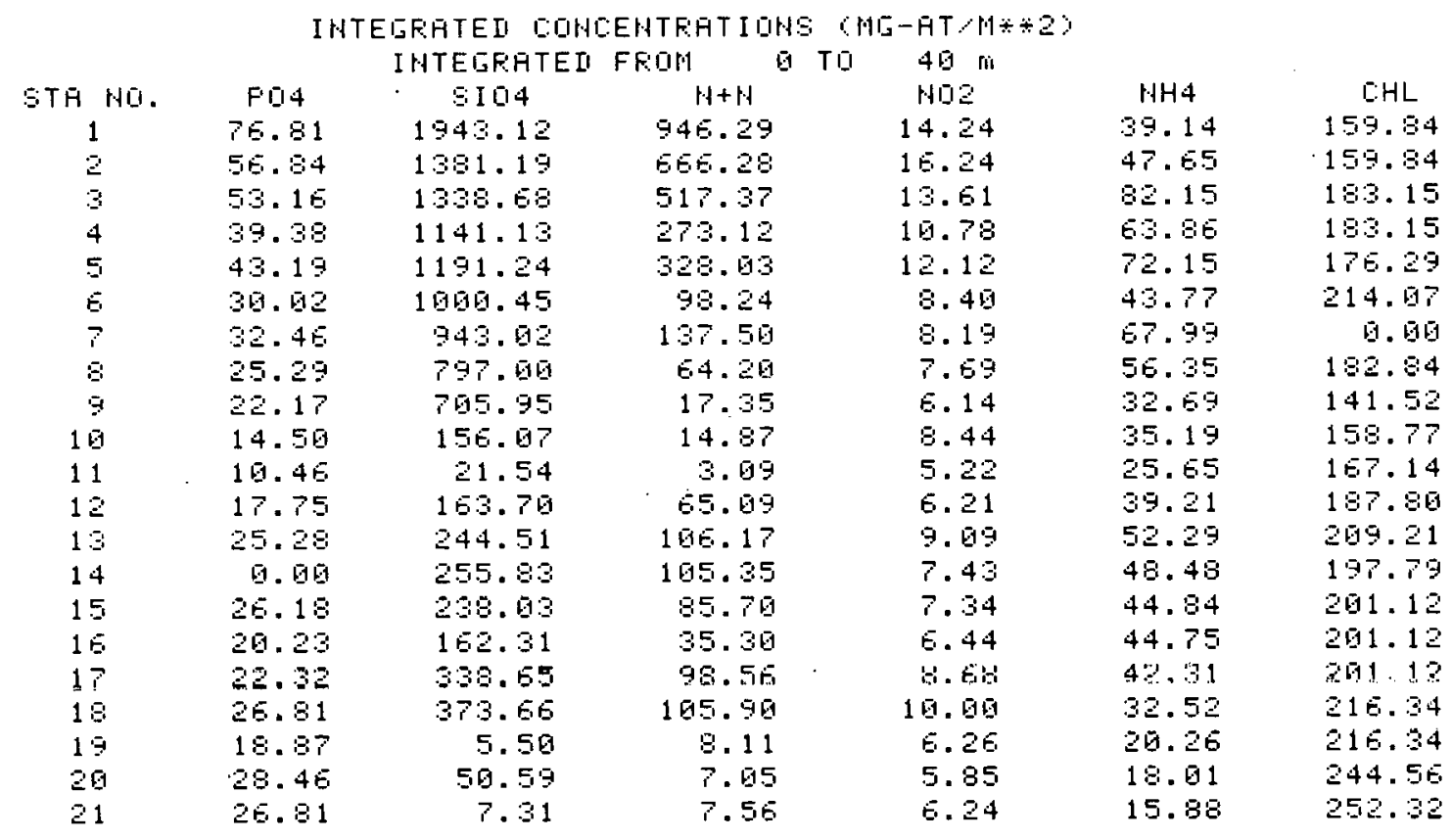

FFOEES LEG IY ETATIONE

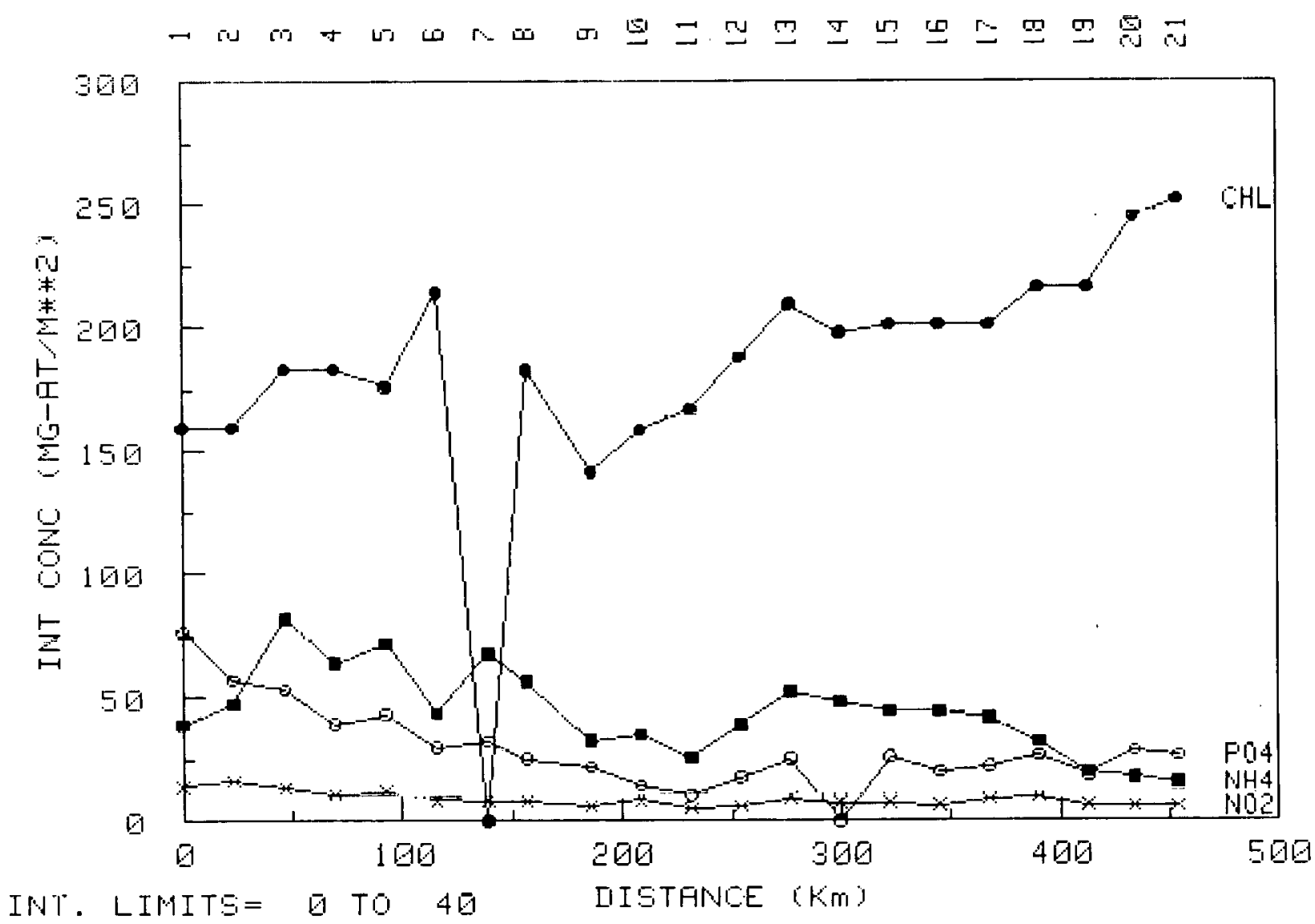




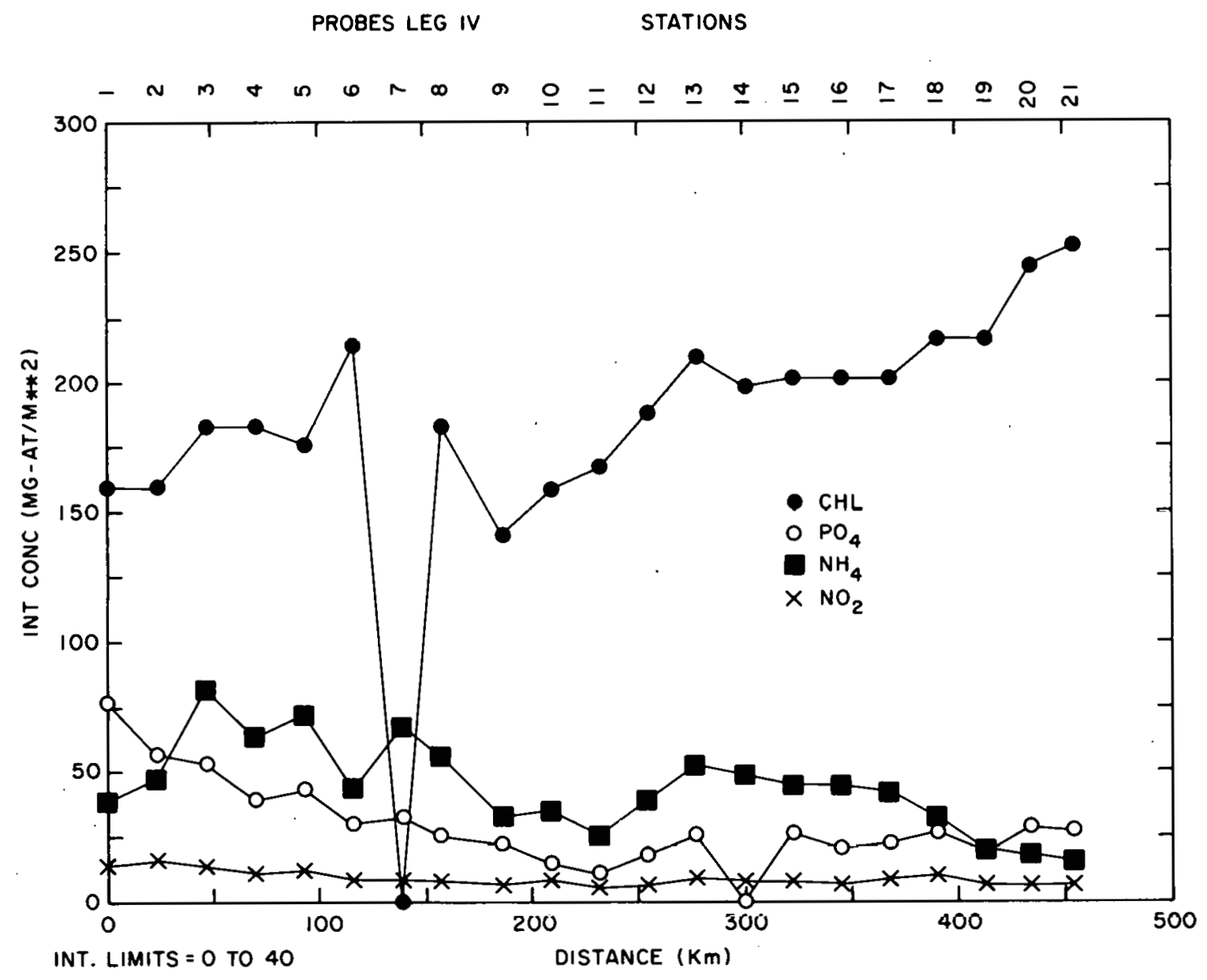




\section{COMPUTER INTERFACING AND HARDWARE MODIFICATIONS}

The task of interfacing a desktop computer to control an AutoAntlyzer can be somewhat confusing so some details of the hardware needed are given in this section. Also the hardware in only a few automated nutrient analysis systems completely satisfy all of the reasonable needs or desires of its operator. Part of the dissatisfaction is the development time required for commercial companies to incorporate the newest technological advances into their instruments. Some instrument users have special. needs which do not have a large enough market to encourage companies to alter their designs. These mismatches between products and users of ten stimulate design changes by some users which make their instruments more useful.

Computer Interfacing

The task of collecting voltage outputs from the 0 th 5 vnlt telemetry oullet on the AAII colorimeter requires an interface to the computer and an analog to digital (A to D) converter. A 16 bit parallel interface card (HP 98032A) can be purchased directly from Hewett Packard. The cable from the interface card connects to the 8 channel A to $D$ converter. The colorimeter from each nutrient channel must be connected to one of the $8 \mathrm{~A}$ to $\mathrm{D}$ ports. Since the computer also commands the sampler, the output of the digital to analog converter (DAC) is connected to the sampler. Additional details about the operation of the interface box follow.

Description of the Analog Multiplexer Interface to Computer

This interface accepts eight analog inputs within $0 . .5$ volts. All inputs are differential for a minimum of common mode noise. A HP programmable calculator model 9845 or 9825 controlls all conversion functions via a 16-bit multiplexer card $98032 \mathrm{~A}$ by executing the proper commands and codes.

In addition to the input channels one analog output is provided. This output is derived trom 8 bits, the full scale being +10V for a binary equivalent of 255. Binary zero corresponds to 0 volts output.

Function Description.

Any analog input channel is addressed (selected) sequentially or randomly by setting the binary bit pattern to the Hewlett Packard output bits D08, D09 and D010, D08 being the least significant bit.

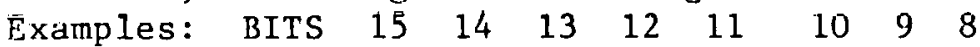

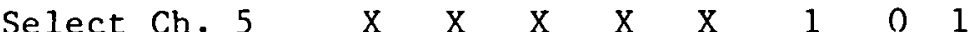

$\begin{array}{llllllllllllllllllll}\text { Select } & C h . & 7 & X & X & X & X & X & 1 & 1 & 1 & X & X & X & X & X & X & X & X\end{array}$

Note: $X$ Don't care

1 Bit true, 0 Bit false

Addressing is performed by executing an output statement, such as write, write byte and equivalent, depending on the particular I/O configuration of the calculator. The least significant 8 bits $(0 . .7)$ are used for the analog output. Thus, if the analog output voltage is to remain constant during a channel address operation, these 8 bits must be treated in a special manner:

1. Before output of the address bits:
a) "AND" the 7 1sb with " 0 "
b) "OR" the desired bit pattern for the output voltage into the 8 $1 \mathrm{sb}$.
c) Now output the word. 
2. Alternate Mode:

a) Set the bit pattern for the desired output voltage into the output variable.

b) Multiply the input address channel by 256, E.G. $3 * 256$.

c) Add this quantity to the variable in step a).

d) Now output the entire word.

Either method will yield the same results, in this manner the operator maintains full controll over input and output operations with a most efficient use of the existing $I / O$ hardware. It is recommended that the above mentioned statements be executed as subroutines that may be called when desired.

Hardware Description

The 8 input signals pass through shielded "DIN" connectors to an analog multiplexer/conversion module (analog devices mod. DAS1128). This module is programmed to accept unipolar signals from 0 to +5 volts. The conversion protocol is programmed to 12 bits straight binary yielding a resolution of 1 in 4096. The module is internally temperature compensated and contains its own precision reference voltage. After setting the three address inputs, a read statement triggers the conversion start. After the end of the conversion cycle a "FLAG" signal is returned to the $98032 \mathrm{~A}$ card, indicating a valid byte on the data line. The calculator now accepts the 12 bits and continues with program execution. Since full scale corresponds to all bits "TRUE", the input voltage is obtained by dividing the result into 4095 and multiplying it by 5 . The value is now read in volts.

F.xample: Input Binary Equivalent: 2048 $2048 * 5 / 4095$ yields 2.5 volts.

The input card is programmed such, that the input appears as negative true. The HP9845 does not recognize this hardware programming. Thus, the complement of the input has to be programmed manually. For 9825 operations, this step is unnecessary since it automatically makes the conversion.

Output Operations

A motorola DAC MC1408L-8 converts the least significant 8 output bits into a constant current, which is calibrated such, that in combination with an OP-AMP A 10 volt full scale is achieved for a binary equivalent of 255 . Calibration is obtalned through a $1 \mathrm{~K}$ triul-Put. A 741 OP-AMP converts the neg. output current into a positive voltage which can be accessed via a rear panel BNC connector. This voltage may be used for oscilloscope displays or plotters:

This interface is self-contained and requires $115 \mathrm{~V} / 60 \mathrm{~Hz}$ only. A fuse ( $1 / 2 \mathrm{amp})$ protects the circuitry. A power switch and a led power indicator are the only front panel controls.

The use of advanced modular electronic packages makes this interface extremely reliable and stable. If required, the module can easily be programmed to accept other input voltages or two uutpul different binary codes.

\section{Software}

The particular software depends on the I/O ROMS installed into the various slots of the calculator. "ROMS" may also be supplied in the form of magnetic tapes from Hewlett Packard that may be updated from time to time. Thus, 
no particular program sequence can be specified. However, the operation of the interface is straight forward and it will take only a few programming Iines once the I/O operations of the calculator are established. Please refer to the general statements within the "Functional Description". 


\begin{tabular}{|c|c|c|c|c|c|c|c|}
\hline \multirow{3}{*}{$\begin{array}{l}1 . \\
2\end{array}$} & \multicolumn{3}{|c|}{ Interface Connector Wiring } & \multicolumn{2}{|c|}{ Interface Connector } & \multirow[t]{2}{*}{ Wiring } & \multirow[t]{2}{*}{$(\operatorname{con} t)$} \\
\hline & $\mathrm{WT} / \mathrm{BK} / \mathrm{GN}$ & GND & & & & & \\
\hline & & & & 26 & $\mathrm{WT} / \mathrm{BK} / \mathrm{RD}$ & GND & \\
\hline 3 & & & & 27 & & DI15 & (GND) \\
\hline 4 & & & & 28 & & DI14 & (GND) \\
\hline 5 & & & & 29 & & DI 13 & $(\mathrm{GND})$ \\
\hline 6 & & & & 30 & & $\mathrm{DI} 12$ & (GND) \\
\hline 7 & $\mathrm{RD} / \mathrm{BK}$ & DO10 & $(20 B)$ & 31 & $\mathrm{WT} / \mathrm{BN} / \mathrm{GN}$ & DI 11 & $(29 T)$ \\
\hline 8 & $\mathrm{RD} / \mathrm{GN}$ & D09 & $(21 B)$ & 32 & $\mathrm{WT} / \mathrm{RD} / \mathrm{VI}$ & DI10 & $(29 B)$ \\
\hline 9 & $\mathrm{RD} / \mathrm{YL}$ & D08 & $(22 B)$ & 33 & $\mathrm{WT} / \mathrm{BN} / \mathrm{BU}$ & DI9 & (30T) \\
\hline 10 & WT/VI & $\mathrm{DO7}$ & (5) & 34 & $\mathrm{WT} / \mathrm{BN} / \mathrm{RD}$ & DI8 & $(30 \mathrm{~B})$ \\
\hline 11 & $\mathrm{WT} / \mathrm{BU}$ & D06 & (6) & 35 & VI & DI7 & $(31 \mathrm{~T})$ \\
\hline 12 & $\mathrm{WT} / \mathrm{GN}$ & D05 & (7) & 36 & $\mathrm{BU}$ & DI6 & $(31 B)$ \\
\hline 13 & WT/YL & DO4 & (8) & 37 & $\mathrm{GN}$ & DI5 & $(32 \mathrm{~T})$ \\
\hline 14 & WT/OR & D03 & (9) & 38 & $\mathrm{YL}$ & DI4 & $(32 B)$ \\
\hline 15 & $\mathrm{WT} / \mathrm{RD}$ & D02 & (10) & 39 & $\mathrm{OR}$ & DI3 & $(33 \mathrm{~T})$ \\
\hline 16 & WT/BN & $\mathrm{DOI}$ & (11) & 40 & $\mathrm{RD}$ & DI2 & $(33 B)$ \\
\hline 17 & WT/BK & DOO & (12) & 41 & $\mathrm{BN}$ & DIl & $(34 \mathrm{~T})$ \\
\hline 18 & WT & GND & & 42 & $\mathrm{BK}$ & DIO & $(34 B)$ \\
\hline 19 & WT / GR & PCTL & & 43 & & & \\
\hline 20 & $\mathrm{WT} / \mathrm{BK} / \mathrm{BN}$ & $\mathrm{I} / 0$ & & 44 & $\mathrm{GR}$ & PFLG & \\
\hline 21 & & & & 45 & & & \\
\hline 22 & & & & 46 & & & \\
\hline 23 & & & & 47 & & & \\
\hline 24 & $\mathrm{WT} / \mathrm{BK} / \mathrm{OR}$ & & & 48 & & . & \\
\hline 25 & & & & 49 & WR / BK/YL & GND & \\
\hline & & & & 50 & & & \\
\hline
\end{tabular}


Computer to AutoAnalyzer Sampler Interface

The 9845 computer controls the AutoAnalyzer IV sampler by a digital to analog converter channel (DAC) that was built into the 8 channel A to $D$ constructed by Interscience Instrumentation. The computer generated signal is then passed through a solid state relay which activates the 110VAC relay in the AutoAnalyzer sampler (Figure 6-1). The real-time clock in the computer is therefore used both to control the sampler and collect the digital data at the appropriate times.

The Knobelsdorff timer is used as an emergency back-up for the computer controlled sampler. This timer is programmable so it can be interfaced with the APILOT program if necessary. The emergency instructions are detailed in the APILOT program description in section 5 .

Hardware Modifications

Most of the hardware changes at our laboratory focus on the sampler. For oceanographic purposes the clinical oriented sampler has several deficiencies which can be improved.with small changes.

For AutoAnalyzer users who do not have a computer-controlled capability, one of the best low cost additions to a system is a precision electronic timer. This timer plugs directly into existing sockets on the standard AutoAnalyzer sampler IV and allows sample wash ratios to be set in a large number of combinations that are not dictated by the speed of rotation of an electric motor. The electronic timer allows wash and sample time to be set with thumb wheels in increments of 5 or 10 secs. A special rate of 10 and $20 \mathrm{sec}$ intervals can be obtained by contacting the manufacturer. This compact and easy to

use device is made by Knobelsdorff Tnstruments Inc., P.0. Box 218, Wcst Hartford, CT 06107 (phone [203] 236-1308) and can he purchased for around $\$ 300$. Log amplifiers are also sold by this vendor to linearize outputs from AAI colorimeters.

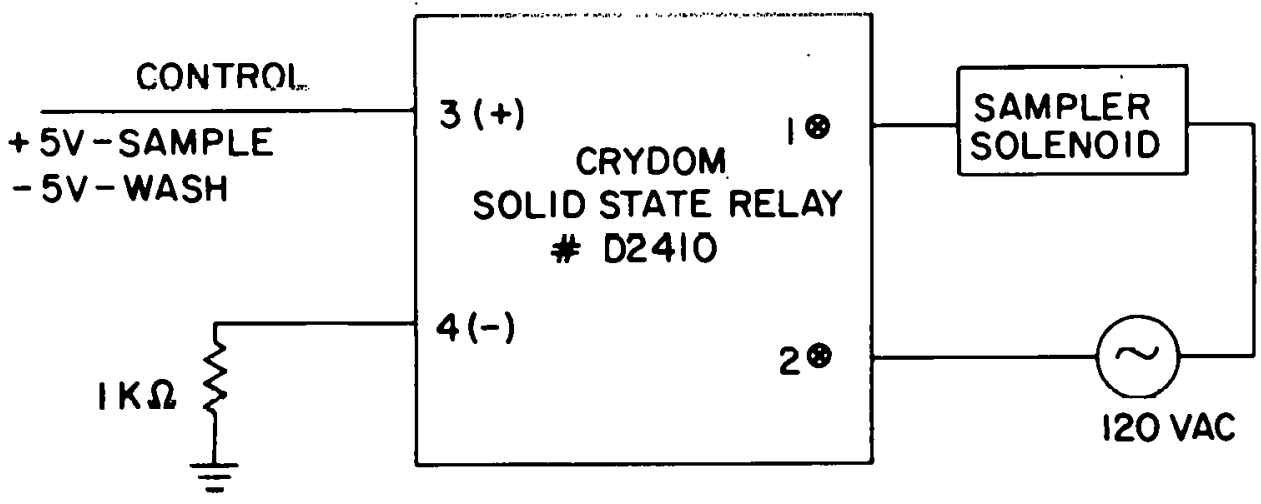

Figure 6-1. Schematic of AutoAnalyzer Sampler Controller that is Interfaced to Computer through DAC Output of the A to D Converter 


\section{Knobelsdorff Precision Sampler Timer Instructions}

\section{Sampler IV Installation}

(1) Turn the Sampler POWER "ON" and move the probe to the sampling position. Switch POWER "OFF."

(2) Open the cover to expose the TIMING MOTOR+CAM ASSEMBLY.

(3) Loosen the single screw (next to the cam) and lift the entire assembly UP and OUT of the space it occupied.

(4) Note the 9-pin jac in the right-hand corner. Plug the TIMER.

(5) Pull the TIMER CABLE through the " $U$ "-shaped cut in the cam-well cover and dress it between the bottom of the " $U$ " and wash reservoir with the cover closed (in such a way that it will not obstruct the probe entry).

(6) Now place the TIMER on top of the cover. Be sure the cable is secure and out of the path of the probe.

(7) Turn the SAMPLER POWER and TIMER POWER "ON." Set desired times and check for proper toperation. NOTE: The first cycle whether SAMPLE or WASH is not accurate - do not have a sample in the first cup.

\section{OPERATION}

1. Setting SAMPLE and WASH cycles - select a desired sampling rate and ratio from Table 6-1 or 6-2. Set the INTERVAL switch to either $x 10$ or x20 seconds and the SAMPLE and WASH switches to any desired digit.

Example: should a $40 / \mathrm{hr}$ sampling rate and a $2: 7$ sample wash be desired, use the settings shown in Table 6-1 as follows:

INTERVAL SWITCH to $x 10$ seconds SAMPLE INCREMENT $=2(\times 10=20$ secs $)$

WASH INCREMENT $=7(x 10=70$ secs $)$

2. START-UP - turn the SAMPLER POWER "ON" then the TIMER "ON."

NOTE: When first starting the TIMER after a period of inactivity, it may require a short period (1-60 seconds) to reset its logic circuits. It may remain in its INITIAL CYCLE (whichever it goes into) for this period before it begins to cycle normally. It is a good idea therefore not to turn the SAMPLER POWER "ON" until the TIMER has gone into its SECOND WASH CYCLE. 
TABLE 6-1

SAMPLING RATES AND RATIOS

for 10 second intervals

\begin{tabular}{|c|c|c|c|c|c|c|c|c|c|}
\hline $\begin{array}{l}\text { Sample } \\
\text { increment } \\
\text { Eettings }\end{array}$ & $\begin{array}{l}{[1]} \\
10 "\end{array}$ & $\begin{array}{l}{[2]} \\
20^{\prime \prime}\end{array}$ & $\begin{array}{l}{[3]} \\
30^{\prime \prime}\end{array}$ & $\begin{array}{c}\text { ash Inc } \\
{[4]} \\
10^{\circ}\end{array}$ & $\begin{array}{c}\text { cement } \\
{[5]} \\
50 "\end{array}$ & $\begin{array}{c}\text { Setting } \\
{[6]} \\
60^{\prime \prime}\end{array}$ & $\begin{array}{l}{[7]} \\
70 "\end{array}$ & $\begin{array}{l}{[8]} \\
80^{\prime \prime}\end{array}$ & $\begin{array}{l}{[9]} \\
90 "\end{array}$ \\
\hline $\begin{array}{l}111 \\
10^{\prime \prime}\end{array}$ & $\begin{array}{c}+80 \\
(1: 1)\end{array}$ & $\begin{array}{c}1: 0 \\
(1: 3)\end{array}$ & $\begin{array}{c}y 0 \\
(1: 3)\end{array}$ & $\begin{array}{c}12 \\
(1: 1)\end{array}$ & $\begin{array}{c}6 y \\
(1: 5)\end{array}$ & $\begin{array}{c}31 \\
(1: 6)\end{array}$ & $\begin{array}{c}13 \\
(1,7)\end{array}$ & $\begin{array}{c}10 \\
(1,8)\end{array}$ & $\begin{array}{c}36 \\
(1,9)\end{array}$ \\
\hline $\begin{array}{l}{[2]} \\
20 "\end{array}$ & $\begin{array}{c}120 \\
(2: 1)\end{array}$ & $\begin{array}{c}90 \\
(1: 1)\end{array}$ & $\begin{array}{c}72 \\
(2: 3)\end{array}$ & $\begin{array}{c}60 \\
(1: 2)\end{array}$ & $\begin{array}{c}51 \\
(2: 5)\end{array}$ & $\begin{array}{c}45 \\
(1: 3)\end{array}$ & $\begin{array}{c}40 \\
(2: 7)\end{array}$ & $\begin{array}{c}36 \\
(1: 4)\end{array}$ & $\begin{array}{c}33 \\
(2: 9)\end{array}$ \\
\hline $\begin{array}{l}{[3]} \\
30^{\circ}\end{array}$ & $\begin{array}{c}90 \\
(3: 1)\end{array}$ & $\begin{array}{c}72 \\
(3: 2)\end{array}$ & $\begin{array}{c}60 \\
(1: 1)\end{array}$ & $\begin{array}{c}51 \\
(3: 4)\end{array}$ & $\begin{array}{c}45 \\
(3: 5)\end{array}$ & $\begin{array}{c}40 \\
(1: 2)\end{array}$ & $\begin{array}{c}36 \\
(3: 7)\end{array}$ & $\begin{array}{c}33 \\
(3: 8)\end{array}$ & $\begin{array}{c}30 \\
(1: 3)\end{array}$ \\
\hline $\begin{array}{l}{[4]} \\
40^{\circ}\end{array}$ & $\begin{array}{c}72 \\
(4: 1)\end{array}$ & $\begin{array}{c}60 \\
(2: 1)\end{array}$ & $\begin{array}{c}51 \\
(4: 3)\end{array}$ & $\begin{array}{c}45 \\
(1: 1)\end{array}$ & $\begin{array}{c}40 \\
(4: 5)\end{array}$ & $\begin{array}{c}36 \\
(2: 3)\end{array}$ & $\begin{array}{c}33 \\
(4: 7)\end{array}$ & $\begin{array}{c}30 \\
(1: 2)\end{array}$ & $\begin{array}{c}28 \\
(4: 9)\end{array}$ \\
\hline $\begin{array}{l}{[5]} \\
50^{\prime \prime}\end{array}$ & $\begin{array}{c}60 \\
(5: 1)\end{array}$ & $\begin{array}{c}51 \\
(5: 2)\end{array}$ & $\begin{array}{c}45 \\
(5: 3)\end{array}$ & $\begin{array}{c}40 \\
(5: 4)\end{array}$ & $\begin{array}{c}36 \\
(1: 1)\end{array}$ & $\begin{array}{c}33 \\
(5: 6)\end{array}$ & $\begin{array}{c}30 \\
(5: 7)\end{array}$ & $\begin{array}{c}28 \\
(5: 8)\end{array}$ & $\begin{array}{c}26 \\
(5: 9)\end{array}$ \\
\hline $\begin{array}{l}{[G]} \\
60 "\end{array}$ & $\begin{array}{c}51 \\
(6: 1)\end{array}$ & $\begin{array}{c}45 \\
(3: 2)\end{array}$ & $\begin{array}{c}40 \\
(2: 1)\end{array}$ & $\begin{array}{c}36 \\
(3: 2)\end{array}$ & $\begin{array}{c}33 \\
(6: 5)\end{array}$ & $\begin{array}{c}30 \\
(1: 1)\end{array}$ & $\begin{array}{c}28 \\
(6: 7)\end{array}$ & $\begin{array}{c}20 \\
(3: 4)\end{array}$ & $\begin{array}{c}24 \\
(2: 3)\end{array}$ \\
\hline $\begin{array}{l}111 \\
70 "\end{array}$ & $\begin{array}{c}45 \\
(7: 1)\end{array}$ & $\begin{array}{c}40 \\
(7: 2)\end{array}$ & $\begin{array}{c}36 \\
(7: 3)\end{array}$ & $\begin{array}{c}33 \\
(7: 4)\end{array}$ & $\begin{array}{c}30 \\
(7: 5)\end{array}$ & $\begin{array}{c}28 \\
(7: 6)\end{array}$ & $\begin{array}{c}26 \\
(1: 1)\end{array}$ & $\begin{array}{c}24 \\
(7: 8)\end{array}$ & $\begin{array}{c}22 \\
(7: 9)\end{array}$ \\
\hline${ }_{80}^{[8]}$ & $\begin{array}{c}40 \\
(8: i)\end{array}$ & $\begin{array}{c}36 \\
(4: i)\end{array}$ & $\begin{array}{c}33 \\
(8: 3)\end{array}$ & $\begin{array}{c}30 \\
(2: i)\end{array}$ & $\begin{array}{c}28 \\
(8: 5) 1\end{array}$ & $\begin{array}{c}26 \\
(4: 3)\end{array}$ & $\begin{array}{c}24 \\
(8 \div 7)\end{array}$ & $\begin{array}{c}22 \\
(1 \div 1)\end{array}$ & $\begin{array}{c}21 \\
(8 \div y)\end{array}$ \\
\hline $\begin{array}{l}{[9]} \\
90 "\end{array}$ & $\begin{array}{c}36 \\
(9: 1)\end{array}$ & $\begin{array}{c}33 \\
(9: 2)\end{array}$ & $\begin{array}{c}30 \\
(3: 1)\end{array}$ & $\begin{array}{c}28 \\
(9: 4)\end{array}$ & $\begin{array}{c}26 \\
(9: 5)\end{array}$ & $\begin{array}{c}24 \\
(3: 2)\end{array}$ & $\begin{array}{c}22 \\
(9: 7)\end{array}$ & $\begin{array}{c}21 \\
(9: 8)\end{array}$ & $\begin{array}{c}20 \\
(1: 1)\end{array}$ \\
\hline
\end{tabular}

The bold numbers represent sampling rates per hour and the numbers in parentheses represent the SAMPLE:WASH ratios. 
TABLE 6-2

SAMPLING RATES AND RATIOS

for 20 second intervals

\begin{tabular}{|c|c|c|c|c|c|c|c|c|c|}
\hline $\begin{array}{l}\text { Sample } \\
\text { increment } \\
\text { settings }\end{array}$ & $\begin{array}{l}{[1]} \\
20^{\prime \prime}\end{array}$ & $\begin{array}{l}{[2]} \\
40 "\end{array}$ & $\begin{array}{l}{[3]} \\
60 "\end{array}$ & $\begin{array}{c}\text { ash Inc } \\
{[4]} \\
80^{\prime \prime}\end{array}$ & $\begin{array}{c}\text { cement } \\
{[5]} \\
100 "\end{array}$ & $\begin{array}{c}\text { Setting } \\
{[6]} \\
120 "\end{array}$ & $\begin{array}{r}{[7]} \\
140 "\end{array}$ & $\begin{array}{r}{[8]} \\
160 "\end{array}$ & $\begin{array}{r}{[9]} \\
180^{\circ}\end{array}$ \\
\hline $\begin{array}{l}{[1]} \\
20^{\prime \prime}\end{array}$ & $\begin{array}{c}90 \\
(1: 1)\end{array}$ & $\begin{array}{c}60 \\
(1: 2)\end{array}$ & $\begin{array}{c}45 \\
(1: 3)\end{array}$ & $\begin{array}{c}36 \\
(1: 4)\end{array}$ & $\begin{array}{c}30 \\
(1: 5)\end{array}$ & $\begin{array}{c}26 \\
(1: 6)\end{array}$ & $\begin{array}{c}22 \\
(1: 7)\end{array}$ & $\begin{array}{c}20 \\
(1: 8)\end{array}$ & $\begin{array}{c}18 \\
(1: 9)\end{array}$ \\
\hline $\begin{array}{l}{[2]} \\
40^{\prime \prime}\end{array}$ & $\begin{array}{c}60 \\
(2: 1)\end{array}$ & $\begin{array}{c}45 \\
(1: 1)\end{array}$ & $\begin{array}{c}36 \\
(2: 3)\end{array}$ & $\begin{array}{c}30 \\
(1: 2)\end{array}$ & $\begin{array}{c}26 \\
(2: 5)\end{array}$ & $\begin{array}{c}22 \\
(1: 3)\end{array}$ & $\begin{array}{c}20 \\
(2: 7)\end{array}$ & $\begin{array}{c}18 \\
(1: 4)\end{array}$ & $\begin{array}{c}16 \\
(2: 9)\end{array}$ \\
\hline $\begin{array}{l}{[3]} \\
60 "\end{array}$ & $\begin{array}{c}45 \\
(3: 1)\end{array}$ & $\begin{array}{c}36 \\
(3: 2)\end{array}$ & $\begin{array}{c}30 \\
(1: 1)\end{array}$ & $\begin{array}{c}26 \\
(3: 4)\end{array}$ & $\begin{array}{c}22 \\
(3: 5)\end{array}$ & $\begin{array}{c}20 \\
(1: 2)\end{array}$ & $\begin{array}{c}18 \\
(3: 7)\end{array}$ & $\begin{array}{c}16 \\
(3: 8)\end{array}$ & $\begin{array}{c}15 \\
(1: 3)\end{array}$ \\
\hline $\begin{array}{l}{[4]} \\
80 "\end{array}$ & $\begin{array}{c}36 \\
(4: 1)\end{array}$ & $\begin{array}{c}30 \\
(2: 1)\end{array}$ & $\begin{array}{c}26 \\
(4: 3)\end{array}$ & $\begin{array}{c}22 \\
(1: 1)\end{array}$ & $\begin{array}{c}20 \\
(4: 5)\end{array}$ & $\begin{array}{c}18 \\
(2: 3)\end{array}$ & $\begin{array}{c}16 \\
(4: 7)\end{array}$ & $\begin{array}{c}15 \\
(1: 2)\end{array}$ & $\begin{array}{c}14 \\
(4: 9)\end{array}$ \\
\hline $\begin{array}{r}{[5]} \\
100 "\end{array}$ & $\begin{array}{c}30 \\
(5: 1)\end{array}$ & $\begin{array}{c}26 \\
(5: 2)\end{array}$ & $\begin{array}{c}22 \\
(5: 3)\end{array}$ & $\begin{array}{c}20 \\
(5: 4)\end{array}$ & $\begin{array}{c}18 \\
(1: 1)\end{array}$ & $\begin{array}{c}16 \\
(5: 6)\end{array}$ & $\begin{array}{c}15 \\
(5: 7)\end{array}$ & $\begin{array}{c}14 \\
(5: 8)\end{array}$ & $\begin{array}{c}13 \\
(5: 9)\end{array}$ \\
\hline $\begin{array}{r}{[6]} \\
120^{\prime \prime} .\end{array}$ & $\begin{array}{c}26 \\
(6: 1)\end{array}$ & $\begin{array}{c}22 \\
(3: 2)\end{array}$ & $\begin{array}{c}20 \\
(2: 1)\end{array}$ & $\begin{array}{c}18 \\
(3: 2)\end{array}$ & $\begin{array}{c}16 \\
(6: 5)\end{array}$ & $\begin{array}{c}15 \\
(1: 1)\end{array}$ & $\begin{array}{c}14 \\
(6: 7)\end{array}$ & $\begin{array}{c}13 \\
(3: 4)\end{array}$ & $\begin{array}{c}12 \\
(1: 3)\end{array}$ \\
\hline $\begin{array}{r}{[7]} \\
140 "\end{array}$ & $\begin{array}{c}22 \\
(7: 1)\end{array}$ & $\begin{array}{c}20 \\
(7: 2)\end{array}$ & $\begin{array}{c}18 \\
(7: 3)\end{array}$ & $\begin{array}{c}16 \\
(7: 4)\end{array}$ & $\begin{array}{c}15 \\
(7: 5)\end{array}$ & $\begin{array}{c}14 \\
(7: 6)\end{array}$ & $\begin{array}{c}13 \\
(1: 1)\end{array}$ & $\begin{array}{c}12 \\
(7: 8)\end{array}$ & $\begin{array}{c}11 \\
(7: 9)\end{array}$ \\
\hline $\begin{array}{r}{[8]} \\
160^{\prime \prime}\end{array}$ & $\begin{array}{c}20 \\
(8: 1)\end{array}$ & $\begin{array}{c}18 \\
(4: 1)\end{array}$ & $\begin{array}{c}16 \\
(8: 3)\end{array}$ & $\begin{array}{c}15 \\
(2: 1)\end{array}$ & $\begin{array}{c}14 \\
(8: 5) 1\end{array}$ & $\begin{array}{c}13 \\
(4: 3)\end{array}$ & $\begin{array}{c}12 \\
(8: 7)\end{array}$ & $\begin{array}{c}11 \\
(1: 1)\end{array}$ & $\begin{array}{c}11 \\
(8: 9)\end{array}$ \\
\hline $\begin{array}{r}{[9]} \\
180^{\circ}\end{array}$ & $\begin{array}{c}18 \\
(9: 1)\end{array}$ & $\begin{array}{c}16 \\
(9: 2)\end{array}$ & $\begin{array}{c}15 \\
(3: 1)\end{array}$ & $\begin{array}{c}14 \\
(9: 4)\end{array}$ & $\begin{array}{c}13 \\
(9: 5)\end{array}$ & $\begin{array}{c}12 \\
(3: 2)\end{array}$ & $\begin{array}{c}11 \\
(9: 7)\end{array}$ & $\begin{array}{c}11 \\
(9: 8)\end{array}$ & $\begin{array}{c}10 \\
(1: 1)\end{array}$ \\
\hline
\end{tabular}

The numbers above the parentheses represent sampling rates per hour and those in the parentheses represent the SAMPLE:WASH ratios. 


\section{CONTROLS}

ON/OFF (POWER) This (red-capped) toggle switch controls the TIMER power. When in the "OFF" position, the TIMER is deactivated and the SAMPLER PROBE will be allowed to be in the wash reservoir.

$x 10 s / x 20 s$

(INTERVALS) This (white-capped) toggle switch allows the selection of either 10 or 20 second intervals for the WASH and SAMPLE cycles simultaneously.

SAMPLE/WASH (INCREMENTS)

The two independent thumbwheel switches allow the independent selection of the duration of the SAMPLE and WASH cycles.

[Example: with the INTERVAL switch at $x 10$ and the SAMPLE and WASH switches at 3 and 5 iespeclively, Lhe SAMPLING TIME would be (3x10) or 30 acconda and the WASIl TTMT: (5x10) or 50 seconds respectively.]

RED/GREEN (LEDs) Either one or the other must be lit when the TIMER is in operation "ON." The RED LED, when lit indicates that the TIMER is in its SAMPLE cycle, whereas the GREEN LED indicates the WASH period.

ELECTRICAL REQUIREMENTS: $0.5 \mathrm{~A}$ at $115 \mathrm{~V}, 60 \mathrm{~Hz}$

FEATURES: TIMING ACCURACY better than $99.99 \%$ TIMING PRECISION better than $99.99 \%$

SERIAL No. 97 (Mode1 IV-10/20)

Conversion of AutoAnalyzer Sampler IV for 2 oz. Poly Bottles

Another significant change in the sampler is ability to analyze samples directly from sample collection bottles rather than the small sample cups. The volume difterence between sample bottles and cups is not a big argument for owitching; but if ammonium io dctcrmincd many contamination problcms arc reduced. The changes that we made to the sampler will allow the small sample cups to still be used, if só deslred, whilè $\dot{z}$ oz. nàigené samplè bott lés arè normally used to collect, analyze, and freeze the samples. The sample bottles can be clearly numbered so fewer mixups concerning sample numbers occur. The two items changed in the sampler is the cam which rotates the sample tray (Figure 6-2). The original plastic cam was replaced by a brass cam which was constructed to rotate the sample tray exactly twice as far as the original. The new sample tray constructed from plexiglass (Figure 6-3) holds 20 of the nalgene sample bottles (Fischer no. 2-923B, Nalgene no. 2002). If the orlginal tray and small cups are used, the cups are placed in every other hole.

\section{Scale Expander}

Another possible modification involves the addition of scale expanders which will catch peaks that would otherwise go offscale. The description and diagram to produce scale expanders, sent to me by colleagues at the Sandy Hook Laboratory of NMFS, are included as I received them. The scale expander circuit effectively doubles the range of the chart, allowing concentrations up to 


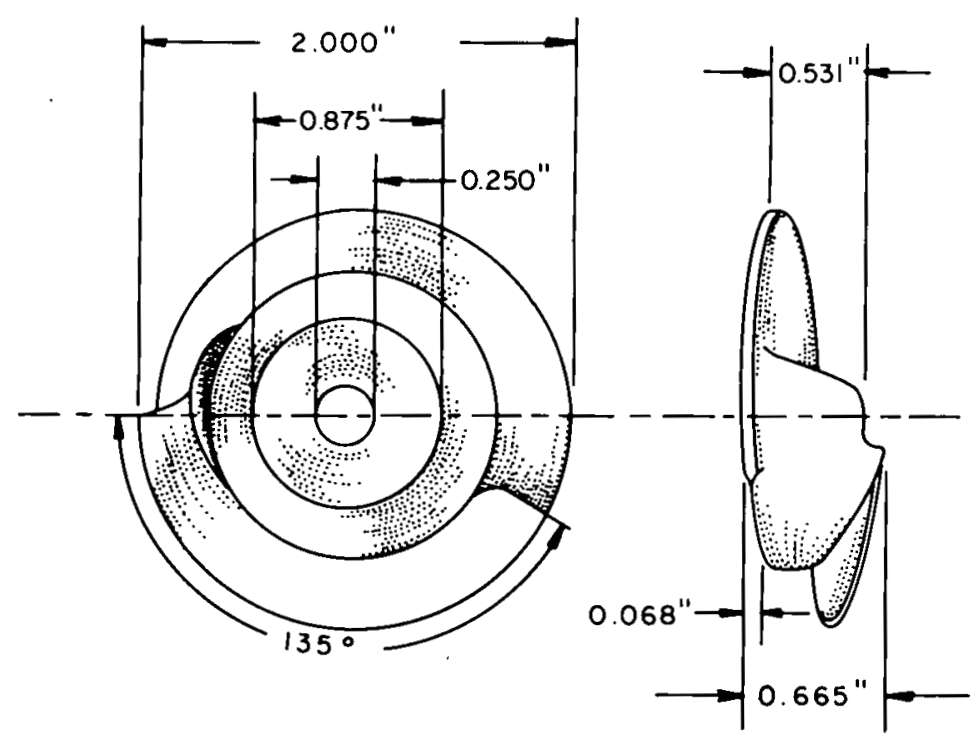

Figure 6-2. Brass Cam for AutoAnalyzer Sampler Modification for 2 oz. Polyethylene Sample Bottles

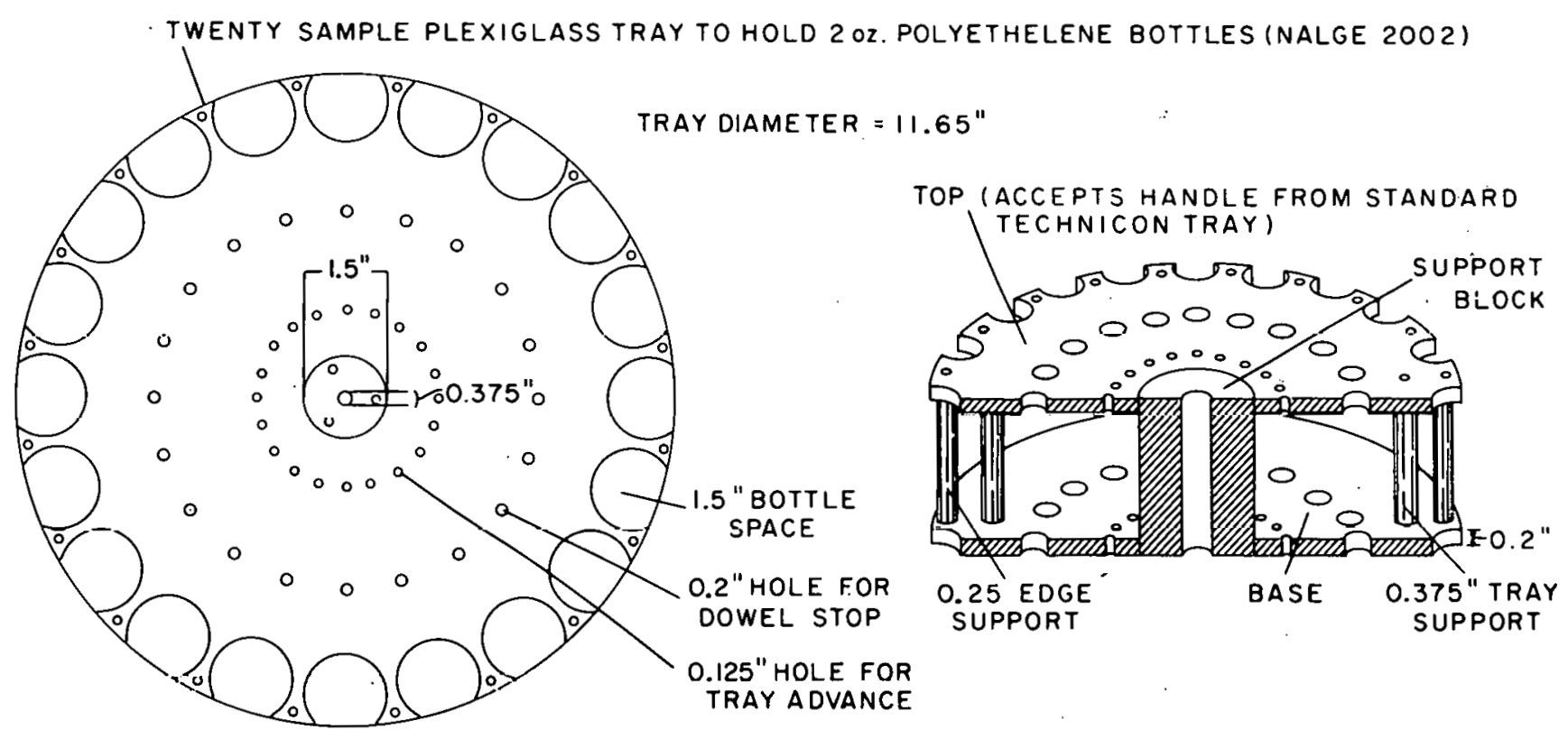

Figure 6-3. Plexiglass Sample Tray for AutoAnalyzer Sampler Modification for 2 oz. Polyethylene Sample Bottles 
two times the standard to be accommodated. If a peak appears to be going of $f$ chart, this circult will decrease the peak size in order to get the total peak height. The circuit is activated through a manual switch (Figure 6-4). The switches (one for each channel) are set up as follows:
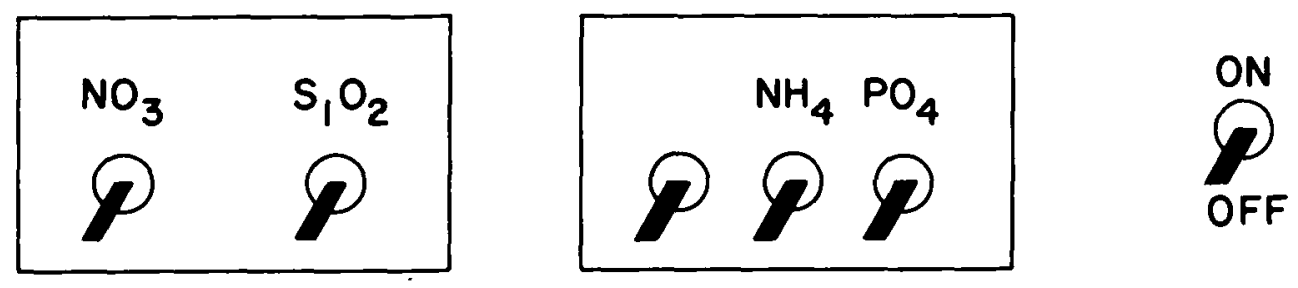

Eigure 6-4. Control Buxes for Scale Expanders

The unmarked switch can be flipped up at the beginning of the run and will "bleep" when a pen reaches contact installed near the top of the chart. The "bleeper" is for operator notification, and need not be used to operate the scale expander control.

Operation is straightforward:

(1) When the "bleep" sounds, flip the appropriate channel switch up. This will cause the pen to drop down to approximately $10 \%$ of the peak height and allows continuation of the peak (callbration is described below).

(2) When the peak has been recorded, the pen will move back down the chart. At this point the switch may be flipped back down.

(3) The actual number of chart divisions "cancelled" in this operation is obtained through calibration (see below). This number is added to the observed peak height to get the total peak height. The srale expander is effective, of course, only if the peak does not go of $f$ the chart.

A wiring diagram for the scale expander circult is given in Figure 6-5.

\section{Scale Expander Calibration}

(1) Set colorimeter on 'zero,' adjust pen to zero with helipot zero control.

(2) Set the recorder setting knob on the colorimeter to full scale (adjust pen to 100 with hellpot).

(3) Turn the chart drive on to establish a small releituce line.

(4) Turin on the 3ealc cupander owitoh, the pen will deflert trim the chart paper to around 10; if you wish the calibration to be exactly 90, you may adjust with the helipot located on the scale expander control box.

(5) Establish another small reference line, and note the exact deflection for use in calculations.

(6) Turn gain control switch off, turn chart drive off and reset recorder to its operational setting.

(7) The distance in chart unfts from the full scale point to where the pen drops is the calibration number. Add this to the observed sample peak height. 


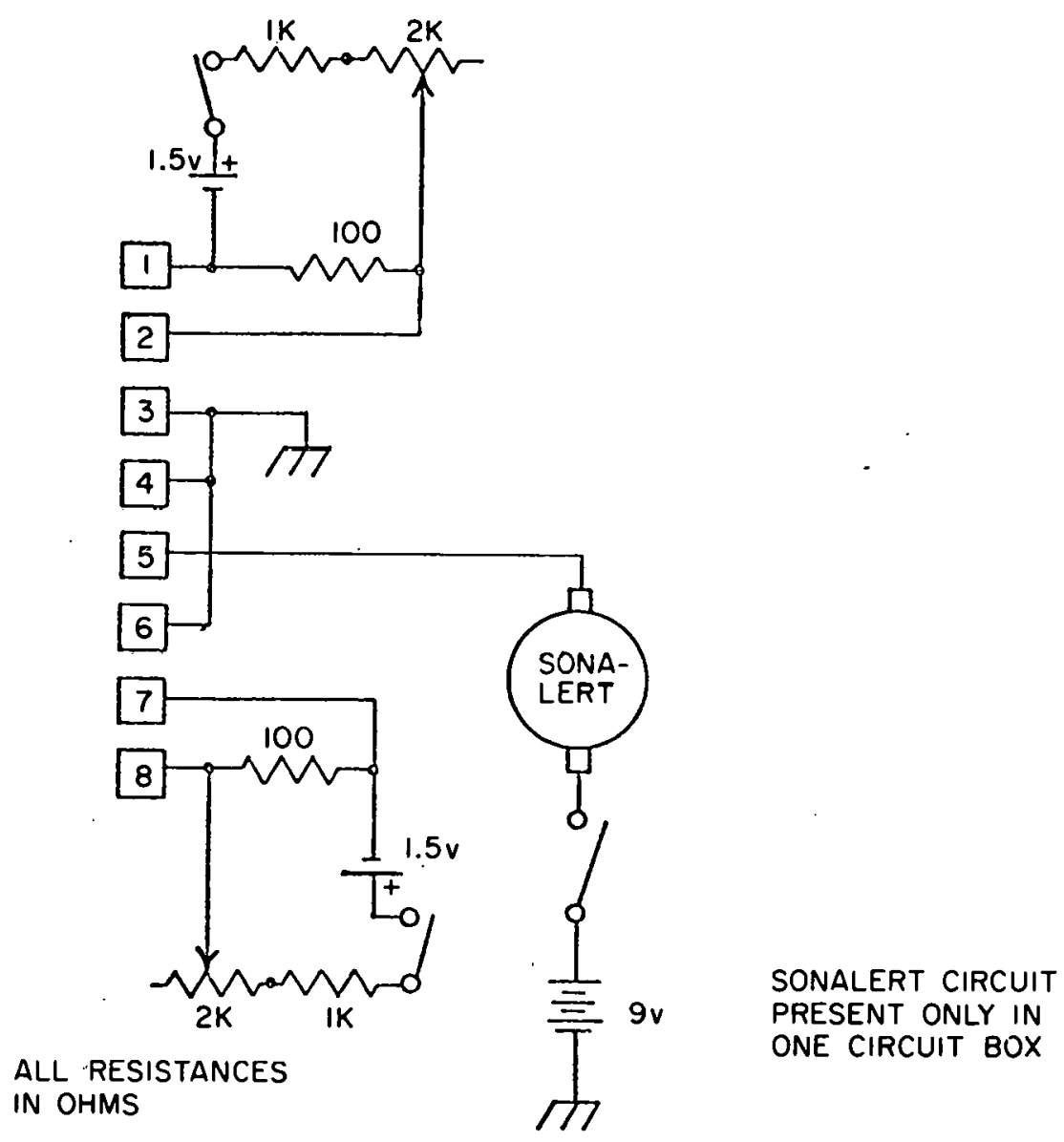

Figure 6-5. Scale Expander Wiring Diagram 


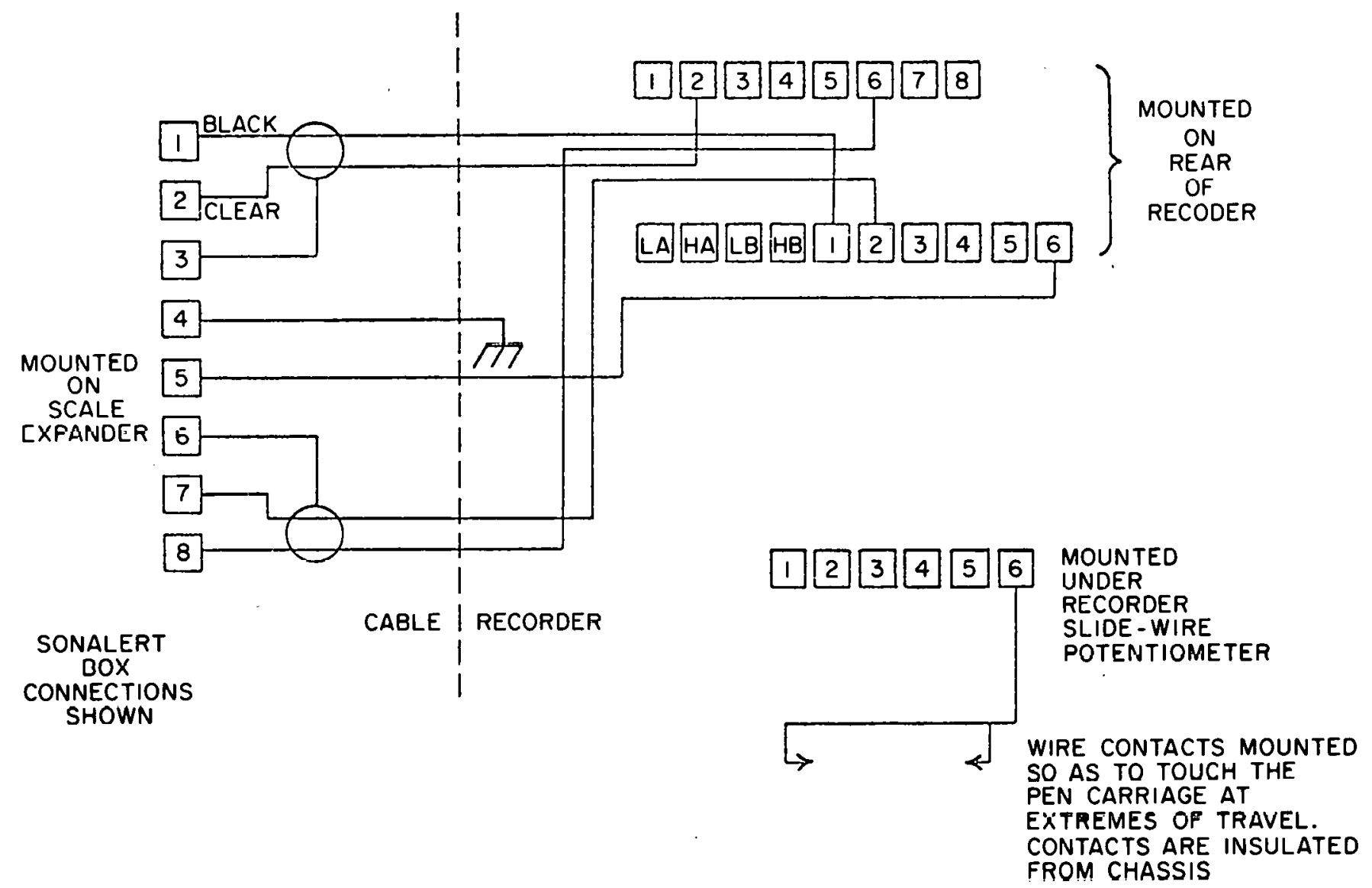

Figure 6-5 (continued). Scale Expander Wiring Diagram

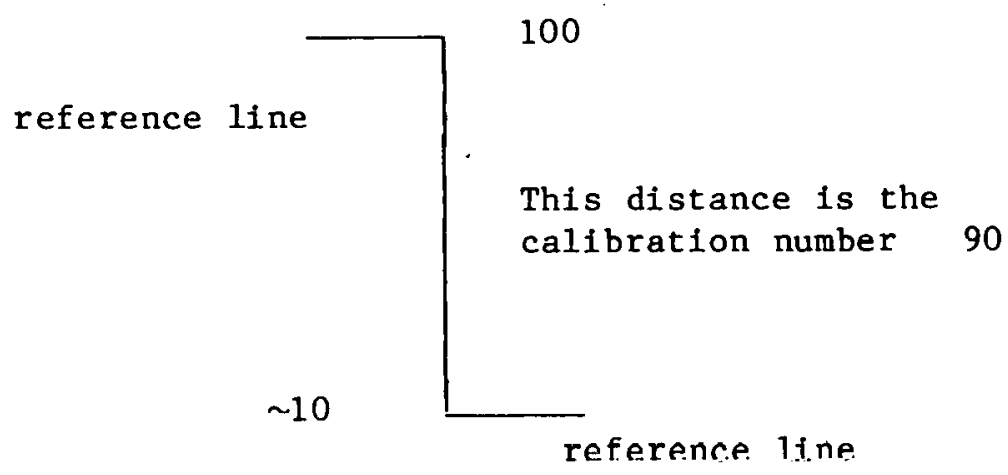




\section{TROUBLE SHOOTING}

Fach continuous flow system has its own unique set of problems which are the result of the manifold configuration; flow rate, flow cell size, glass and pump tube diameter, reaction chemicals, and other variables. After several years of development and operation, we have narrowed down the number of persistent problems to a few. With the present system, only routine maintenance and adherence to the steps below will ensure optimum machine performance.

\section{Ammoni un}

In our experience, the ammonium channel is subject to periodic fluctuations. A good portion of this instability is the result of flow problems in the heating bath assembly. In the most troublesome cases, a persistent irregular bubble pattern is observed as the flow stream emerges from the bath. We are successful in stabilizing and smoothing the flow by one or a combination of the following steps.

1. Add more Brij-35 to the dilution complex. Up to $2-3 \mathrm{ml} / \ell$ have been used without adversely affecting the sensitivity or color development.

2. Make new reagents especially the dilution complex, reagent $A$ and reagent $B$.

3. Change the pump tube for the dilution complex and reagents $A$ and $B$. The $\mathrm{pH}$ and the ratio of the reagents must be very precise or the method will not work properly. The reagents used for the ammonium determination cause a rapid decline in the pumping rate of the pump tubes, so change them of ten to stay out of trouble.

4. Increase the reaction temperature to $75-80^{\circ} \mathrm{C}$. No 10 s of sensitivity has been observed at this temperature range.

5. Flush the coil. Regular and direct flushing of the heating bath coil with a $5 \mathrm{ml}$ syringe filled with $70 \% \mathrm{HCl}$ is recomnended for every 4-6 hours of operation. This treatment not only improves the flow but cleans the flow cell and makes for cleaner peaks.

6. Replace the old heating bath coil. The ammonium reagents are apparently very hard on the bath coll either by chemical action or direct deposition of stubborn precipitates. The old coil should be replaced if the ammonium channel has been used heavily during its last year of operation and if none of the previous steps provides remedy.

Poor flow is also experienced in the flow cell. Typically, air bubbles are sucked into the flow cell because of retarded movement of the stream across the tygon bridge joining the flow cell proper and the flow cell extension (199-0084-01). This piece of tygon should be replaced as the ammonium reaction products coat the tubing and make it "sticky." Clean the inside diameter of the new bridge with a "Q-tip" dipped in Brij-35. In addition, if the waste 11 ne is old and coated, the waste air sample stream will back up and force air into the flow cell. Clean and replace this line as described. Should the flow cell continue to suck air bubbles after all of the above conditions have been satisfled, it will be necessary to try different tube combinations on the waste and pull through lines. 
Phosphate and Silicate

Problems associated with the phosphate heating bath or flow cell should be tackled using the procedures outlined for the ammonium channel. However, sodium launyl sulfate should be used for lubricating new tubing. After continuous operation, a positive baseline drift and noisy peaks are indicative of flow cell and/or reagent line coating with ammonium molybdate. Flush the channel with $0.1 \mathrm{~N} \mathrm{KOH}$ or $\mathrm{NaOH}$. Similarly, the silicate molybdate line should be washed if the baseline is drifting upward or when a white precipitate is observed in the injector fitting (116-0489-01).

Nitrate plus Nitrite, Nitrite

As the first step in the operation of the nitrate plus nitrite channel put the ammonium chloride reagent on line first. After ammonium chloride has llowed through the manffold for a few minutes, open the 4-way Hamilton valve to allow its passage through the $\mathrm{Cu}-\mathrm{Cd}$ column. Failure to run $\mathrm{NH}_{4} \mathrm{Cl}$ through the system first may result in the accidental destruction of the column with wash $\mathrm{HCl}$.

The apparent loss of sensitivity of the nitrate plus nitrite may be caused by several factors.

1. Deterioration of the standards. Nitrate standards are subject to rapid biological breakdown if not preserved with chloroform and refrigerated. If the primary stock is suspect, discard it. Secondary standards should be prepared fresh daily.

2. Drop in cadmium column efficiency. Continuous analyses on the channel will gradually diminish the level of cadmium in the column. Replenish the column as explained in Repacking the Column. If the cadmium itself is suspect, treat it again with $2 \%$ copper sulfate.

3. Pump tube plugging. Both nitrate plus nitrite and nitrite channels are subject to line constriction by reagent blockage. The NNED reagent will coat the pump tube turning it orange-brown and restrict the flow. Change this tubing periodically. In addition, the acidic sulfanilamide will corrode the metal nipple of the stream divider sending particles in the flow stream. Eventually this fitting will be eaten through. Check the sulfanilamide stream divider for leaks and weaknesses and replace if necessary. 


\section{Appendix A - References of Additional Reading}

Adamski, J. M., 1976. Slmplified Kjeldahl nitrogen determination for seawater by a semiautomated persulfate digestion method. Anal. Chem. 48:1194-1197.

Afghan, B.K. and J.F. Ryan, 1965. A modified procedure for the determination of nitrate in sediments and natural waters. Environmental Letters 9: $59-73$.

Amador, E., 1972. Polyethylene colls for continuous-flow analyzers. Clin. Chem., 18:164.

Ambe, M., J. Kaj1wara, T. Yoshihara and K. Sugawara, 1975. Preparation of the standard solutions of nitrate and their application to seawater and freshwater. J. Ocean. Soc. Jap., 31:85-92.

Armstrong, F. A. J., 1951. The determination of silicate in seawater, J. Mar. biol. Ass. U.K., 30: 149 .

Armstrong, F. A. J., 1965. The determination of phosphorus in seawater. Oceanogr. Mar. Bio. Ann. Rev. 3:79-93.

Armstrong, F. A. J., P. M. Williams, and J. D. H. Strickland, 1966. Photo-oxidation of organic matter in sea water by ultra-violet radiation, analytical and other applications. Nature, 211:481-483.

Armstrong, F.A.J. and E. C. LaFond, 1966. Chemical nutrient concentrations and their relationship to internal waves and turbidity off southern California. Limnol. Oceanogr., 11:538-547.

Armstrong, F. A. J., C. R. Stearns, and J. D. H. Strickland, 1967. The measurement of upwelling and subsequent biological processes by means of the Technicon AutoAnalyzer and associated equipment. Deep-Sea Res., $14: 381-389$.

Armstrong, F. A. J. and S. T1bbits, 1968. Photochemical combustion of organic matter in seawater, for nitrogen, phosphorus and carbon determinations. J. Mar. biol. Ass. U. K., 48:143.

Atlas, E. L., S. W. Hager, L. I. Gordon, and P. K. Park, 1971. A practical manual for the use of the Technicon AutoAnalyzer in seawater nutrient analyses; revised, Technfcal Report 215, Dept. of Oceanogr., Oregon State Univ., Corvallis, $55 \mathrm{pp}$.

Atwood, D. K., T. E. Whitledge, J. H. Sharp, A. Y. Cantillo, G. A. Berberian, J. Parker, P. G. Hanson, J. P. Thomas and J. E. O'Reilly, 1979. Chemical Factors. In: Oxygen depletion and associated benthic mortalities in New York Bight, 1976, R. L. Swanson and C. J. Sinderman (eds.), NOAA Professional Paper No. 11, pp. 79-123. 
Ballester, A., A. Cruzado and G. Macchi, 1969. Analyse Chimique Continue de la Mer II. Mission Internationale "Mechelen" 1968 en Mediterranee. Bu11. Inst. r. Sci. nat. Belg., 45:1-29.

Beale, R.N. and D. Croft, 1961. A sensitive method for the colorimetric determination of urea. J. Clin. Path., 14:418-424.

Begg, R.D., 1974. Data reconstruction techniques for the Technicon AutoAnalyzer. Anal. Chem., 46:171-173.

Bendschneider, K. and R. J. Robinson, 1952. A new method for the determination of nitrite in seawater. J. Mar. Res., 11:87-96.

Benesch, R. and P. Mangelsdorf, 1972. Eine Methode zur colorimetrischen Bestimmung von Ammoniak in Meerwasser. Helgol. Wiss. Meersunters., $23: 365-375$.

Bernhard, M., E. Torti, M. Ghibaudo, G. Rossi, and A. Bruschi, 1967. An underwater apparatus for in situ determinations with the AutoAnalyzer. In: Automation in Analytical Chemistry, L.T. Skeggs [ed.], Technicon Symposium, Mediad, Inc., New York, pp. 391-394.

Bernhard, M. and A. Piro, 1971. The use of automatic chemical anaysis in oceanography. Thalassia Jugoslavica, 7:601-618.

Bernhardt, H. and A. Wilhelms, 1967. The continuous determination of low level iron, soluble phosphate and total phosphate with the AutoAnalyzer. Technicon Symp., 1:386.

Bolleter; W. T., C. J. Bushman, and P. W. Tidwe11, 1961. Spectrophotometric determination of ammonia as indophenol. Anal. Shem., 33:592-591.

Brewer, P. C. and I. P. Riley, 1965; The automatic deturmination of nierate in seawater. Deep-Sea Res., 12:765-772.

Brewer, P. G. and J. P. Riley, 1966. The automatic determination of silicate-silicon in natural waters with special reference to sea water. Anal. Chim. Acta., 35:514-519.

Brewer, F. G. and J. Y. KAley, 196/. A study of some manual and automatic procedures for the determination of nitrate and silicate in ocean water. Deep=Sea. Res., 14:475-477.

Bruce, A. W., C. M. Leiendecker, and E. F. Freier, 1978. Two-point determination of plasma ammonia with the centrifugal analyzer. C1in. Chein., $24: 782-787$.

Burton, J.D., 1973. Plublews in the analysis of phosphorus compounds. Water Research, 7:291-307. 
Chalmers, R. A. and A. G. Sinclair, 1965. Analytical applications of $\beta$-heteropoly acids. Part I. Determination of arsenic, germanium and silicon. Ana1. Chim. Acta., 33:384-390.

Chalmers, R. A. and A. G. Sinclair, 1966. Analytical applications of B-heteropoly acids. Part II. The influence of complexing agents on selective formation. Anal. Chim. Acta., 34:412-418.

Chan, K. M. and J. P. Riley, 1966. The automatic determination of phosphate in seawater. Deep-Sea Res., 13:467-471.

Chirillo, R., G. Caenaro, B. Pavan and A. Pin, 1979. The use of immobilized enzyme reactors in continuous-flow analyzers for the determination of glucose, urea and uric acid. C1in. Chem., 25:1744-1748.

Colliss, J.S. and J.M. Knox, 1978. The use of immobilized urease for the determination of plasma urea by continuous flow analysis. Med. Lab. Science 34:275-282.

Conway, H. L., J. I. Parker, E. M. Yaguchi, and D. L. Mellinger, 1977. Biological utilization and regeneration of silicon in Lake Michigan. J. Fish. Res. Board Can., 34:537-544.

Coughenower, D. D. and H. C. Cur1, 1975. An automated technique for total dissolved amino acids in seawater. Limnol. Oceanogr., 20: $128-131$.

Cruzado, A., 1971. Sequential statistical analysis of continuous underway oceanographical data. Invest. Pesq., 35:261-267.

Cruzado, A., A. Ballester and C. Bas, 1971. Resultats de 1'expedico Oceanografica "Sahara I" a les costes del NW Africa. Treballs de la Societat Catalana de Biologia, $\underline{32}, 19-35$.

Cruzado, A. and J. C. Kelley, 1973. Continuous measurements of nutrient concentrations and phytoplankton density in the surface water of the Western Mediterranean, Winter 1970. Thalassia Jugosavica, 9:19-24.

Cruzado, A., 1974. Resultados del analisis continue en Africa del NW entre $23^{\circ} \mathrm{N}$ y $28^{\circ} \mathrm{N}$. Res. Exp. Cient. B/O CORNIDE, $3: 117-128$.

Cruzado, A. and J. C. Kelley, 1974. Continuous measurement of nutrient concentrations and phytoplankton density in the surface water of the Western Mediterranean, Winter 1970. Rapp. Comm. Int. Mer Medit., 22:119-120.

De Jong, E.B.M. and A.H. Weyden, 1980. Fast analysis rates in continuous flow methods by using a modified method of curve regeneration. Anal. Chim. Acta, 114:311-317.

Degobbis, D., 1973. On the storage of seawater samples for ammonia determination. Limnol. Oceanogr., 18:146-150. 
DeManche, J. M., H. Cur1 and D. D. Coughenower, 1973. An automated analysis for urea in seawater. Limnol. Oceanogr. 18:686-689.

Eaton, A. D. and V. Grant, 1979. Sorption of ammonium by glass frits and filters: Implications for analyses of brackish and freshwater. Limnol. Oceanogr., 24:397-399.

Emmet, R. T., 1968. Direct spectrophotometric analysis of ammonia in natural waters by the phenol-hypochlorite reaction. Report 2570, Annapolis Division, Nava1 Ship Research and Development Center, 11 pp.

Emmet, R. T., 1969. Spectrophotometric determination of urea and ammonia in natural waters with hypochlorite and phenol. Anal. Chem. 41:1648-1652.

Emmet, R. T., 1969. Spectrophotometric determination of urea in natural waters with hypochlorite and phenol. Report 2663. Annapolis Division, Naval Ship Research and Development Center, 12 pp.

Font, J., 1978. Correccion numerica automatica de las senales obtenidas con autoanalizadores Technicon. Invest. Pesq., 42:1-12.

Friederich, G. E. and T. E. Whitledge, 1972. AutoAnalyzer Procedures for Nutrients, In: Phytoplankton Growth Dynamics: Technical Series I Chemostat Methodology Chemical Analyses. S. P. Pavolv (ed.), Special Report No. 52, Dept of Oceanog., Univ. of Wash., Seattle, p. 38-60.

Garside, C., G. Hu11 and S. Murray, 1978. Determination of submicromolar concentrations of ammonia in natural waters by a standard addition method using a gas-sensing electrode. Limnol. Uceanogr., 23: $10 \% 3-10 / 6$.

Gilbert, T. R. and A. M. Clay, 1973. Determination of ammonia in aquaria and in sea water using the ammonia electrode. Anal. Chem., 45: $1757-1759$.

Gllinartin, M., 1967. Changes in 1norganic phosphace concentration occurring during seawater sample storage. Limnol. Oceanogr., 12:325-328.

Gine, M.F., H. Bergamin, E.A.G. Zagatto and B.F. Reis, 1980. Simultaneous determination of nitrate and nitrite by flow injection analysis. Anal. Chlin. Acta, 114:191-197.

Goulden, P. D., 1972. The chemical analysis of nutrients, H. E. Allen and J. R. Kramer (cds.), In: Nutrients in Natural Waters, John Wiley and Sons, p. 125 .

Grasshoff, K., 1964. On the determination of silica in sea water. Deep-Sea Res., 11:597-604.

Grasshoff, K., 1964. Zur Bestimmung von Nitrat in Meer-und Trinkwasser. Kieler Meeresforsch., 20:5-11. 
Grasshoff, K., 1965. On the automatic determination of silicate, phosphate, and fluoride in seawater. I.C.E.S. Hydrographic Comittee Report No. 1.29 , Rome.

Grasshoff, K., 1966. Uber eine methode zur automatischen bestimmung von gesamptphosphat in meerwasser durch autschluss mit ultraviolettenlight. Z. Anal. Chem., 220:89-95.

Grasshoff, K., 1968. Uber eine empfindliche und direkte Methode zur automatischen und manuellen Bestimmung von Ammoniak in Meerwasser. Z. Analyt. Chem., 234:13-22.

Grasshoff, K., 1970. A simultaneous multiple channel system for nut.rient analysis in sea water with analog and digital data record. Technicon Quarterly, 3: $: 7-17$.

Grasshoff, K., 1976. Methods of Seawater Analysis, Verlag Chemie, New York, 317 pp.

Grasshoff, K. and K. Chan, 1969. An automatic method for the determination of hydrogen sulfide in natural water. In: Technicon International Congress, June 4-6, 1969, pp. 147-150.

Grasshoff, K. and J. Johannsen, 1972. A new sensitive and direct method for the automatic determination of ammonia in seawater. J. Cons. Int. Explor. Mer., 34:516-521.

Grasshoff, K. and H.P. Hansen, 1978. The towed chemical profiler, a versatile system for continuous measurements of environmental parameters in seawater. Int1. Council for the Exploration of the Sea C.M. 1978, C:4.

Gravitz, N., and L. Gleye, 1975. A photochemical side reaction that interferes with the phenolhypochlorite assay for ammonia. Limnol. Oceanogr., 20:1015-1017.

Hager, S. W., L. I. Gordon, and P. K. Park, 1968. A practical manual for use of the Technicon AutoAnalyzer in seawater nutrient analysis, Final report to the Bureau of Commercial Fisheries, contract 14-17-0001-1759. Oregon State University, Dept. of Oceanog., Ref. 68-33, 31. pp.

Hager, S.W., E.L. Atlas, L.I. Gordon, A.W. Mantyla and P.K. Parks, 1972. A comparison at sea of manual and AutoAnalyzer analyses of phosphate, nitrate and silicate. Limnol. Oceanogr. 17:931-937.

Hampson, B.L., 1977. The analysis of ammonia in polluted sea water. Water Res., $11: 305-308$.

Harwood, J.E. and D.J. Huyser, 1970. Automated analysis of ammonia in water. Water Res., 4:695-704.

Head, P. C., 1971. An automated phenolhypochlorite method for the determination of ammonia in seawater. Deep-Sea Res., 18:531-532. 
Hosokawa, I. and F. Ohshima, 1973. An improved method of phosphorus analysis In seawater. Water Research, $7: 283-289$.

Hurd, D.C., 1973. Interactions of biogenic opal, sediment, and seawater. in the central equatorial Pacific. Geochim. Cosmochim. Acta., $37: 2257-2282$.

Ijpma, S. T., B. G. Blijenberg, and B. Leijnse, 1978. Evaluation of the DuPont aca ammonia procedure. Cl1n. Chem., 24:489-492.

Jacklyn, C. L., M. A. MacAulay, J. M. Mathers, C. A. Munro, and C. D. Kriz, 1978. Application of curve regeneration to the determination of electrolytes by the Flame-IV Auto-Analyzer using a mini-computer. Clin. Biochem., $11: 16-22$.

Johnson, D. L., 1971. Simultaneous determination of arsenate and phosphatc in natural watere. Environ. Ec1. Technol., 5:411-414.

Johnston, R., 1966. Determination of ammonia in sea water as rubazoic acid. Int1. Council for the Exploration of the Sea. C.M. 1.966, $\mathrm{N}: 10$.

Josefsson, B., P. Lindroth and G. Ostling, 1977. An automated fluorescence method for the determination of total amino acids in natural waters. Ana1. Chim. Acta, 89:21-28.

Kaczmarek, C., S. Arnold, and H. Peterson, Jr., 1974. An operation manual for a Technicon AutoAnalyzer II includinc data prosessing techniquca. MARMAP Contrib. No. 9., Univ. of Rhode Island.

Kelley, J. C. and A. Cruzado, 1974. Fluctuations and interrelationships among nutrient concentrations and phytoplankton density in the Western Mediterranean, Winter 1970. Rapp. Comm. int. Mer Medit., 22:121-122.

Kelley, J. C., T. E. Whitledge, and R. C. Dugdale, 1974. A shipboard data acquisition system for ecosystem analysis. Special report no. 58 (Ref. No. M74-80) Department of Oceanography, Unjuersity of Washington, Seattle, $20 \mathrm{pp}$.

Kelley, J. C., T. E. Whitledge, and R. C. Dugdale, 1975. Results of sea surface mapplng in the Peru Upwelling System. Limnol. Oceanogr. 20:784-794.

Koroleff, F., 1966. Dlrect spectrophotometric determination of ammonia in precipitation. Tellus, 18:562.

Koroleff, F., 1969. Direct determination of ammonia in natural waters as indophenol blue. Int1. Council for the Exploration of the sea. CM $1969, C: 9,19$. 
Koroleff, F., 1970. Direct determination of ammonia in natural waters as indolphenol blue. Informtion on techniques and methods for sea water analysis, Interlab. Rep. (3), 19-22.

LeCorre, P. and P. Trequer, 1978. Dosage de l'ammonium dans l'eau de mer: comparaison entre deux methodes d'analyse automatique. J. Cons. int. Explor. Mer, 38:147-153.

Liddicoat, M. I., S. Tibbitts, and E. I. Butler, 1975. The determination of ammonia in seawater. Limnol. Oceanogr., 20:131-132.

Loder, T. C. and P. M. G1ibert, 1977. Blank and salinity corrections for automated nutrient analysis of estuarine and sea waters.

University of New Hampshire Cont. No. UNH-SG-JR-101, 29 pp.

Lubochinsky, B. and J. Zalta, 1954. Microdosage colorimetrique de lazote ammoniacal. Bull. Soc. Chim. biol., 36:1363-1366.

MacAulay, M. A., J. M. Mathers, C. L. Jacklyn, and C. A. Munro, 1976. Curve prediction in automated analyses in routine laboratories. Clin. Biochem., 9:111-116.

Macisaac, J. J., 1967. Ammonia determinations by two methods in the northeast equatorial Paciflc Ocean. Limnol. Oceanogr., 12:552-554.

MacIsaac, J. J. and R. K. Olund, 1971. An automated extraction procedure for the determination of ammonia in sea water. Inv. Pesq., $35: 221-232$.

Manabe, T., 1966. New modification of Lubochinsky's indolphenol method for direct microanalysis of ammonia-N in sea water. Jap. Soc. Sci. Fish. Bull., 35:897-906.

Manny, B. A., M. C. Miller, and R. G. Wetzel, 1971. U1traviolet combustion of dissolved organic nitrogen compounds in lake waters. Limnol. Oceanogr., 16:71-85.

Marvin, K. T. and R. R. Proctor, 1965. Stabilizlng the ammonia nitrogen content of estuarine and coastal waters by freezing. Limnol. Oceanogr., 10:288-289.

May, B.Z., 1960. Stabilization of the carbohydrate content of sea water samples. Limnol. Oceanogr., $\underline{5}: 342-343$.

McCarthy, J. J., 1970. A urease method for urea in seawater. Limnol. Oceanogr., 15:303-313.

Merks, A. G., 1975. Determination of ammonia in sea water with an ion-selective electrode.' Neth. J. Sea Res., 9:371-375. 
Morrison, I. R. and A. L. Wilson, 1963. The absorptiometric determination of silicon in water. Part I. Formation, stability and reduction of $\alpha-$ and B-molybdosilicic acids. Analyst., 88:88-99.

Morrison, I. R. and A. L. Wilson, 1963. The absorptiometric determination of silicon in water. Part II. Method for determining "reactive" silicon in power-station waters. Analyst., 88:100-104.

Morrison, I. R. and A. L. Wilson, 1963. The absorptiometric determination of silicon in water. Part III. Method for determining the total silicon content. Analyst., 88:446-455.

Morrison, I. R. and A. L. Wilson, 1969. The absorptiometric determination of silicon in water. Part VI. Determination of polymeric sillcic acid. Analyst., 94:54-61.

Mullin, J. B. and J. P. Riley, 1955. The spectrophotometric determination of silicate-silicon in natural waters with special reference to seawater. Allal. Chliw. Acta., 12:162-176.

Murphy, J. and J.P. Riley, 1962. A modified single solution method for the determination of phosphate in natural waters. Anal, Chim. Acta. 27:31-36.

Neeley, W. E. and H. C. Sing, 1974. Use of a programmable desk-top calculator for on-line acquisition, processing, computing, and reporting of data from automated laboratory instruments. Am. J. Clin. Path., 61:804-809.

Neeley, W. E., S. C. Wardlaw, and H. C. Sing, 1974. Design and performance of a miniaturized high-speed continuous-flow analyzer. Clin. Chem., $20: 424-427$.

Neeley, W. E., S. Wardlaw and M. E. T. Swinnen, 1974. Design and operation

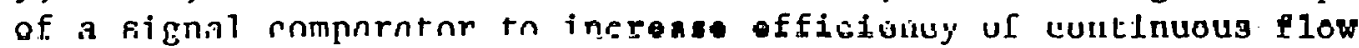
analyzers. C1in. Chem., 20:78-80.

Newel1, B. and G. DalPont, 1964. Ammonia in sea water. Nature, 201:36-37.

Newe11, B. S., 1967. The determination of ammonla in sea warer. J. Mar. biol. Ass. U. K. 47:271-280.

Newe11, B. S., B. Morgan and J. Cundy, 1967. The determination of urea in sed waler. J. Mar. Res., 25:201-202.

Nydah1, F., 1976. On the optimum conditions for the reduction of nitrate to nitrite by cadmium. Tantala, 23:349-357.

Patton, C. J. and S. R. Crouch, 1977. Spectrophotometric and kinetic investigation of the Berthelot reaction for the determination of ammonia. Anal. Chem., 49:464-469. 
P1ro, A. and G. Rossi, 1969. Determinazione dei nutrienti mediante autoanalyzer. Pubbl. Staz. Zool. Napoli, 37:290-297.

Prochazkova, L., 1964. Spectrophotometric determination of ammonia as rubazoic acid with bispyrazalone reagent. Anal. Chem., 36:865-871.

Proctor, R.R., Jr., 1962. Stabllization of the nitrite content of sea water by freezing. Limnol. Oceanogr., 7:479-480.

Rahmatu1lah, M. and T.R.C. Boyde, 1980. Improvements in the determinations of urea using diacetyl monoxime; methods with and without deproteinisation. Clin. Chim. Acta, 107:3-9.

Richards, F. A. and R. A. Kletsch, 1964. The spectrophotometric determination of ammonia and labile amino compounds in fresh and sea water by oxidation to nitrite. In: Recent researches in the fields of hydrosphere, atmosphere and nuclear geochemistry, Y. Mi yake and T. Koyama (eds.), Maruzen, Tokyo, p. 65-81.

Riley, J. P., 1953. The spectrophotometric determination of ammonia in natural waters with particular reference to sea-water. Anal. Chim. Acta., 9: 575-589.

Riley, J. P. and P. Sinhaseni, 1957. The determination of ammonia and total inorganic nitrogen in seawater. J. mar. bio. Ass. U.K., $36: 161-168$.

Riley, J. P., K. Grasshoff, and A. Viopio, 1972. Nutrient chemicals, In: E. D. Goldberg (ed.), A Guide to Marine Pollution, Gordon and Breach, New York, p. 81-110.

Roskam, R. T. and D. Delangen, 1964. A simple colorimetric method for the determination of ammonia in sea water. Anal. Chim. Acta., 30:56-59.

Sagi, T., 1966. Determination of ammonia in sea water by the indopheno1 method and its application to coastal and off-shore waters. The Oceanographical Magazine, 18:43-51.

Satsmadjis, J., 1978. The simultaneous determination of nutrients by AutoAnalyzer in Greek coastal waters. Thalassographica, 2:173-190.

Senn, D. R. and P. W. Carr, 1976. Determination of nitrate ion at the part per billion level in environmental samples with a continuous flow immobilized enzyme reaction. Anal. Chem., 48:954-958.

Slawyk, G and J. J. MacIsaac, 1972. Comparison of two automated ammonium methods in a region of coastal upwelling. Deep-Sea Res., 19:521-524.

Snyder, L. R., 1976. Reaction colorimeters as detectors in high-performance liquid chormatography. Extra-column band broadening with segmented flow through the reaction coil. J. Chromatogr., 125:287-306. 
Snyder, L. R. and H. J. Adler, 1976. Dispersion in segmented flow through glass tubing in continuous flow analysis: the ideal model. Anal. Chem., 48:1017-1022, 1976 .

Snyder, L. R. and H. J. Adler, 1976. Dispersion in segmented flow through glass tubing in continuous flow analysis: the nonideal model. Anal. Chem., 48: 1022-1027.

Snyder, L., J. Levine, R. Stoy, and A. Coretta, 1976. Automated Chemical Analysis: Update on continuous-flow approach. Anai. Chem., 48: 942A-956A.

Snyder, L.R., 1980. Continuous-flow analysis: Present and future. Anal. Chim. Acta, 114:3-18.

Solorzano, L., 1969. Determination of ammonia in natural waters by the phenolhypochlorite method. Linnul. Ocealugr., 14:799-801.

Solorzano, L. and J.ll. Sharp, 1980. Determination of total dissolved phosphorus and particulate phosphorus in natural waters. Limnol. Oceanogr., 25:754-758.

Solorzano, L. and J.H. Sharp, 1980. Determination of total dissolved nitrogen in natural waters. Limnol. Oceanogr., 2.5:751-754.

Stainton, M.P., 1974. Simple, efficient reduction columns for use in the automated determination of nitrate water. Anal. Chem., 46:1616.

Stevens, K., 1970. Automated measurement of dissolved nutrients. Deep-Sea Res., 17:393-396.

Strickland, J. D. H., 1952. The preparation and properties of silicomolybdic. acid. I. The properties of alpha silicomolybdic acid. J. Am. Chem. Soc. $74: 862-867$.

Strickland, J. D. H., 1952. The preparation and properties of silicomolybdic acid. II. Preparation and properties of B-silicomolybdic acid. .T. Am. Chem. Soc., 74:868-871.

Strickland, J. D. H., 1952. The preparation and properties of siliconmolybidic acid. III. The combination of silicate and molybdate. J. Am. Chem. Soc. 74:872-876.

Strlckland, J. D. H. and K. H. Austin, 1959. The direct estimation of ammonia in sea water with notes on "reactive" iron, nitrate, and inorganic phosphorus. J. Cons. int. Explor. Mer, 24:446-451.

Strickland, J. D. H. and T. R. Parsons, 1972. A Practical Handbook of Seawater Analysis. Bull, Fish. Res. Bd. Can., 167, 310 pp. 
Sundaram, P.V., M.P. Igloi, R. Wassermann, W. Hinsch and K.-J. Knoke, 1978. Immobilized-enzyme nylon-tube reactors for routine determination of urea and citrulline in serum. C1in. Chem., 24:234-239.

Sundaram, P.V. and S. Jayaraman, 1979. Immobilized enzyme pipette, impette. Routine estimation of serum and urine urea. Clin. Chim. Acta, 94: 309-316.

Thayer, G. W., 1970. Comparison of two storage methods for the analysis of nitrogen and phosphorus fractions in estuarine water. Chesapeake Sci., $11: 155-158$.

Thiers, R. E. and K. M. Oglesby, 1964. The precision, accuracy and inherent errors of automatic continuous flow methods. Clin. Chem., 10:246-257.

Thiers, R. E., R. R. Cole, and W. J. Kinsch, 1967. Kinetic parameters of continuous flow analysis. Clin. Chem., 13, 451-467.

Thomas, R. F. and R. L. Booth, 197.3. Selective electrode measurement of ammonia in water and wastes. Environ. Sci. Technol., 7:523-526.

Truesdale, V. W. and C. J. Smith, 1975. The formation of molybdosilicic acids from mixed solutions of molybdate and silicate. Analyst., $100: 203-212$.

Truesdale, V. W. and C. J. Smith, 1976. The automat1c determination of silicate dissolved in natural fresh water by means of procedures involving the use of either $\alpha$ or $\beta$-molybdosilicic acid. Analyst., $101: 19-31$.

Van Den Berg, J.H.M., R.S. Deelder and H.G.M. Egberink, 1980. Dispersion phenomena in reactors for flow analysis. Anal. Chim. Acta, 114:91-104.

Walker, W. H. C., 1971. Curve regeneration in continuous flow analysis. Clin. Chim. Acta., 32:305-306.

Walker, W. H. C., C. A. Penncock, and G. K. McGowan, 1970. Practical considerations in continuous flow analysis. Clin. Chim. Acta., $27: 421-435$.

Walker, W. H. C., J. D. Shepherdson and G. K. McGowan, 1971. Theoretical considerations in continuous flow analysis. Clin. Chim. Acta., 35: $455-460$.

Walker, W. H.'C., J. Townsend, and P. M. Keane, 1972. Analog device for curve regeneration in continuous flow analysis. Clin. Chim. Acta., 36:119-125.

Webber, H. M. and A. L. Wilson, 1964. The absorptiometric determination of silicon in water. Part IV. Method for determining "reactive" silicon in power-station waters containing phosphate. Analyst., 89:632-641. 
Webber, H. M. and A. L. Wilson, 1969. The absorptiometric determination of silicon in water. Part VII. Improved method for determining the total silicon content of high-purity water. Analyst., 94:110-120.

Whitledge, T. E. and R. C. Dugdale, 1972. Creatine in seawater. Limnol. Oceanogr., 17:309-314.

Wiesenburg, D. A., P. Setser, and K. Bottom, 1978. Sampling sea water and analyzing for nutrients while underway cuts ship running costs for Texas A M. Technicon Industrial System News 4 : 6 .

Wilson, A. L., 1965. The absorptiometric determination of silicon in water. Part V. Continuous automatic determination of reactive silicon. Analyst., 90:270-277.

Wood, E. D., F. A. J. Armstrong, and F. A. Richards, 1967. Determination of nitrate in seawater by cadmium-copper reduction to nitrite. J. Mar. biol. Ass. U. K., 47:23-31.

Zadorojny, C., S. Saxton, and R. Finger, 1973. Spectrophotometric determination of ammonia. J. Water Poll Control. Fed., 45:905-912.

Zitomer, F. and J. L. Lambert, 1962. A new method for the determination of ammonia. Ana1. Chem., 34:1738-1740. 
All of the individual components of mixing coils, injection fittings, nipples, and heating baths are listed for each of the six analyses. Also included are colorimeter flow cell sizes, phototubes, and interferance filters used in the AutoAnalyzer single channel industrial colorimeters. The brand and grade of chemicals used in preparing reagent solution is included for most analyses. 


\section{Phosphate Channel}

\section{Description}

1. Injector fitting with $\mathrm{N}-6$ nipple

2. 5-Turn coil, right hand

3. Fitting connector, A6

4. 20-Turn coil

5. "G" coil $7.7 \mathrm{ml} 35.5$ turns

6. Heating bath assembly for " $G$ " coil

7. Connector, water jacket straight

8. Flow cell assembly $50 \mathrm{~mm} \times 1.5 \mathrm{~mm}$ I.D.

9. Filter assembly, $880 \mathrm{M}_{\mathfrak{l}}$

10. Adjustable temperature controller for heating bath
Technicon Part Number

$116-0489-01,116-0004-01$

$170-0103-01$

$116-\mathrm{B} 008-01$

$157-\mathrm{B} 089-01$

$157-0225-01$

$157-B 273-32$

Made at BNL

199-8007-01

$170-\mathrm{B} 070-48$

$170-$ B070-28
Reagents

Ascorbic acid

Ammonium molybdate

Sulfuric acid

Sodium lauryl sulfate

Potassium phosphate (standard)
Manufacturer

Fisher

Mallinckrodt

Mallinckrodt

Sigma Chemical

J.T. Baker Chemical

\section{Silicate Channel}

\section{Descripr1on}

1. Injector fitting with $\mathrm{N}-6$ nipple

2. 20-Turn coil

3. Fitting connectir, AG

4. 20-Turn coil

5. Flow cell assembly $15 \mathrm{~mm} \times 1.5 \mathrm{~mm}$

6. Filter assemhly $820 \mathrm{M}$
Teshnicon Part Number

$116-0489-01,116-0004-01$.

$157-0248-01$

$1.18-\mathrm{B} 008-01$

157-B089-01

199-B018-01

$170-B 070-57$

\section{Reagents}

Ammonium molyhdate

Antimony potassium tartrate $1 / 2$ hydrate

Stannous chloride

Tartaric acid

Acetone

Sulfuric acid

Sodium lauryl sulfate

Sodium hexafluorosilicate (standard)

\section{Manufacturer}

Mallinckrodt, Tnr. J.T. Baker Chemical Company Mallinckrodt, Inc. Matheson, Coleiuan, and Bell J.T. Baker Chemical Company Mallinckrodt, Inc. Sigma Chemical Co. Alfa/Ventron Corporation 


\section{Nitrate + Nitrite Channe 1}

Description

1. Injector fitting with $\mathrm{N}-6$ nipple

2. 5-Turn coil, right hand

3. Fitting connector, A2

4. Injector fitting with $\mathrm{N}-6$ nipple

5. 20-Turn coil

6. 10-Turn coil, right hand

7. 4-Way valve, no. 1

8. Flow cell assembly $50 \mathrm{~mm} \times 1.5 \mathrm{~mm}$

9. Filter assembly, $540 \mathrm{M \mu}$

10. Flow cell assembly, $15 \mathrm{~mm} \times 1.5 \mathrm{~mm}$ I.D.
Technicon Part Number

$116-0489-01,116-0004-01$

$170-0103-01$

$116-0200-02$

$116-0489-01,116-0004-01$

157-B089-01

157-0251-01

4MMMM4 (Hamilton)

199-B007-01

$177-\mathrm{B} 070-40$

199-B018-01
Chemicals

N-1-Naphthylethylene-diamine dihydrochloride Sulfanilamide

Ammonium Chloride

Hydrochloridic acid

Bri j-35

Potassium nitrate (standard)
Manufacturer

Eastman Kodak Sigma Chemical Co.

J.T. Baker Chemical Company J.T. Baker Chemical Company Technicon Instruments Co.

J.T. Baker Chemical Company

Nitrite Channel

Description

1. Injector fitting with $\mathrm{N}-6$ nipple

2. 5-Turn coil, right hand

3. Fitting connector, $A 6$

4. 20-Turn coil

5. 10 Turn coll, left hand

6. Flow cell assemb1y $15 \mathrm{~mm} \times 1.5 \mathrm{~mm}$

7. Filter assembly $540 \mathrm{M} \mu$

\section{Reagents}

N-1-Naphthylethylene -.diamine dihydrochloride Sulfani lamide

Hydrocliloric acid

Bri j-35

Sodium nitrite
Technicon Part Number

$116-0489-01,116-0004-01$

170-0103-01

116-B008-01

157-B089-01

$1.57-0226-01$

199-B018-01

177-B070-40

\section{Manufacturer}

Eastman Kodak

Sigma Chemical Co.

I.T. Baker Chemical Company Technicon Instruments Co.

J.T. Baker Chemical Company 


\section{Ammonium Channe1}

\section{Description}

1. Injector fitting with $\mathrm{N}-6$ nipple

2. 5-Turn coil, right hand

3. Fitting connector, A6

4. 20-Turn coil

5. "G" $\operatorname{coi} 17.7 \mathrm{~m} 135.5$ turns

6. Heating bath assembly for "G" coil

7. Adjustable temperature controller for heating bath

8. Connector water jacketed, straight

9. Filter assembly, $640 \mathrm{M} \mu$

10. Flow cell assembly $50 \mathrm{~mm} \times 1.5 \mathrm{~mm} \mathrm{I.D.}$

Reagents

Phenol

Sodium nitroprusside

Sodium cttrate, dihydrate

Sodium hydroxide

Sodium hypochlorite

Brij-35

Ammonium chloride (standard)
Technicon Part Number

$116-0489-01,116-0004-01$

$170-0103-01$

$116-8008-01$

157-B089-01

157-0225-01

157-B273-32

170-B070-28

Made at BNL

$170-\mathrm{B} 173-02$

199-B007-01

\section{Manufacturer}

J.T. Baker Chemical Company J.T. Baker Chemical Company J.T. Baker Chemical Company J.T. Baker Chemical Company Chlorox Company Technicon Instruments Co. J.T. Baker Chemical Company 


\section{Urea Channe1}

Description

1. Injector fitting with $\mathrm{N}-6$ nipple

2. 10-Turn coil, right hand

3. Fitting connector, $A 6$

4. 20-Turn coil

5. 2-"SS" coil, $10.4 \mathrm{ml}$

6. Adjustable temperature controller for heating bath

7. 2-Heating bath assembly for "SS" coil

8. Connector, water jacketed

9. Flow cell assembly $50 \mathrm{~mm} \times 1.5 \mathrm{~mm}$ I.D.

10. Filter assembly, $520 \mathrm{M \mu}$
Technicon Part Number

$116-0489-01,116-0004-01$

$157-0251-01$

116-B008-01

157-B089-01

$170-6060$

$170-B 173-02$

1.57-B273-41

Made at BNL

199-B007-01

177-B070-28

\section{Reagents}

Diacetyl monoxime

Semicarbazide hydrochloride

Potassium phosphate

Potassium nitrate

Sulfuric acid

Sodium chloride

Brij-35

Urea (standard)
Manufacturer

J.T. Baker Chemical Company Sigma Chemical Co.

J.T. Baker Chemical Company

J.T. Baker Chemical Company Mallinckrodt, Inc.

J.T. Baker Chemical Company Technicon Instruments Co. Sigma Chemical Co.

\section{Miscellaneous Parts}

Plastic Connectors and Stream Dividers

N-8 Nipple (placed on both ends of of the silirone air-har tubing.

N-6 Nipple (mounts on injector fitting carrying air to manifold; also connects to colorimeter "to pump" out let)

Stream Divider, PT02

Stream Divider, PTIO

Stream Divider, PT11
Technicon Part Number

$116-0003-01$

$116-0004-01$

116-B000-01

$116-\mathrm{B} 042$

116-B043 


\section{Appendix C - Software Listings}

This section contains the listings of the BASIC programs used for nutrient analyses on the Hewlett Packard $9845 \mathrm{~S}$. The only additional routines not listed here that are required, I/O binary routines, can be obtained from Hewlett-Packard at no cost. Most of the listings contain REM statements at the beginning and at critical points in the program that describe the task being done. 


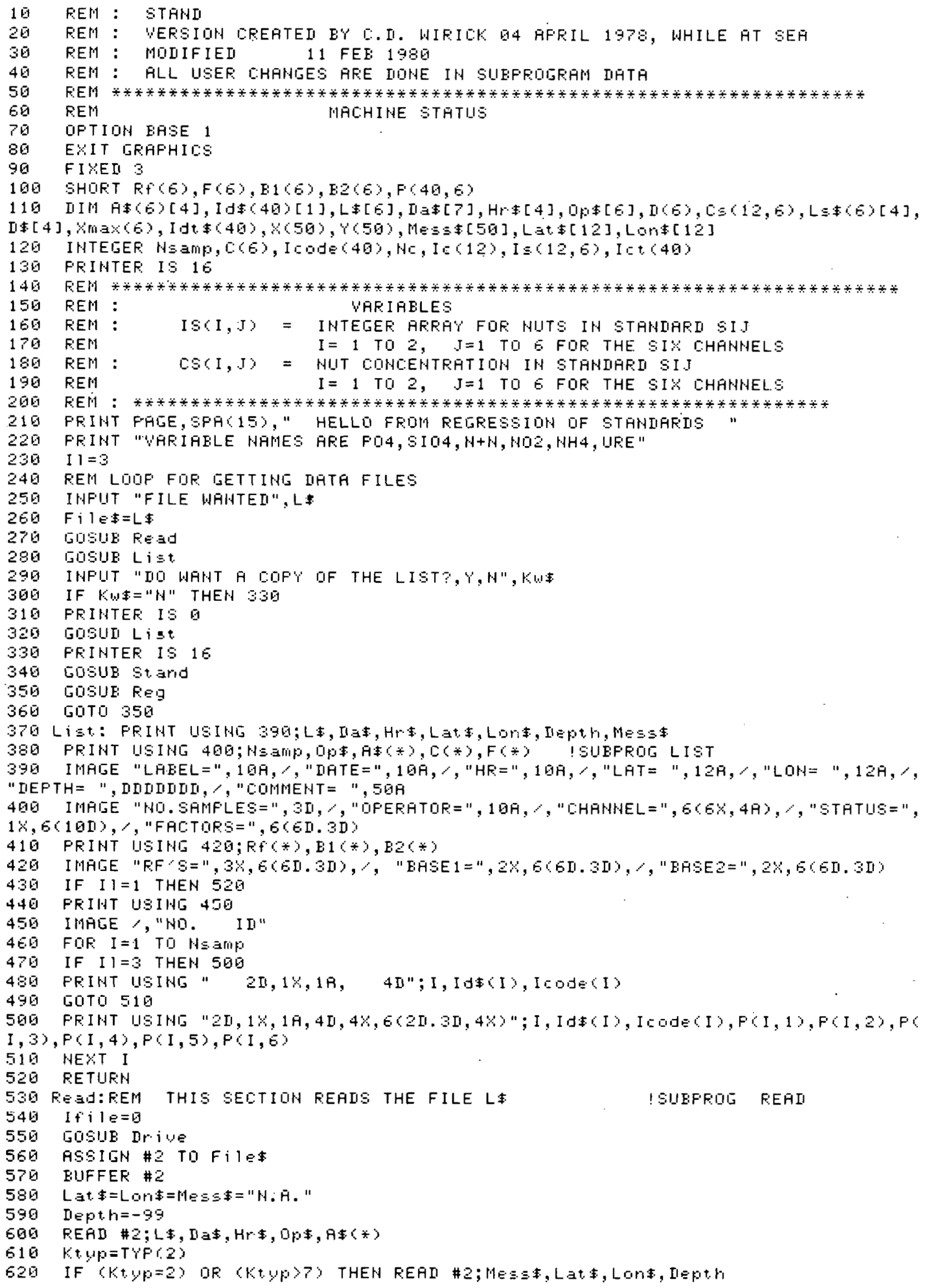




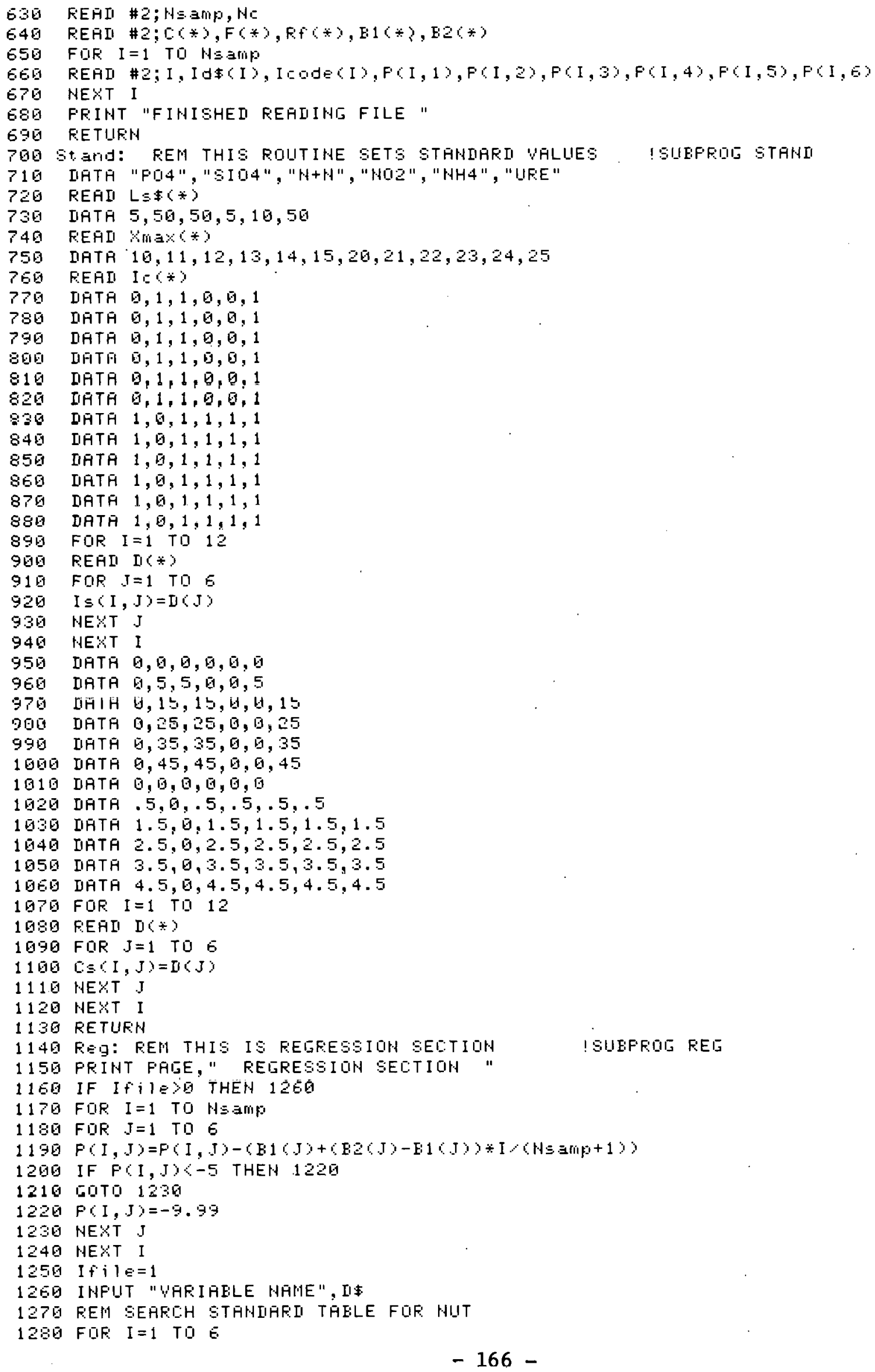




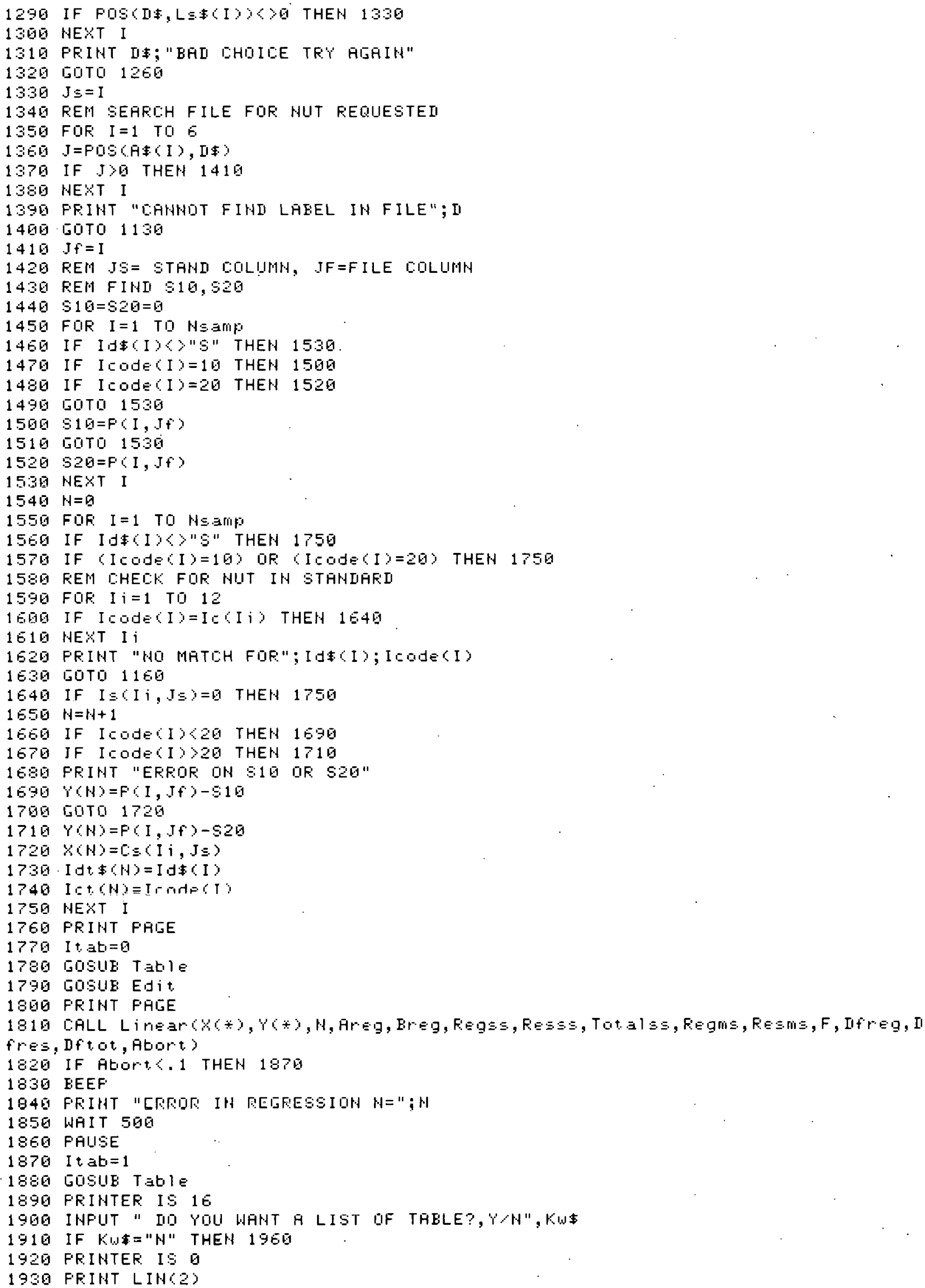




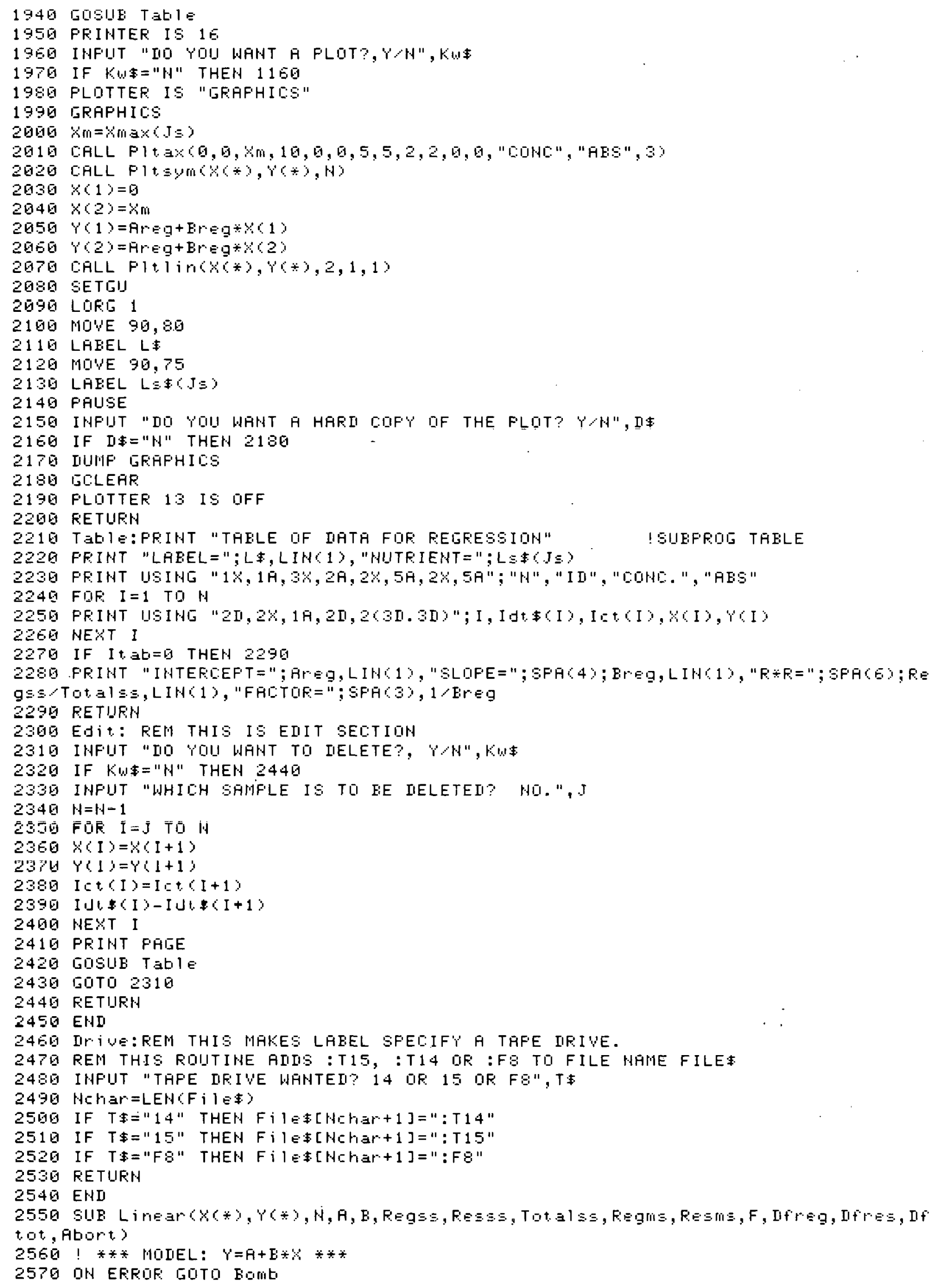




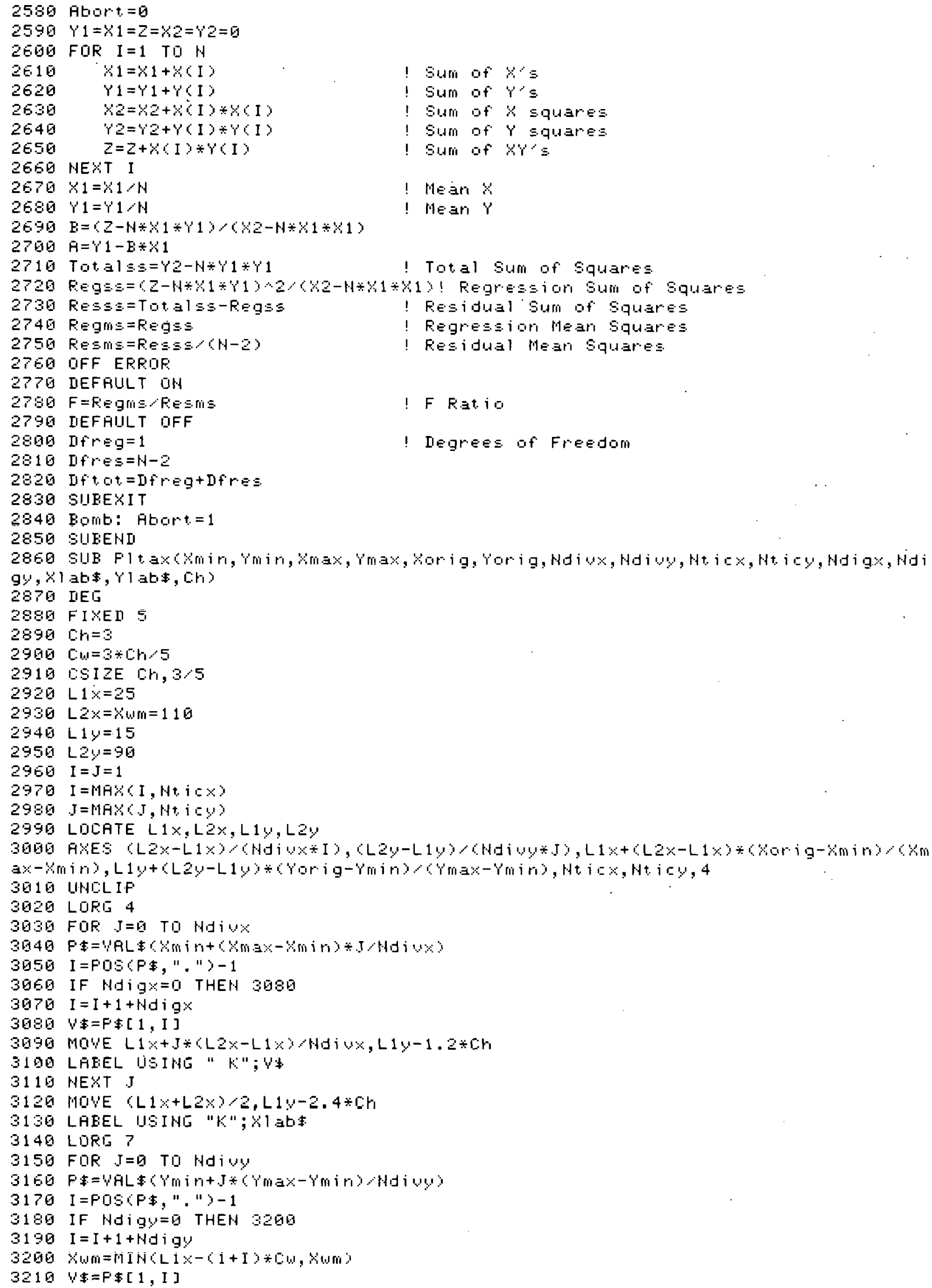




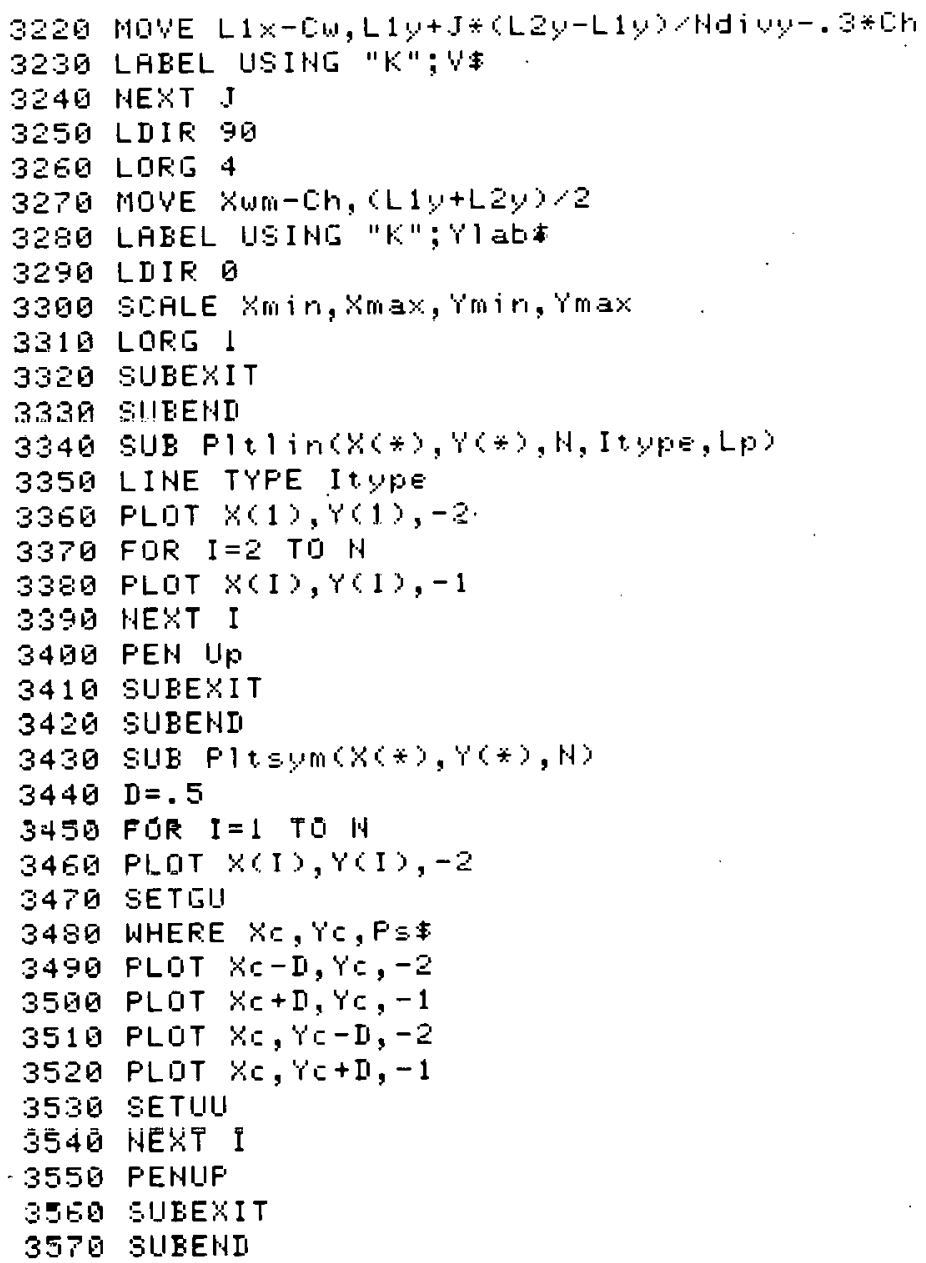




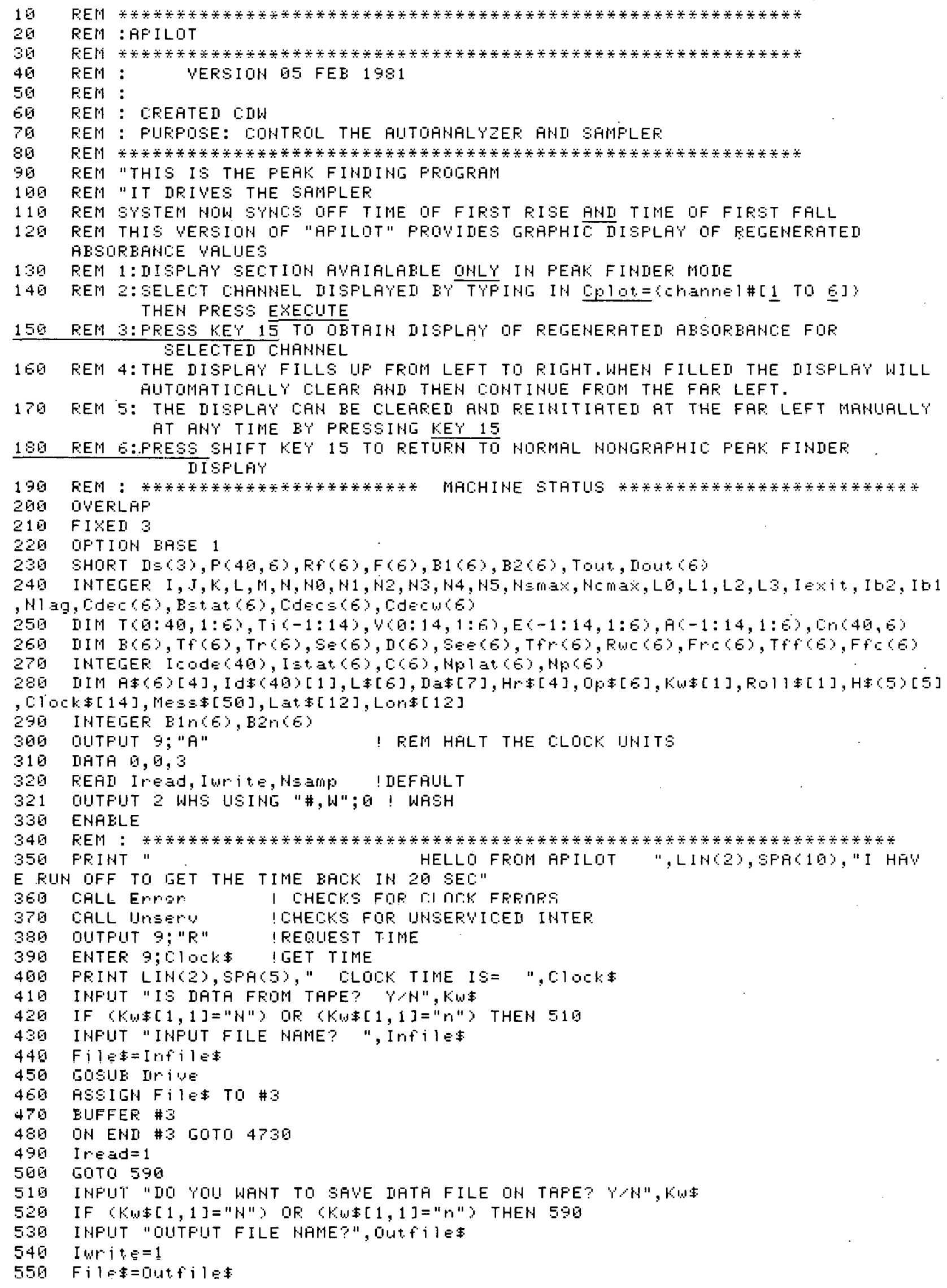




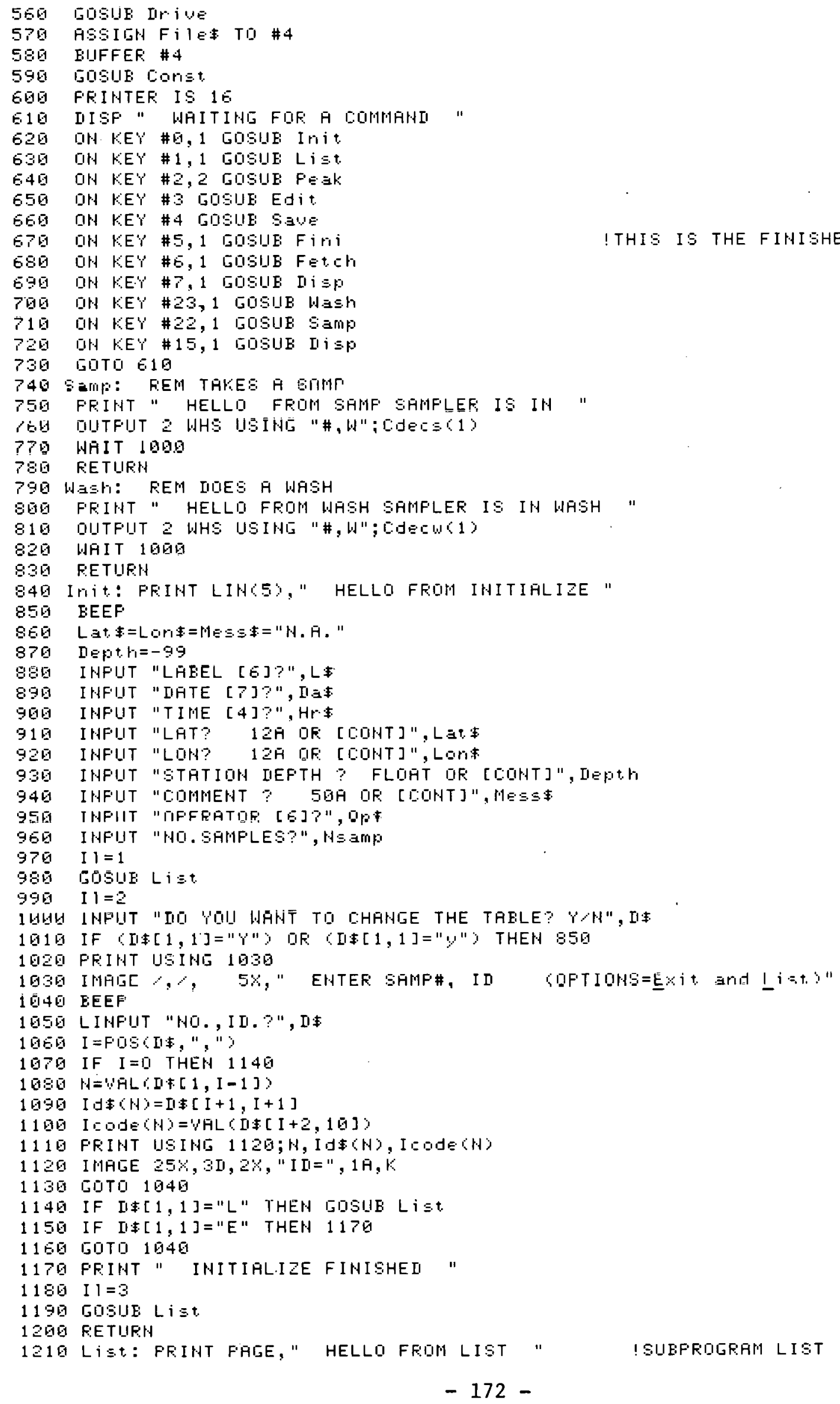




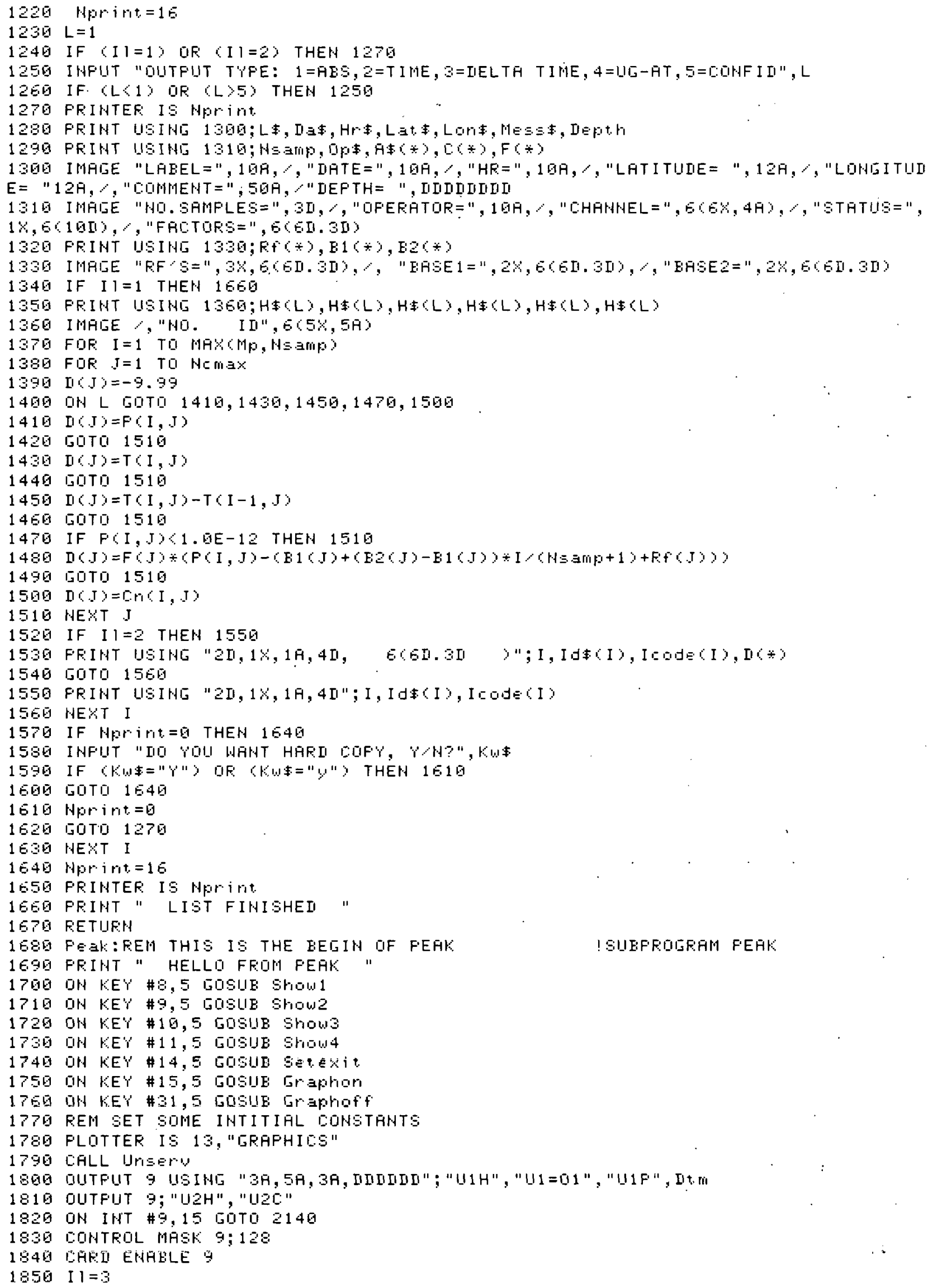




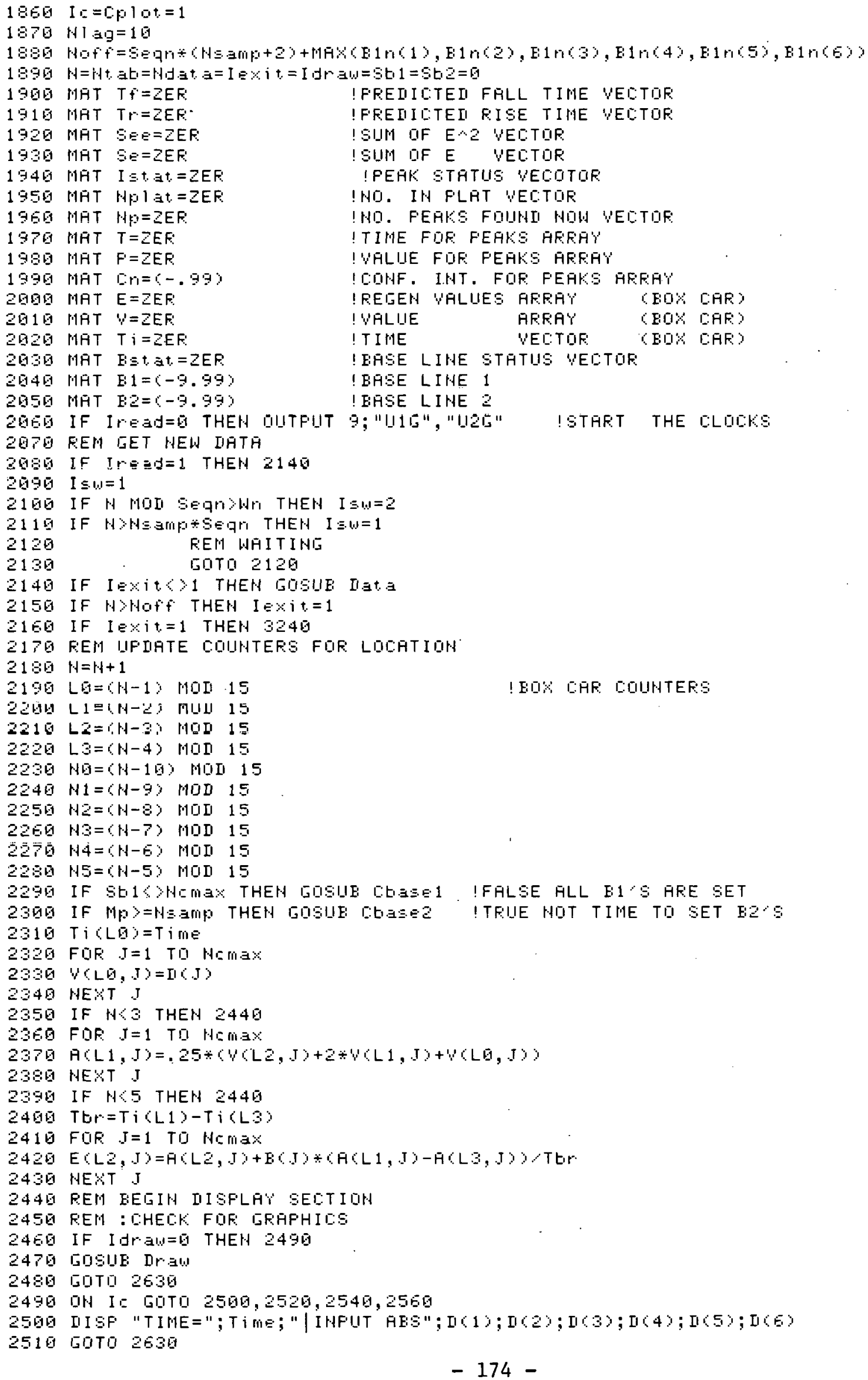




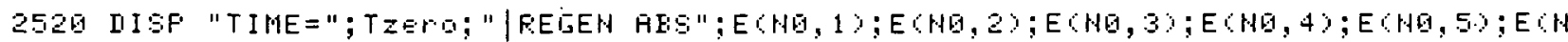
$\overline{0}, 6)$

$2530 \quad 50100 \quad 2630$

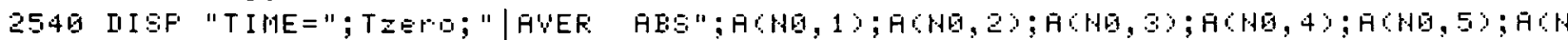

$0,6)$

2550 10T0 2630

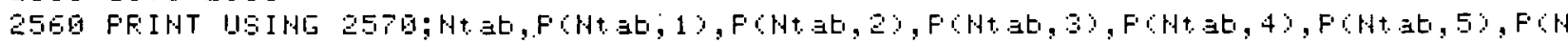
t. 35,6 ?

2570 IMAGE $2 \%, 4 \pi, 6(4 \%, 211.3 I)$

2580 Ht $a t=H t . a t+1$

2596 IF Ht ab $=M p$ THEH 20.00

26日6 FRIHT "FINISHEII TIME="; TEER

2610 Ht $a t=0$

2620 I $L=1$

26:G REM SFBIE HOLIEF EHII OF IISFLA' SELTIOH

2646 TZER $0=T$ i $(\mathrm{HB})$

265日 FEM EEGIH DF PEAK FIHIIHG SEITIOH

2EE $F$ DR J=1 TO NEli $3 \%$

2670 FEM LHELK HNI SEE IF FLL EMFEITEII FEAKS HEE IH

2680 IF EEt. $3 t(J)<>1$ THEN 3210

2690 I $\equiv$ t. at $j=I \equiv . t, a t . j)$

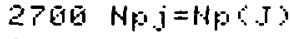

2710 IF Ist.at j=1 THEN 2810

272G FEM LUOKIHI FOR A FISE

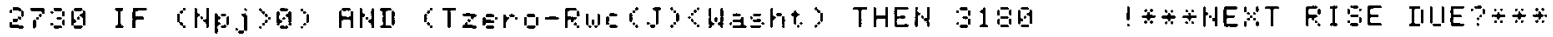

2746 IF CECH2, J)-ECH1, J) Y

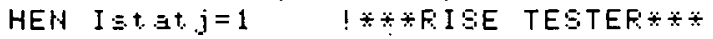

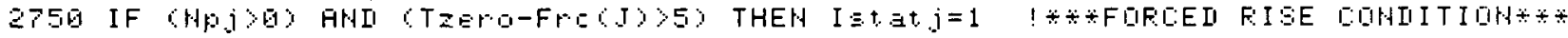

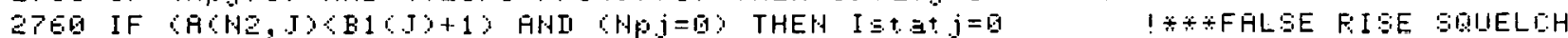
$E F \div \div: \div$

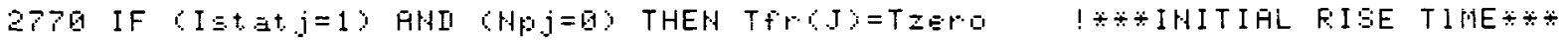

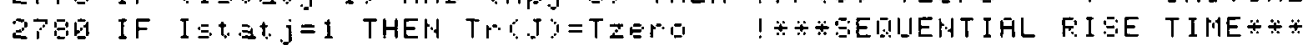

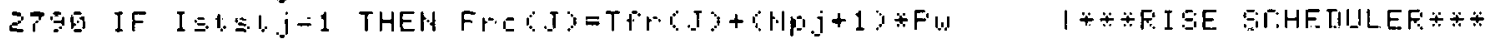

$280100 T 0 \quad 3180$

2810 REM LOOKIHG FOR A FLATEAII AHII THEH A FRLL

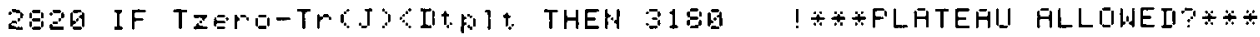

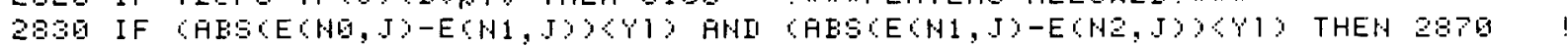
***FLATEHU TESTER:***

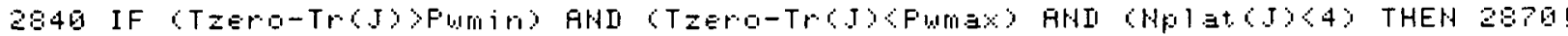

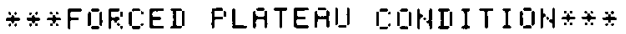

2956 FEM FLALIEHIJ FIIHT IS EAD

2860 GOTO 2946

2870 REM FLATEHU IS A GOIII OHE

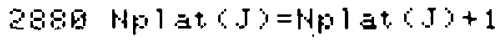

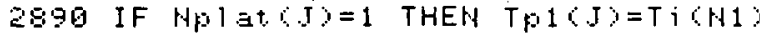

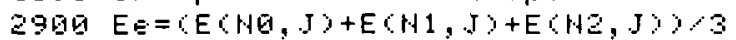

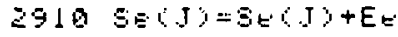

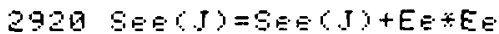

$2930 \mathrm{TP} 2 \mathrm{O} \mathrm{J}=\mathrm{Ti}(\mathrm{H} 1)$

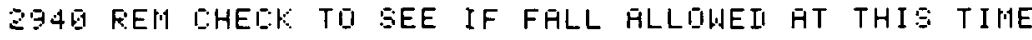

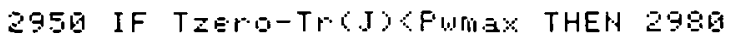

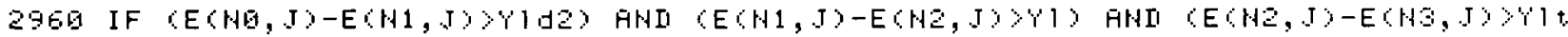
2) THEH 3000

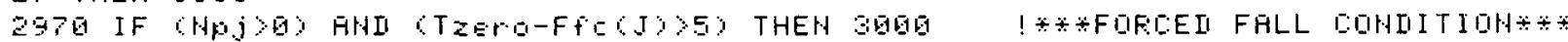

2980 REM HO FHLL FOUHII

2990 LOTO 3180

3000 FEM FALL FOUND

3910 IF Haj $j=0$ THEH $T f f(j)=1 \Sigma E M 0$

$3620 \quad F f(C)=T+f(J)+(H) j+1) \div F(n$

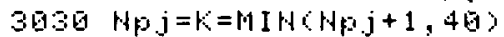

3040 MF=MAK(K, MF)

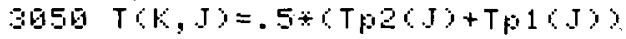

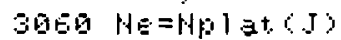

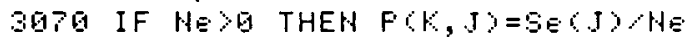

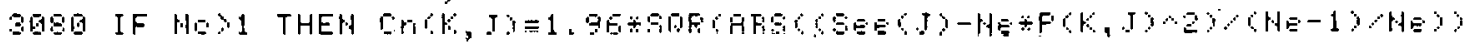

$3090 \quad I \leq t .3 t, j=0$ 


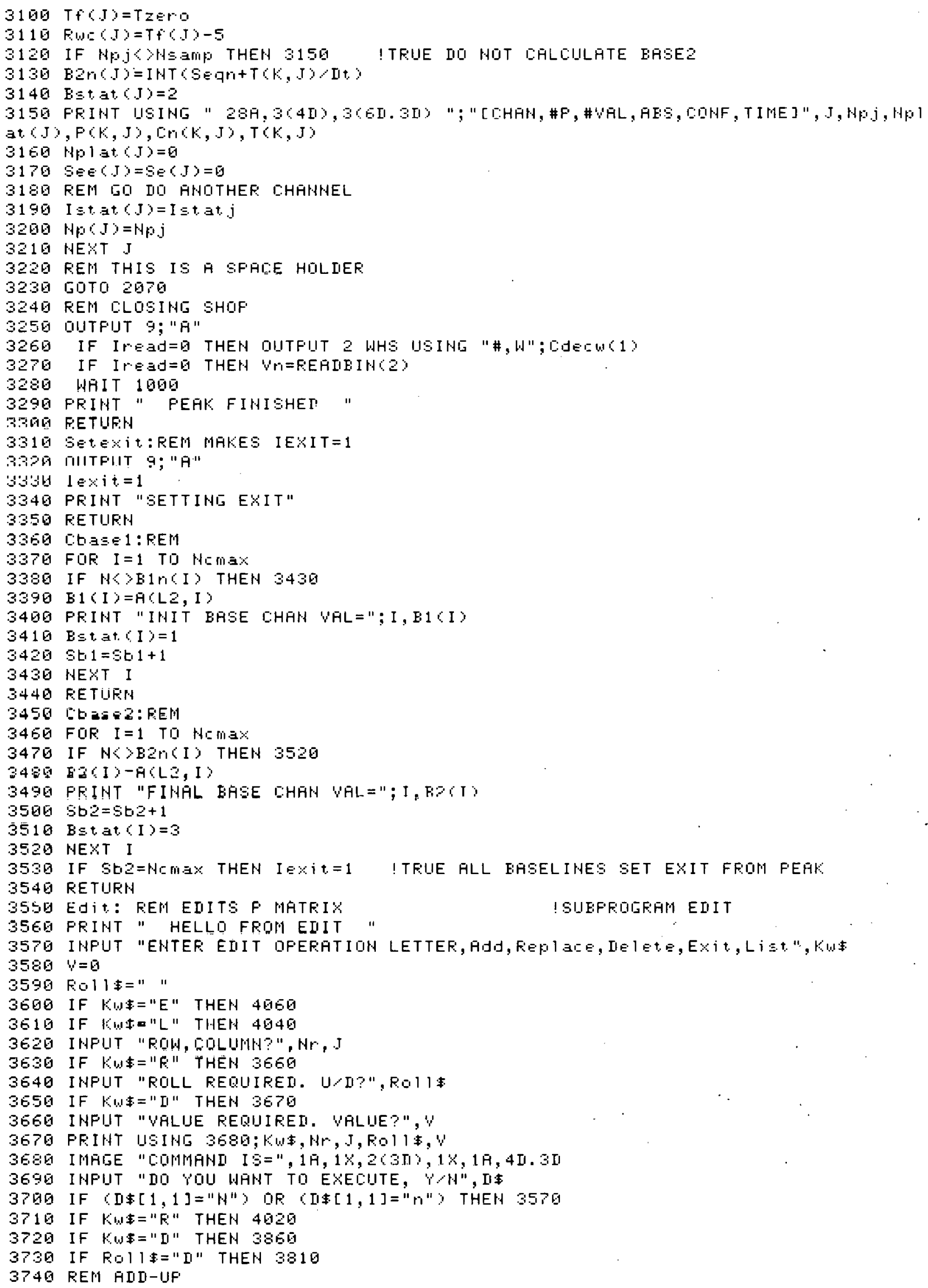




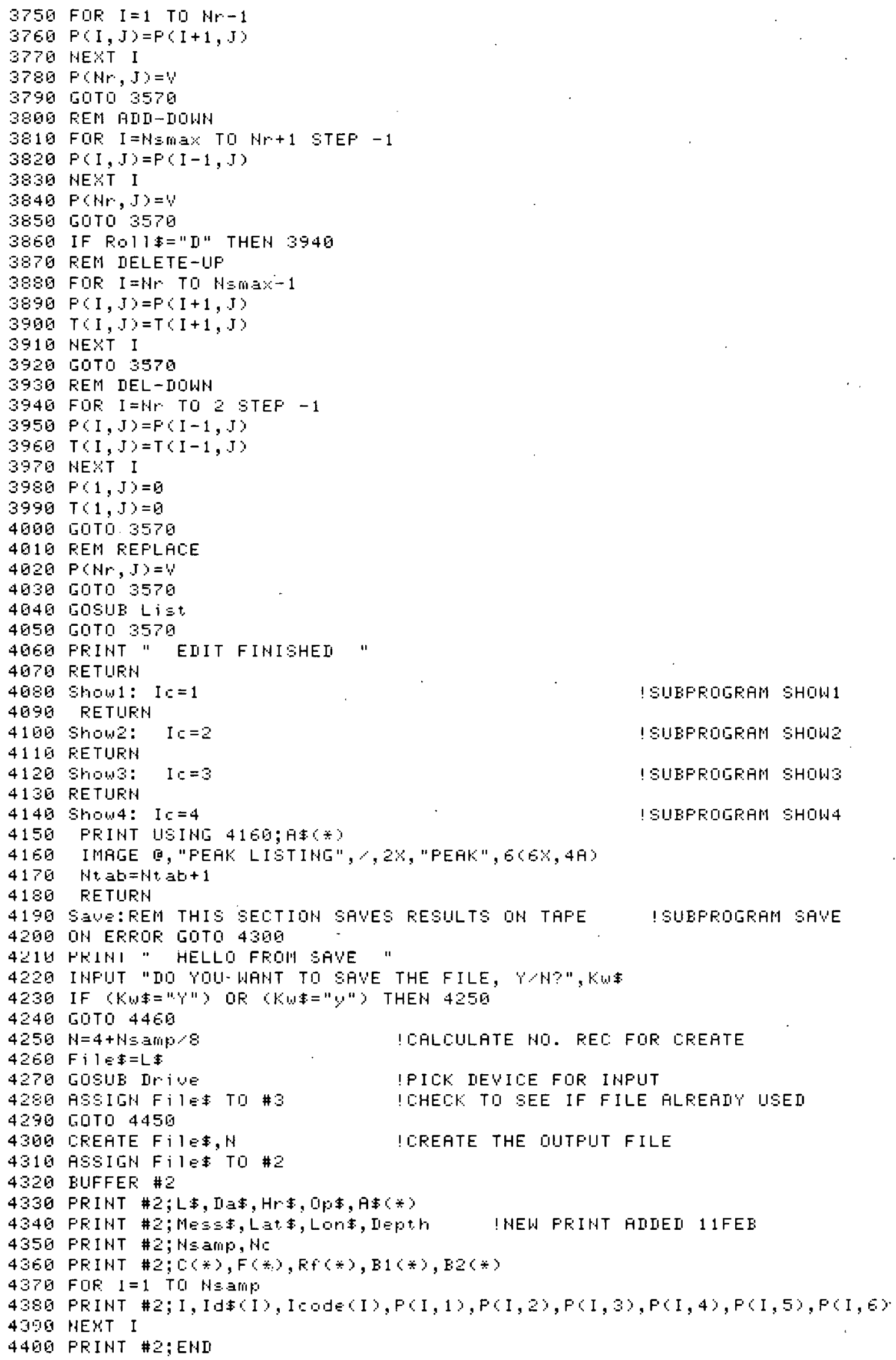




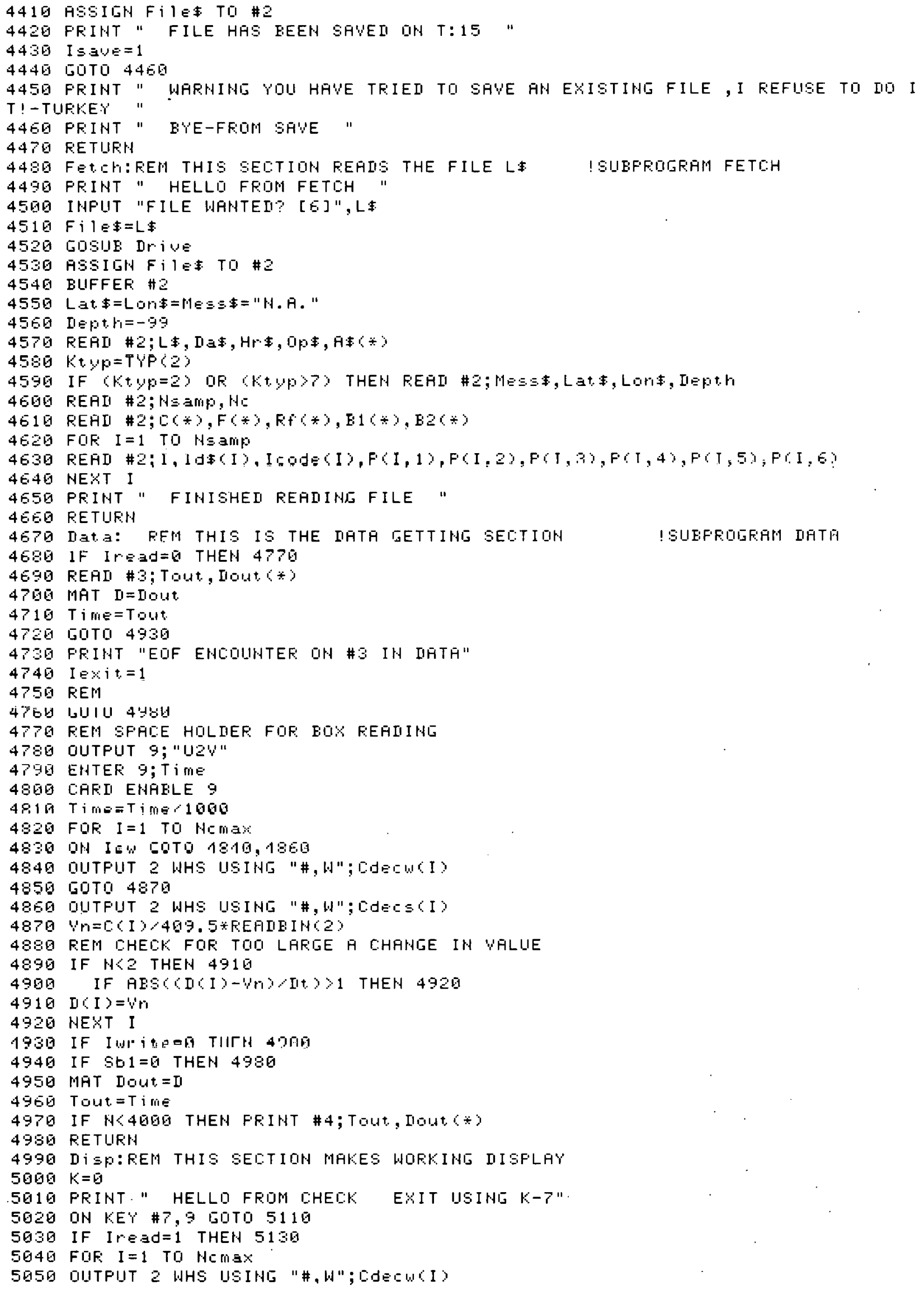




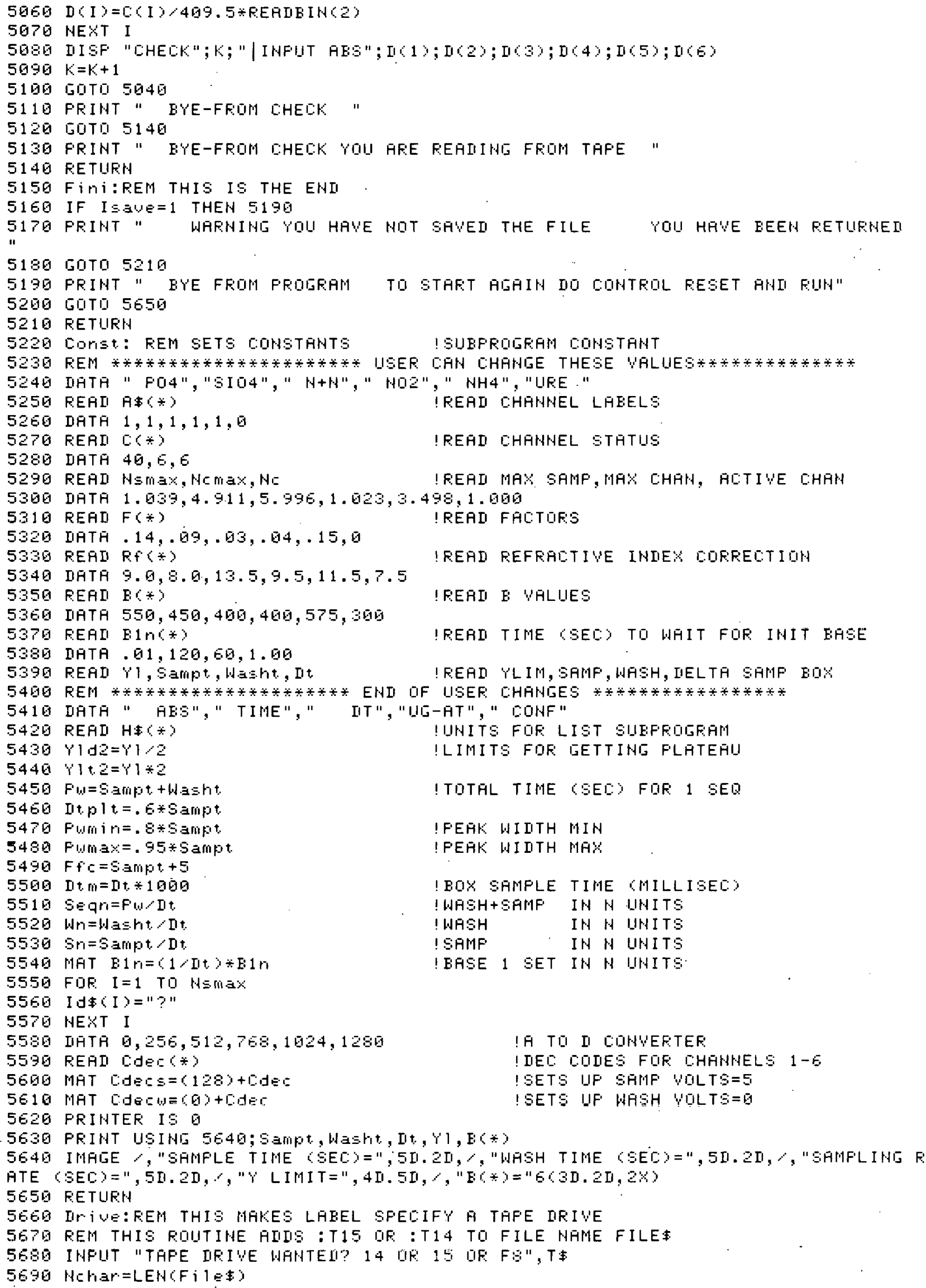

I A TO II COHWERTEF:

! IEE CDIIES FQIF C:HAHHELS $1-E$

ISETS LIF SAMF VILTS=5

ISETS IIF HASH WULTS= 


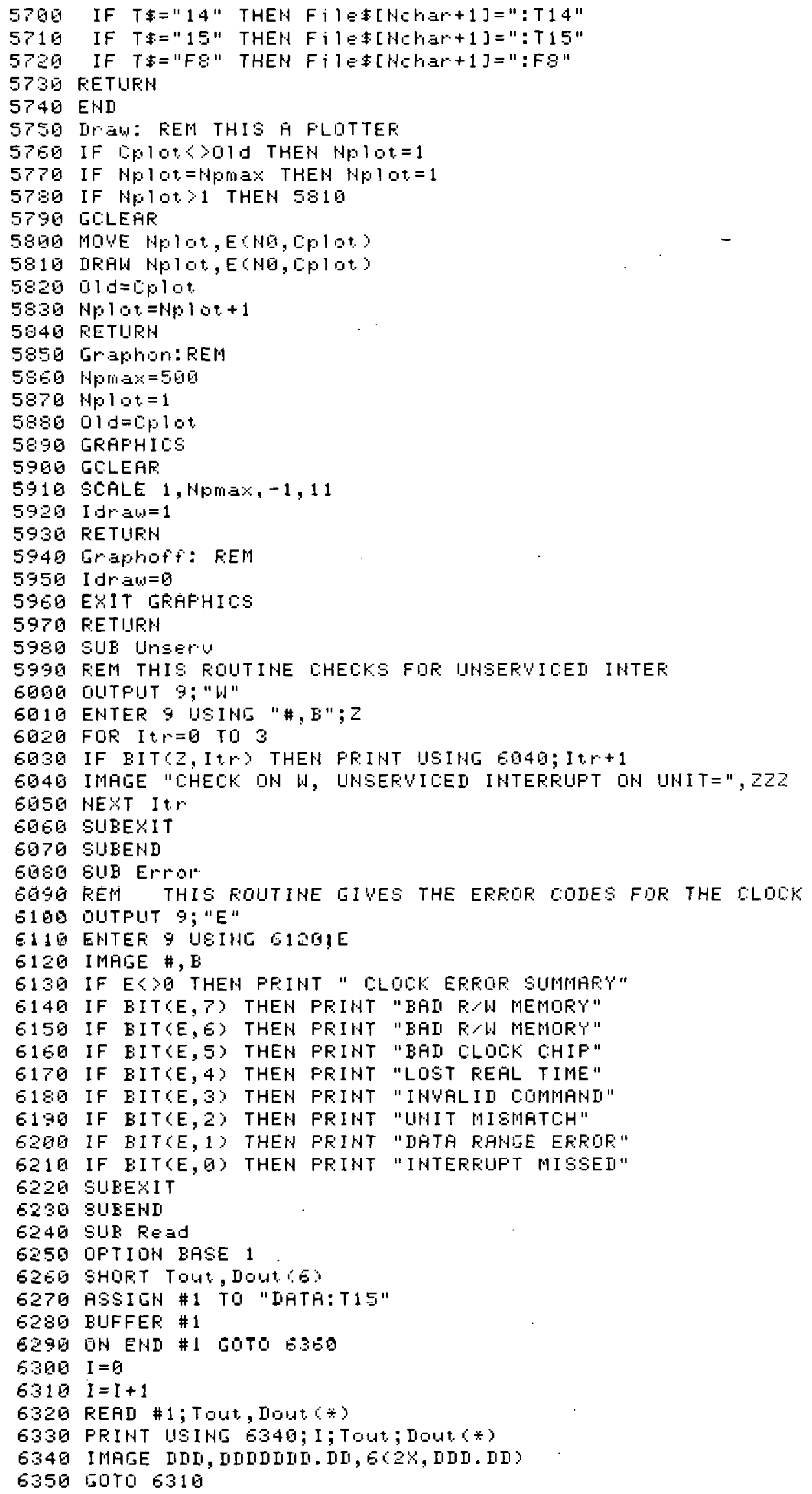


6360 PRINT "EGF REAII"

6370 SUEEXIT

6080 SUEEHI 


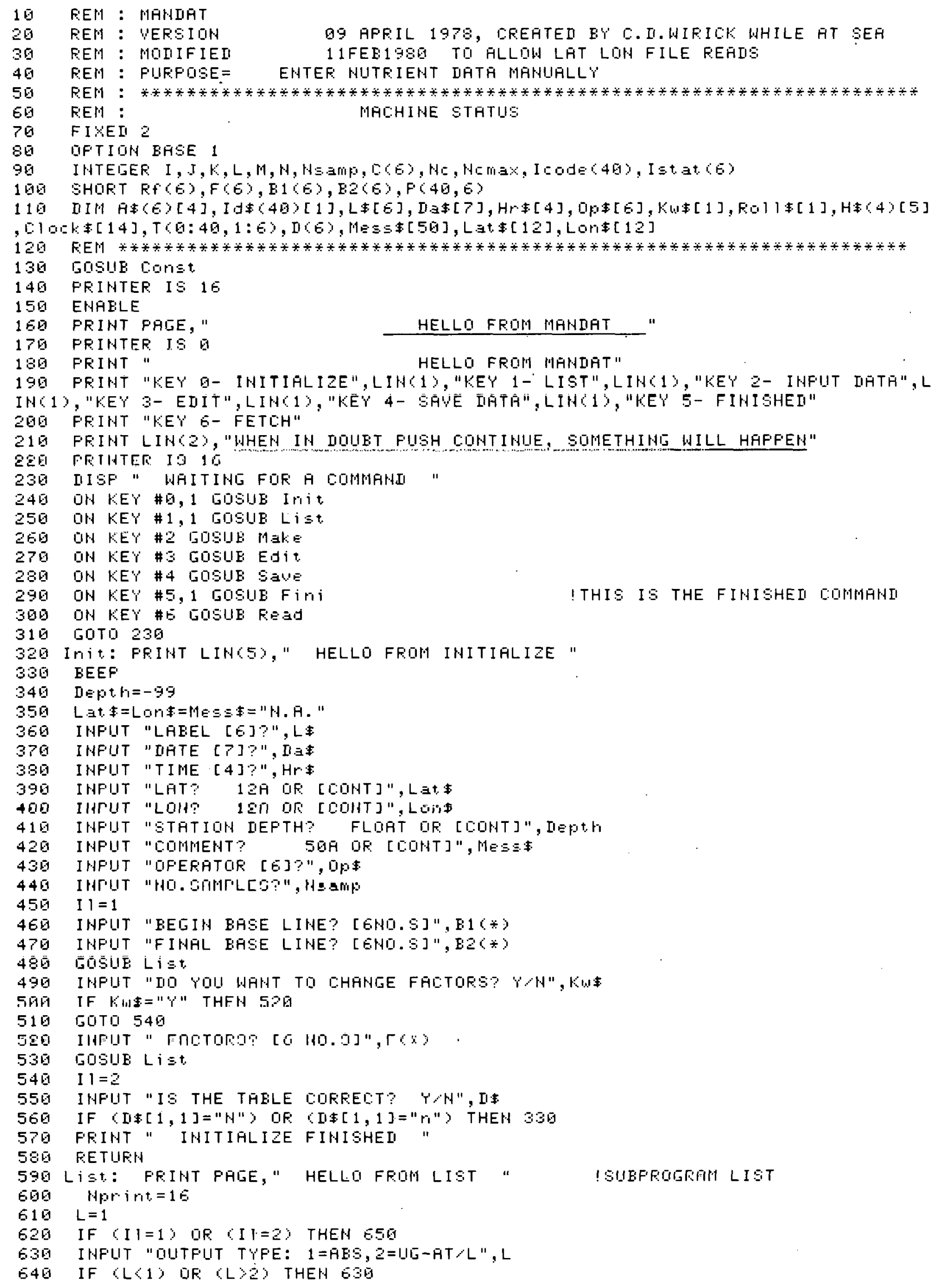


6.50 FRINTER: IS HFrint

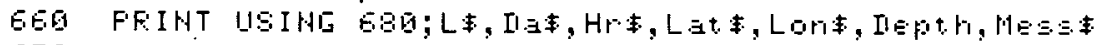

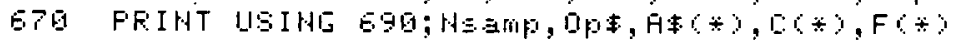

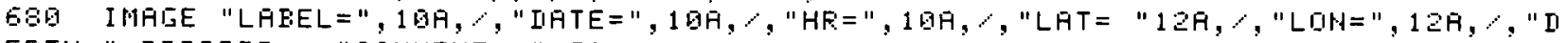

EF'TH= ", DIIIIII, , "COMHEHT = ", 50H

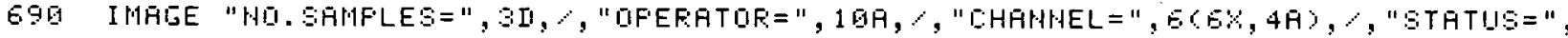

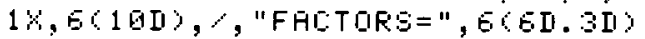

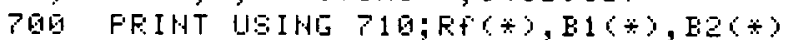

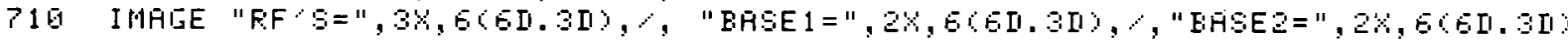

720 IF II $=1$ THEN 990

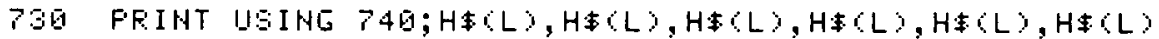

74 INAGE, "NO. II", $6(5 \times, 5 \mathrm{~S})$

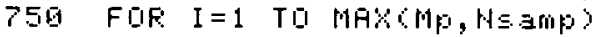

76 FIIF $J=1$ TO HEMax

770 ON L GOTO 780,800

780 II $S \mathrm{I})=\mathrm{P}(\mathrm{I}, \mathrm{I})$

790 50T0 850

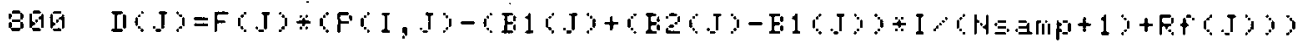

819 IF FCI, J) 0.0001 THEH 850

$820 \quad$ IL $5>0$

830 IF F(I, J) $>-1$ THEH 850

840 II $(\mathrm{J})=-99$

856 HEXT. J

860 IF II=2 THEH 890

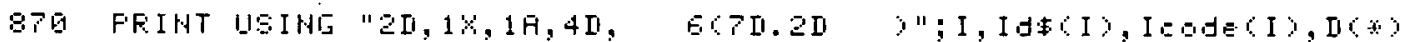

$890 \quad 50 T 0 \quad 900$

890 FRINT LISINI "2I, $18,1 \mathrm{H}, 4 \mathrm{I} "$; I, I J

906 HEUT I

919 IF HFr int=0 THEH 970

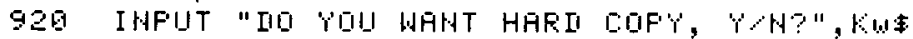

930 IF Kw: $="$ H" THEH 970

$946 \quad H F=$ int $=0$

950 G0T0 650

960 HEXT I

970 Harinte=1E

980 FRINTER IS Har int

990 PRIHT " LIST FIHISHEI"

1090 RETURH

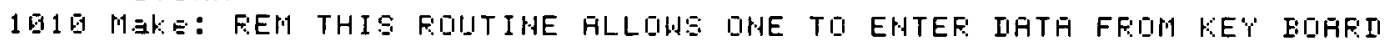

1920 I $1=3$

1930 PRIHT LIHC2), SFAC25)," HELLO FRIOM MAKE "

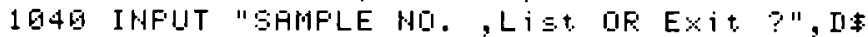

1659 I.F IH: $[1,1]=$ "E" THEN 1170

166 IF IS $[1,1]=" L "$ THEH 1140

$1670 \quad I=U A L(D=9)$

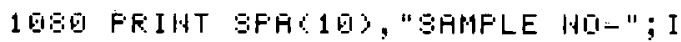

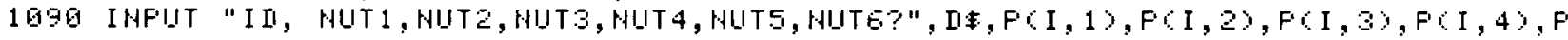

$(I, 5), P(I, 6)$

$1100 \mathrm{~L}=\mathrm{LEH}$ (I)

1119 I $d \div(\mathrm{I})=[1 \neq[1,1]$

1120 I 0 de $(I)=V R L(I t)[2, L])$

1130 GOTO 1040

1140 GOSUE Li $=$ t.

1150 FFIHT " YOU ARE STILL IH MAKE "

1160 GOTE 1940

1170 FEIHT " EYE FFOM MAKE "

11 BG FETIJEH

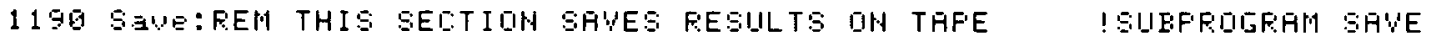

12 GO OH EREOF: GOTO 1300

1210 FFIHT " HELLO FRIMN SAVE "

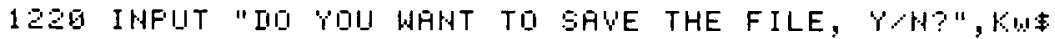

1230 IF (KWD="Y") DF (KW:="Y") THEN 1250

$12460 T 0 \quad 1450$

$1256 \quad N=4+H \leq a \ln 18$

$126 \mathrm{FilE}=\mathrm{F}=$

1270 GISUE Ir. IUE 


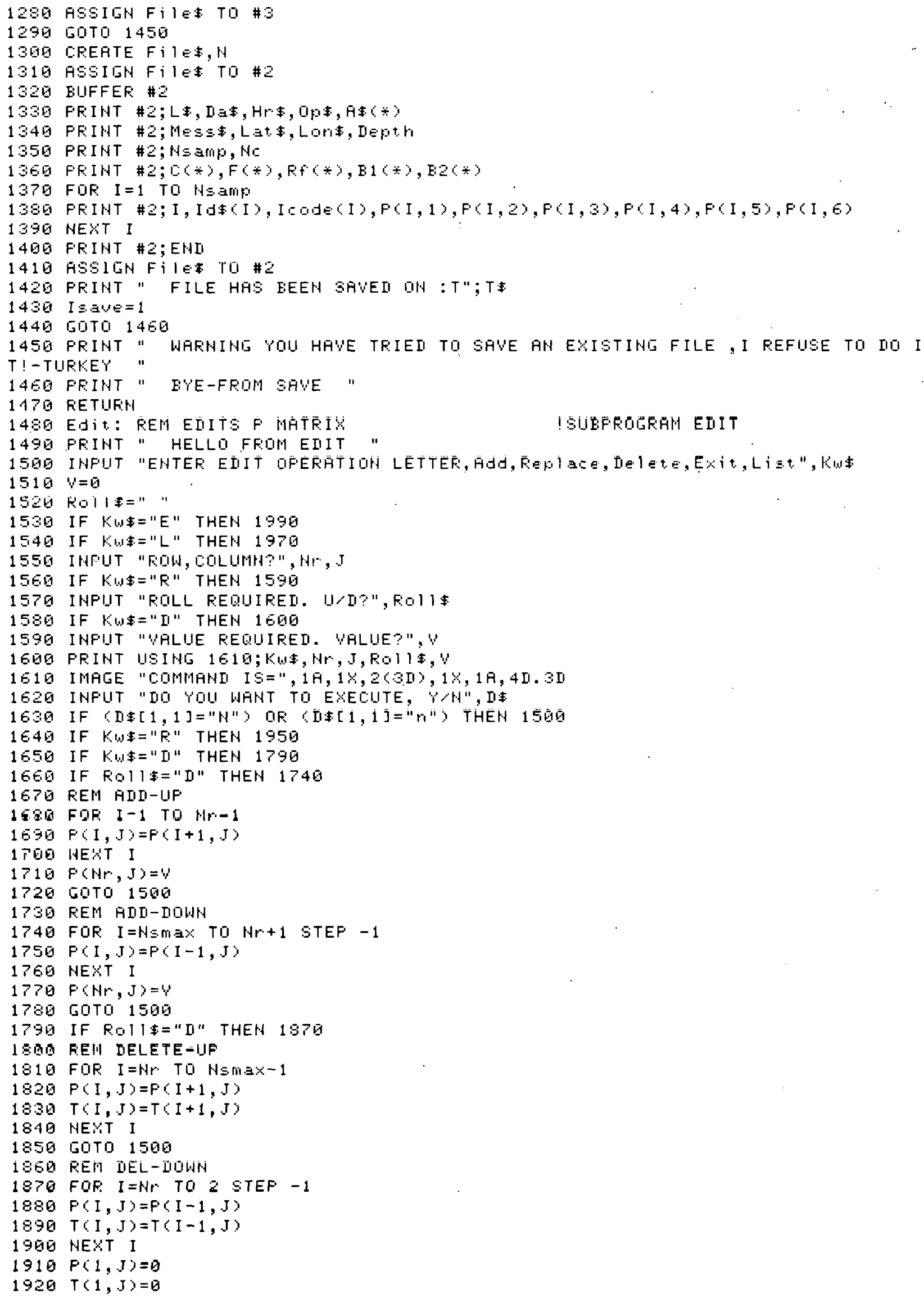




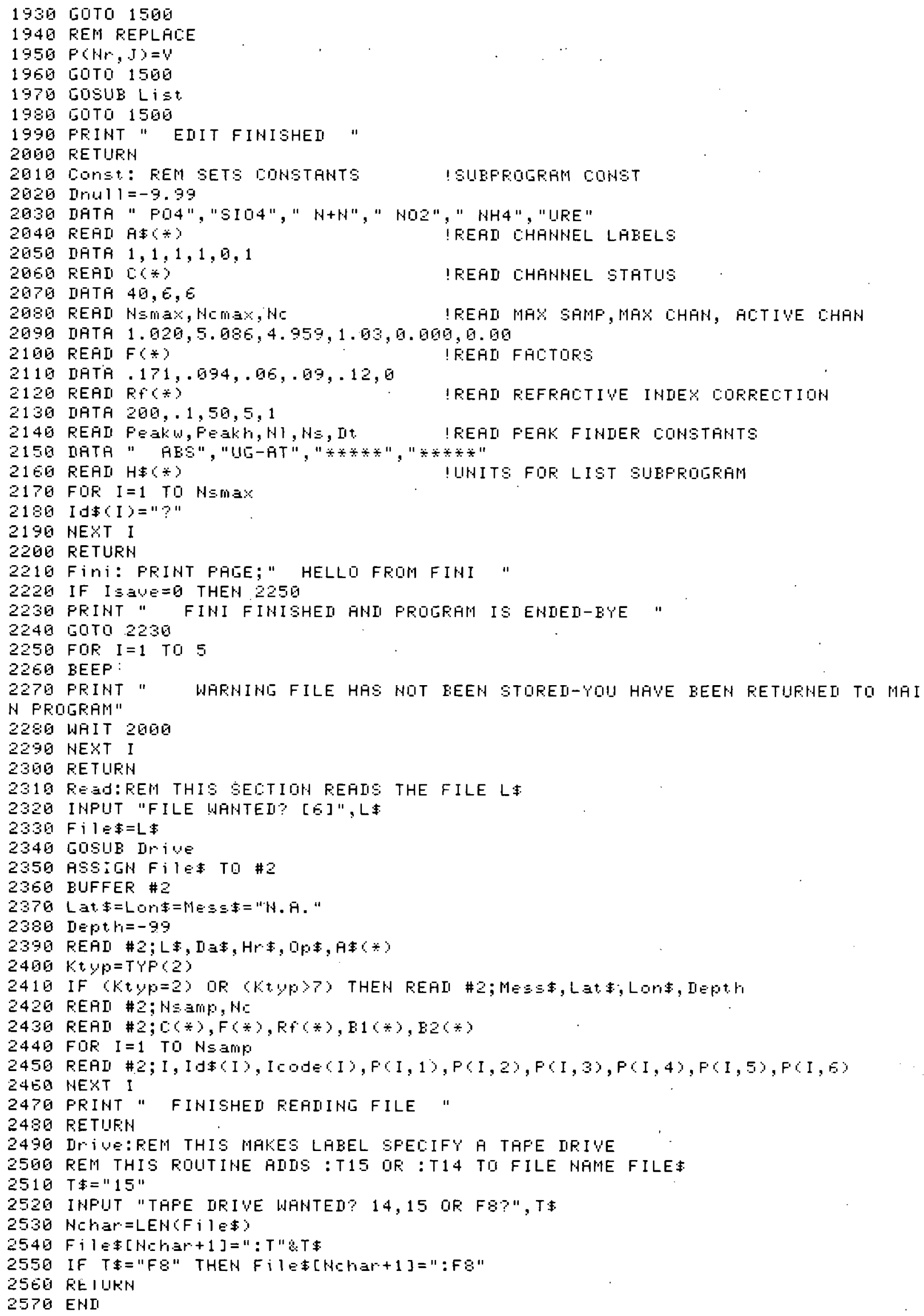




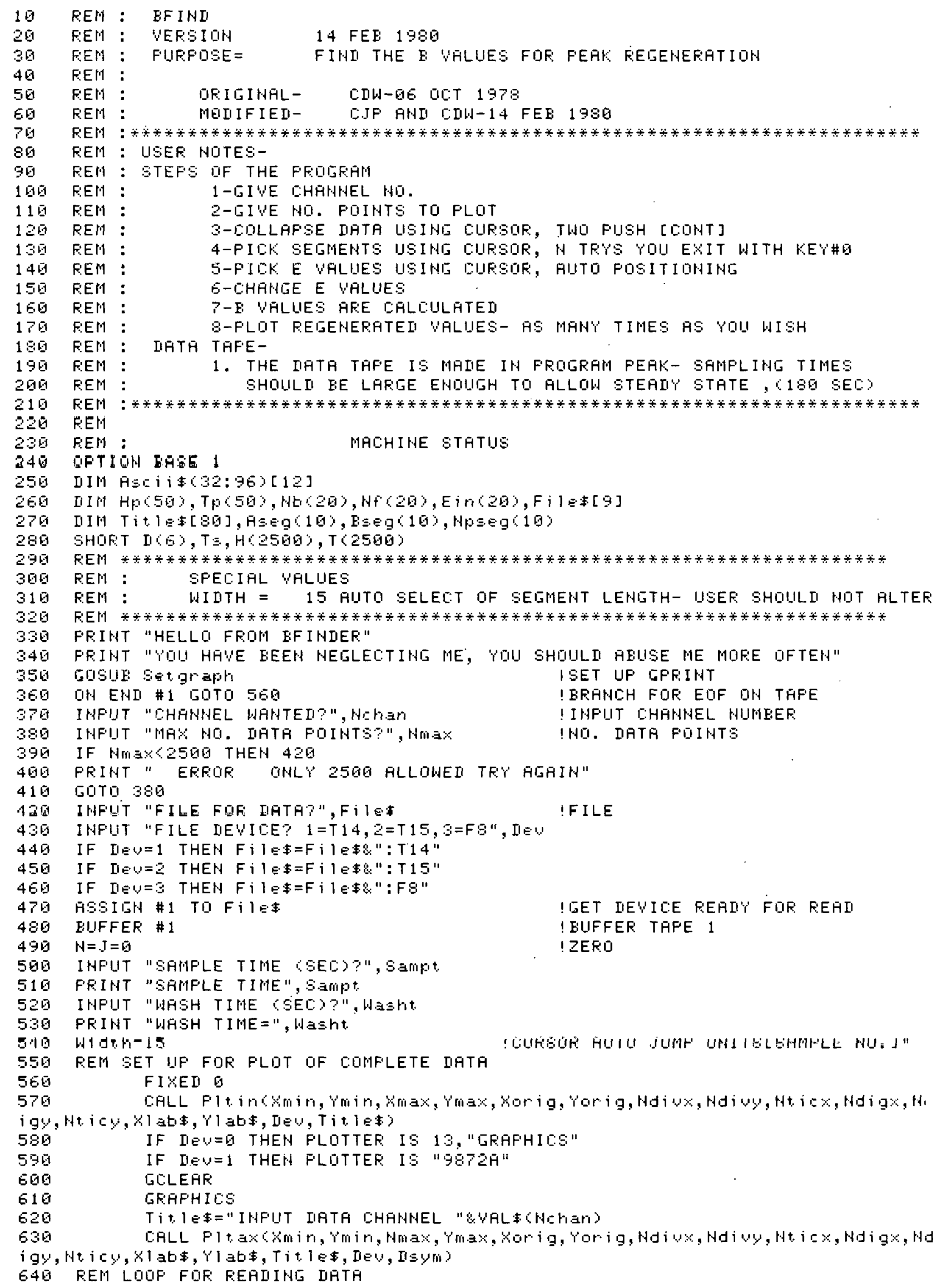




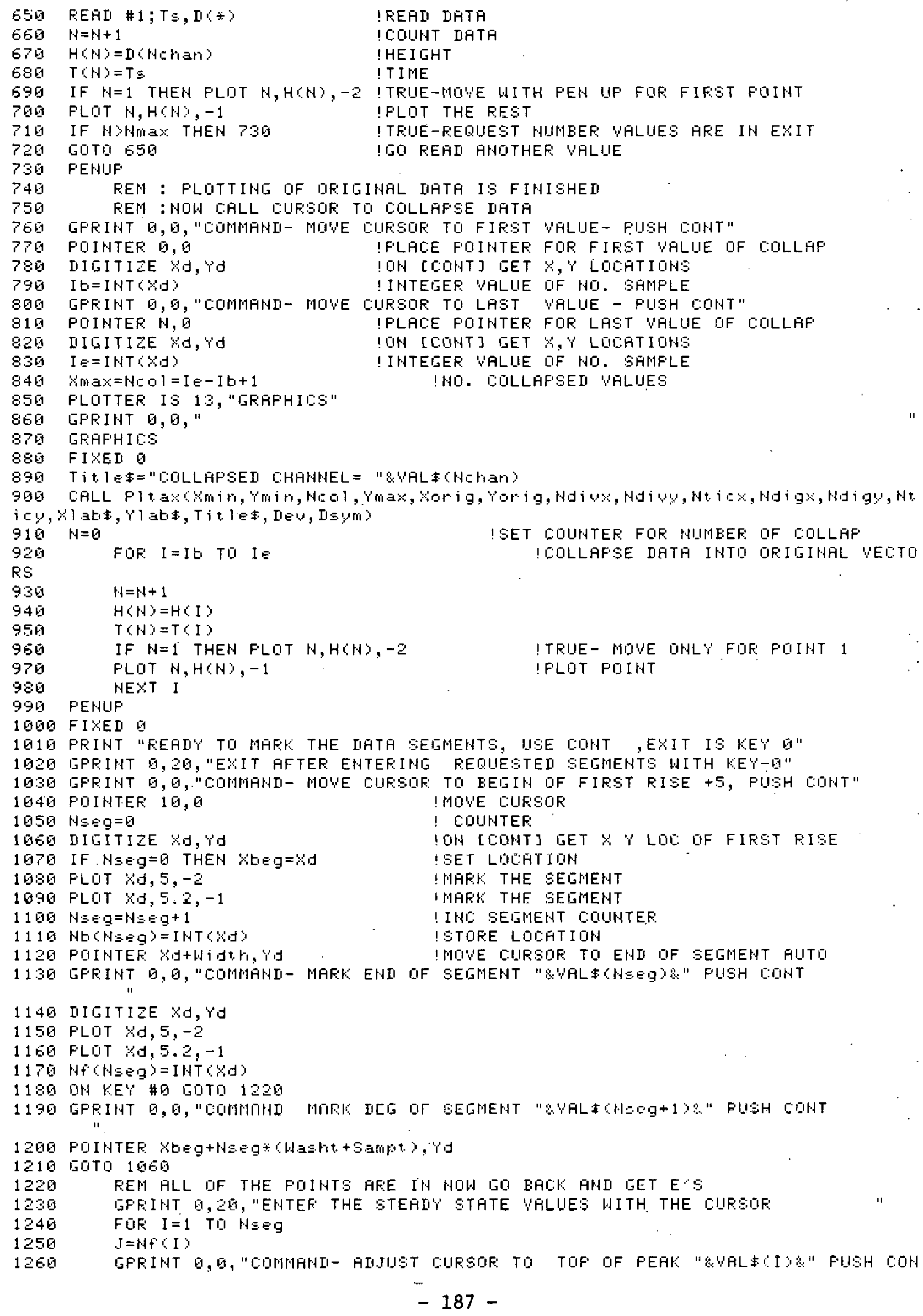


$T$

1270

1289

1296

1361

1315

1920

1309

1345

1350

1306

1376

1380

1396

1460

1410

1420

J $4: 3$

1446

1450

$146 \mathrm{G}$

1470

1400

1495

1590

1510

1520

1596

1540 GOTD 1580

1550 IHFUT "FEAK ND.,E?", I, XG

1560 EincI) $=\mathrm{xd}$

1576 GOTO 1390

1580 FRINTER IS $1 \mathrm{E}$

1590 REM EEIIH FLOTT SET IIP

1609 Tm $\mathrm{A} \%=\mathrm{Nm} \mathrm{A} \times=\mathrm{O}$

$161 \mathrm{G}$ FDF I-1 TO HEE

$1629 \quad J=H(t)(I)$

$1630 \quad K=H F(I)$

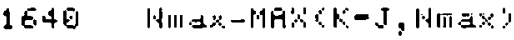

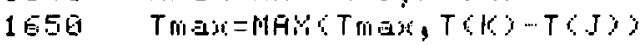

$1 E E G$ HEXT I

$1679 \quad \mathrm{~B}=0$

1690 FLOTTER IS 13 , "GFAFHI

1699 GCLEAR

1700 GRAFHICS

1710 Tit 1 Et="RELRESSION"

1720

$1 \in t, \mathrm{D} \in \Psi, \mathrm{I} \equiv y \mathrm{~m})$

1730 FOF I $s=g=1$ TO $H S E g$

$1740 \mathrm{H}=0$

$1750 \quad E=E$ ir $(I S E g)$

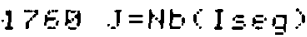

$1>>0$ TE $=T$ T. I ?

1780

1790

1806

1810

1820

1330

1849

185

$18 E$ IF $H>$ , Ifreg, Ifres, Ilf tot, Atort.

$1870 A \equiv 8 g(I) E g)=A$
IMOWE TO EXFECTED TOF DF FEAK

! OH [OOHT] GET $X, Y$ LOLATI DH 


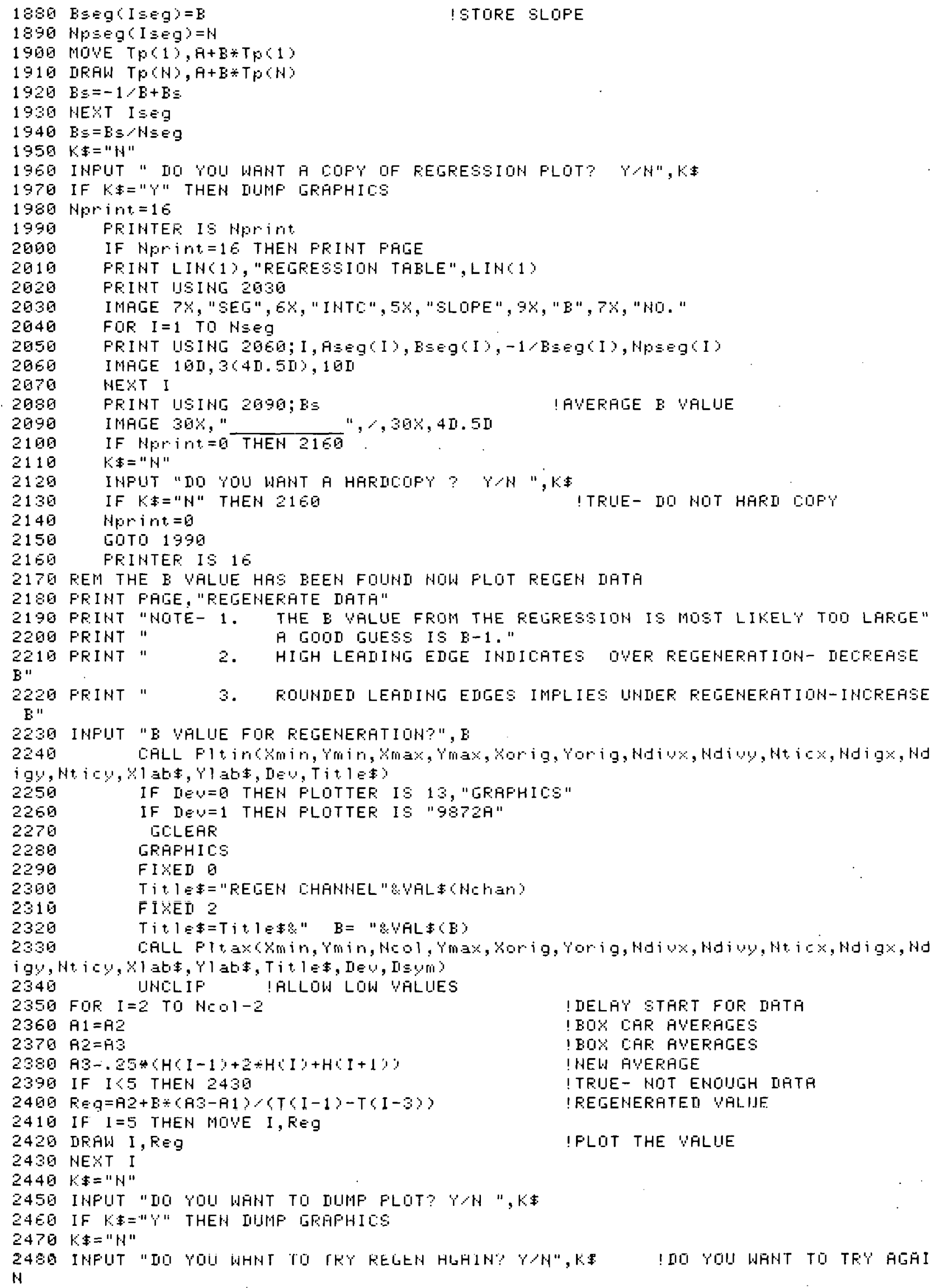




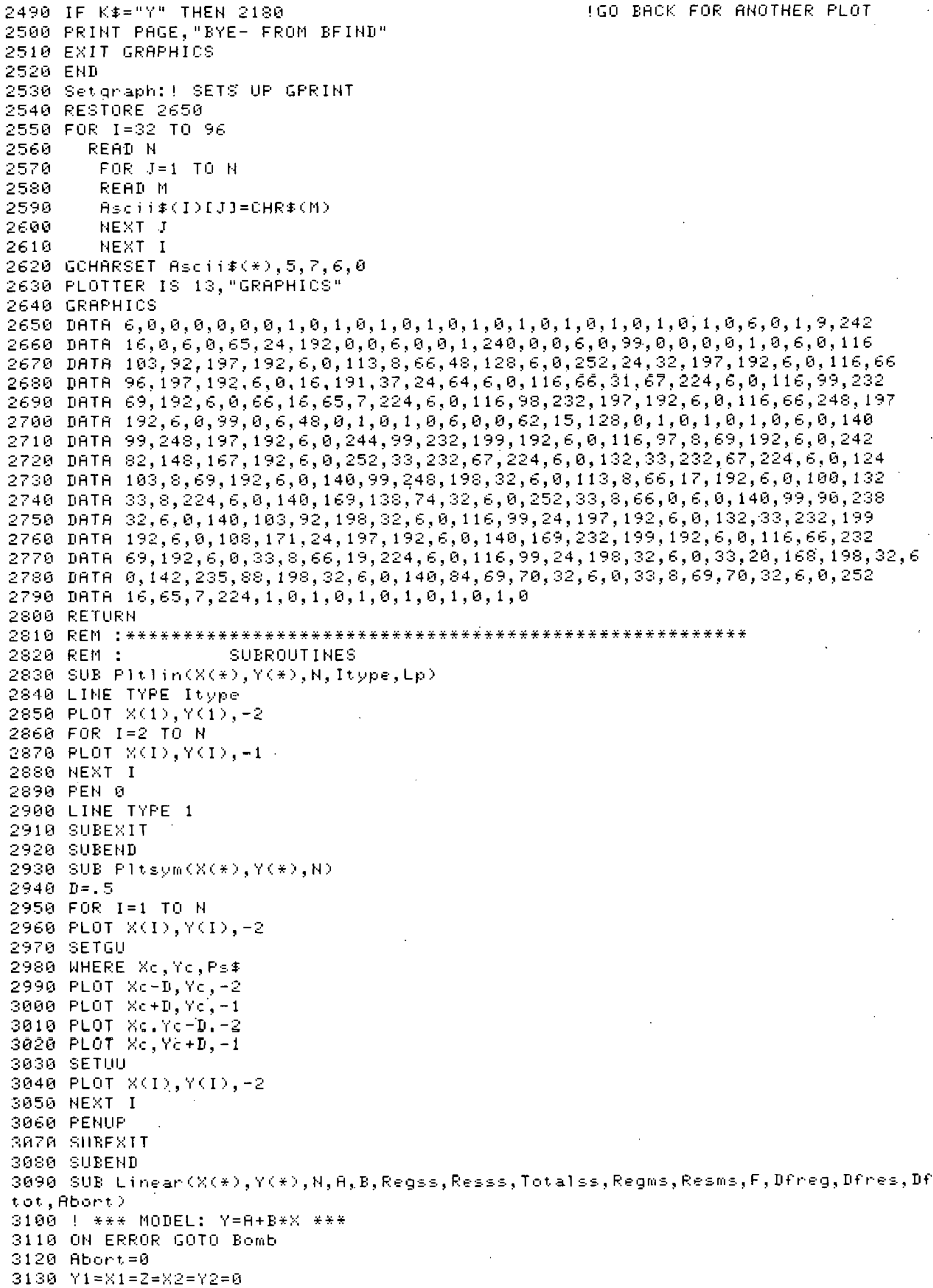




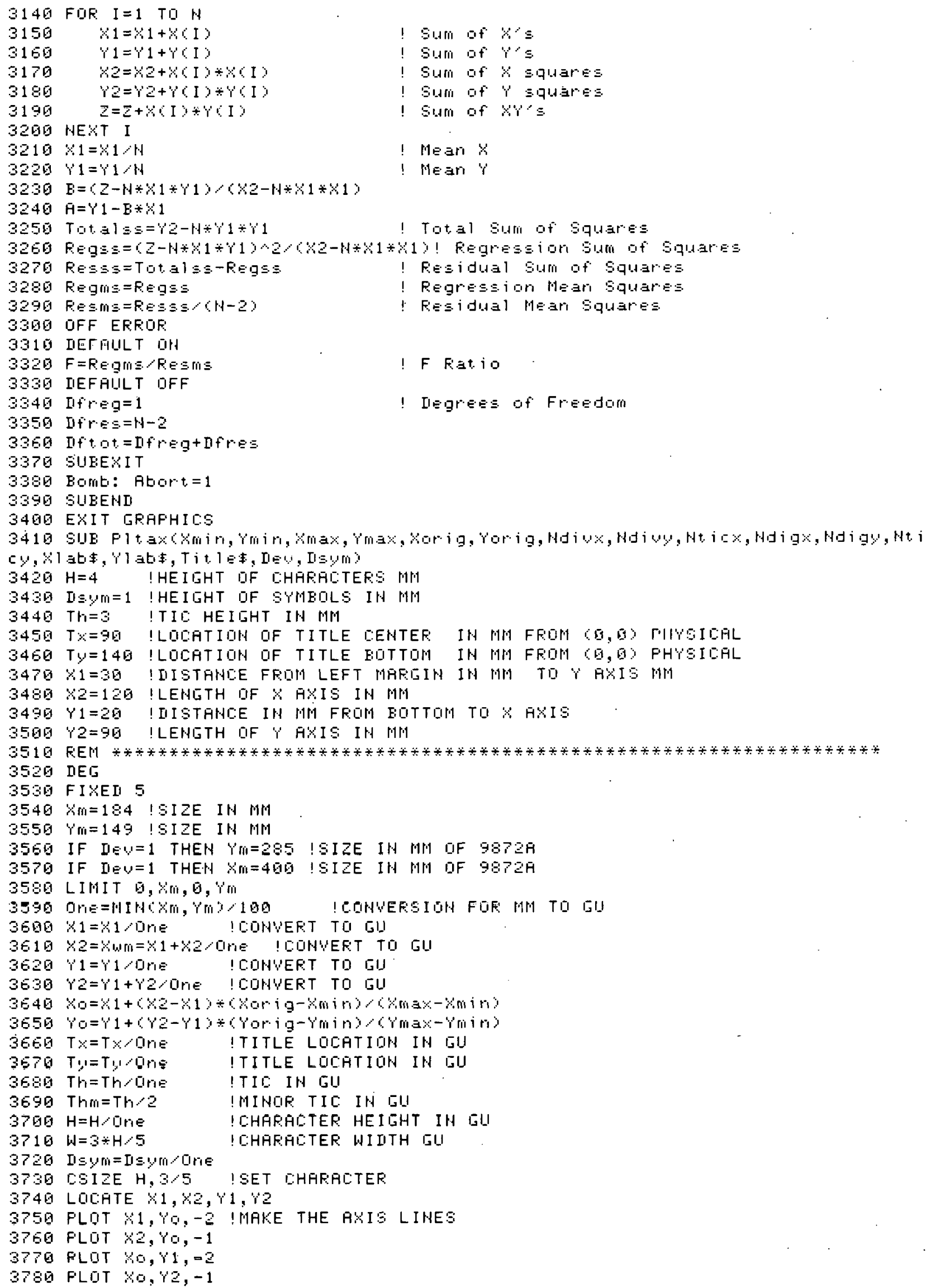




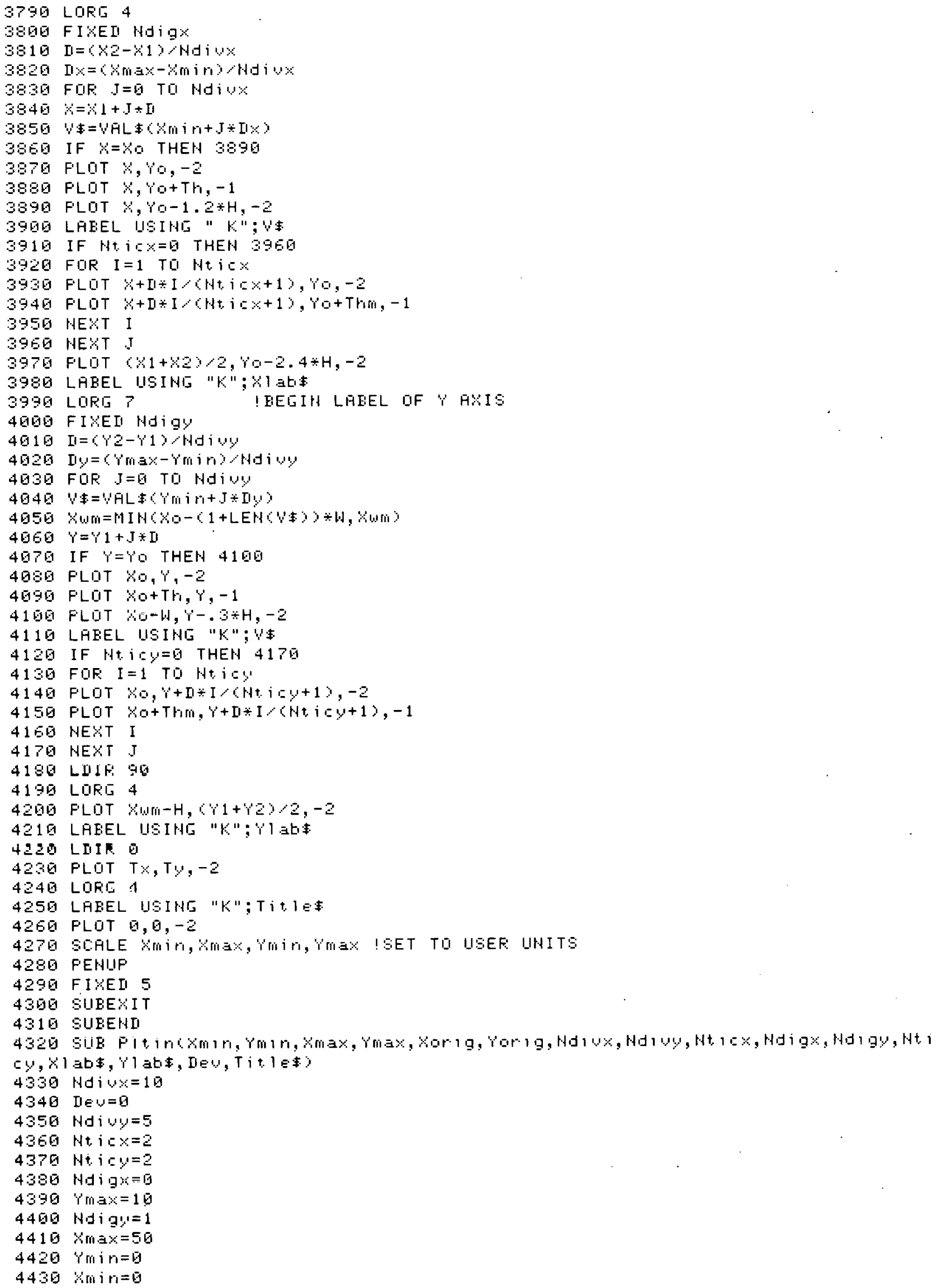


$4440 \times 1$ at: = SHMFLE HQ."

4450 "'lats="FEAK (ABS)"

446. Tit IE

4479 Xorig

4486 rorig

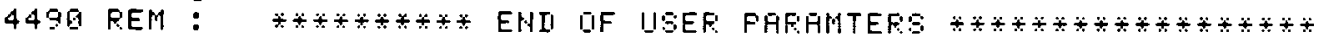

45 DU SUBEKIT

4510 SIIEEND 


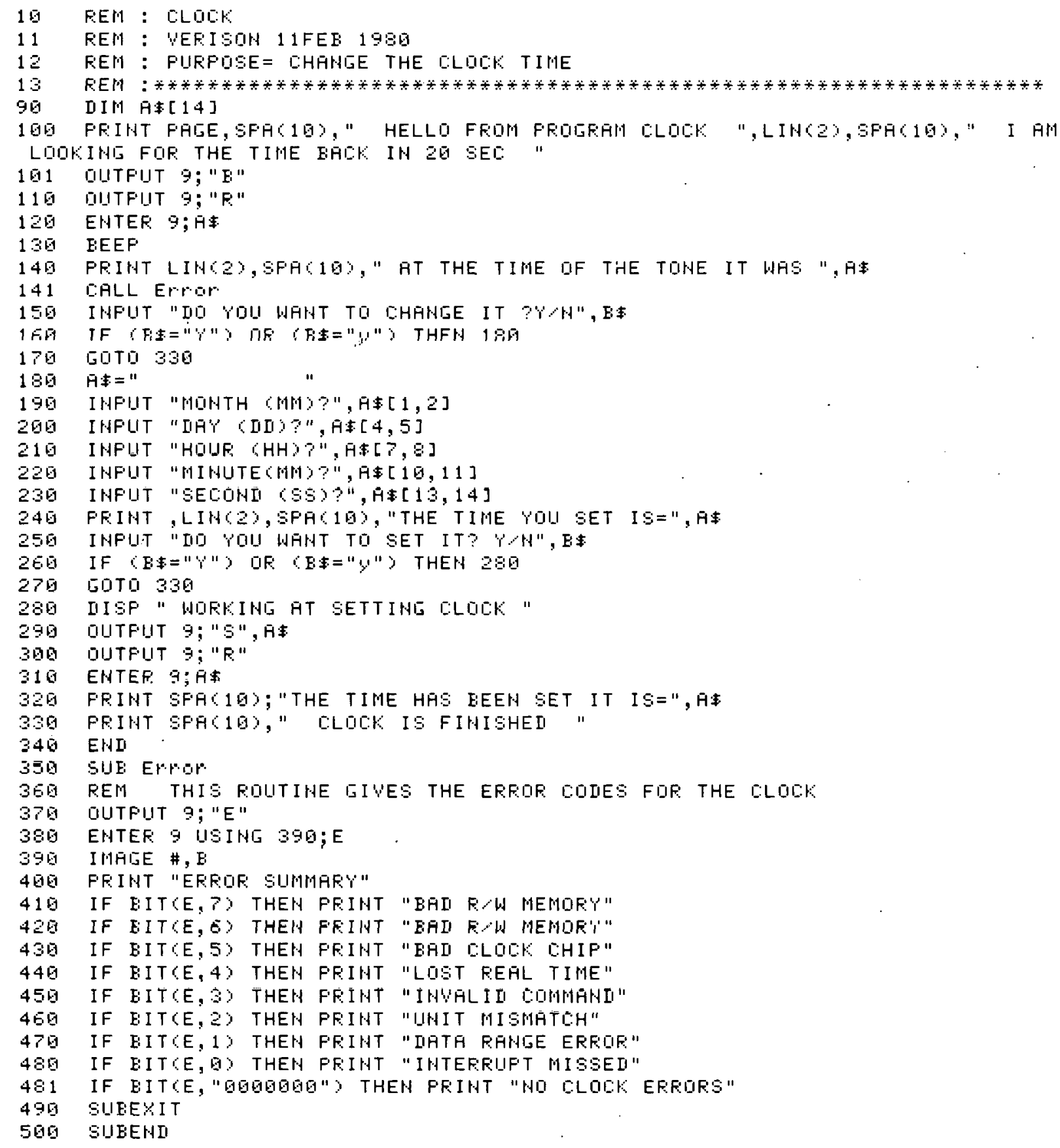




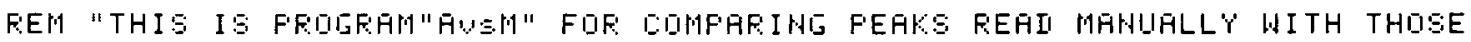
FDINHI EY FEOIFEAM "APILDT"

29 PFIHT "HELLO FFOM FUTOMATII: \& MAHUAL FERK COMFARATOR "

30 FEH THIS IS VEFSIDH 27 SEFT 1979, EY EIHCE.jP?

49 FISEII 2

5 DFTION EASE 1

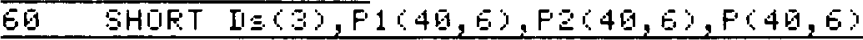

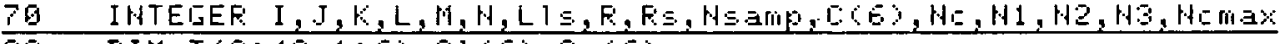

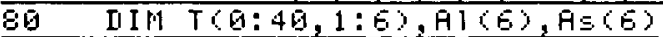

90 DIM Ti(0:100), $\mathrm{A}(0: 100,1: 6)$

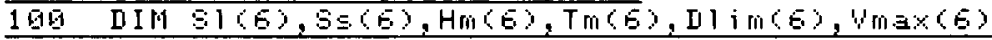

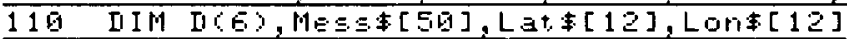

120 SHORT Rf(E),F(E), B1(E),EZ(E)

130 IHTEGER I code(40), Ist at $(6)$

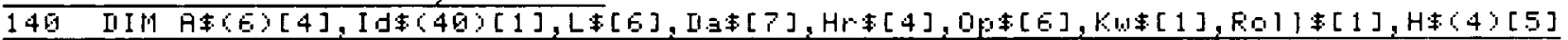

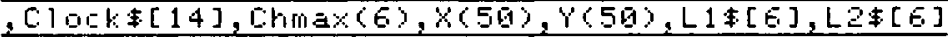

150 IIATA $10,5 \overline{0}, 5 \overline{0}, 1 \overline{10}, 1 \overline{0}, 5 \overline{8}, 6$

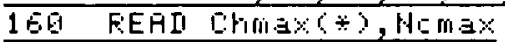

179 I $s=1$

180 G0S11 Read

$190 \mathrm{~L} 1 \mathrm{t}=\mathrm{L} \$$

$200 \quad \mathrm{I} \equiv=2$

210 GUSUE REEU

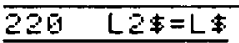

230 IHFUT "CHAHHEL WAHTEI IH FLOT?", IEW

240 EXIT ERAFHICS

250 पiatit [1]="1"

260 Ylatit [1]="2"

$270 \times 1 . a t+[3]=A \neq(I \subset \omega)$

280 Ylati[3]=Aक(ICW)

290 FFINT "THIS IS A THELE OF MAHUAL AHII COMFUITER REAI AESUREAHEE FQR", ALCIEW)

$30 \bar{G}$ PRINT "1="; L1

$31 \mathrm{G}$ FRIHT "Z=";LZ

320 PRINT USIHG 330;\%lat, Ylabt

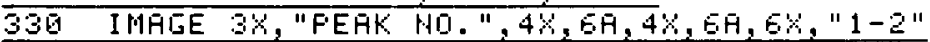

34 FDR $I=1$ TD NEAmE

$350 \quad \times($ I $)=I$

360 Y $(\mathrm{I})=\mathrm{F}_{1}(\mathrm{I}, \mathrm{I}, \mathrm{w})-\mathrm{F} 2(\mathrm{I}, \mathrm{I}, \mathrm{w})$

370 FRIHT USIHE "10I, 3C7D.2I)"; I, P16I, I GU),P2(I, IE, Y), I)

380 NEXT I

$3 \overline{90}$ FRINTER IS 15

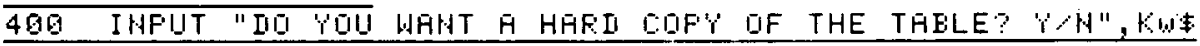

$41 \mathrm{G}$ IF KWะ="H" THEH 450

420 IF KuI $=" Y "$ THEH PRINTER IS 9

$430 \quad 50 T 0 \quad 296$

440 PFINTER IS 16

430 G0SUB F10

465 WAIT 5 GEG

479 FRINT FRIE

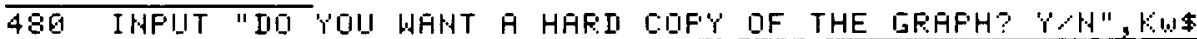

490 IF KW"="W" THEH 520

5 G日 IF KU\$ $=" Y "$ THEH 510

51 D IUMF GRAPHISS

520 GOTO 239

530 LiSt: PRINT FAGE, "HELLO FROM LIST " ISIBFFIIIFAM LIST

54 Aprint $=16$

$556 \quad L=1$

560 FFIITER IS Har int

570 FRIHT "THIS IS A LIST FOR IIATA SET=", IS

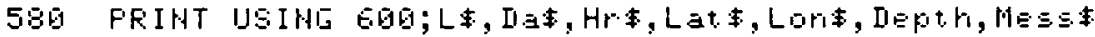

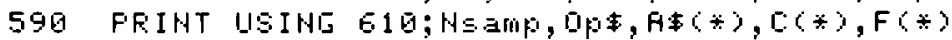

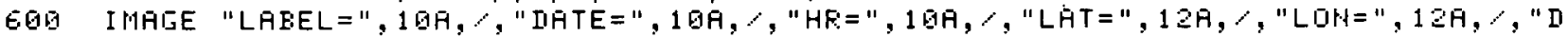

EFTH= ", DIIII, /, "EOHAENT = ", 50R

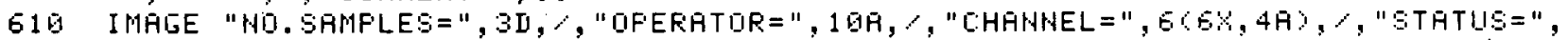

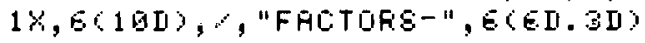

620 PRINT USIHG 630;Rf $\div), B 1(\%), B 2(\%)$ 


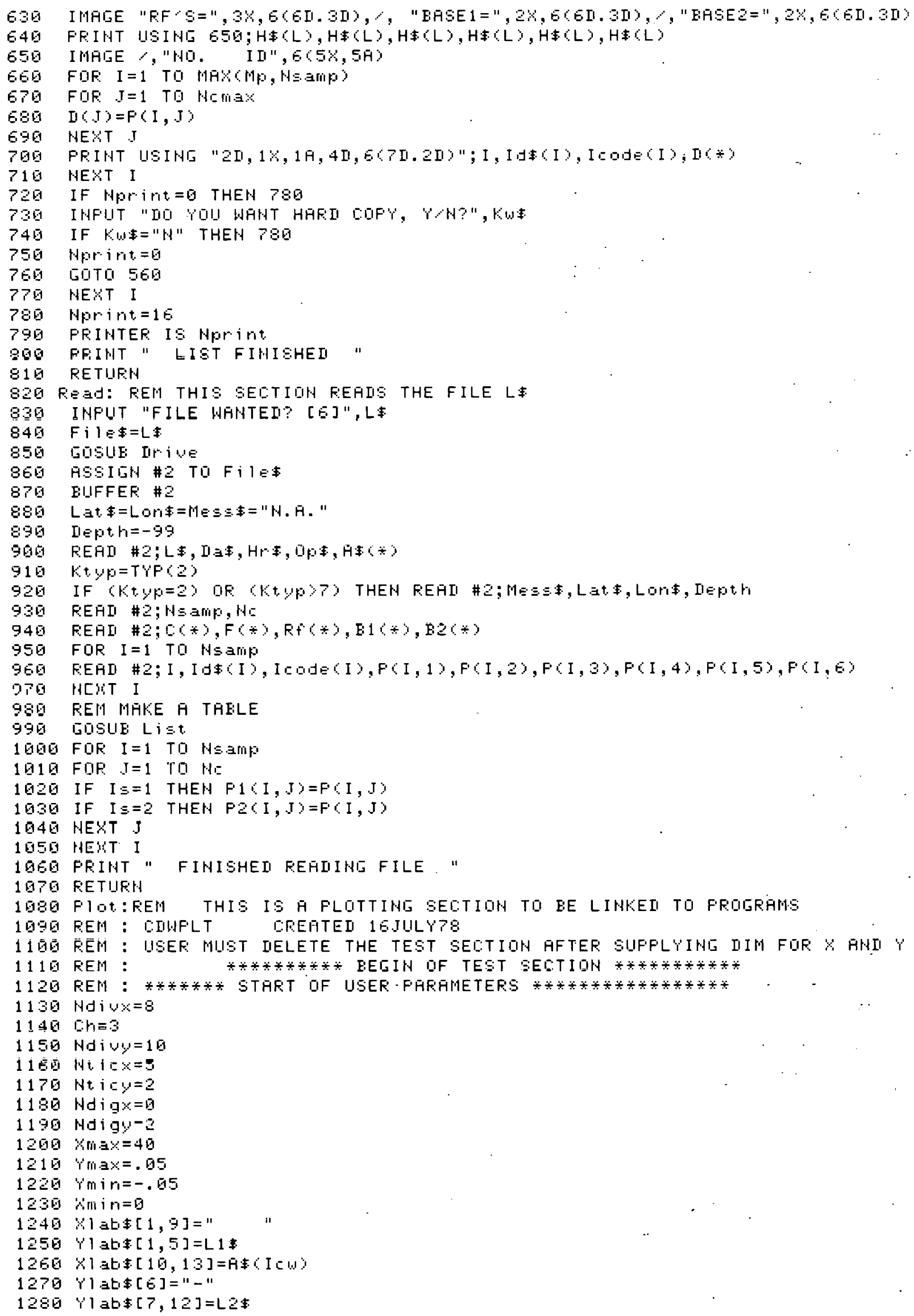




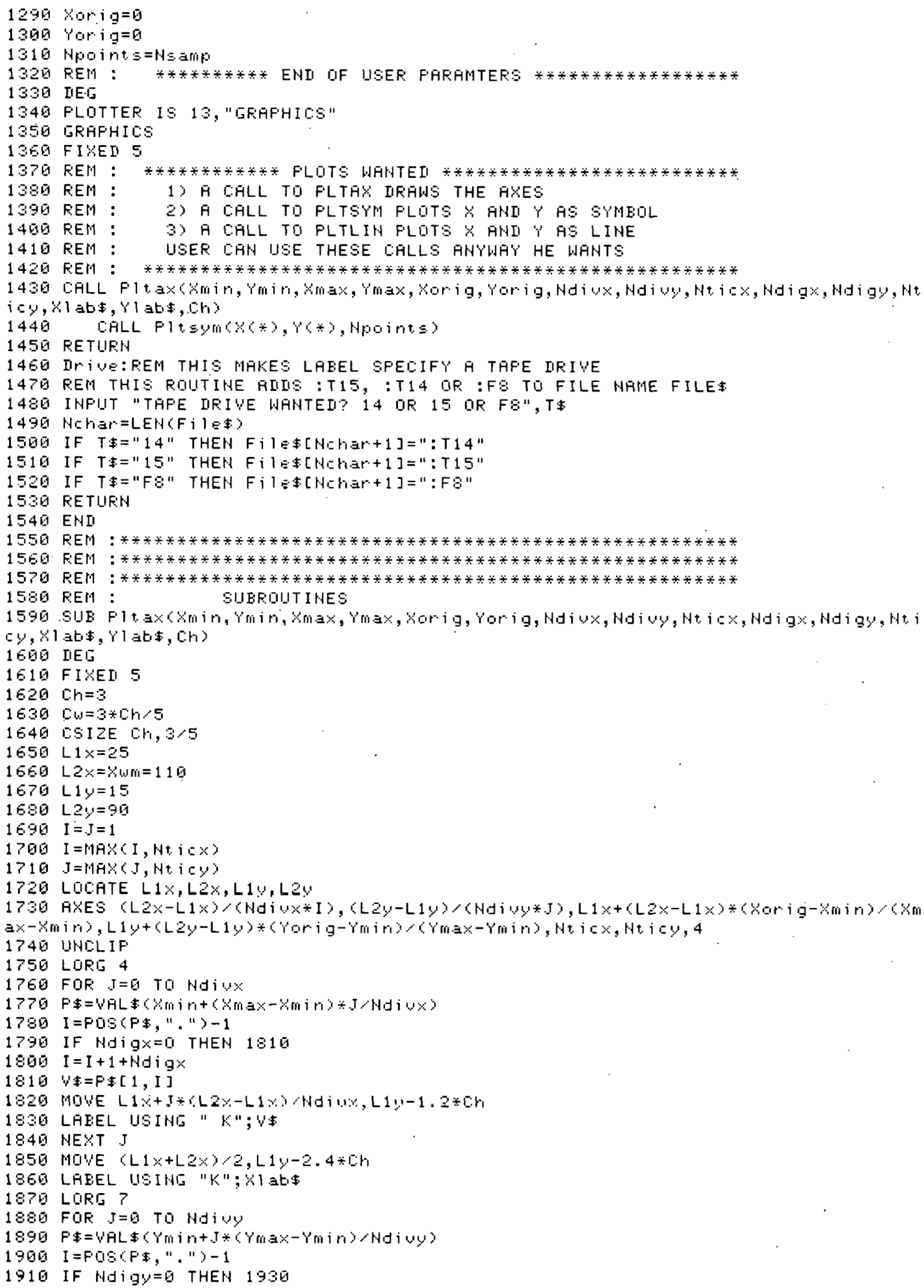




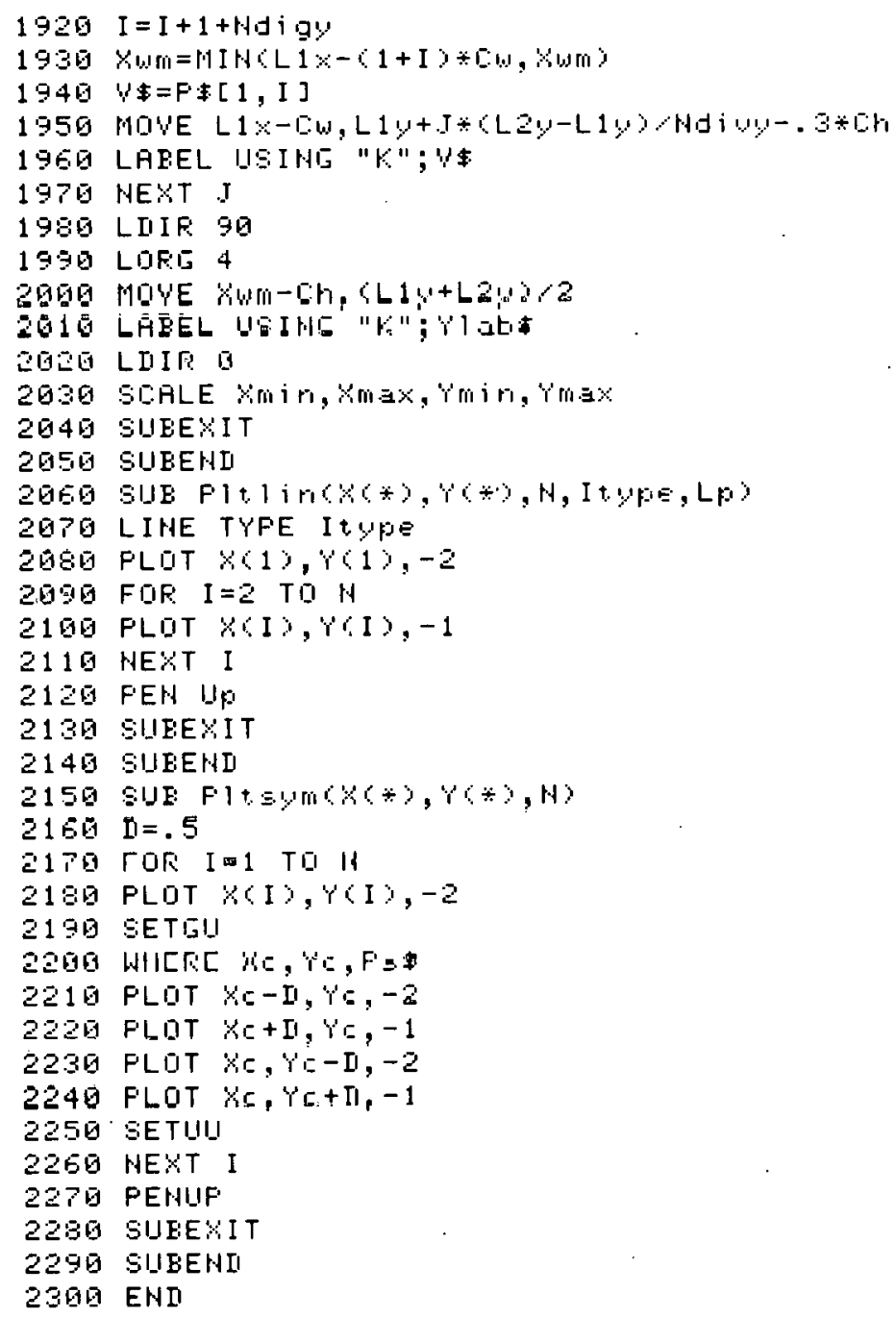




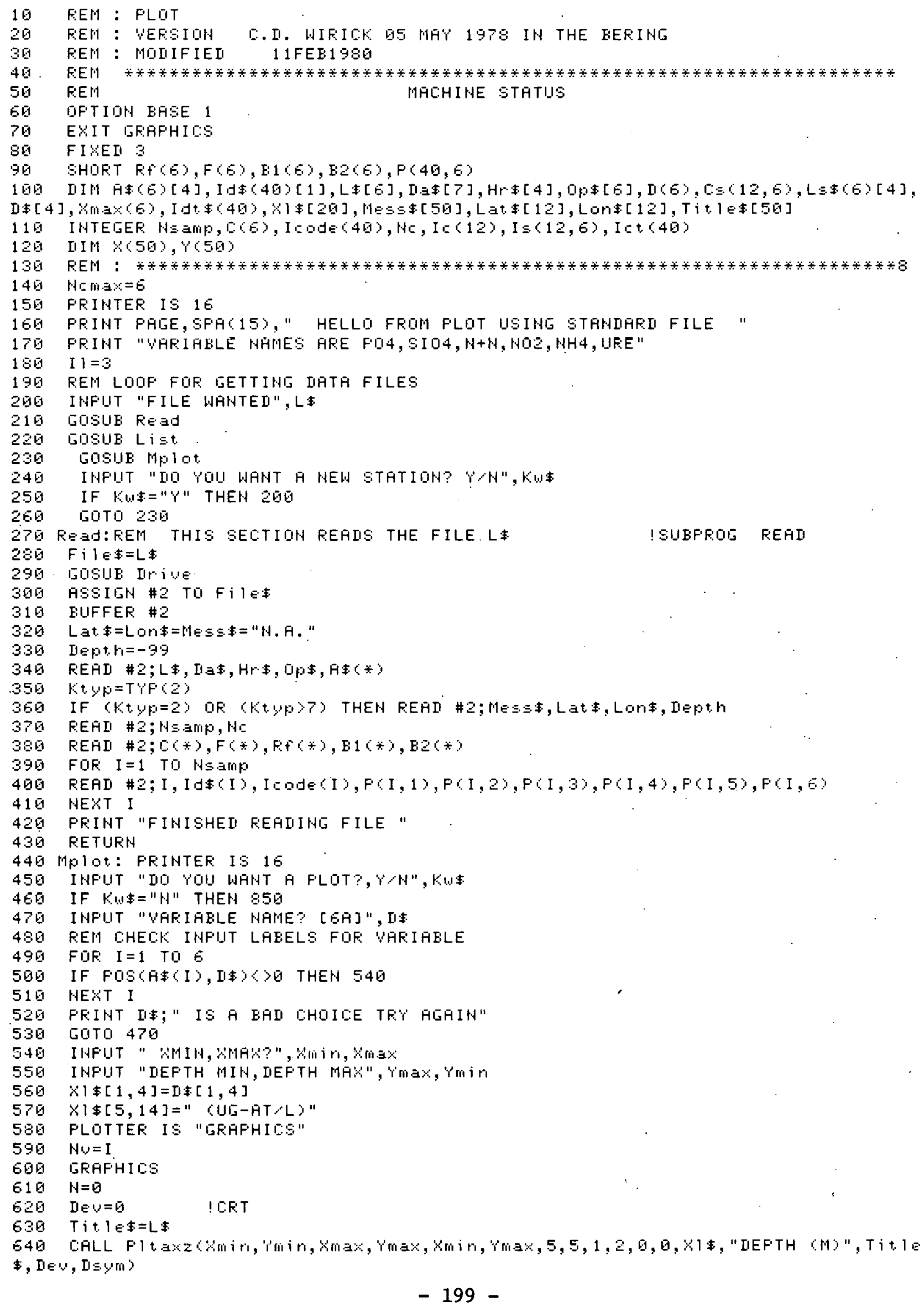




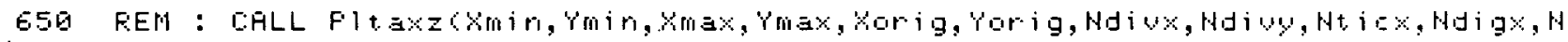
di $g y, H$, i $=y, K 1$,

GE REM SERREH FOR HVIFO HHD IEFTH

G7日 $\quad W=\square$

680 FQR I=1 TÖ Hsamp

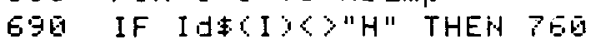

$7010 \mathrm{~N}=\mathrm{N}+1$

$710 . J=40$

$720 \quad x(N)=0$

730 IF (F(I, I)=0) DIR $(F(I, J)=9.99)$ THEH 750

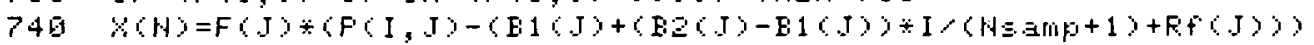

$750 \quad Y(N)=I[O U E(I)$

76 HEXT I

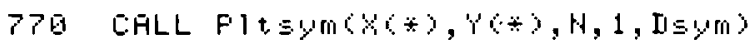

780 WHIT 20 BE

790 IHFUT "DO YOU WHHT A HAFD COFY DF THE FLDT? $\%$, IH",

80G IF II:=" $Y$ " THEN 820

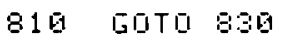

82G IUMF IRRFHICS

530 GLEAF.

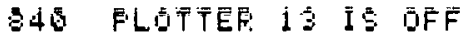

85 RETUFH

879

880

896

900

910

920

930

945

956

960

978

Li $\equiv$ t.: FEIINT FHIE, "

Herint $=16$

$H \neq(1)="$ AES"

$H \neq(2)=" U I-A T "$

$L=1$

IF (II=1) OR: (II=2) THEN 940

IHFIT "OUTFIIT T'YFE: $1=$ HES, $2=I J G-A T / L ", L$

IF (LC1) OR (L) 2 ) THEH 920

FRIHTER IS-Nar int.

FRIHT USIHG 970; L

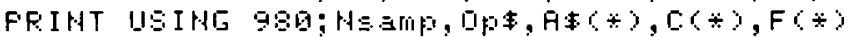

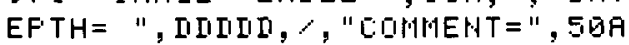

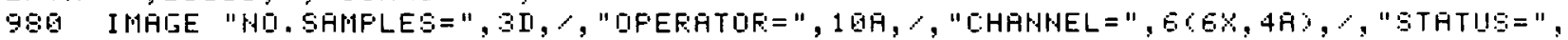

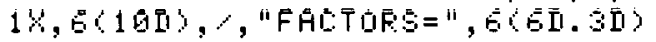

99日 PRIHT USING $1000 ; \mathrm{R}+6 \% \mathrm{~B} 1(\%), \mathrm{E} 2 \%$

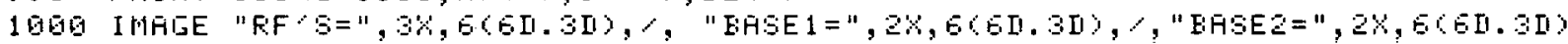

1919 IF I $1=1$ THEN 1364

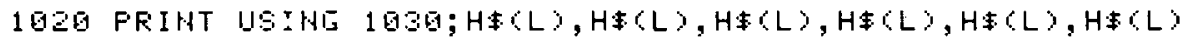

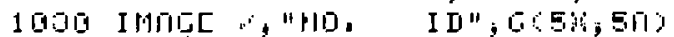

1640 FUR $I=1$ TO MAX(MF, NSamp?

1050 TOR $J=1$ TO HE H.S\%

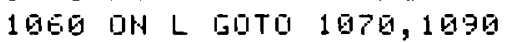

1970 II $(\mathrm{T})=\mathrm{F}(\mathrm{I}, \mathrm{J})$

1080 G0TO 1140

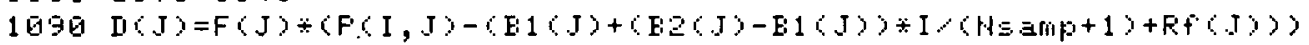

1160 IF $F(I, J)>0001$ THEH 1140

$1119 I(J)=0$

1120 IF $F(I, I)>-1$ THEH 1140

1130 II J $)=-99$

1140 HEXT I

1190 IF II $=2$ THEW 1130

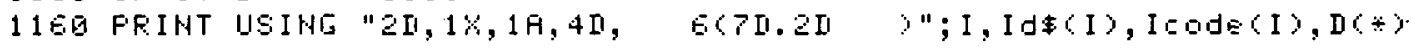

$1170 \quad 50 T 01190$

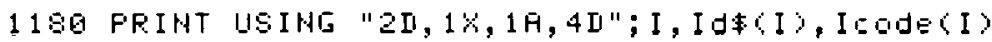

1190 NEXT I

1200 IF Nprint $=0$ THEH 1280

$1219 \mathrm{KW} \equiv " \mathrm{H}$

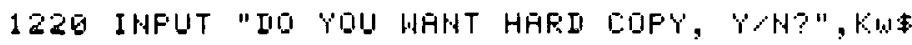

1230 IF Kw: " $Y$ " THEN 1250

1240 GOTO 1280

1256 Nprint $=0$

1260 GOTO 940

$12 P Q$ HEXT I 


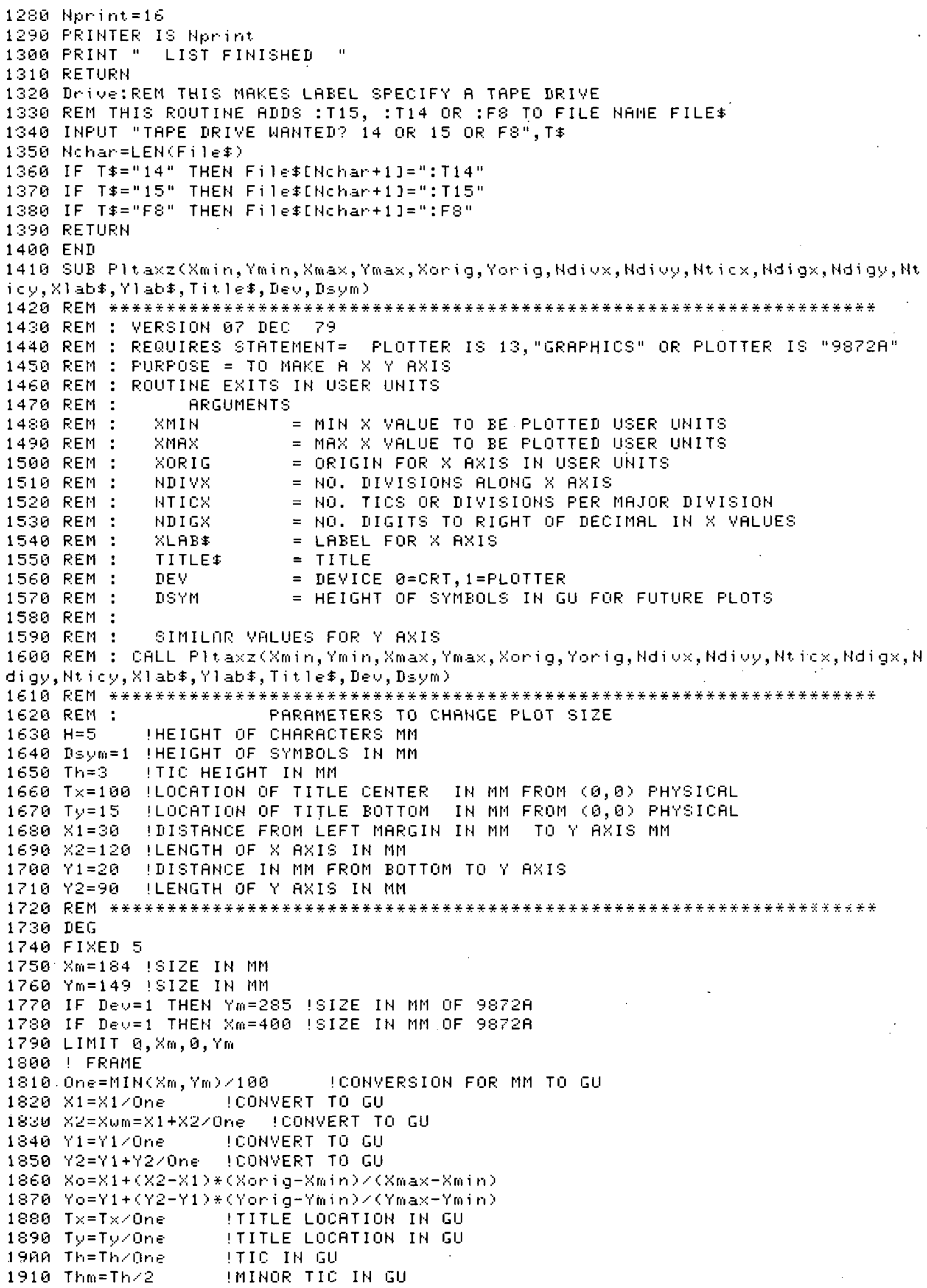




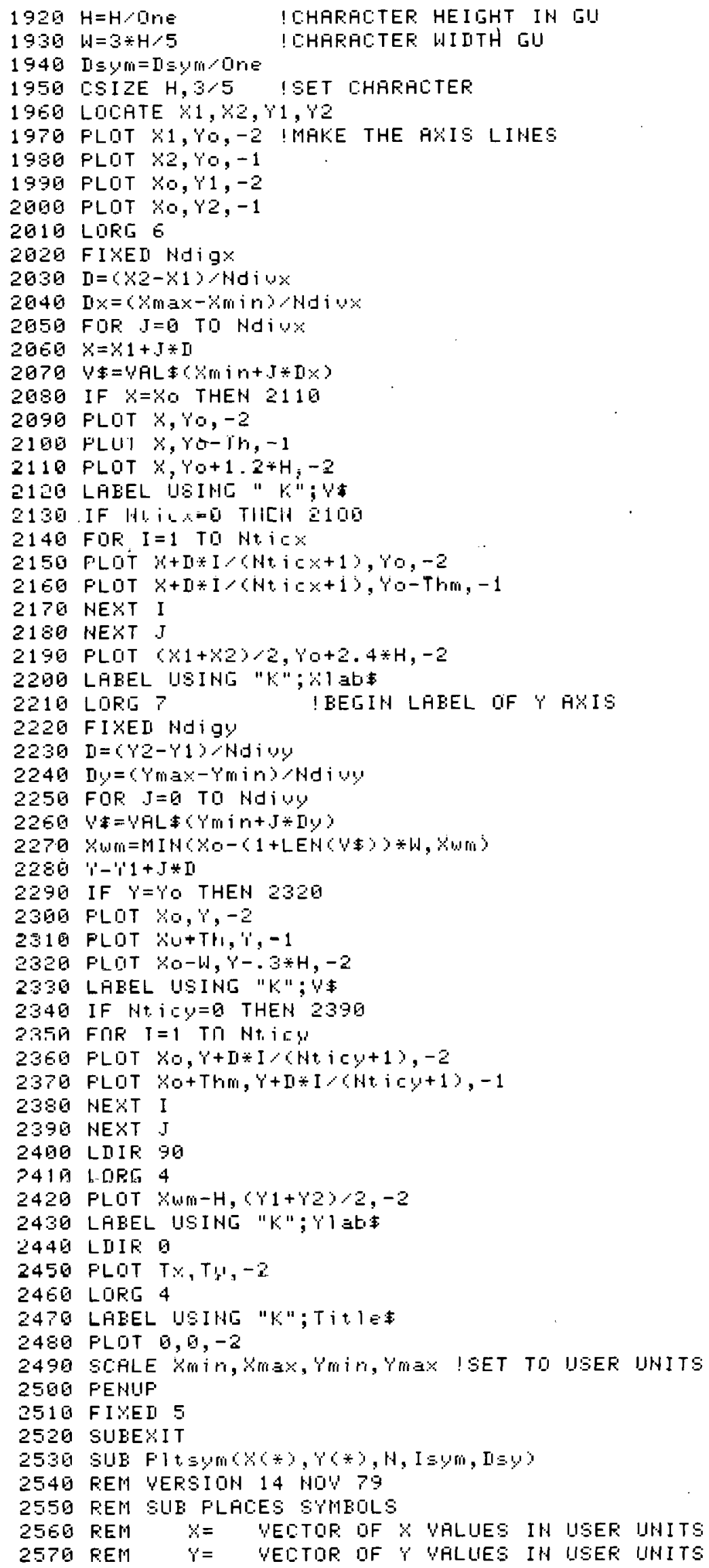




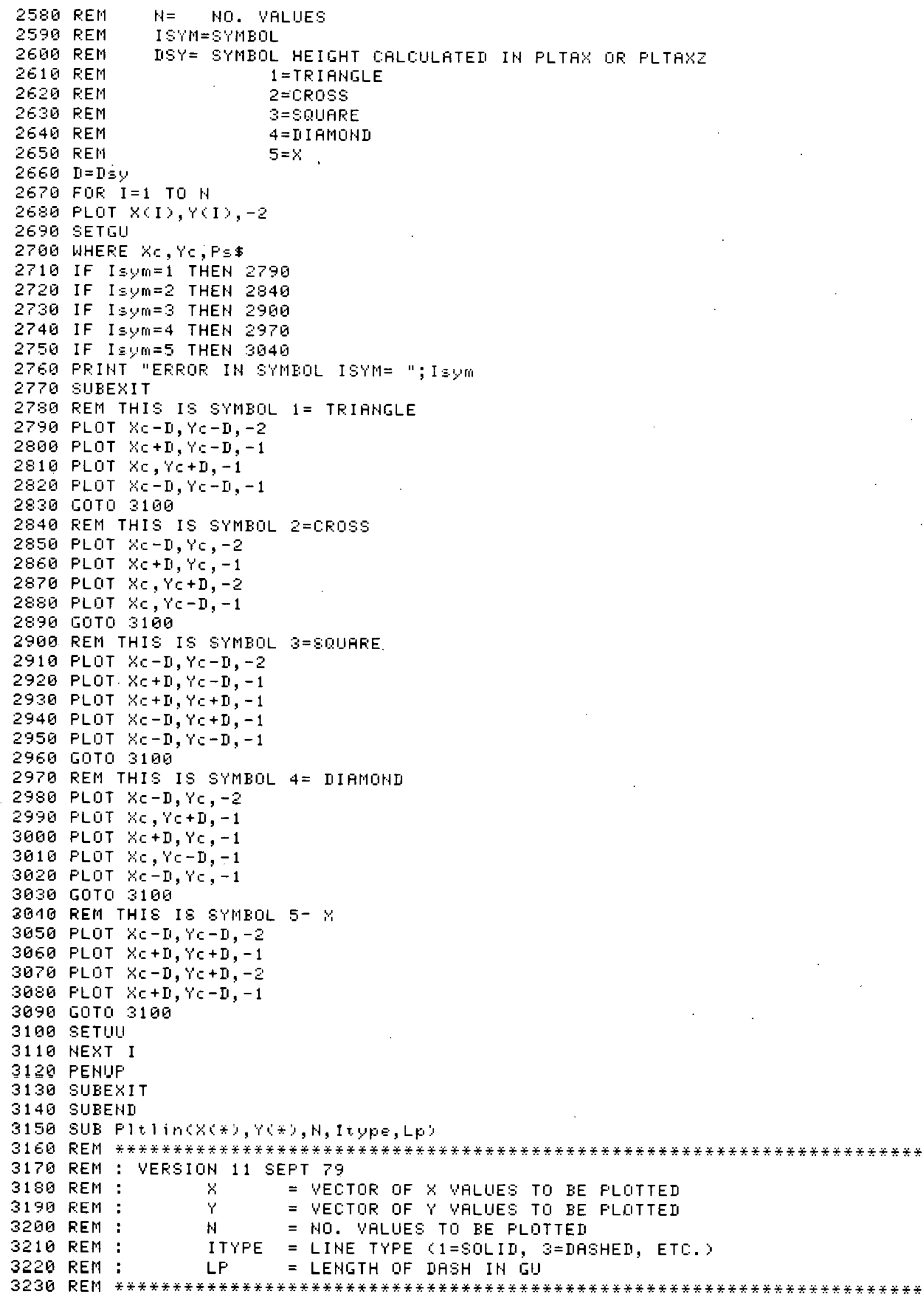


324G LIHE T'YFE I TYpE, LP

3250 FLOT YO1), Y(1),

3260 FQR I $=2$ TO H

3270 FLOT R(I), YCI), 1

328 HEXP I

3290 FEHUF

33EG SUEEYIT

3310 SUEEHI 


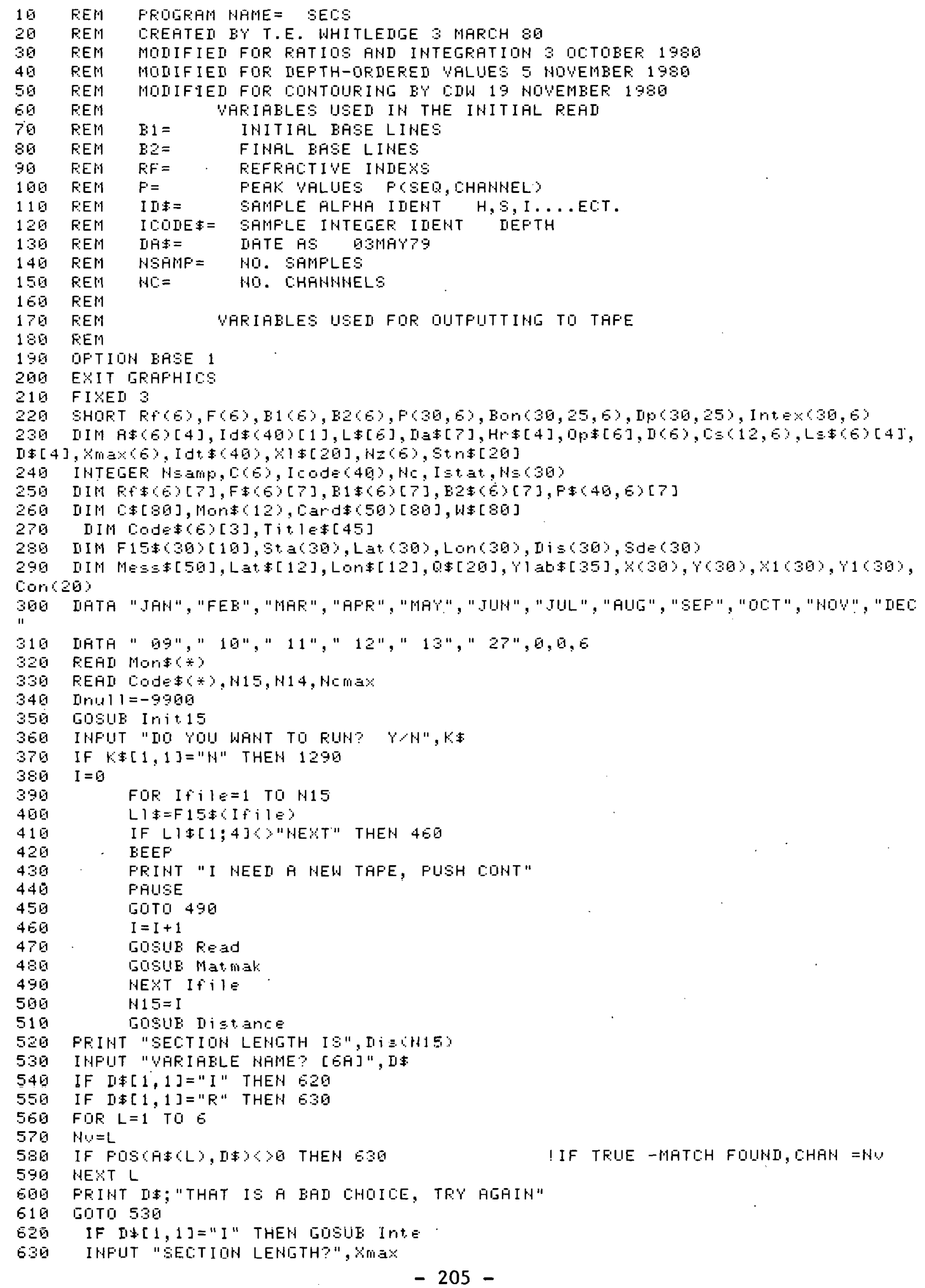




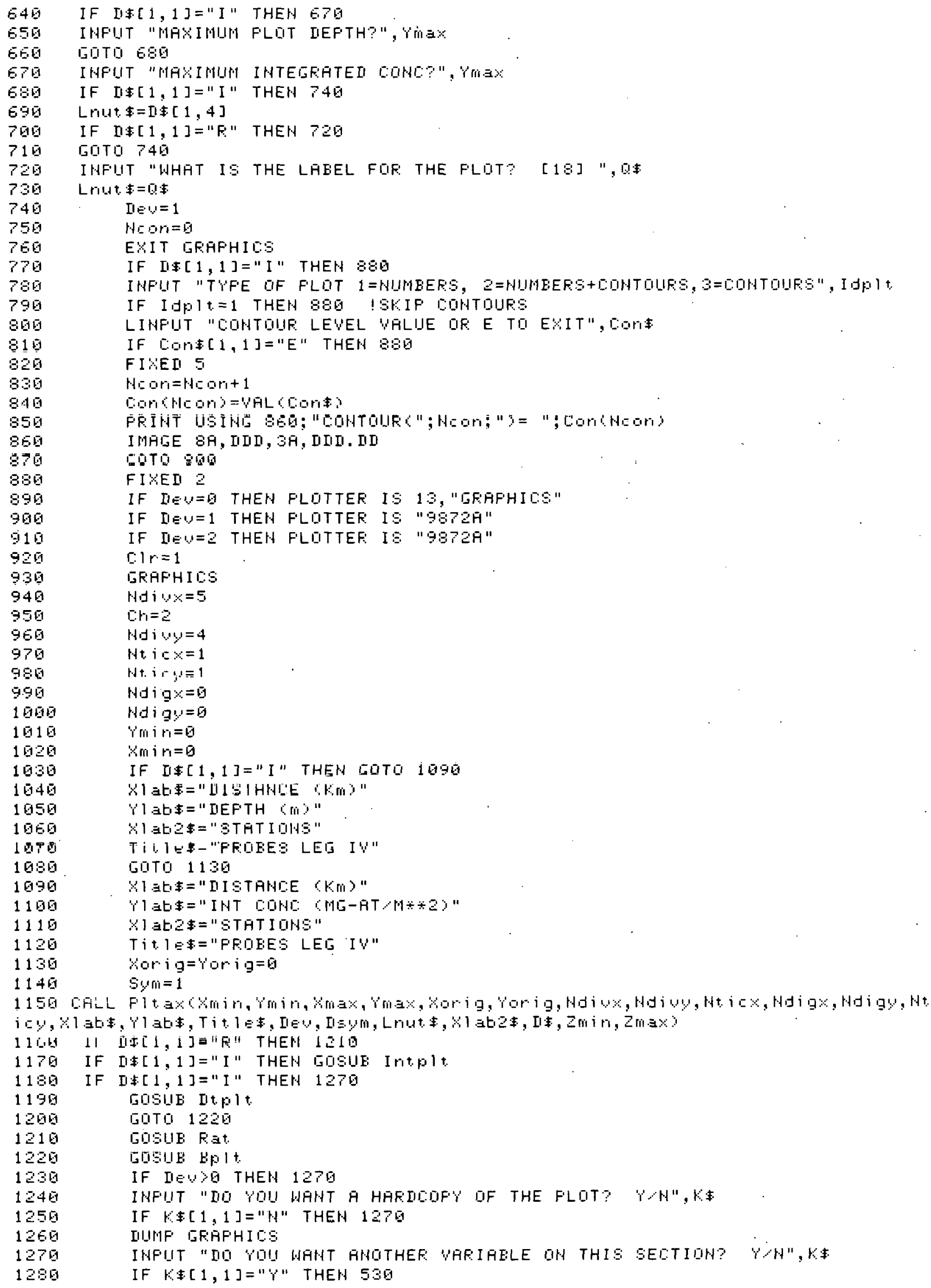

1015

1520

1030

1646

1650

1060

1090

1080

1090

1100

1110

1126

1136

1146

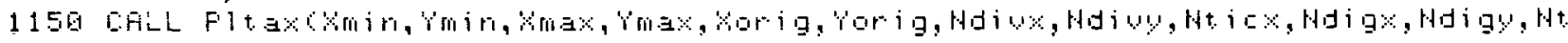

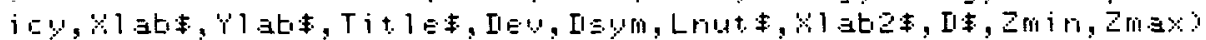

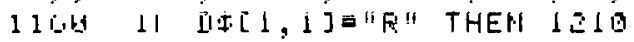

1179 IF II:[1,1]="I" THEH GISUE Intplt

11 B日 IF II: $[1,1]="$ I" THEH 1270

1196

1260

1210

1220

1230

1240

1250

1260

1270

1280 


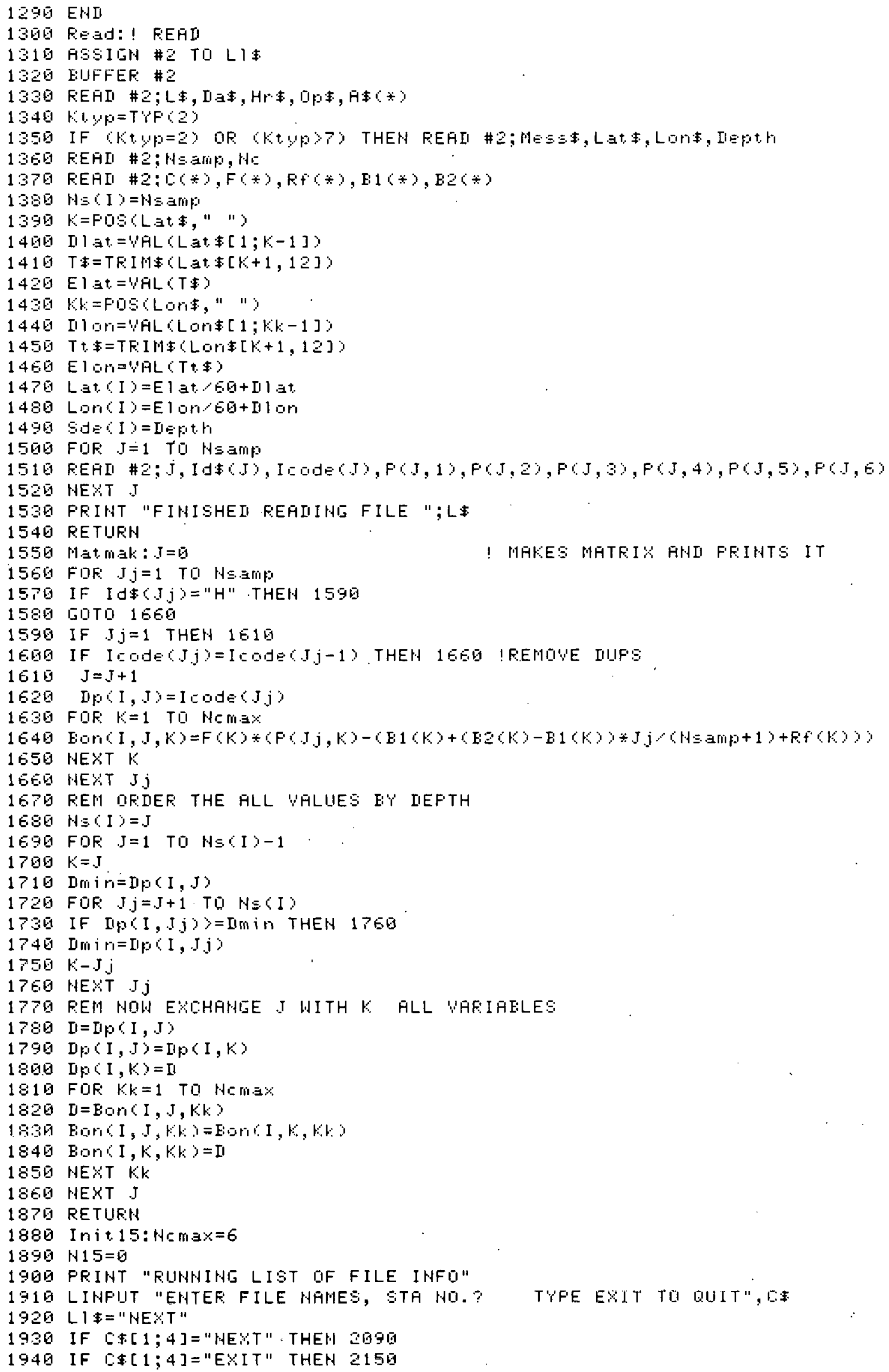




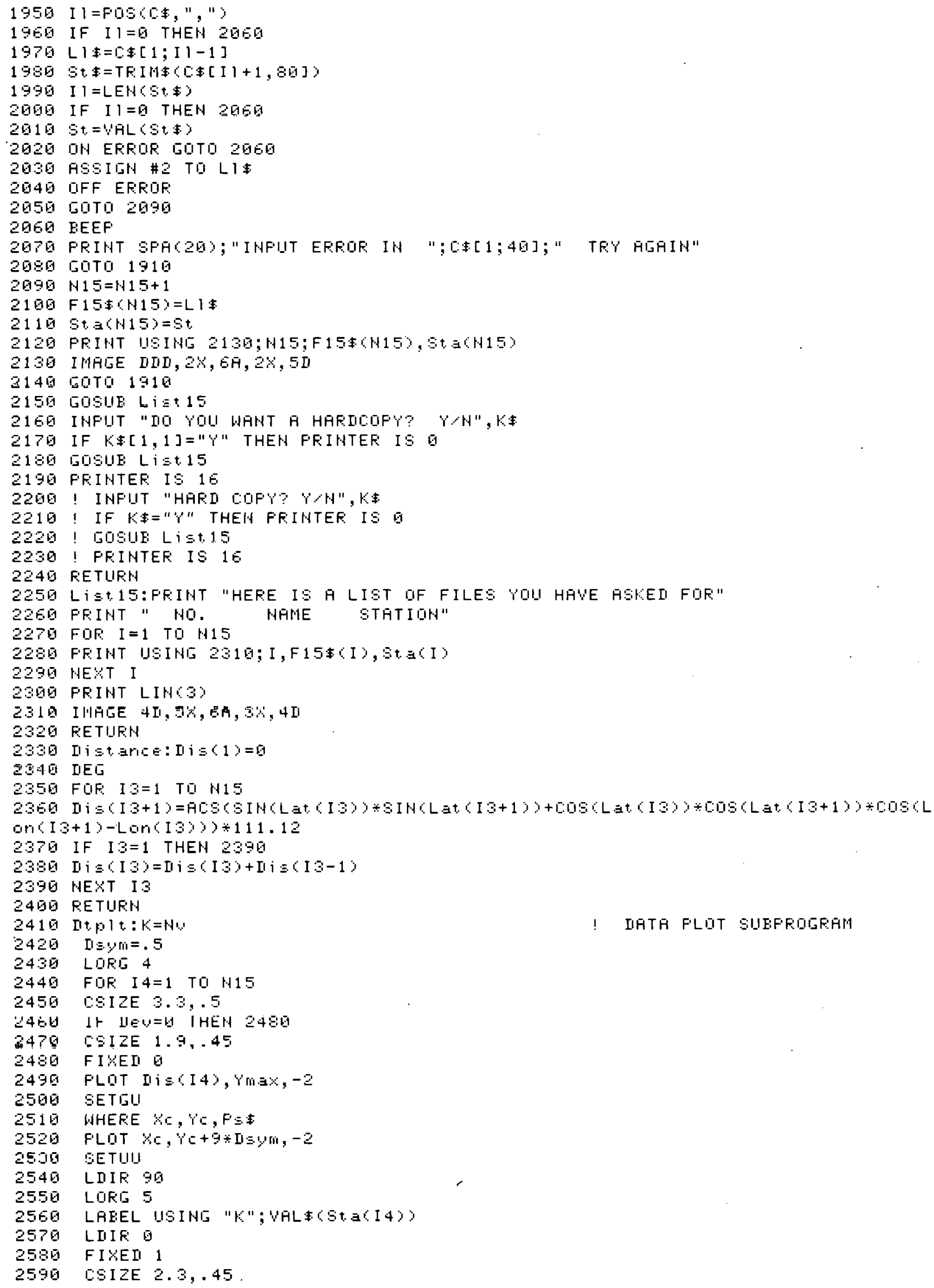




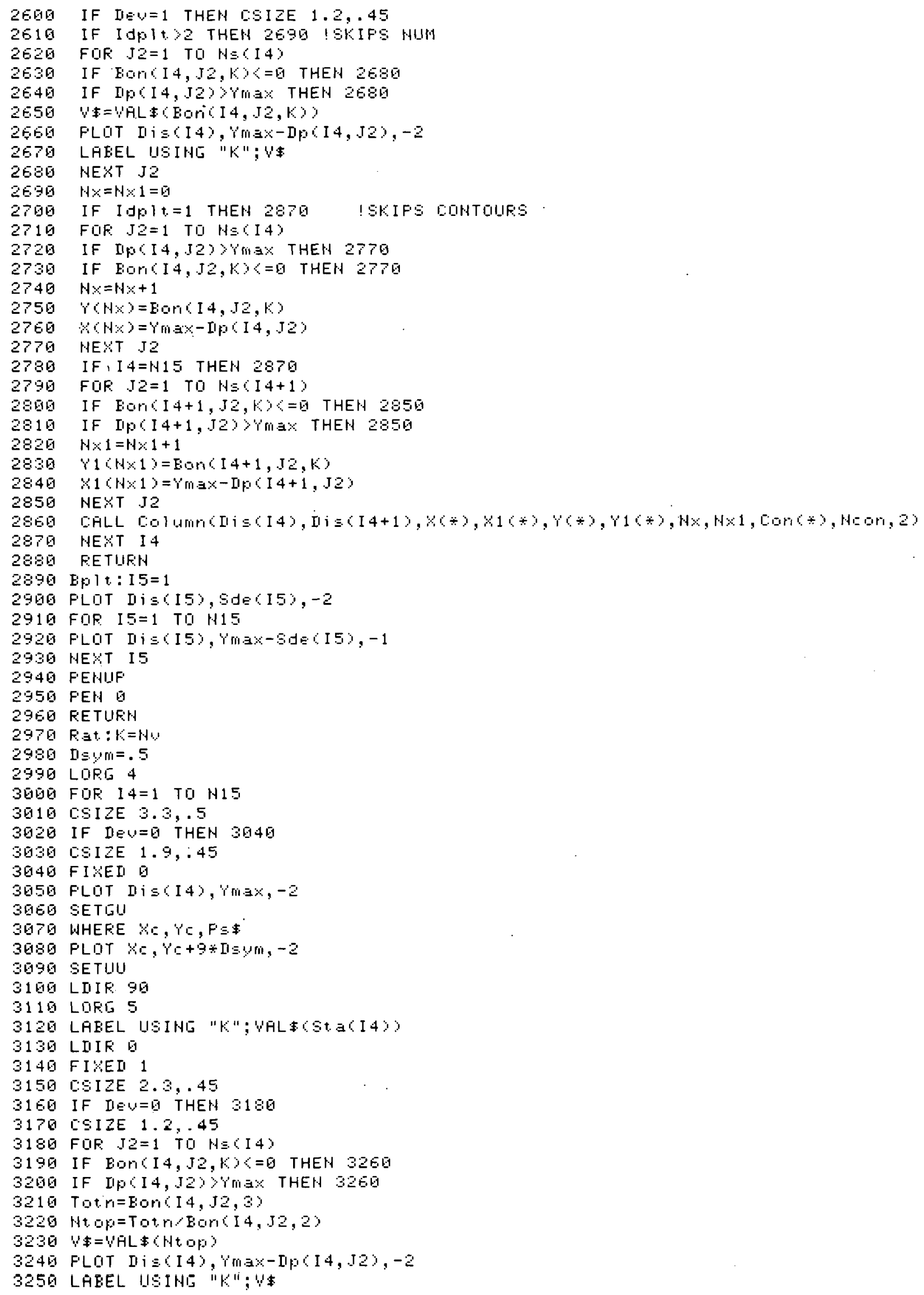




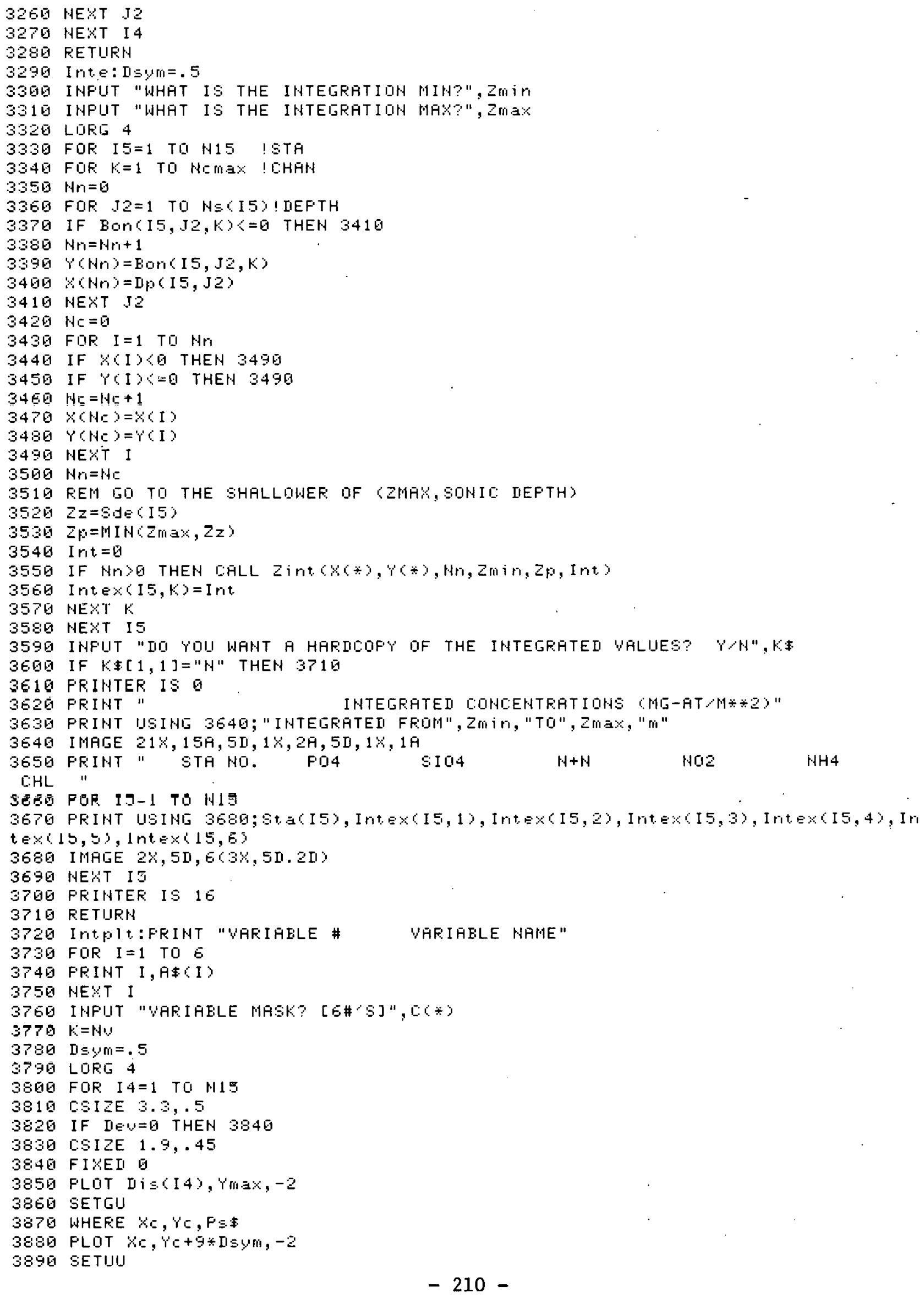


396日 LIIR 90

3910 LORE 5

3920 LABEL USIHE "R"; VALT(Sta(I4)

3930 HEXT I 4

3940 LIIIR 0

3950 GEAFHICS

3960 FUR $K=1$ TO HEmax

3970 IF C.K $=9$ THEH $496 \overline{0}$

3980 FOR $I=1$ TO N1S

3990 Y(I)=IntEX(I, K)

$4000 \quad X(I)=I i \leq(I)$

4010 HEKT I

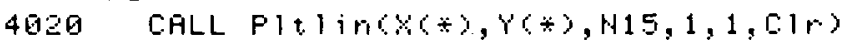

! FLOT THE LIHE

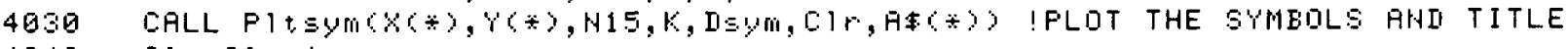

$4040 \quad C 1 r=11 r+1$.

4950 IF $C: 1 r>4$ THEH $[: 1 r=1$

4060 NEXT K

4070 FEETIRN

4096 SUB Pl axCKmin, Ymin, Kmax, Ymax, Xorig, Yorig, Haiux, Hdi yy, Ht icx, Hdigx, Hdigy, Hti

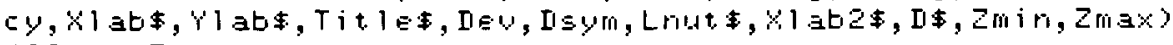

$4990 \mathrm{H}=5$

4100 IISymil $=1$

$4110 \quad T h=3$

4120 IF IEU=0 THEN 4160

$4130 \quad \mathrm{~T} \times=85$

$4140 \quad T y=195$

4150 GOTO $418 \mathrm{G}$

$4160 \quad T \times=60$

$4170 \quad T y=145$

$4180 \quad \times 1=25$

$4190 \times 2=153$

$4200 \quad Y_{1}=20$

$4215 \quad Y 2=105$

4220 IF DEV $=2$ THEN 4270

4230 IF IIEU $=9$ THEN 4290

$4240 \times 2=210$

$4250 \quad \because 2=155$

4260 जOTO 4296

$4270 \times 2=300$

$4289 \quad Y 2=155$

4290 Trix $=30$

4300 Try $=7$

4310 DEG

4320 FIXED 5

$4330 \quad X_{m}=184$

$4340 \quad Y_{m}=149$

4350 IF IEU=1 THEN Ym=285 !SIZE IH MM OF $9872 \mathrm{H}$

4369 IF DEW=2 THEN $\gamma m=285$ !SIZE IN MM DIF 9872R

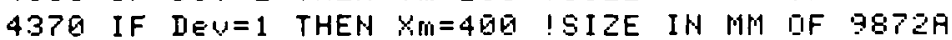

4380 IF DeU $=2$ THEH $X m=400$ !SIZE IN MM DF $9872 \mathrm{R}$

4390 LIMIT $0, X_{m}, \bar{G}, Y_{\mathrm{m}}$

4400 Dne $=1 I N\left(X_{m}, Y m\right) / 100$

$4410 \times 1=X 1<0$ rie

$4420 \times 2=\times w m=\times 1+\times 2>0 n E$

$4430 \quad Y 1=Y 1 / 0 \mathrm{Qriz}$

$444 \dot{B} Y 2=Y 1+Y 2 /$ Une

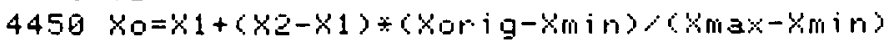

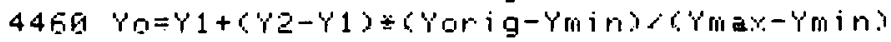

$4470 \quad T \times=T \times / 0 n e$

4480 Ty=Ty'One

$4495 \quad T n x=T n x / 0 n e$

4500 Tny=Try

$4510 \quad T h=T h / 0 n e$

$4520 \quad T h m=T h / 2$

$4530 \mathrm{H}=\mathrm{H} / \mathrm{One}$

$4540 W=3 * H / 5$ 


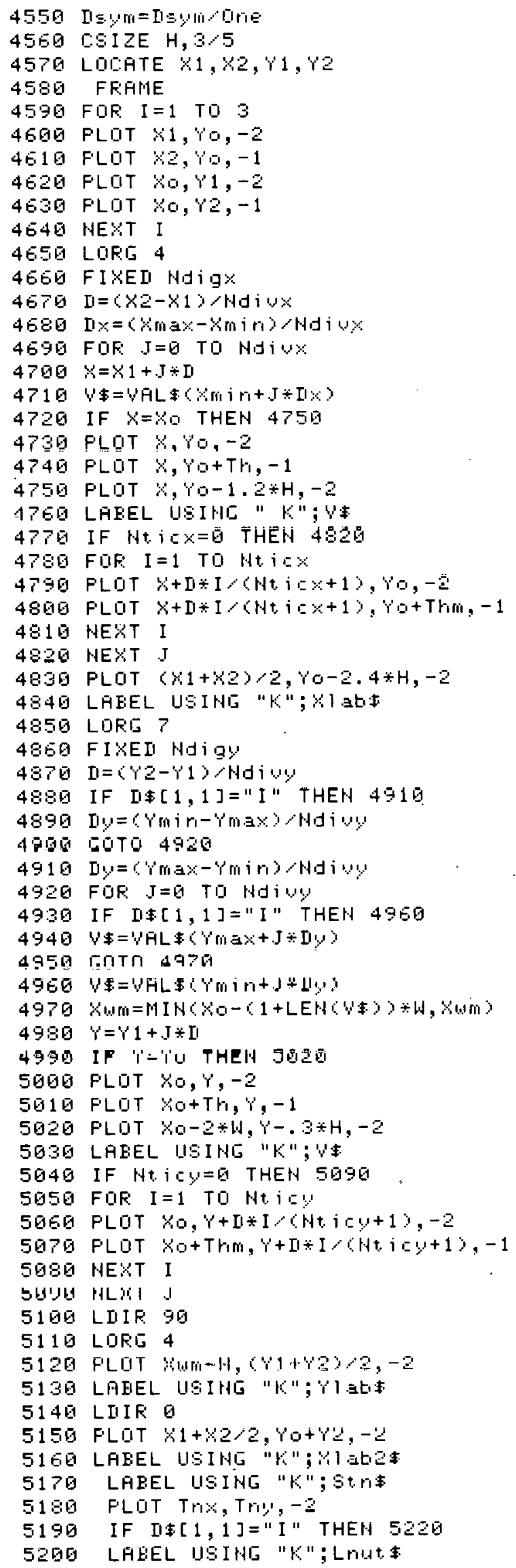




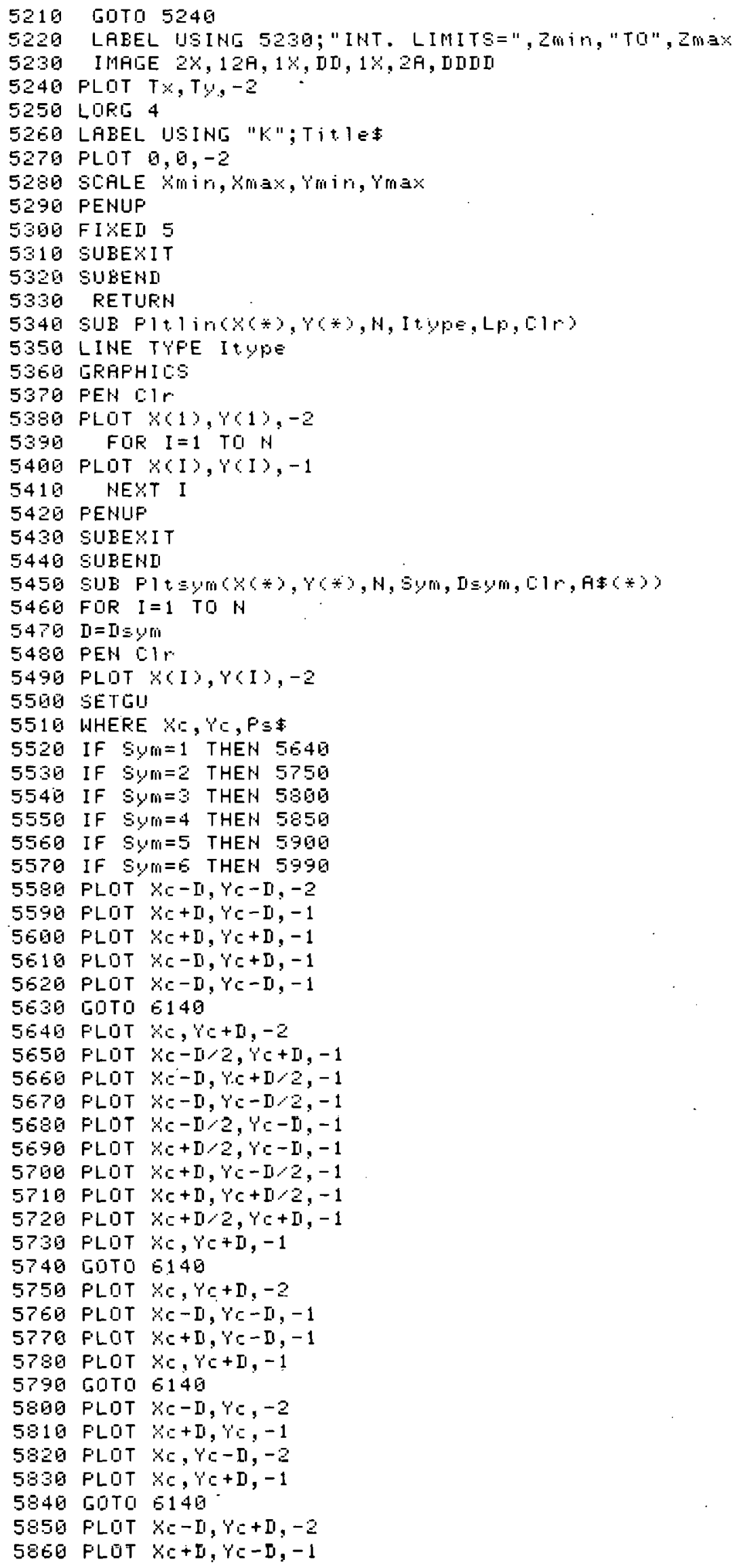




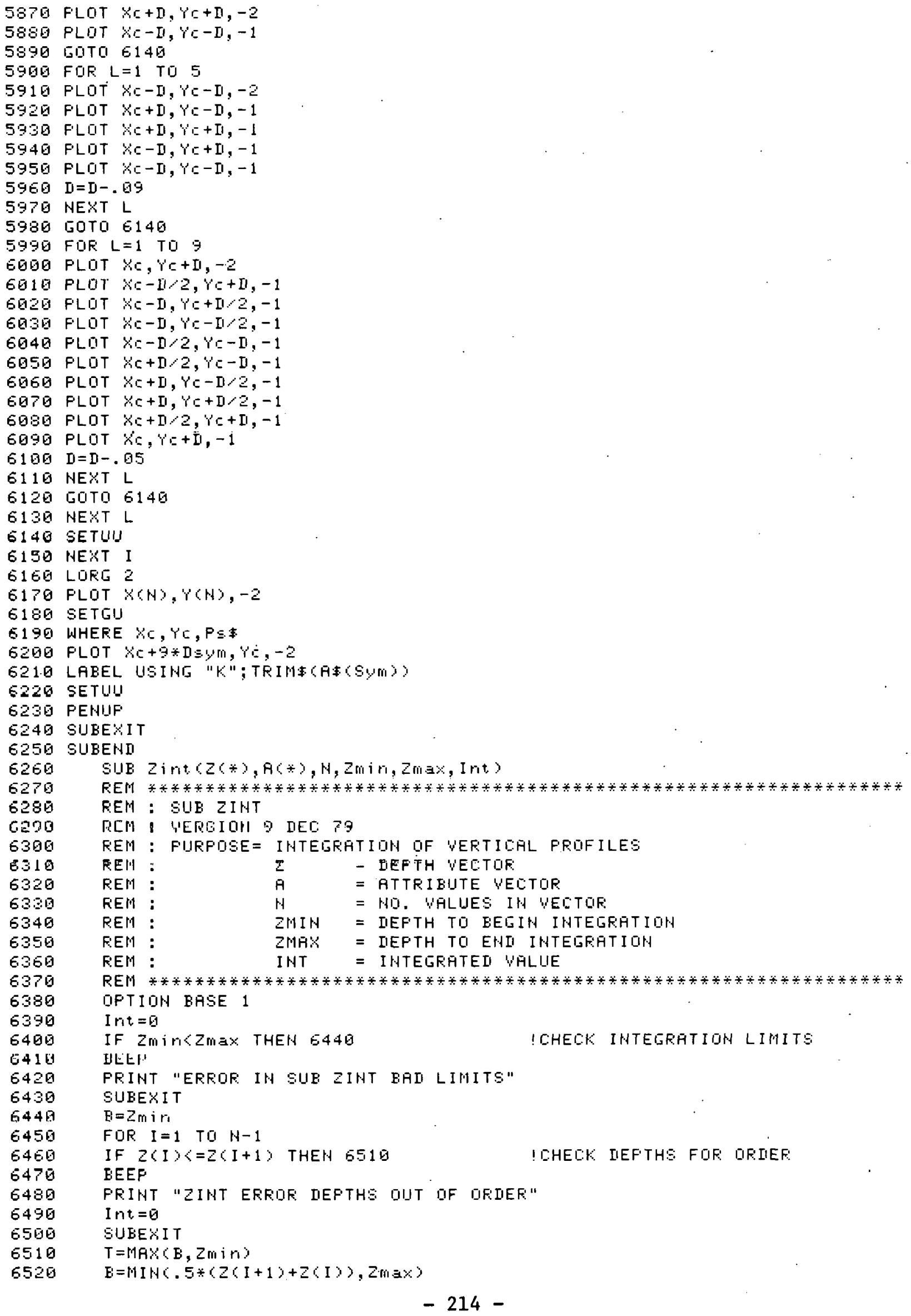




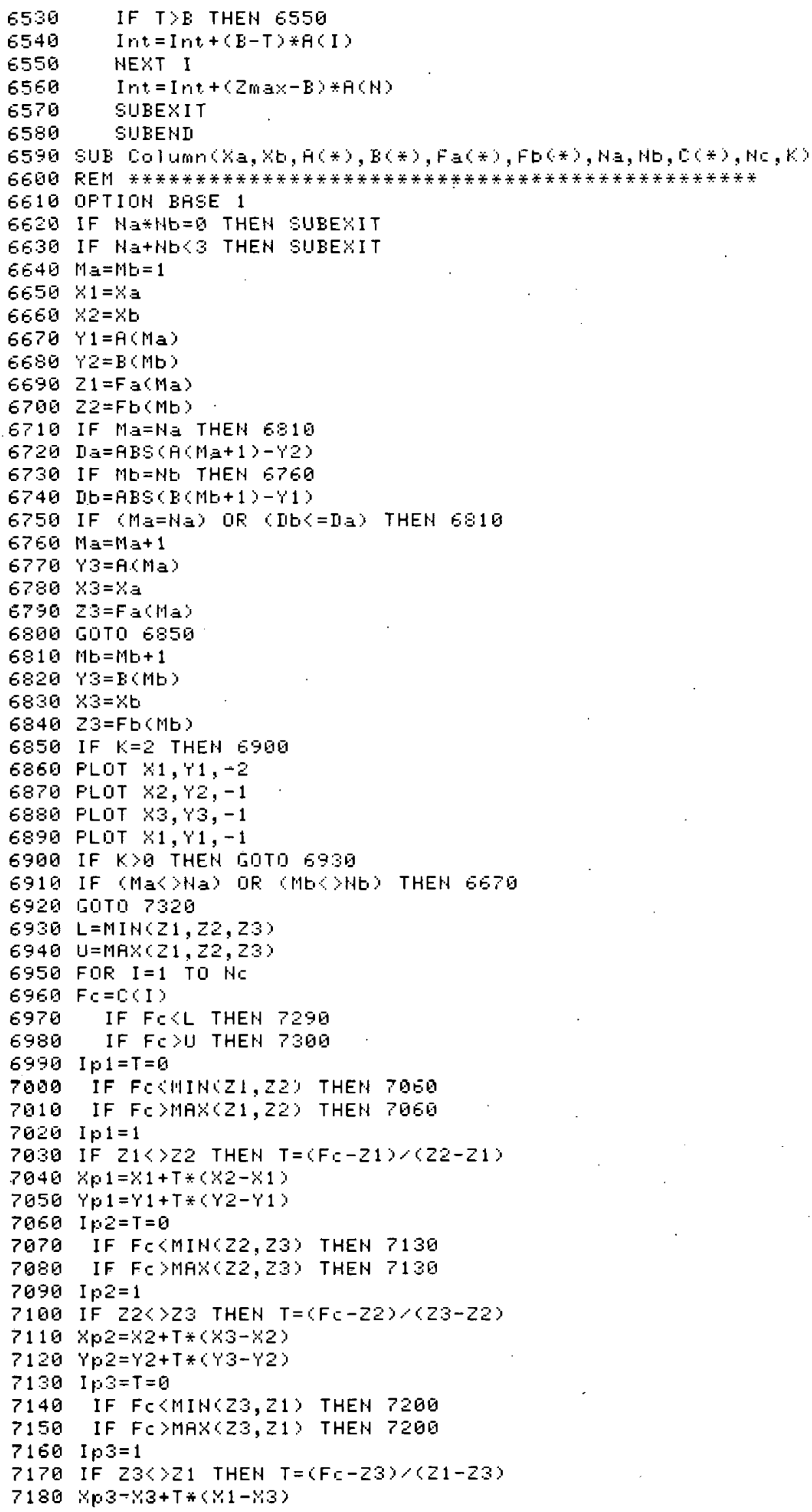




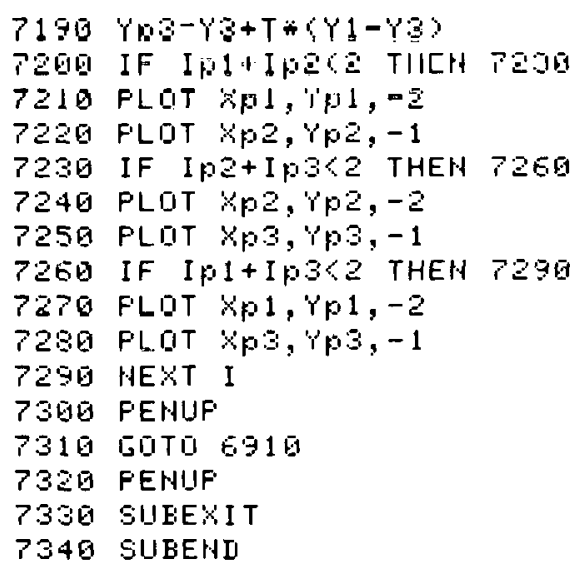

* U.S. GOVERNMENT PRINTING OFFICE: 714-037\#18 